\author{
UNIVERSIDADE DE SÃo PAULO \\ FACUldade DE Filosofia, LeTRAS E CiÊnCIAS Humanas
}

ANTÔNIA FERnANdA DE SOUZA NogueIRA

\title{
Predicação na língua Wayoro (Tupi): propriedades de finitude
}




\section{Predicação na língua Wayoro (Tupi): propriedades de finitude}

Tese apresentada à Faculdade de Filosofia, Letras e Ciências Humanas da Universidade de São Paulo para obtenção do título de Doutora em Letras.

Área de concentração: Semiótica e Linguística Geral

Orientadora: Profa. Luciana Raccanello Storto

Co-Orientadora: Profa. Ana Vilacy Galucio

Versão Corrigida

São Paulo 
Autorizo a reprodução e divulgação total ou parcial deste trabalho, por qualquer meio convencional ou eletrônico, para fins de estudo e pesquisa, desde que citada a fonte.

Catalogação na Publicação

Serviço de Biblioteca e Documentação

Faculdade de Filosofia, Letras e Ciências Humanas da Universidade de São Paulo

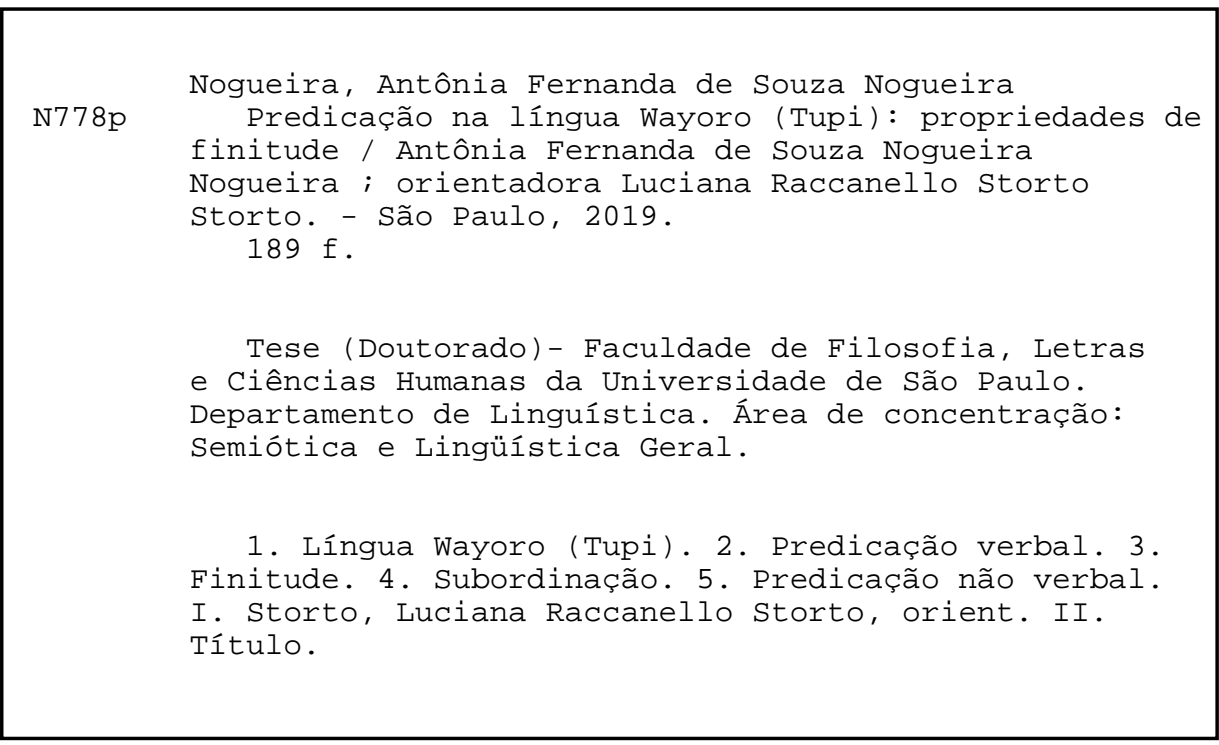




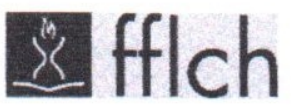

UNIVERSIDADE DE SÃO PAULO

FACULDADE DE FILOSOFIA, LETRAS E CIÊNCIAS HUMANAS

ENTREGA DO EXEMPLAR CORRIGIDO DA DISSERTACC̃OO/TESE

Termo de Ciência e Concordância do (a) orientador (a)

Nome do (a) aluno (a): Antônia Fernanda de Souza Nogueira

Data da defesa: $15 / 205 / \underline{2019}$

Nome do Prof. (a) orientador (a): LUCIANA RACCANELLO STORTO

Nos termos da legislação vigente, declaro ESTAR CIENTE do conteúdo deste EXEMPLAR

CORRIGIDO elaborado em atenção às sugestões dos membros da comissão Julgadora na sessão de defesa do trabalho, manifestando-me plenamente favorável ao seu encaminhamento e publicação no Portal Digital de Teses da USP.

São Paulo, $17,07,2019$

$\frac{\text { Luvama R. StrAt }}{\text { (Assinaturado (a) orientador }(a)}$ 


\section{Predicação na língua Wayoro (Tupi): propriedades de finitude}

Tese defendida no Programa de Pós-Graduação do Faculdade de Filosofia, Letras e Ciências Humanas da Universidade de São Paulo como requisito parcial para obtenção do título de Doutor em Letras, aprovada em $<15>$ de $<$ maio $>$ de 2019, pela Banca Examinadora constituída pelos professores:

Profa. Luciana Raccanello Storto

Faculdade de Filosofia, Letras e Ciências Humanas - USP

Presidente da Banca

Prof. $<$ Hein van der Voort $>$

$<$ Museu Paraense Emílio Goeldi $>-<$ MPEG $>$

Prof. $<$ Denny Albert Moore $>$

$<$ Museu Paraense Emílio Goeldi $>-<$ MPEG $>$

Prof. $<$ Thomas Daniel Finbow $>$

$<$ Universidade de São Paulo $>-<$ USP $>$ 
Ao povo Wajuru (Wayoro) e aos demais povos da Terra Indígena Rio Guaporé (Rondônia) 


\section{Agradecimentos}

Agradeço a todos que dedicaram seu tempo para que este trabalho pudesse existir hoje. Como me explicou, certa vez, o amigo Ricardo Wajuru existimos porque nos ajudamos.

Aos falantes da língua Wayoro, pela confiança e paciência, e ao povo Wajuru, bem como a toda a comunidade da Terra Indígena Rio Guaporé, especialmente a aldeia Ricardo Franco, pela colaboração e apoio durante o desenvolvimento da pesquisa.

As minhas orientadoras pela precisão e relevância de cada comentário, correção e sugestão.

Aos professores e colegas do Departamento de Linguística da USP pelo enriquecedor compartilhamento de saberes.

Aos colegas do SEDYL - Structure et Dynamique des Langues, Villejuif-França, que se disponibilizaram a me receber e discutir os dados de Wayoro, durante o estágio de três meses — Bolsa LABEX-The Laboratory of Excellence "Empirical Foundations of Linguistics” (EFL), sob orientação da Dra. Katharina Haude.

Agradeço às famílias amigas em Guajará-Mirim: onombit Waika (Rosana Makurap) e sua família, Elenisa Tupari e sua família, Dulce Ana e sua família.

A toda minha família, especialmente, aos meus irmãos Flávia e sua filha Alice, Fabiane e seus filhos Davi e Sofia, Neto, por estarem aqui.

Aos meus amigos, por terem escolhido me acompanhar.

Ao meu companheiro Marcos, por fazer parte do que traduz em mim a palavra tiap da língua Wayoro, 'estar/ser vivo' e, ao mesmo tempo, 'estar/ser alegre'.

Agradeço à Fundação Nacional do Índio (FUNAI) pela autorização 56/CGEP/08, pela autorização 119/AAEP/10 e pela autorização 84/AAEP/PRES/2017. 
Os brancos pensam que só os macacos são gente,

Senhora da etnia Makurap, aldeia Ricardo Franco, Guajará-Mirim (Rondônia). 


\section{Resumo}

Nogueira, A. F. de S. Predicação na língua Wayoro (Tupi): propriedades de finitude. São Paulo, 2019. 190p. Tese de Doutorado Faculdade de Filosofia, Letras e Ciências Humanas, Universidade de São Paulo.

Geralmente, as propriedades das orações principais-declarativas-afirmativas-ativas são tomadas como protótipo de orações verbais finitas, ou seja, o modelo a partir do qual orações não-finitas se diferenciarão (GIVÓN, 2016, p. 272). A literatura prevê que tal diferenciação ocorra nos seguintes ambientes sintáticos: orações subordinadas (CRISTOFARO, 2005) e nominalizações, configurando-se este último como fenômeno claramente predominante nas línguas sul-americanas (GIJN; HAUDE; MUYSKEN, 2011a). Esta tese tem como foco as propriedades da finitude nesses três ambientes sintáticos: sentença matriz, oração subordinada e nominalização. Em várias línguas há um morfema que cria nomes a partir de verbos intransitivos e transitivos indicando semanticamente o "lugar onde $\mathrm{X}$ acontece" ou "um instrumento para X”(COMRIE; THOMPSON, 2007). Na língua Wayoro (subfamília Tupari, Tupi), este morfema é - $p \sim-m$ 'nominalizador'. Contudo, notamos construções com um morfema homófono que aparecem como complementos de verbos e que permitem propriedades oracionais. Seriam esses complementos melhor analisados como nominalizações ou como orações subordinadas? As propriedades das sentenças matrizes (marcas morfossintáticas de finitude) identificadas - marcas de pessoa, morfemas de alteração de valência, marcas de tempo e aspecto, tipos sentenciais, modalidade e polaridade - serviram à comparação entre as orações subordinadas e as nominalizações. Com base nas propriedades de finitude, analisamos como nominalização a construção que se comporta sintaticamente como sintagma nominal, sem qualquer marca de finitude. Como oração subordinada (infinitiva), analisamos a construção com $-p \sim-m$ que funciona como objeto de um verbo e que permite marcas de aspecto e expressão de sujeito pronominal cliticizado ou não pronominal. Dessa forma, as marcas de finitude nos permitem: (i) distinguir, por um lado, nominalização de oração subordinada e, por outro lado, orações matrizes de orações subordinadas, uma vez que sentenças matrizes apresentam concordância e indicação de tempo, o que não ocorre nas orações subordinadas infinitivas; (ii) distinguir predicados verbais (sentenças matrizes e orações subordinadas) de predicados não verbais, visto que a cópula e os verbos existenciais não ocorrem com afixos de tempo/aspecto e marcas de pessoa.

Palavras-chave: Língua Wayoro (Tupi). Predicação verbal. Finitude. Subordinação. Nominalização. Predicação não verbal. 


\section{Abstract}

Nogueira, A. F. de S. Predication in the Wayoro language (Tupi): properties of finiteness. São Paulo, 2019. 190p. PhD. Thesis Faculty of Philosophy, Letters and Human Sciences. University of são Paulo.

Generally, the properties of the main-declarative-affirmative-active clauses are the finite verbal clause prototype, that is, the prototype from which non-finite clauses will deviate (GIVÓN, 2016, p. 272). As mentioned in the literature, such deviation will occur in the following syntactic environments: subordinate clauses (CRISTOFARO, 2005) and nominalizations, being the latter a clearly predominant phenomenon in the South American languages (GIJN; HAUDE; MUYSKEN, 2011a). This thesis focuses on the properties of finiteness in these three syntactic environments: matrix sentence, (infinitive) subordinate clause, and nominalization. In several languages, there is a morpheme that creates nouns from intransitive and transitive verbs with the meaning of "a place where X happens"or "an instrument for X"(COMRIE; THOMPSON, 2007). In the Wayoro language (Tupari subfamily, Tupian), this morpheme is $-p \sim-m$ 'nominalizer'. However, we noticed constructions with a homophonous morpheme that appear as complements of verbs and that show properties of clauses. Are these complements better analyzed as nominalizations or as subordinate clauses? The property of main clauses (morphosyntactic finiteness features) - person marking, valency-changing morphemes, tense and aspect markers, sentential type, modality, and polarity - serve to compare the subordinate clauses and the nominalizations. Based on the morphosyntactic finiteness features, we analyze as nominalization the construction that behaves syntactically as a noun phrase without any finiteness feature. We analyze as a subordinate (infinitive) clause the $-p \sim-m$ construction which functions as an object of a verb and allows aspect markers and expression of cliticized pronominal subjects or non-pronominal subjects. In this way, morphosyntactic finiteness features allow us: to distinguish, on the one hand, nominalization from subordinate clauses and, on the other hand, matrices from subordinate clauses, since matrix sentences exhibit agreement and tense marking, which do not occur in infinitive subordinate clauses; to distinguish verbal predicates (matrix sentences and subordinate clauses) from nonverbal predicates, since copula and existential verbs do not occur with person marking and tense/aspect affixes.

Keywords: The Wayoro language (Tupian). Vebal predication. Finiteness. Subordination. Nominalization. Nonverbal predication. 


\section{Lista de Abreviaturas}

1 primeira pessoa

2 segunda pessoa

3 terceira pessoa

ABL ablativo

AG agente

ALA alativo

ANT anterior

AUX auxiliar

C correferencial

CAUS causativo

CONJ conjunção

COP cópula

DECL declarativo

DEIT dêitico

DEM demonstrativo

DESID desiderativo

DIF diferente

DIST distante

ENF enfático

ESPEC especulativo

EXCL exclusiva

EXIST existencial

EXTR extração

FOC foco do objeto

FRUST frustrativo

FUT futuro

GEN genitivo

HORT hortativo 


\begin{tabular}{|c|c|}
\hline IMM & immediate \\
\hline INAL & inalienável \\
\hline INCL & inclusiva \\
\hline INF & infinitivo \\
\hline INS & instrumental \\
\hline INTENS & intensificador \\
\hline INTERR & interrogativo \\
\hline INTR & intransitivo/intransitivizador \\
\hline IPFV & imperfectivo \\
\hline IRR & irrealis \\
\hline ITER & iterativo \\
\hline INTJ & interjeição \\
\hline LOC & locativo \\
\hline MED & voz média \\
\hline $\mathrm{N}$ & nome \\
\hline NEG & negação \\
\hline NFUT & não-futuro \\
\hline NMLZ & nominalizador/nominalização \\
\hline OBJ & objeto \\
\hline OBL & oblíquo \\
\hline ONTP & onomatopeia \\
\hline PASS & passado \\
\hline PFV & perfectivo \\
\hline PL & plural/pluracionalidade \\
\hline PL.INCL & plural inclusivo \\
\hline $\mathrm{POSP} / \mathrm{P}$ & posposição \\
\hline QU & palavra interrogativa \\
\hline QUANT & quantificador \\
\hline QUOT & quotativo \\
\hline $\mathrm{R} 1$ & relacional 1 \\
\hline $\mathrm{R} 2$ & relacional 2 \\
\hline RED & reduplicação \\
\hline REM & remoto \\
\hline REP & repetição \\
\hline RES & resultativo \\
\hline$S$ & sintagma \\
\hline SG & singular \\
\hline SIM & similativo \\
\hline SOC & sociativo \\
\hline SUB & subordinador \\
\hline SUJ & sujeito \\
\hline
\end{tabular}


TOP tópico

TR transitivizador

V verbo

V.T vogal temática

VZR verbalizador

falante feminino

$\sigma^{7}$ falante masculino 


\section{Lista de Figuras}

1.1 Mapa atualizado da rota de Emil-Heinrich Snethlage e os povos visitados por ele (círculos vermelhos indicam localizações dos Wajuru) - Fonte (MERE, 2013, p. 781), mapa elaborado por Siegfried Schacht.

1.2 Fonemas vocálicos

1.3 Articulação da $1^{\mathrm{a}}$ e da $2^{\mathrm{a}}$ vogal na palavra oti 'minha mãe'

1.4 Articulação da $1^{\mathrm{a}}$ e da $2^{\mathrm{a}}$ vogal na palavra oto 'minha testa' 10

1.5 Articulação da $1^{\mathrm{a}} \mathrm{e}$ da $2^{\mathrm{a}}$ vogal na palavra otut 'minha espada' 


\section{Lista de Tabelas}

1.1 População Wajuru TI Rio Guaporé (FUNDAÇÃO NACIONAL DE SAÚDE (FUNASA), 2016)(SESAI/FUNASA, 2016)

1.2 Variação Dialetal lexical entre subgrupos Wajuru 4

1.3 Tradução Português-Wayoro do verbo djapnga 'fritar' 6

1.4 Solicitação de Julgamento de gramaticalidade sobre o verbo engukwa 'suar' 7

1.5 Quadro de fonemas consonantais 8

1.6 Quadro de alofones consonantais 8

1.7 Quadro de segmentos consonantais e grafemas correspondentes 9

$\begin{array}{lll}1.8 & \text { Evidências de realização do fone ? } & 11\end{array}$

2.1 Pronomes pessoais livres 15

$\begin{array}{lll}2.2 & \text { Prefixos/clíticos pessoais } & 15\end{array}$

2.3 Marcadores verbais de $3^{\text {a }}$ pessoa $\quad 34$

2.4 Homofonia entre marcas de pessoa $\quad 37$

2.5 Possíveis ideofones em Wayoro 45

4.1 Morfemas de tempo e aspecto em Wayoro $\quad 75$

4.2 Morfemas de tempo, aspecto, modalidade e polaridade em Wayoro 92

4.3 Morfemas de modalidade em Mekens (GALUCIO, 2014b) e Wayoro 92

5.1 Escala de finitude $\quad 95$

5.2 morfema -rara -ara REP e verbos em subordinação e em nominalização $\quad 118$

5.3 Controle com os verbos matrizes ndia e toa 125

5.4 Exemplos de verbos intransitivos nominalizados em Wayoro 138

5.5 Exemplos de verbos transitivos nominalizados em Wayoro 138

5.6 Verbos testados como complemento de toa 'ver' em Wayoro 138

5.7 Verbos intransitivos em sentença matriz, em subordinada e em nominalização 141

5.8 Verbos transitivos em sentença matriz, em subordinada e em nominalização 141

6.1 Funções semânticas e morfemas característicos 146

6.2 Lista não exaustiva de adjetivos em Wayoro 156

6.3 Exemplos de marcas de pessoa em Predicados de Propriedade e SVs intransitivos 163 
6.4 Marcas de pessoa em Predicados de propriedade e SVs intransitivos

6.5 Nomes inerentemente duplicados 


\section{Sumário}

Lista de Abreviaturas $\quad$ vi

Lista de Figuras $\quad$ ix

Lista de Tabelas $\quad x$

1 Introdução 1

1.1 Povo Wajuru e língua Wayoro (subfamília Tupari, Tupi) 1

1.2 Trabalhos de campo, metodologia e armazenamento de dados 4

1.3 Fonemas e fones 8

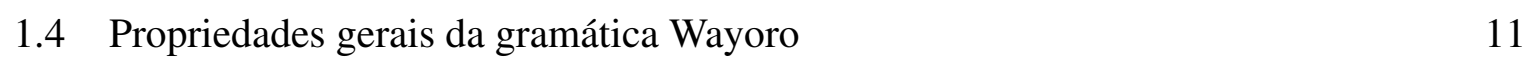

$\begin{array}{lll}1.5 & \text { Estrutura da Tese } & 13\end{array}$

I Predicação verbal: formas finitas e não finitas 14

2 Morfologia verbal: pronomes, prefixos e clíticos pessoais 15

2.1 Pronomes pessoais livres, prefixos pessoais e marcadores clíticos de pessoa $\quad 15$

2.1.1 Omissão da $3^{\mathrm{a}}$ pessoa em Wayoro e ausência de hierarquia de pessoa para a marcação de morfemas pessoais no verbo ${ }^{1} \quad 20$

2.1.2 Lenição e pronomes iniciados por vogal em posição final 23

2.2 Verbos transitivos 26

$\begin{array}{ll}\text { 2.2.1 Paradigma de pessoa com verbos transitivos } & 27\end{array}$

$\begin{array}{ll}\text { 2.2.2 Cliticização dos pronomes livres } & 30\end{array}$

2.3 Verbos intransitivos $\quad 32$

2.3.1 O morfema te- $3^{\mathrm{a}}$ pessoa anafórica: concordância nos verbos intransitivos 34

2.4 homofonia entre prefixo, clítico e pronome livre 37

2.5 Nota sobre SNs e pronome de $1^{\text {a }}$ pessoa do singular em posição inicial 39

2.6 Verbos auxiliares 41

2.7 Itens com semântica de evento sem morfologia verbal 43

2.8 Sumarizando os fatos sobre pronomes, prefixos e clíticos 47

3 Morfologia verbal: causativo e voz média 48

3.1 Transitivização/causativização via prefixo $m \tilde{o}-\sim \tilde{o}-$

3.2 Prefixo transitivizador ete- 'sociativo' 51

3.3 Voz média via prefixo $e$ - $\quad 55$

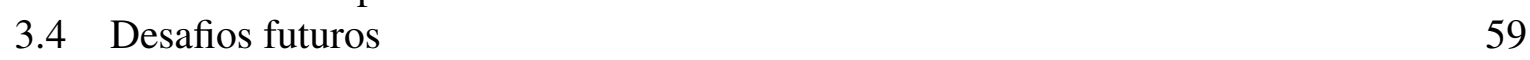


4 Tempo e aspecto, tipos sentenciais, modalidade e polaridade

$\begin{array}{lll}4.1 & \text { Tempo e Aspecto } & 62\end{array}$

$\begin{array}{lll}\text { 4.1.1 Verbalizadores e vogal temática } & 62\end{array}$

4.1.2 Análise do sufixo - $t$ como "não-futuro" 65

$\begin{array}{lll}\text { 4.1.3 Morfema na 'futuro' } & 67\end{array}$

4.1.4 Aspecto repetitivo/habitual e iterativo (intensificação e pluracionalidade do evento) 71

4.1.5 Sumarizando os fatos sobre morfemas de tempo e aspecto 74

4.2 Investigação sobre tipos sentenciais: declarativo, imperativo, hortativo $\quad 75$

$\begin{array}{lll}\text { 4.2.1 Declarativo e imperativo } & 76\end{array}$

$\begin{array}{lll}\text { 4.2.2 Hortativo } & 78\end{array}$

4.2.3 Sumarizando os fatos sobre tipos sentenciais declarativo, imperativo e $\begin{array}{ll}\text { hortativo } & 80\end{array}$

4.3 Distinções de Modalidade e Polaridade $\quad 81$

$\begin{array}{lll}\text { 4.3.1 Frustrativo } & 81\end{array}$

$\begin{array}{lll}\text { 4.3.2 } & \text { Especulativo } n \text { gwat } & 85\end{array}$

4.3.3 Elemento pega 'irrealis' e pare 'irrealis negativo' 86

$\begin{array}{lll}\text { 4.3.4 Enfático emõ } & 87\end{array}$

$\begin{array}{lll}\text { 4.3.5 Partícula kaat 'quotativo' } & 88\end{array}$

$\begin{array}{lll}\text { 4.3.6 Elemento tika 'desiderativo' } & 89\end{array}$

$\begin{array}{lll}\text { 4.3.7 Similativo nengan } & 89\end{array}$

$\begin{array}{lll}4.4 & \text { Polaridade negativa: sufixo - ap } & 90\end{array}$

4.5 Considerações finais 91

5 Nominalização, Subordinação e Finitude $\quad 94$

5.1 Nominalização, subordinação e finitude $\quad 94$

5.1.1 Nominalização em Proto-Tupi e na subfamília Tupari 97

5.1.2 Nominalização vs. subordinação em Wayoro 99

5.2 Nota sobre Gramaticalização envolvendo construções com $-p \sim-m \quad 100$

5.3 Nominalização de sintagma verbal (SV) via sufixo - $p \sim-m \quad 103$

5.3.1 Nominalização como modificador de nome inalienável 109

5.4 Subordinação via sufixo $-p \sim-m \quad 111$

$5.53^{\mathrm{a}}$ pessoa correferencial: distinção entre orações completivas dos verbos ndia $\begin{array}{ll}\text { 'querer' e toa 'ver' } & 118\end{array}$

5.5.1 Verbo toa 'ver' com sintagma nominal e com orações como complemento 121

5.5.2 Verbo ndia 'querer' com sintagma nominal e com orações como complemento 124

5.6 Verbos que exigem uma oração complemento em diversas línguas 125

$\begin{array}{ll}5.7 \text { Construções interrogativas com }-m \sim-p & 130\end{array}$

$\begin{array}{lll}\text { 5.7.1 Expressões interrogativas } & 131\end{array}$

5.7.2 Movimento de constituinte de oração completiva e a dificuldade em elicitar sentenças bioracionais 134

5.8 Produtividade e Previsibilidade Semântica 137

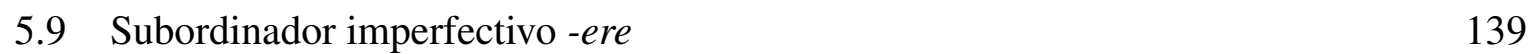

5.10 Comparação entre propriedades de Nominalização e Subordinação (infinitivas) 140 


\section{Predicação não verbal}

6 Predicação não verbal

$\begin{array}{ll}\text { 6.1 Predicação negativa com cópula } e \text { - } & 147\end{array}$

$\begin{array}{ll}\text { 6.1.1 A cópula } e \text {-: evidência sintática } & 148\end{array}$

6.1.2 A cópula $e$-: processos morfofonológicos 150

6.1.3 Identificação/Categorização e Negação de Identificação 152

$\begin{array}{lll}\text { 6.1.4 Posse e Negação da Posse } & 153\end{array}$

6.2 Propriedade e Negação de Propriedade: Adjetivo vs. Nome vs. Verbo 154

$\begin{array}{ll}\text { 6.2.1 Adjetivos vs. Nomes } & 156\end{array}$

6.2.2 Adjetivos e Verbos: Negação e $3^{\text {a }}$ pessoa 158

$\begin{array}{lll}\text { 6.2.3 Duplicação e categorias gramaticais } & 164\end{array}$

$\begin{array}{ll}\text { 6.2.4 Adjetivos e morfemas de mudança de categoria } & 166\end{array}$

6.3 mbiro: verbo irregular 'existencial, ter' e posposição 'com' 167

$\begin{array}{ll}\text { 6.3.1 Usos de mbiro como posposição 'com' } & 169\end{array}$

6.4 Localização e Existencial negativo 'ãam 169

$\begin{array}{lll}\text { 6.4.1 Estrutura argumental de 'ãam: posposição ou verbo? } & 171\end{array}$

6.4.2 Casos de incorporação: tandjora 'engravidar', ekentakwa 'vomitar', piora 'cavar' e 'ãamngora 'procurar (sem encontrar)' 173

$\begin{array}{ll}\text { 6.5 Considerações finais } & 177\end{array}$

7 Considerações finais $\quad 180$

$\begin{array}{ll}\text { Referências Bibliográficas } & 182\end{array}$ 


\section{Introdução}

\subsection{Povo Wajuru e língua Wayoro (subfamília Tupari, Tupi)}

O povo Wajuru (também denominado Wayoró, Ajuru, Ayuru) está localizado, atualmente, na Terra Indígena (TI) Rio Guaporé (município de Guajará-Mirim, Estado de Rondônia, Brasil) e em Rolim de Moura do Guaporé (município de Alta Floresta d'Oeste, Rondônia) (SESAI, 2013; ISA, 2018; SOARES-PINTO, 2009). A presente pesquisa se desenvolveu na aldeia Ricardo Franco, Terra Indígena Rio Guaporé.

O Povo Wajuru vivia, antes do contato, nas cabeceiras dos rios Colorado e Terebito (SNETHLAGE, 1937; MALDI, 1991). No entanto, em 1912, tal povo foi expulso de suas terras tradicionais. Nesse período, como consequência dos primeiros contatos, os Wajuru foram ainda vítimas de uma epidemia de sarampo que praticamente os dizimou (SOARES-PINTO, 2009).

No mapa 1.1, é possível ver o processo de deslocamento (registrado por Emil-Heinrich Snethlage, em 1934) sofrido por grupos Wajuru para o Seringal São Luiz e depois para a TI Rio Guaporé. 
Figura 1.1: Mapa atualizado da rota de Emil-Heinrich Snethlage e os povos visitados por ele (círculos vermelhos indicam localizações dos Wajuru) Fonte (MERE, 2013, p. 781), mapa elaborado por Siegfried Schacht.

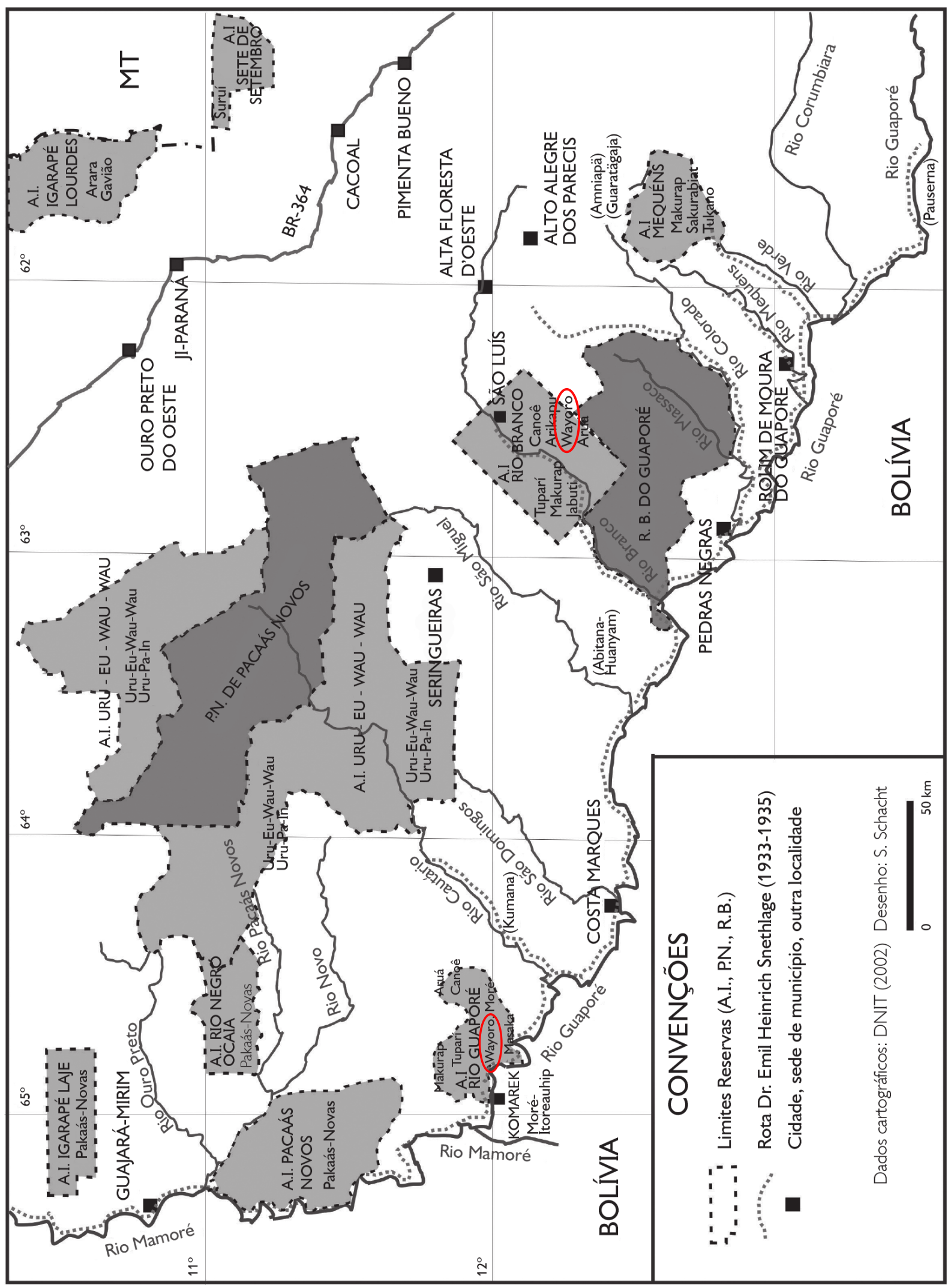


Atualmente, a população Wajuru é de cerca de 250 pessoas (FUNDAÇÃO NACIONAL DE SAÚDE (FUNASA), 2016 apud ISA, 2018). Dados da FUNASA/SESAI Guajará-Mirim de 2016 contabilizam 87 pessoas da etnia Wajuru vivendo na TI Rio Guaporé (aldeias Baia das Onças, Baia Rica, Urussari, Ricardo Franco), como se pode observar na Tabela 1.1.

Tabela 1.1: População Wajuru TI Rio Guaporé (FUNDAÇÃO NACIONAL DE SAÚDE (FUNASA), 2016)(SESAI/FUNASA, 2016)

\begin{tabular}{l|c|c|c|c|c|c|c}
\hline Aldeia & Criança & Adolescente & Adulto & Idoso & Homem & Mulher & Total \\
\hline Baia Das Onças & 3 & 2 & 6 & & 6 & 5 & 11 \\
\hline Baia Rica & 3 & & 2 & & 2 & 3 & 5 \\
\hline Urussari & 5 & 1 & 5 & & 1 & 10 & 11 \\
\hline Ricardo Franco & 26 & 14 & 18 & $2^{1}$ & 32 & 28 & 60 \\
\hline Total & $\mathbf{3 7}$ & $\mathbf{1 7}$ & $\mathbf{3 1}$ & $\mathbf{2}$ & $\mathbf{4 1}$ & $\mathbf{4 6}$ & $\mathbf{8 7}$ \\
\hline
\end{tabular}

A língua Wayoro não é mais falada diariamente. Há 3 pessoas idosas (idade entre 70 e 88 anos) que podem ser consideradas falantes fluentes ${ }^{2}$ em Wayoro. Dois desses falantes fluentes são de etnias diferentes que passaram a viver entre os Wajuru quando crianças, como consequência das relações interétnicas na região do Médio Guaporé (SOARES-PINTO, 2009). Um deles é bilíngue Djeoromitxi-Wayoro e outro é de semifalante Makurap. Com relação à língua portuguesa, os três falantes fluentes de Wayoro têm relativa fluência em português brasileiro. Há 11 semifalantes e não há criança ou adolescente que tenha aprendido a língua, recentemente (NOGUEIRA, 2011).

No Atlas of the World's languages in Danger, Moseley (2010) classifica a língua Wayoro como língua severamente ameaçada (catalogada como Ajuru). Uma língua severamente ameaçada é descrita como língua falada por avós ou gerações mais velhas, enquanto que a geração dos pais, apesar de entende-la, não fala a língua para seus filhos ou entre os demais (MOSELEY, 2010). Pode-se constatar que os Wajuru sofreram constantes violações de direitos humanos, dentre eles, a violação aos direitos linguísticos. Recorrentemente relatam que foram proibidos de falar sob ameaças de castigos e humilhações.

Na TI Rio Guaporé convivem 10 etnias diferentes, a saber, Makurap, Tupari, Wajuru, Djeoromitxi, Cujubim, Kanoé, Aruá, Arikapú, Massaká e indivíduos de diferentes subgrupos Wari'. Observa-se o uso do português, quase que hegemonicamente, e o desuso das línguas indígenas entre as etnias. Membros da comunidade e professores têm se esforçado para valorizar as línguas da comunidade, desenvolvendo atividades de consulta aos idosos que ainda falam as línguas indígenas e conferindo importância fundamental à disciplina Língua Materna ${ }^{3}$. O

\footnotetext{
${ }^{1}$ Destes dois idosos, apenas um deles é falante fluente da língua Wayoro.

${ }^{2}$ Adotaremos a diferença entre falantes fluentes (fluent speakers) e semifalantes (semi-speakers) proposta por Grinevald e Bert (2011, p. 49-51). Os dados relacionados aos semifalantes são registrados em Moore (2011, comunicação pessoal).

${ }^{3}$ Alguns professores comentaram sobre o desejo de aumentar a carga horária semanal da disciplina, solicitação em discussão com a Secretaria de Educação. Tal disciplina se refere ao estudo de línguas das etnias da TI Rio Guaporé, na escola da aldeia Ricardo Franco. Vale frisar que as novas gerações da TI Rio Guaporé têm aprendido o português brasileiro como primeira língua.
} 
trabalho de documentação, descrição e análise da língua Wayoro foi iniciado em 2008. Entre 2012-2013, realizamos pequisas voltadas à construção de materiais pedagógicos para a língua Wayoro. Resultaram destas pesquisas a proposta de sistema ortográfico (NOGUEIRA, 2012) e dois materiais didáticos (produção técnica elaborada pela Comunidade Wajuru da TI Rio Guaporé, sob consultoria linguística da presente autora em 2015 e 2017) - um material de apoio à alfabetização Wayoro-Português (séries iniciais) e outro material (acompanhado de vocabulário Wayoro-Português) direcionado ao público jovem.

A língua Wayoro pertence à família linguística Tupari, tronco Tupi, assim como as línguas Akuntsú, Makurap, Sakurabiat (ou Mekens) e Tupari, também de Rondônia (MOORE; GALUCIO; JUNIOR, 2008).

Durante sessões de elicitação e transcrição de textos, os colaboradores têm apontado diferenças lexicais relacionadas aos subgrupos da etnia Wajuru. Soares-Pinto (2009, p. 7879) descreve três subgrupos: Ngwayoroiat 'povo da Pedra', Ngwãkuyãian 'povo dos Cotia' e Kupndiiriat 'povo do Mato'. Identificamos, até o momento, variação lexical entre os subgrupos Ngwayoroyat/Wayoroiat e Kupndiiriat.

Tabela 1.2: Variação Dialetal lexical entre subgrupos Wajuru

\begin{tabular}{lll}
\hline Ngwayoroiat/Wayoroiat & Kupndiiriat & \\
\hline \hline ipit & otape & 'vagina' \\
ndeke & ege & 'ele (3SG)' \\
txire/txi- & kire/ki- & 'nós' (1PL.INCL) \\
djat & eat & 'vocês (2PL)' \\
kanin & uruk & 'moça (vocativo)' \\
\hline
\end{tabular}

Uma variação fonológica registrada entre estes subgrupos é encontrada nas palavras com

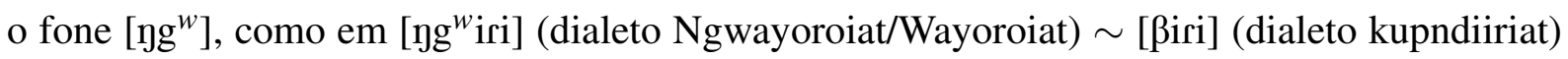
'açaí'. A identificação do subgrupo como Ngwayoroiat $\sim$ Wayoroiat é, igualmente, um exemplo dessa variação fonológica.

\subsection{Trabalhos de campo, metodologia e armazenamento de dados}

Os dados apresentados nesta tese foram coletados em Guajará-Mirim, Rondônia (Brasil). Trata-se majoritariamente de dados primários gravados/anotados durante cerca de 11 meses no total: junho de 2008; fevereiro de 2010; março de 2010; outubro de 2010; junho de 2012; outubro de 2012; abril de 2013; dezembro de 2013; novembro de 2015; outubro de 2016; novembro 
de $2017^{4}$. As gravações em audio (formato .WAV) e vídeo (formato .MPEG) realizadas somam cerca de 65 horas e fazem parte das seguintes categorias: sessões de elicitação e de transcrição de textos; narrativas individuais; narrativas tradicionais; descrição de procedimentos; conversas; músicas. Há, ainda, dados oriundos de elicitação com uso de estímulos como ferramenta, especificamente figuras (digitais ${ }^{5}$ ou desenhadas manualmente por colaboradores indígenas).

Há 35 textos dos quais 21 apresentam transcrição (total ou parcial) ${ }^{6}$. As anotações de itens em Wayoro somam cerca de 7.000 registros (incluindo evidências negativas) anotados em, aproximadamente, 590 páginas $^{7}$.

Gippert, Himmelmann e Mosel (2006, p. 72) apontam para a necessidade de se respeitar os diferentes tipos de talento dos colaboradores. Rangel (2017, p. 119), em estudo sobre os tipos de falantes de Ayapaneco (família mixe-zoque, México), chama a atenção para a variação na competência linguística de acordo com os eventos comunicativos. Menciona Rangel (2017): "há falantes capazes de contar uma história mas incapazes de sustentar uma conversação ou vice-versa" ${ }^{\circ}$. Os falantes fluentes com quem trabalhamos na pesquisa foram sugeridos pela comunidade Wajuru da Terra Indígena Rio Guaporé. Ao longo da pesquisa, buscamos adequar o tipo de investigação linguística ou documentação às características de cada colaborador. Como mencionamos anteriormente, os falantes fluentes de Wayoro caracterizam-se como pessoas idosas. Há, ainda, particularidades que devem ser consideradas na investigação linguística com pessoas idosas, como a inadequação de trabalhos por longos períodos, tal como observa Bowern $(2008)^{9}$.

Como mencionamos, há onze semifalantes da língua Wayoro. Grinevald e Bert (2011, p. 50) definem a categoria de semifalante da seguinte maneira: "[trata-se de] uma ampla categoria que inclui todos os membros da comunidade com habilidade de recepção satisfatória, mas com distintos níveis de habilidade de produção" ${ }^{10}$. A colaboração de semifalantes da Terra Indígena Rio Guaporé é essencial para a tradução de textos. Como afirma Bowern (2008, p. 138), "semifalantes podem ter várias habilidades diferentes. Podem não ser capazes de contar

\footnotetext{
${ }^{4}$ Segue a descrição do financiamento: junho/2008 Museu Paraense Emílio Goeldi/Ministério da Ciência e Tecnologia; as pesquisas realizadas durante o mestrado, fevereiro, março, outubro/2010 bem como durante o doutorado, setembro/2015, tiveram financiamento CAPES/Departamento de Linguística/USP; junho e outubro/2012 Bolsa Programa de Capacitação Institucional-PCI, processo 300193/2012-2, Museu Paraense Emílio Goeldi/Ministério da Ciência e Tecnologia; outubro/2016 Instituto do Patrimônio Histórico e Artístico Nacional (IPHAN) - Inventário Nacional da Diversidade Linguística; abril e dezembro/2013 foram ralizados por conta própria.

${ }^{5}$ Lima, S.; Rothstein, S. The count/mass distinction questionnaire. Não publicado.

${ }^{6}$ Um exemplar de texto transcrito pode ser conferido em Nogueira, Macurap e Wajuru (2019). Disponível em: https://revistas.ufrj.br/index.php/rl/article/view/25574

${ }^{7}$ A soma de itens inclui palavras isoladas. Como lembra Himmelmann (2011, p. 173), a enunciação de uma palavra isolada pode constituir um enunciado mínimo, apresentando importância, por exemplo, à prosódia.

8 "certaines situations montrent des locuteurs capables de raconter une histoire mais incapables de soutenir une conversation ou vice versa. On parle alors de compétences variées en fonction des CE [communicative event]." (RANGEL, 2017, p. 119)

9“The last speakers may be fluent, but old and frail, and not able to work for long periods" (BOWERN, 2008, p. 131).

10 “a large category which includes all members of the community with appropriate receptive skills in the language, but varying levels of productive skills." (GRINEVALD; BERT, 2011, p. 50)
} 
histórias, mas podem ainda conhecer práticas tradicionais, ou ter amplo vocabulário de palavras e frases isoladas. Podem não ser capazes de fazer julgamentos de gramaticalidade, porém ainda podem ser capazes de traduzir" ${ }^{11}$. Apesar da limitação da produção, há semifalantes de Wayoro com amplo vocabulário de palavras e frases isoladas, bem como capazes de traduzir textos.

Bowern (2008, p. 8, itálico do autor) sugere um modelo de trabalho de campo "que equilibra a elicitação (ou seja, fazer perguntas sobre a língua) com coleta de dados por outros métodos, incluindo conversa livre, gravação de narrativa e entrevistas" ${ }^{\prime 2}$. Temos investido neste modelo de trabalho de campo.

Como método de coleta de dados usamos diferentes técnicas de elicitação: (a) tradução de português para Wayoro, (b) tradução de Wayoro para português, (c) manipulação de dados, (d) solicitação de julgamento de gramaticalidade, (e) questões sobre sentenças já elicitadas ou sobre sentenças de textos (BOWERN, 2008, p. 77). Veja um exemplo da técnica de tradução de português para Wayoro, na Tabela 1.3, e de solicitação de julgamento de gramaticalidade, na Tabela 1.4 (FN-Fernanda Nogueira).

Tabela 1.3: Tradução Português-Wayoro do verbo djapnga 'fritar'

\begin{tabular}{lc}
\hline \multicolumn{2}{l}{ Tradução Português-Wayoro do verbo djapnga 'fritar' } \\
\hline FN: & 'Eu fritei o peixe', por exemplo, como a senhora diria? \\
\hline Colab: & 'Uwoy midjapnga \\
\hline FN: & Uwoy ... \\
\hline Colab: & 'Uwoy midjapnga \\
\hline FN: & Dá para falar também on 'uwoy djapnga? \\
\hline Colab & Também. \\
\hline FN: & 'Eu fritei o peixe'. Fale, por favor. \\
\hline Colab: & on 'uwoy djapngat \\
\hline
\end{tabular}

É importante ressaltar que consideraremos como agramaticais as respostas da colaboradora "não dá, não", "não tem" (ou similares), quando solicitado o julgamento de gramaticalidade de uma sentença, tal como podemos observar (em negrito), na transcrição da sessão de elicitação sobre o verbo engukwa 'suar'.

As razões que levam à falha ou ao julgamento da sentença como agramatical podem não estar relacionadas a um fator específico, mas a fatores diversos e independentes (sintáticos, semânticos, fonético-fonológicos e pragmáticos), como aponta Adger (2003, p. 66). Por esse motivo, quando realizamos a tradução de Wayoro para português e testes de julgamento de gramaticalidade sempre solicitamos aos colaboradores a repetição da sentença duas vezes. Ao reproduzir a sentença, o colaborador faz os ajustes necessários (como a indicação de tempo)

\footnotetext{
11 "semispeakers can have many different skills. Someone might not be able to tell stories but they might still know traditional practices, or have a large vocabulary of single words and phrases."(BOWERN, 2008, p. 138)

12 "In this book I discuss a model which balances elicitation (i.e., asking questions about the language) with data collection by other methods, including free conversation, narrative recording and interviewing."(BOWERN, 2008, p. 8)
} 
Tabela 1.4: Solicitação de Julgamento de gramaticalidade sobre o verbo engukwa 'suar'

\begin{tabular}{lc}
\hline \multicolumn{2}{l}{ Solicitação de Julgamento de gramaticalidade sobre o verbo engukwa 'suar' } \\
\hline FN: & Vamos trabalhar com 'suar', agora ... 'Eu suei' \\
\hline Colab: & mengukwaron \\
\hline FN: & Existe eengukwakwa 'você está suando muito'? \\
\hline Colab: & eengukwakwa, não, tem não [risos]. Só se for teengungukat. \\
\hline FN: & teengungukat. Isso vai ser para muita gente? \\
\hline Colab: & Ele está suando muito, aí diz teengungukat. \\
\hline
\end{tabular}

ou fornece uma sentença bem formada que é correspondente ou se aproxima à interpretação solicitada.

Sessões desse tipo foram empregadas para a obtenção de sentenças complexas (incluindo orações subordinadas). Bowern (2008, p. 75) aponta que os princípios de elicitação funcionam exatamente da mesma maneira para dados mais complexos. Tais sessões de estudo sobre orações subordinadas foram essenciais para a constituição de um conjunto de dados passíveis de generalizações, uma vez que são poucas as ocorrências de subordinadas nos textos traduzidos (cf. no Capítulo 5 que existe uma tendência nas línguas para produção de sentenças curtas). Bowern (2008, p. 73) explica que "alguns aspectos de uma língua são descobertos somente através de elicitação - eles aparecem em textos tão raramente que será quase impossível conseguir informação suficiente sobre eles" ${ }^{\prime 13}$.

Noonan (2007, p. 149) considera que a melhor técnica para obter dados sobre sistemas de complementação é a elicitação com falantes nativos. Seguimos ainda a orientação do autor de que se deve elicitar dados sobre sentenças complexas somente após o exame das sentenças simples e da elaboração de um esboço da morfologia verbal e nominal.

Como explicita Bowern (2008, p. 14), uma descrição adequada de uma língua precisará utilizar variados métodos, incluindo (mas não se limitando à) elicitação.

As transcrições de sentenças e textos foram registradas em cadernos de campo, em documentos de arquivos Word (.DOCX) e arquivos Transcriber File (.TRS, Transcriber ${ }^{14}$ ). Como ferramenta para armazenamento de dados, utilizamos o programa FieldWorks Language Explorer (FLEx $)^{15}$, o qual permite a inserção de informações morfológicas/glosas que otimizam a análise de sentenças. Outra função do FLEx é a construção de dicionários através da ferramenta Léxico. A partir do uso dessa ferramena, um Vocabulário Wayoro-Português foi agregado ao material didático Wayoro emẽto (não publicado). Atualmente, as transcrições de textos em audio e vídeo tem sido efetuadas exclusivamente com o programa ELAN-EUDICO Linguistic Annotator $^{16}$ (arquivos .EAF).

\footnotetext{
13 "Some aspect of a language are only discoverable through elicitation - they will appear in texts so seldom that it will be almost impossible to get enough information about them." (BOWERN, 2008, p. 73).

14 http://www.etca.fr/CTA/gip/Projets/Transcriber/

15 http://fieldworks.sil.org/flex

16 https://tla.mpi.nl/tools/tla-tools/elan/
} 
Os dados aqui apresentados estão armazenados no Acervo Digital de Línguas e Culturas Indígenas do Museu Paraense Emílio Goeldi, seguindo o padrão IMDI de metadados (ISLE Meta Data Initiative - IMDI), a saber, código ISO-ano e mês da gravação-sigla do pesquisador(sigla do colaborador)-descrição sucinta do conteúdo. Tal código é indicado entre parênteses ao final de cada exemplo, tal como em (1), a seguir. Dados publicados anteriormente serão indicados pela referência bibliográfica. A apresentação dos dados segue as convenções de Leipzig propostas em Bickel, Comrie e Haspelmath (2015) e são organizados em quatro linhas: transcrição ortográfica, segmentação morfológica, glosas correspondentes, tradução em português.

(1) Mãkirẽy ugu nãn.

Mãkirẽy ugu nẽ-a-n

Mãkirẽy água fazer-V.T-NFUT

'Mãkirẽy fez [surgir] a água.' (WYR-20080616-AVG-ANT-Hist-agua-107)

Utilizaremos colchetes na linha da tradução para adicionar informação extra que auxilie a compreensão do dado, bem como a tradução literal de termos, quando necessário.

\subsection{Fonemas e fones}

O quadro de fonemas e alofones de Wayoro é apresentado nas Tabelas 1.5 e 1.6. Como descrito em Nogueira (2011), as consoantes nasais têm alofones pós-oralizados.

Tabela 1.5: Quadro de fonemas consonantais

\begin{tabular}{lllllll}
\hline & bilabial & alveolar & palato-alveolar & palatal & velar & lábio-velar \\
\hline \hline oclusiva & $\mathrm{p}$ & $\mathrm{t}$ & & & $\mathrm{k}$ & $\mathrm{k}^{\mathrm{w}}$ \\
nasal & $\mathrm{m}$ & $\mathrm{n}$ & & $\mathrm{j}$ & $\mathrm{y}$ & $\mathrm{\eta}^{\mathrm{w}}$ \\
tepe & & $\mathrm{r}$ & & & & \\
africada & & & $\mathrm{t} \int$ & & & \\
fricativa & $\beta$ & & & & \\
\hline
\end{tabular}

Tabela 1.6: Quadro de alofones consonantais

\begin{tabular}{lll}
\hline & fonema & alofones \\
\hline \hline nasal bilabial & $/ \mathrm{m} /$ & {$[\mathrm{m}, \mathrm{mb}]$} \\
nasal alveolar & $/ \mathrm{n} /$ & {$[\mathrm{n}, \mathrm{nd}]$} \\
nasal palatal & $/ \mathrm{p} /$ & {$\left[\mathrm{n}, \mathrm{j}, \tilde{\mathrm{j}}, \mathrm{nd}_{3}, \mathrm{~d}_{3}, \mathrm{j}^{\mathrm{t}}\right]$} \\
nasal velar & $/ \mathrm{y} /$ & {$\left[\mathrm{y}, \mathrm{jg}, \mathrm{gg}^{\mathrm{w}}, \mathrm{g}^{\mathrm{w}}, \mathrm{g}^{\mathrm{w}}\right]$} \\
\hline
\end{tabular}

O quadro de fonemas difere de Nogueira (2011) pela ausência dos segmentos oclusivos velar e lábio-velar vozeados $[\mathrm{g}] \mathrm{e}\left[\mathrm{g}^{\mathrm{W}}\right]$. Tais segmentos são melhor analisados como alofones dos fonemas nasais $/ \mathrm{y} /$ e $/ \mathrm{y}^{\mathrm{w}} /$, respectivamente, ocorrendo em ambiente intervocálico, entre vogais orais (NOGUEIRA, pesquisa em andamento). 
Como ilustrado no diagrama 1.2, os segmentos vocálicos são os seguintes: anteriores /i/, /ع/; centrais $/ \mathrm{u} /, / \mathrm{a} /$; posterior $/ \mathrm{o} /$. Essas vogais apresentam contraste quanto à duração e quanto à nasalidade.

Figura 1.2: Fonemas vocálicos

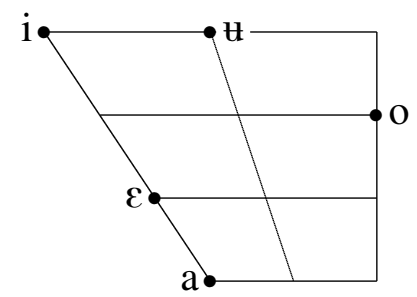

O quadro de grafemas da língua é constituído da seguinte maneira (NOGUEIRA, 2012) ${ }^{17}$. Grafemas Wayoro

- Consoantes: g, gw, k, kw, m, mb, n, nd, ng, ngw, p, r, t, w, tx, y, dj, ' (apóstrofo)

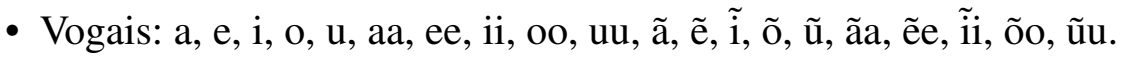

Confira na Tabela 1.7 a indicação dos segmentos consonanatais com os grafemas correspondentes.

Tabela 1.7: Quadro de segmentos consonantais e grafemas correspondentes

\begin{tabular}{|c|c|c|c|c|c|c|c|}
\hline & bilabial & alveolar & palato-alveolar & palatal & velar & Lábio-velar & Glotal \\
\hline oclusiva & $\mathrm{p}<\mathrm{p}>$ & $t<t>$ & & & $\mathrm{k}<\mathrm{k}>$ & $\mathrm{k}^{\mathrm{W}}<\mathrm{kw}>$ & {$[?]<\left\langle^{\prime}>\right.$} \\
\hline nasal & $\mathrm{m}<\mathrm{m}, \mathrm{mb}>$ & $\mathrm{n}<\mathrm{n}, \mathrm{nd}>$ & & $\mathrm{n}<\mathrm{y}, \mathrm{dj}>$ & $\mathrm{y}<\mathrm{ng}, \mathrm{g}>$ & $\mathrm{n}^{\mathrm{w}}<\mathrm{ngw}, \mathrm{gw}>$ & \\
\hline & & $\mathrm{f}<\mathrm{r}>$ & & & & & \\
\hline africada & & & $\mathrm{t} \int<\mathrm{tx}>$ & & & & \\
\hline fricativa & $\beta<w>$ & & & & & & \\
\hline
\end{tabular}

Quanto às vogais, temos a seguinte correspondência: $/ \mathrm{a} /<\mathrm{a}\rangle, / \varepsilon /<\mathrm{e}\rangle, / \mathrm{i} /<\mathrm{i}\rangle, / \mathrm{o} /<\mathrm{o}\rangle$, $/ \mathrm{u} /<\mathrm{u}>$.

A seguir, faremos observações sobre dois fones de Wayoro - a vogal central arredondada e a consoante oclusiva glotal — que não foram tratados em Nogueira (2011).

\section{Vogal central}

Nogueira (2011) representa a vogal central como um segmento não arredondado. Contudo, a descrição fonética da língua Wayoro realizada por Santos (2010) registra a existência da vogal alta central arredondada (além da vogal alta central não arredondada).

Desta forma, são necessárias evidências fonéticas para se definir o grau de arredondamento da vogal alta central da língua. A literatura indica efeitos notáveis do arredondamento dos lábios sobre o segundo formante, geralmente, diminuindo os valores do F2 (CATFORD, 1988).

\footnotetext{
${ }^{17}$ Processos morfofonológicos, como espalhamento de nasalidade e espirantização/sonorização em fronteira de palavras, não são indicados na ortografia, cf. materiais didáticos Wayoro, bem como Nogueira (2012).
} 
Revimos a transcrição corrente com base em pistas visuais, disponíveis na fase atual. Seguindo Ladefoged (2003, p. 32-36), foram coletadas a partir de imagens (gravação audiovisual) para visualização lateral e frontal da articulação da vogal central, utilizando um espelho contra um lado da face da colaboradora. Pudemos, assim, visualizar a articulação da vogal central, em contraste com vogais da língua com arredondamento /o/ e sem arredondamento /i/, como mostram as Figuras abaixo.

Figura 1.3: Articulação da $1^{a}$ e da $2^{a}$ vogal na palavra oti 'minha mãe'

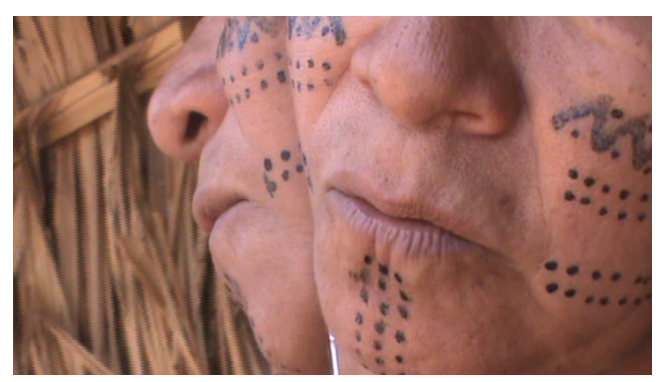

(a) $/ o / t i$

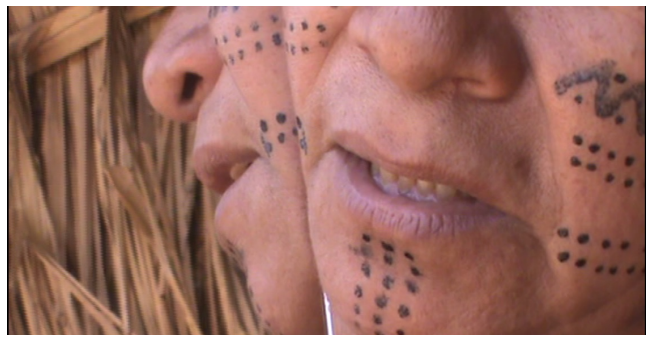

(b) $o t / i /$

Figura 1.4: Articulação da $1^{a}$ e da $2^{a}$ vogal na palavra oto 'minha testa'

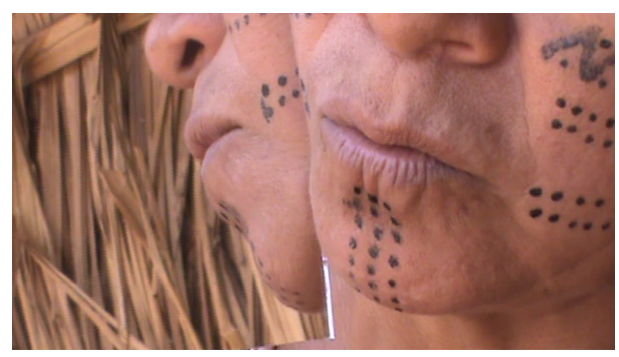

(a) $/ o / t o$

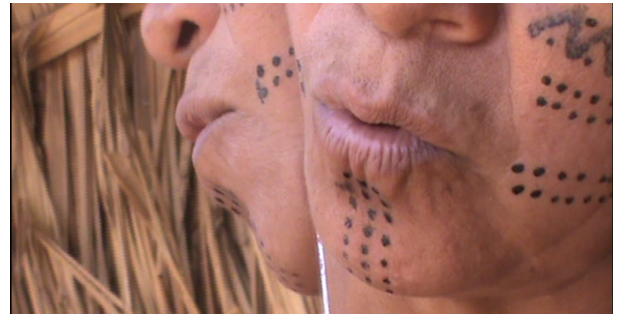

(b) $o t / o /$

Figura 1.5: Articulação da $1^{a}$ e da $2^{a}$ vogal na palavra otut 'minha espada'

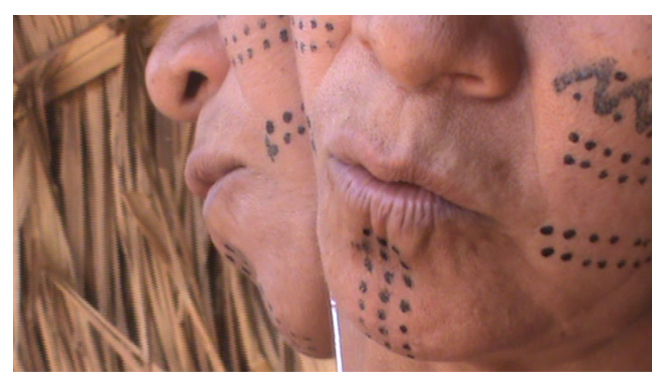

(a /o/to

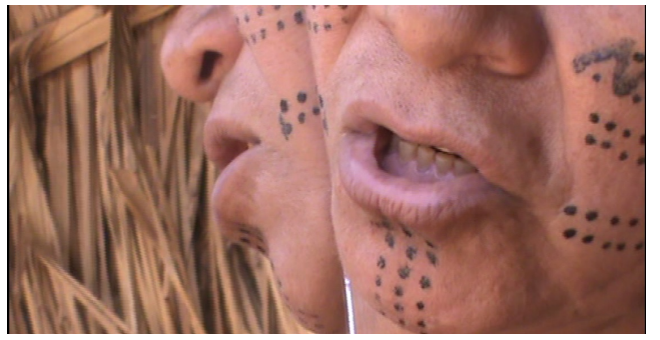

(b) $o t / w / t$

Essas imagens permitem visualizar um arrendondamento/protrusão dos lábios durante a produção da vogal central, embasando a revisão da transcrição. 


\section{Consoante Glotal}

A consoante glotal foi identificada foneticamente em Nogueira (2012). Os alomorfes da língua dão pistas sobre a existência dessa consoante. Por exemplo, o alomorfe de ' 1 a pessoa do singular' diante de radicais iniciados por vogal oral é $m b$-, diante de vogal nasal é $m$ - e diante de radicais iniciados por consoante é $o$-.

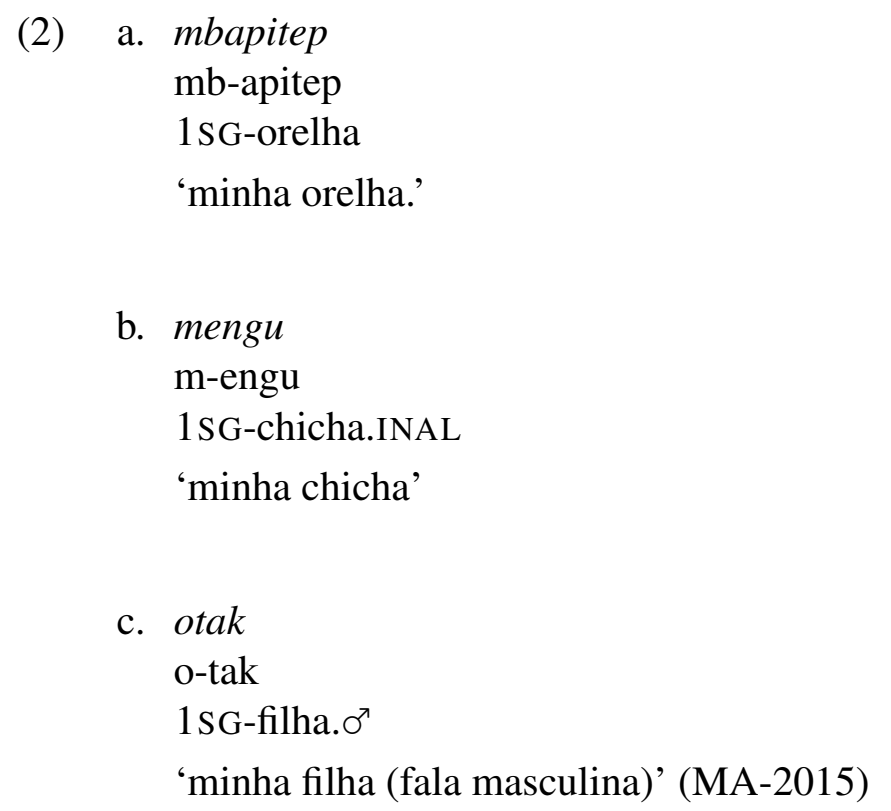

A presença do alomorfe $o$ - ' 1 a pessoa do singular' diante de palavras, como $2 u \beta a$ 'pote' e Pعga 'soluço' (cf. Tabela 1.8), indica que há uma consoante no início do radical. O último dado da tabela mostra que a glotal também pode ocorrer no interior da palavra.

Tabela 1.8: Evidências de realização do fone?

$$
\begin{aligned}
& \text { o- } \mathrm{z} \beta \mathrm{a} \text { 'meu pote' } \\
& \text { o-Prga 'meu soluço' } \\
& \text { a.pa.?a 'costurar rede horizontalmente' }
\end{aligned}
$$

Os dados apresentam a consoante oclusiva glotal sempre em início de sílaba. São necessárias mais investigações para se definir o valor fonológico dessa consoante em Wayoro.

\subsection{Propriedades gerais da gramática Wayoro}

A ordem básica de constituintes na língua Wayoro é Objeto-Verbo; o sujeito pode vir antes ou depois da unidade OV (NOGUEIRA, 2011). Trata-se de uma língua de núcleo final, pois, além do complemento do verbo, o complemento da posposição aparece imediatamente antes do núcleo (en eri 'de você', on mẽ 'para mim'). Não há morfologia de caso nos argumentos dos verbos. 
Tal como as demais línguas Tupi, Wayoro diferencia duas classes de morfemas pessoais: pronomes (livres) e prefixos/clíticos pessoais (formas presas). O comportamento dos pronomes e prefixos/clíticos pessoais pode ser usado como uma das ferramentas para se identificar as categorias gramaticas de Wayoro. Nogueira (2014) aponta que nomes podem ocorrer com prefixos como possuidor em uma construção possessiva (mb-apitep 'minha orelha', apitep 'orelha'). Adjetivos indicam obrigatoriamente o argumento modificado através de prefixos pessoais ( $m b$ akara 'eu estou/sou gorda', *akara). Há alguns nomes inalienáveis que também devem ocorrer com prefixo pessoal possuidor obrigatório (mb-ape 'meu caminho', *ape 'caminho'). Uma maneira de distinguir nomes e adjetivos é a possibilidade de coocorrência com pronomes livres: adjetivos permitem tal coocorrência (on mb-akara 'eu sou gorda') ${ }^{18}$, ao passo que os nomes não permitem (*mb-apitep on 'minha orelha').

Do ponto de vista morfológico, verbos se diferenciam de nomes e adjetivos por poderem apresentar: vogal temática - $a$; prefixos de alteração de valência, como $e$ - voz média e $m \tilde{o}$ - $\sim \tilde{o}$ transitivizador/causativo; por poderem indicar tempo 'não-futuro' por meio do sufixo - $t \sim-n$ e tempo futuro através do sufixo - $p$ 'infinitivo' mais o morfema na 'futuro'; por poderem indicar aspecto através de sufixos como $-k w a$ 'iterativo/pluracionalidade'. Algumas dessas características podem ser conferidas em (3).

a. txiewato

Mãkirẽy teatoa,

tet.

txi-ewato

Mãkirẽy te-ato-a

tet

1 PL.INCL-avô.INAL Mãkirẽy 3C-banhar.se-V.T ir

'Nosso avô Mãkirẽy se banhou, foi embora.' (WYR-20080616-AVG-ANT-Histagua-010)

b. emõatokwat

on.

$\mathrm{e}=\mathrm{mõ}-\mathrm{ato}-\mathrm{kwa}-\mathrm{t}$

on

$2 \mathrm{SG}=\mathrm{CAUS}-\mathrm{b} a n h a r . s e-I T E R-N F U T$ eu

'Eu banhei você.' (NOGUEIRA, 2011, p. 149)

$\mathrm{O}$ argumento absolutivo é indicado no verbo: formas presas ocorrem como marca de concordância com o sujeito do verbo intransitivo, como te- 'terceira pessoa correferencial', em (3a), e como marcadores clíticos de pessoa objeto, como $e=$ 'segunda pessoa do singular', em (3b). Os pronomes livres ocorrem como sujeito de verbos transitivos, como on 'eu', em (3), e

\footnotetext{
${ }^{18} \mathrm{Tal}$ comportamento pode ser motivado pelo fato de se tratarem de predicados em uma construção de cópula, em que a cópula foi apagada. Construções de cópula serão investigadas no Capítulo 6. Adicionalmente, note, a seguir, que, além do adjetivo akara 'gordo, largo', há o verbo intransitivo atua 'engordar' (com o morfema causativo, específico a esses verbos).
}

(1) emõatuat.

$\mathrm{e}=$ mõ-atu-a-t

$2 \mathrm{SG}=\mathrm{CAUS}$-engordar-V.T-NFUT

'(Ele) engordou você.' (PM-2016) 
como sujeitos de verbos intransitivos (opcionalmente), apontando para um sistema nominativoabsolutivo (GALUCIO; NOGUEIRA, 2018). Os pronomes livres funcionam ainda como objeto de posposição (en eri 'de você', on ere 'em mim').

Além de nomes, adjetivos, verbos e posposições, constatamos a categoria de advérbios (como ndaikut 'amanhã'). Há ainda morfemas livres que indicam propriedades sentenciais, como as marcas de modalidade.

\subsection{Estrutura da Tese}

A presente tese se organiza em dois blocos: Parte I Predicação verbal: formas finitas e não finitas e Parte II Predicação não-verbal. A Parte I discute os elementos de finitude identificados na gramática da língua, bem como os casos em que tais elementos não se fazem presentes ou estão reduzidos (como as ocorrências de verbos sem morfologia verbal e as orações subordinadas). Iniciamos discutindo, no Capítulo 2, os marcadores de pessoa da língua Wayoro, a saber, pronomes pessoais livres, prefixos pessoais e marcadores clíticos de pessoa. O intuito do capítulo é refinar as análises propostas em Nogueira (2011), Nogueira (2013), com base em novos dados. No Capítulo 3, são listados os processos de transitivização e intransitivização identificados na língua. No Capítulo 4, descrevemos os núcleos funcionais relacionados à indicação de tempo (como o sufixo de não-futuro) e aspecto (como o sufixo de repetição/habitual), tipos sentenciais, modalidade e polaridade. No último capítulo da Parte I, Capítulo 5, discutimos os temas da nominalização e subordinação, mencionando as propriedades da finitude relevantes para diferenciação dessas construções. Na Parte II, Capítulo 6, descrevemos as estratégias de predicação não verbal em Wayoro. Tais estratégias contrastam com as propriedades de finitude da predicação verbal. 


\section{Parte I}

\section{Predicação verbal: formas finitas e não finitas}




\title{
Morfologia verbal: pronomes, prefixos e clíticos pessoais
}

\author{
Teamõyã, tetiapkwa, tepaga aramĩraian \\ ngwaykupiat. \\ Os homens e as mulheres dançam, \\ alegram-se, embriagam-se. (Paulina \\ Macurap, sobre as festas antigas)
}

\subsection{Pronomes pessoais livres, prefixos pessoais e marcadores clíticos de pessoa}

As Tabelas 2.1 e 2.2 apresentam os pronomes e os prefixos/clíticos pessoais em Wayoro.

Tabela 2.1: Pronomes pessoais livres

\begin{tabular}{l|l|l|l}
\hline & Singular & Plural & \\
\hline \hline $1^{\mathrm{a}}$ pessoa & on & $\begin{array}{l}\text { txire } \\
\text { ote }\end{array}$ & $\begin{array}{l}\text { (inclusiva) } \\
\text { (exclusiva) }\end{array}$ \\
\hline $2^{\mathrm{a}}$ pessoa & en & djat & \\
\hline $3^{\mathrm{a}}$ pessoa & ndeke & ndeat & \\
\hline
\end{tabular}

Tabela 2.2: Prefixos/clíticos pessoais

\begin{tabular}{|c|c|c|c|}
\hline & Singular & Plural & \\
\hline $1^{\mathrm{a}}$ pessoa & $m-/ m b-\sim o^{1}$ & $\begin{array}{l}\text { txi- } \\
\text { ote- }\end{array}$ & $\begin{array}{l}\text { (inclusiva) } \\
\text { (exclusiva) }\end{array}$ \\
\hline $2^{\mathrm{a}}$ pessoa & $e-$ & djat- & \\
\hline $3^{\mathrm{a}}$ pessoa & $\begin{array}{l}t e- \\
y-\sim d j-\sim \emptyset-\end{array}$ & $\begin{array}{l}t e- \\
y-\sim d j-\sim \emptyset-\end{array}$ & $\begin{array}{l}\text { (sujeito de verbo intransitivo) } \\
\text { (objeto) }\end{array}$ \\
\hline
\end{tabular}

\footnotetext{
${ }^{1}$ Os alomorfes consonantais ocorrem diante de raízes iniciadas por vogais: $m$ - diante de vogais nasais e $m b$ diante de vogais orais. O alomorfe $o$ - ocorre diante de raízes iniciadas por consoantes (NOGUEIRA, 2011, 2013, 2014).
} 
As formas de $3^{\mathrm{a}}$ pessoa $<\mathrm{y}->$ [n] e $<\mathrm{dj}->$ [dz] são usadas diante de raízes iniciadas por vogais nasais e orais, respectivamente. Diante de consoantes, há o alomorfe zero. Como explicitado em Nogueira (2011, p. 81), "quando verbos transitivos são iniciados por consoantes há a possibilidade de que o argumento objeto não seja realizado fonologicamente" ${ }^{2}$. Em Wayoro, os pronomes livres ndeke ' $3^{\mathrm{a}}$ pessoa singular' e ndeat ' $3^{\mathrm{a}}$ pessoa plural' podem ser usados na função de objeto, em substituição ao alomorfe zero, muito provavelmente para evitar a ambiguidade ou tornar a referência mais explícita (uma vez que estas formas de $3^{\mathrm{a}}$ pessoa distinguem singular e plural). ${ }^{3}$

A distinção observada em Wayoro entre primeira pessoa do plural inclusiva txire/txi- e primeira pessoa do plural exclusiva ote/ote- ocorre em todas as famílias linguísticas do tronco Tupi. Tal fato leva Rodrigues e Cabral (2012, p. 533) a assumirem que Proto-Tupi também distinguia uma primeira pessoa do plural inclusiva de uma primeira pessoa do plural exclusiva, embora com base nos cognatos apenas para esta última seja possível propor uma reconstrução $\left(*^{*} o r^{j} e\right)$.

Essa distinção na primeira pessoa do plural é uma característica comum às línguas da América do Sul, especialmente na região oeste, conforme estudos realizados por Birchall (2014, p. 205) e por Crevels e Muysken (2005).

A distinção entre os dois marcadores de pessoa, em Wayoro, fica evidente na tradução de textos, em trechos de discurso direto em que os personagens utilizam as formas de $1^{\text {a }}$ pessoa do plural inclusiva ou exclusiva. Em uma versão do mito das Amazonas, as mulheres, comandadas por sua chefa (cacique-feminina), tentam exterminar todos os homens, matando cada uma o seu marido e, depois, ingerindo-os. As mulheres dão início a uma matança generalizada dos homens. Para se vingar e evitar seu extermínio, os homens travam guerra com as mulheres. $\mathrm{O}$ trecho em (4) conta que um rapaz foi designado para espioná-las. Ao constatar o fato, o rapaz usa a primeira pessoa do plural inclusiva $t x i=$.

(4) toat $\quad$ on $^{4}$, nemõ, aramĩraian txipikiat!

top-a-t on n-emõ aramĩra-ian txi=piki-a-t

ver-V.T-NFUT eu ?-ENF mulher-PL 1 PL.INCL=acabar-V.T-NFUT

“"Eu vi, é mesmo, a mulherada está acabando com a gente.” (WYR-20080627-FN-PMa-chefe-das-mulheres 51)

\footnotetext{
${ }^{2}$ Um alomorfe zero para a terceira pessoa objeto do verbo transitivo é também atestado em Tupari por Singerman (2018).

${ }^{3}$ Agradeço a sugestão ao professor Dr. Enrique L. Palancar, na ocasião de minha apresentação no Seminário Description et typologie linguistiques, em 26 de junho de 2018, no Centro de pesquisa linguística SeDyL (Languages Structures and Dynamics), Villejuif-França.

${ }^{4}$ Em posição pós-verbal, os pronomes on ' 1 a pessoa do singular', en ' $2^{\mathrm{a}}$ pessoa do singular' e ote ' 1 a pessoa do plural exclusiva' se unem fonologicamente ao sintagma verbal, como em $y=$ ombaa- $\mathrm{r}=$ on 'Eu bati nele/a(s)'. A consoante final sofre espirantização e sonorização, mudando de [t] para [r]. Esse fenômeno será descrito na seção 2.1.2. Uma vez que os dados aqui apresentados estão em transcrição ortográfica, o processo de lenição (espirantização) da consoante final de um verbo diante de pronome iniciado por vogal será indicado apenas quando for necessário.
} 
O diálogo abaixo é entre os homens e duas garotas, a irmã mais velha e a irmã mais nova, que foram poupadas por afirmarem não ter comido outro homem, no caso, o irmão. O dado é um exemplo de uso da primeira pessoa do plural exclusiva ote.
a. Djarokwa korom nen djat?
djat-okwa ko-rom nẽn djat
2PL-irmão.९ ingerir-NEG INTERR. 2 vocês
'Vocês não comeram o irmão de vocês?'

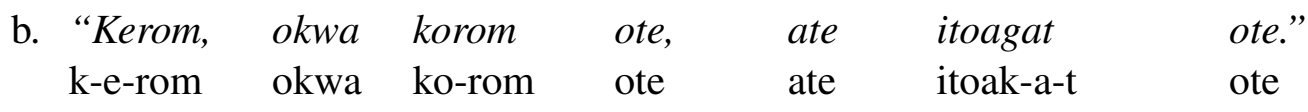

?-COP-NEG irmão.९ comer-NEG nós.EXCL somente chorar-V.T-NFUT nós.EXCL

'Não, nós não comemos nosso irmão, estamos só chorando por ele.' (WYR20080627-FN-PM-a-chefe-das-mulheres-61-62)

As orações em Wayoro são predominantemente OV, se transitivas — SOV ou OVS - e VS ou SV, se intransitivas. Não há marcação de caso nos argumentos sujeito e objeto da oração ${ }^{5}$. No trecho de texto em (6), podemos ver claramente a posição anterior ao verbo como relacionada à função de objeto, aramĩra 'mulher' e txi= ' $1^{\mathrm{a}}$ pessoa do plural inclusiva'. Discutiremos, adiante, que, na posição de objeto, não coocorre marca de pessoa com um SN ou pronome livre correspondente. Em aramĩra ombokwap nã txire 'Nós vamos matar a mulher', não há marca de objeto no verbo. Quando o objeto é marcado por morfema de pessoa ligado ao verbo, como em aramĩra txipikiat 'a mulher está nos acabando', não coocorre o pronome livre correspondente, no caso a $1^{\mathrm{a}}$ pessoa do plural inclusiva txire.

(6) Pare! enã aramĩra ombokwap nã txire. Txiandoap nã, pare enã aramĩra ombo-kwa-p nã txire txi-?ando-a-p nã bom agora mulher bater-VZR-INF FUT nós.INCL 1 PL.INCL-?vingar-VZR-INF FUT aramĩra txipikiat, pare aramĩra txi=piki-a-t pare mulher 1PL.INCL=acabar-V.T-NFUT bom 'Está bom! agora, nós vamos matar a mulher. Vamos nos vingar, a mulher está acabando com a gente, está bom!' (WYR-20080627-FN-PM-a-chefe-das-mulheres 55)

Outros exemplos textuais de marcadores de pessoa como objeto do verbo podem ser conferidos a seguir.
a. otoromboga, ugu eriat emõ toa
[o=top-romb-oga] ugu eriat emõ top-a $1 \mathrm{SG}=$ ver-NEG-FRUST água dono ENF ver-V.T

\footnotetext{
${ }^{5}$ Argumentos adjuntos, contudo, podem aparecer em um sintagma posposicional ou apresentar marcas de caso, como instrumental/essivo/alativo $m \tilde{o} \sim \tilde{o}$. Tais marcas de caso são também identificadas em posposições, como $p i=\tilde{o}$ 'para dentro [dentro=ALA]'. As marcas de caso se distinguem de posposição por se unirem fonologicamente ao núcleo a que se ligam, as posposições não tem esse comportamento.
} 
'Iriam me ver, mas não viram, viram só o dono da água.' (WYR-20080616-AVGANT-Hist-agua-66-67)

b. djauwa, yindiakwa auwa, djuwape auwa, djatoap [dj=au-wa] y-indiakwa au-wa dj-uwape au-wa dj-ato-a-p 3=curar-VZR 3-comida curar-VZR 3-bebida curar-VZR 3-banhar.se-V.T-NMLZ auwa.

au-wa curar-VZR

'(Ele [o marido]) está rezando/curando isso, curando a comida para ela/dela, curando a bebida dela, curando o banho dela.' (WYR-20100326-FN-PM-mulherestrela-12)

c. tximõoran $\tilde{e} e, \quad$ txiewato Mãkirẽy.

[txi=mõ-ot-a-n] ẽe txi-ewato Mãkirẽy 1 PL.INCL=CAUS-chegar-V.T-NFUT DEM 1PL.INCL-avô.INAL Mãkirẽy 'Esse fez nós chegarmos, nosso avô Mãkirẽy.' (WYR-20080616-AVG-ANT-Hist123)

Vale enfatizar, nos dados em (7), que a marca de pessoa objeto não coocorre com os pronomes livres ou SN correspondentes. Esta ausência de concordância nas marcas de pessoa em função de objeto é a pista fundamental para caracterizá-los como clíticos de pessoa, diferenciando-os dos prefixos pessoais nos verbos intransitivos, que são marcas de concordância com o SN ou pronome livre. Trata-se, portanto, de uma diferença estabelecida com base no comportamento sintático das formas pronominais presas. Vejamos.

Além de objeto, os morfemas de pessoa que aparecem ligados ao verbo indicam o sujeito, quando o verbo é intransitivo. Note, em (8), que o prefixo txi- primeira pessoa do plural inclusiva é sujeito do verbo atoa 'banhar-se'. Veremos, na seção 2.3, que, nos predicados verbais intransitivos, o pronome livre é opcional.

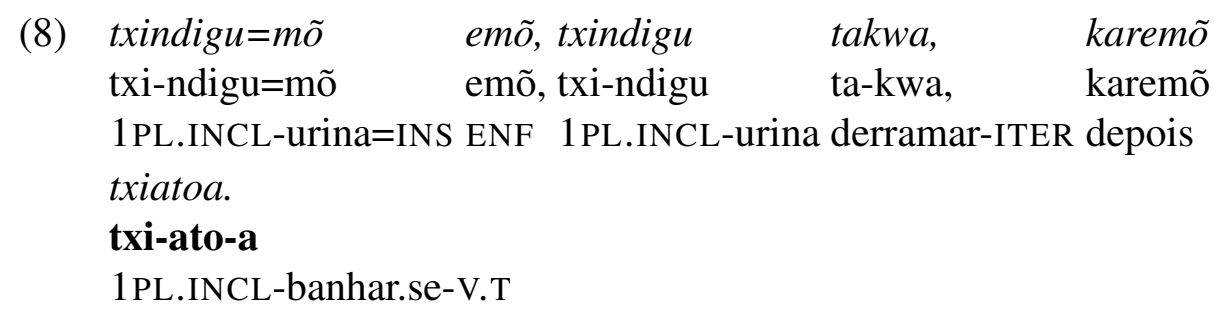

'[Quando não havia água] era mesmo com a nossa urina, urinávamos [lit. derramar nossa urina], depois nós nos banhávamos.' (WYR-20080616-AVG-ANT-Hist-agua002)

Os morfemas de pessoa ligados a verbos intransitivos apresentam a seguinte característica: coocorrem com o pronome livre ou SN correspondente, concordando com os mesmos. Veja, em 
(9), exemplos com txi- $1^{a}$ pessoa do plural inclusiva e com te- terceira pessoa correferencial.

(9) a. txire txiengukwat.

txire txi-engukwa-t

nós 1PL.INCL-Suar-NFUT

'Nós (inclusivo) estamos suando.' (PM-2017)

b. txiewato

Mãkirẽy teatoa,

tet

txi-ewato

Mãkirẽy te-ato-a

tet

1PL.INCL-avô.INAL Mãkirẽy 3C-banhar.se-V.T ir

'Nosso avô Mãkirẽy se banhou, foi embora.' (WYR-20080616-AVG-ANT-Histagua-010)

Comparando os dados em (8) e (9), podemos notar que, nas sentenças intransitivas, é opcional a presença do $\mathrm{SN}$ ou pronome livre com o qual o prefixo pessoal concorda.

Apresentamos, agora, exemplos textuais de morfemas livres usados como sujeito de verbo transitivo.

a. "mõendop toap nã on"

mõendop top-a-p nã on

conhecimento ver-V.T-INF FUT eu

'(Ele disse) "Eu vou ver o jeito dela [Lit. o saber dela]".' (WYR-20100326-FN-PM-

caracol-26)

b. "ndaikut, en emen ombaa".

ndaikut, en e-men ombo-a

amanhã você 2 SG-marido bater-V.T

“"Amanhã, você mata seu marido".' (WYR-20080627-FN-PM-a-chefe-dasmulheres-03)

c. "ãa! djitogo eteia djat."

ãa dj-i-togo ete-ip-a djat

INTJ 3-OBJ.NMLZ-mascar SOC-vir-V.T vocês

'(A mulher-caracol disse) "Ah, vocês estão trazendo masca dela/para ela." (WYR20100326-FN-PM-caracol-17)

Pode-se dizer que pronomes livres expressam o sujeito de verbos transitivos e intransitivos (opcionalmente, nas orações intransitivas), o que corresponde a um padrão nominativo de alinhamento. Por outro lado, os marcadores de pessoa presos expressam o sujeito de verbo intransitivo (comportando-se como concordância) e o objeto de verbos transitivos (comportando-se como clíticos de objeto) - padrão absolutivo (cf. Galucio e Nogueira (2018); para ver mais exemplos de sistemas nominativo-absolutivo em outras línguas, cf. Gildea e Alves (2010)). 
Rodrigues e Cabral (2012) reconstroem para o Proto-Tupi duas séries de marcadores pessoais: o grupo I, marcadores de pessoa no verbo em função absolutiva (formas reconstruídas $* *_{\mathrm{o}}$ ' $1 \mathrm{sg}$ ', **e '2sg', '** $\mathrm{or}^{j} \mathrm{e}^{\mathrm{e}}$ ' 1 pl.excl' e $* * *_{\mathrm{ej}}$ ' $2 \mathrm{pl}^{\prime}{ }^{6}$ ); o grupo II, marcadores de pessoa pronominais (**on '1sg', **en '2sg', **or ${ }^{j}$ e '1pl.excl' e **ej '2pl'). O dado (11) apresenta a proposta de reconstrução de uma sentença transitiva e de uma intransitiva, em Proto-Tupi, com os marcadores verbais de pessoa em função absolutiva.

(11) Marcadores de pessoa em Proto-Tupi: padrão absolutivo (RODRIGUES; CABRAL, 2012, p. 544)
a. **e kjet
2SG dormir
'Você dorme'
b. **e-top
2SG-ver
'Ver você'

Na reconstrução proposta, não há definição sobre o status das formas pessoais reconstruídas quanto ao comportamento como clíticos ou afixos. No dados, os marcadores de pessoa aparecem representados tanto com hífen **o-, **e- (RODRIGUES; CABRAL, 2012, p. 546), quanto sem o hífen **o '1sg', **e '2sg' (RODRIGUES; CABRAL, 2012, p. 545).

Veremos, neste capítulo, que tal distinção entre clíticos e afixos é relevante para a análise dos marcadores de pessoa nas sentenças da língua Wayoro.

Antes, porém, devemos descrever duas características dos pronomes pessoais em Wayoro importantes para a compreensão dos dados: a omissão da $3^{a}$ pessoa, sem qualquer relação com o tema da hierarquia de pessoa; e a união fonológica de pronomes iniciados por vogal em posição final com o verbo precedente.

\subsubsection{Omissão da $3^{\text {a }}$ pessoa em Wayoro e ausência de hierarquia de pessoa para a marcação de morfemas pessoais no verbo ${ }^{7}$}

Veremos, nesta subseção, exemplos de omissão de terceira pessoa, questionando-nos se tal omissão estaria relacionada a uma hierarquia de pessoa na gramática Wayoro.

\footnotetext{
${ }^{6} \mathrm{~A}$ notação ${ }^{* *} \mathrm{x}$ (com dois asteriscos) será usado para indicar uma forma reconstruída para uma proto-língua em nível de família; a forma *x (com um asterisco) será usada para indicar formas reconstruídas no nível de subfamílias linguísticas, por exemplo, Proto-Tupari. Quando falamos em juízos de gramaticalidade, o símbolo * (asterisco) significa agramatical.

${ }^{7}$ Agradeço a sugestão da discussão sobre hierarquia de pessoa a um dos pareceristas anônimos do artigo From object nominalization to object focus (GALUCIO; NOGUEIRA, 2018).
} 


\section{Omissão da $3^{\text {a }}$ pessoa}

Como ressalta Siewierska (2010), muitas línguas que não apresentam marcas para a terceira pessoa usam, em substituição, demonstrativos (como Basco e Mapuche), ou, mais raramente, um SN genérico, como 'homem', ou mesmo uma forma zero, ou seja, a ausência de uma expressão pronunciada sendo interpretada com a denotação de $3^{a}$ pessoa. Em Wayoro, é comum a terceira pessoa não ser pronunciada na posição de sujeito. Veja, em (12) e (13), que a omissão de sujeitos pode envolver tanto sujeitos de verbos intransitivos (12) quanto de verbos transitivos (13). Quando se trata de sujeitos diferentes de verbos transitivos, temos a expressão explícita dos SNs ou pronomes, como em (14).

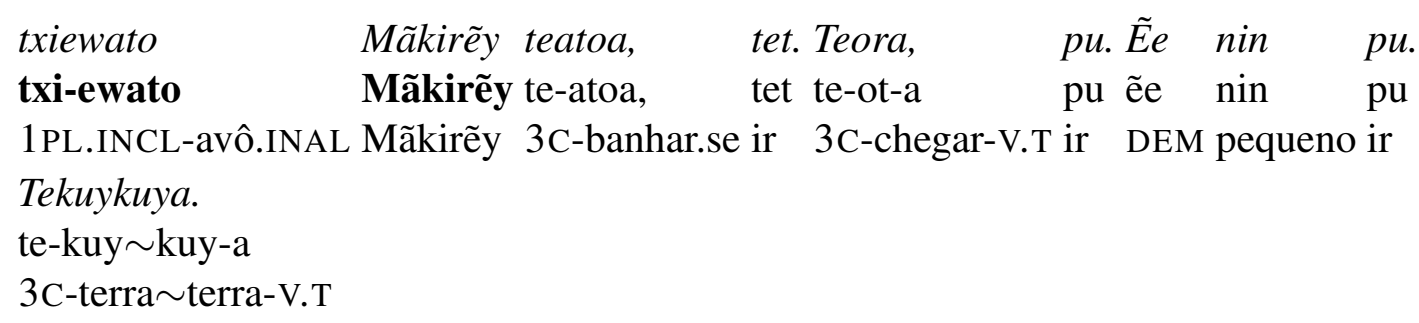

'Nosso avô Mãkirẽy se banhou, foi embora. Chegou e foi. Não demorou, foi. Se sujou [com terra].' (WYR-20080616-AVG-ANT-Hist-agua-010-13)

(13) Tuero ndera neran, tembopoe puga. tuero nder-a nẽran te-mbopoe pug-a chicha moer-V.T novamente 3C-rápido cozinhar-V.T '(A mulher-caracol) fazia chicha de novo, ela cozinhava rápido.' (WYR-20100326-FNPM-caracol-30)

$\begin{array}{lllll}\text { en nge pãkwa-rere, } & \text { on atiti ndaap } & \text { na on. } \\ \text { en nge pã-kwa-rere } & \text { on atiti nda-a-p } & \text { nã on }\end{array}$
você roça cortar-ITER-SUB $1 \mathrm{SG}$ milho plantar-V.T-INF FUT eu 'Enquanto você roça, eu vou plantar milho.' (PM-2012)

Exemplos de sujeito de verbo intransitivo e transitivo em orações subordinadas infinitivas serão tratados no Capítulo 5. Em Mekens, a estratégia de omissão de sujeitos se aplica tanto em sentenças independentes quanto na relação entre sentenças dependentes/independentes (GALUCIO, 2014a, p. 381). É interessante notar, segundo Galucio (2014a, p. 381), que nas orações adverbiais nominalizadas de Mekens, como em (15), não há posição disponível para a marcação de sujeito no verbo, de forma que o mesmo aparece em um sintagma oblíquo.

(15) Mekens (subfamília Tupari)

o-jarap- $k w a \quad k o t$ ot $\sim \tilde{o t} \quad k w e \quad m i-a-a p=e s e \quad$ pe $=\tilde{e} t$.

1 SG-feliz-VZR FUT eu $\sim$ ENF animal matar-VT-NMLZ $=$ LOC OBL $=$ você 
'Eu ficarei feliz quando/se você matar um animal de caça. []Lit. Eu ficarei feliz no matar de um animal de caça por você].' (GALUCIO, 2014a, p. 382)

Embora as construções adverbais não sejam objeto de investigação detalhada nesta tese, o exemplo (16) indica que, em Wayoro, os argumentos do verbo da oração subordinada infinitiva (objeto da posposição ere) podem ser expressos de forma direta, tanto o sujeito quanto o objeto.

(16) ndeke "ẽe kupkuya ẽe" kaat, Durafogo djauwap ere.

ndeke ẽe kupkuya ẽe kaat [Durafogo dj=au-wa-p ere]

ele DEM raiz/veneno DEM QUOT D. 3=curar/rezar-VZR-INF em

'Quando Durafogo o rezou, ele falou/contou "É veneno isso, é isso".' (WYR-200308-

DM-PK-tratamentodetertuliano)

\section{Ausência de hierarquia de pessoa para a marcação de morfemas pessoais}

Uma questão que se coloca é se a omissão da terceira pessoa teria relação com uma hierarquia de pessoa. Para Birchall (2014, p. 72), a marcação hierárquica de pessoa (onde a primeira e segunda pessoas têm precedência sobre a terceira) é de interesse central para a discussão sobre marcação argumental verbal. $\mathrm{O}$ autor afirma que a marcação hierárquica de pessoa é um padrão complexo de marcação argumental verbal comum, especialmente, em línguas da América do Sul.

Em Munduruku, de acordo com Gomes (2006), há uma hierarquia entre os morfemas pessoais para se marcar o sujeito ou o objeto no verbo. Se o objeto for $1^{\mathrm{a}}$ ou $2^{\mathrm{a}}$ pessoa, marca-se o objeto no verbo, se o objeto não for $1^{\mathrm{a}}$ ou $2^{\mathrm{a}}$ pessoa, marca-se o sujeito no verbo. Em (17a) e (17b), o argumento objeto é de $1^{\mathrm{a}}$ e $2^{\mathrm{a}}$ pessoa, respectivamente, de maneira que o marcador de pessoa que aparece no verbo se refere ao objeto. Em (17c), no entanto, o objeto é de $3^{\mathrm{a}}$ pessoa, assim, o marcador de pessoa verbal se refere ao sujeito de $1^{\text {a }}$ pessoa. Contrastando os exemplos (17a) e $(17 \mathrm{c})$ - que apresentam o morfema $o=$ afixado ao verbo - pode-se perceber que a hierarquia é determinante para a interpretação de sujeito e objeto do verbo.

(17) Hierarquia de pessoa em Munduruku

a. wamõat $o=\emptyset$-nomuwã

pajé $\quad 1 \mathrm{OBJ}=\mathrm{R} 1$-chamar.PFV

'O pajé me chamou' (GOMES, 2006, p. 49)

b. wamõat $e=\emptyset$-nomuwã

pajé 2OBJ-R1-chamar.PFV

'O pajé te chamou' (GOMES, 2006, p. 49)

c. (bio) $o=y-a o k a$

(anta) $1 \mathrm{SUJ}=\mathrm{R} 2$-matar.PFV

'Eu a matei (a anta)' (GOMES, 2006, p. 51) 
Em Wayoro, não constatamos tal relação hierárquica de marcação argumental verbal. Em uma sentença transitiva, sempre é o objeto do verbo que será indicado pela marcação de pessoa, independentemente de à qual pessoa se refira. Nos dados em (18a-18b), podemos ver que os morfemas $o=$ ' 1 a pessoa do singular' e $e=$ ' $2^{\text {a }}$ pessoa do singular' funcionam como objeto. De forma semelhante, em (18c), $y=3^{\mathrm{a}}$ pessoa também está funcionando como objeto. Portanto, Wayoro indica no verbo transitivo sempre objeto, mesmo que este seja uma $3^{\text {a }}$ pessoa.

(18) Ausência de hierarquia de pessoa em Wayoro

a. ngwaykup otoat.

ngwaykup o=top-a-t

homem $1 \mathrm{SG}=$ ver-V.T-NFUT

'O homem me viu' (NOGUEIRA, 2011, p. 159)

b. etoat.

$\mathrm{e}=$ top-a-t

$2 \mathrm{SG}=$ ver-V.T-NFUT

'Ele viu você. ${ }^{8}$ ' (PM-1998)

c. yombaat on

$\mathrm{y}=$ ombo-a- $\mathrm{t}$ on

$3=$ bater-NFUT eu

'Eu bati nele/a(s).' (NOGUEIRA, 2011, p. 68)

Os dados em (19) mostram que, em uma sentença independente, um sujeito de $3^{a}$ pessoa pode ser omitido.

(19) Omissão da $3^{\text {a }}$ pessoa argumento sujeito de verbo transitivo

a. mbikat.

$\emptyset=$ mbik-a- $\mathrm{t}$

$3=$ flechar-V.T-NFUT

'Ele flechou algo.' (NOGUEIRA, 2011, p. 58)

b. etoat.

$\mathrm{e}=$ top-a-t

$2 \mathrm{SG}=$ ver-V.T-NFUT

'Ele viu você.' (PM-1998)

\subsubsection{Lenição e pronomes iniciados por vogal em posição final}

Outro tema relevante para a compreensão dos dados é a lenição (espirantização e sonorização) que afeta a consoante final do verbo quando seguido por alguns pronomes.

\footnotetext{
${ }^{8}$ Note, adicionalmente, que para expressar a $2^{\mathrm{a}}$ pessoa do singular como sujeito de verbo transitivo será utilizado o pronome livre en 'você' (cf. os exemplos 24a e 24c, como ilustração).
} 
Na língua Mekens, há um processo de cliticização que ocorre com os pronomes livres em posição pós-verbal. Galucio (2001, p. 42) afirma que os pronomes livres oscilam entre uma posição inicial e uma posição final pós-verbal. Processos fonológicos de espirantização, nasalização e sonorização de obstruintes em fronteira de morfema que afetam os pronomes $\tilde{o t}$ ' $1^{\mathrm{a}}$ pessoa do singular', êt ' $2^{\mathrm{a}}$ pessoa do singular' e ose ' $1^{\mathrm{a}}$ pessoa do plural exclusiva' apontam para a hipótese de que os mesmos foram reanalisados como clíticos e perderam o status de palavra fonológica na língua. Segundo a autora, trata-se de um "estágio intermediário no desenvolvimento dos pronomes livres para pronomes clíticos" (GALUCIO, 2001, p. 41, tradução nossa). No dado (20), abaixo, o pronome de $1^{\text {a }}$ pessoa do singular õt está cliticizado ao verbo. O morfema de passado - $t$ sofre lenição e sonorização, mudando para [r].

(20) Cliticização dos pronomes livres em posição pós-verbal em Mekens

$$
\begin{aligned}
& o-e-p \dot{i} b o r-a-t[r]=\tilde{o} t \\
& 1 \mathrm{SG}-\mathrm{INTR}-\mathrm{chegar}-\mathrm{V} . \mathrm{T}-\mathrm{PASS}=\mathrm{eu}
\end{aligned}
$$

'Eu cheguei.' (GALUCIO, 2014, p. 171)

Na língua Wayoro, também ocorre lenição da consoante final do verbo diante dos pronomes livres on, en e ote (cognatos aos morfemas de Mekens), em posição pós-verbal. Os processos de espirantização e sonorização que afetam as consoantes anteriores ao pronome livre são: [t, n] 'não-futuro' $>[\mathrm{r}] ;[\mathrm{p}, \mathrm{m}]>[\beta] ;[\mathrm{k}]>[\mathrm{g}]$.

(21) Lenição e sonorização diante dos pronomes livres em posição final em Wayoro

a. $\emptyset=m b i-k a-[r]=o n$

$3=$ flechar-VZR-NFUT=eu

'Eu flechei (algo).' (NOGUEIRA, 2011, p. 58)

b. m-engu- $k w a-[r]=o n$

1SG-suar-VZR-NFUT=eu

'Eu estou suando'

c. e-engu- $k w a-[r]=e n$

2SG-suar-VZR-NFUT=você

'Você está suando."

d. ote-engu- $k w a-[r]=$ ote

1 PL.EXCL-suar-VZR-NFUT=nós.EXCL

'Nós (exclusivo) estamos suando.' (PM-2008; PM-2010)

e. $o-p i a k o[\beta]=o n$

$1 \mathrm{sG}-q u e n t e=\mathrm{eu}$

'Eu estou quente.' (NOGUEIRA, 2011, p. 58) 


\section{f. $o-p i i t i[g]=o n$ \\ $1 \mathrm{SG}-$ frio=eu}

'Eu estou com frio.' (NOGUEIRA, 2011, p. 59)

Os demais pronomes de Wayoro (ndeke, ndeat, txire, djat) são iniciados por consoante o processo de lenição se aplica apenas em ambientes intervocálicos (NOGUEIRA, 2011) - e aparecem em posição inicial ou final (22).

(22) Pronome iniciado por consoante: posição inicial ou final

a. txire txiengukwat.

txire txi-engu-kwa-t

nós.INCL 1 PL.INCL-suar-VZR-NFUT

'Nós (inclusivo) estamos suando' .

b. txipiitokarat

txire.

txi-piito-kara-t

txire

1 PL.INCL-respiração-VZR-NFUT nós.INCL

'Nós respiramos.' (NOGUEIRA, 2011, p. 69)

Pronomes em posição inicial - posição em que são claramente pronunciados com acento próprio - não desencadeiam lenição, mesmo que configurem um ambiente intervocálico. Assim, em (23a), o pronome on de $1^{\text {a }}$ pessoa do singular, diante da palavra améko 'cachorro', não sofre lenição na consoante [n] diante da vogal [a]. Também não ocorre lenição entre a vogal final de ndeke e a consoante inicial do verbo, em (23b). Nossa hipótese é que tais pronomes tenham acento próprio, na posição inicial, e, por isso, não formem uma unidade fonológica com a palavra seguinte. Em (23c), a lenição também não ocorre entre o SN sujeito, na posição inicial, e a palavra seguinte.

(23) a. on amẽko ombaat.

on amẽko ombo-a-a-t

eu cachorro bater-?-V.T-NFUT

'Eu bati no cachorro.'

b. ndeke tengungukat. ndeke te-engu-ngu-ka-t

ele $3 \mathrm{C}$-suar $\sim$ RED-VZR-NFUT

'Ele está suando muito.' (PM-2008)

c. auwat aimbe ũwã.

auwat aimbe ũw-a

pajé rapé inalar-V.T

'O pajé inala rapé.' (JA-2013) 


\subsection{Verbos transitivos}

Compare os exemplos abaixo para um panorama do que será discutido nesta seção. Note que, nestes dados, os prefixos pessoais funcionam como objetos enquanto que os pronomes livres funcionam como sujeitos, com respeito à $1^{\mathrm{a}}$ e $2^{\mathrm{a}}$ pessoas do singular. Note que a $1^{\mathrm{a}}$ pessoa do singular quando funciona como o objeto do verbo é realizada por $o=$, em $(24 \mathrm{a}$ e $24 \mathrm{c})$, e quando funciona como sujeito do verbo transitivo é realizada por on (24b). A $2^{\mathrm{a}}$ pessoa apresenta comportamento semelhante: realiza-se como forma leve $e=$ quando objeto, no entanto, ocorre como forma plena en quando funciona como sujeito (24a e 24c).

(24) Verbos transitivos: $1^{\mathrm{a}}$ e $2^{\mathrm{a}}$ pessoas do singular como argumento objeto $(\mathrm{O})$ e sujeito do verbo transitivo (A)

a. en otigaat.

en $\mathrm{o}=$ tiga-a-t

você $1 \mathrm{SG}=$ pintar.corpo-V.T-NFUT

'Você me pintou.' (PM-2012)

b. on, etigaat

on.

on e=tiga-a-t

on

eu $2 \mathrm{SG}=$ pintar.corpo-V.T-NFUT eu

'Eu pintei você.' (PM-2012)

c. opurugat en.

$\mathrm{o}=$ purug-a- $\mathrm{t} \quad$ en

$1 \mathrm{SG}=$ furar-V.T-NFUT você

'Você me furou.' (NOGUEIRA, 2011, p. 155)

d. epuruga.

$\mathrm{e}=$ purug-a

$2 \mathrm{SG}=$ furar/tirar.virgindade- $\mathrm{V} . \mathrm{T}$

'Tirar sua virgindade.' (Lit: 'Furar você.') (PM-2015)

Confira, em (25) adiante, que, com verbos intransitivos, os prefixos pessoais (os quais são obrigatórios) referem-se ao sujeito. Os morfemas pessoais livres podem ocorrer opcionalmente (precedendo ou seguindo o verbo); se presentes, são correferenciais ao prefixo pessoal. Dessa maneira, pode-se dizer que os prefixos pessoais, nos verbos intransitivos, comportam-se como concordância.

(25) Verbos intransitivos: $1^{\mathrm{a}}$ e $2^{\mathrm{a}}$ pessoas do singular como argumento $\mathrm{S}$ (pronome livre é opcional) 
a. ongõyãn on.

o-ngõy-ã-n on

1SG-Sentar-V.T-NFUT eu

'Eu sentei.' (NOGUEIRA, 2011, p. 122)

b. engõyãn.

e-ngõy-ã-n

2SG-sentar-V.T-NFUT

'Você sentou.' (NOGUEIRA, 2011, p. 76)

Assim, nas sentenças intransitivas, morfemas livres e prefixos pessoais concordam. No entanto, nas sentenças transitivas, na função de objeto, ocorre uma distribuição complementar entre formas fracas de pronomes e formas plenas (pronomes livres), o que indica que, nos verbos transitivos, as marcas de pessoa são pronomes cliticizados.

Discutiremos os seguintes pontos nesta subseção:

- A distribuição mencionada em sentenças transitivas mostra que não há concordância entre prefixos pessoais na função de objeto e pronomes ou SN;

- Uma possível análise para tais fatos é de que há cliticização obrigatória dos pronomes na posição de objeto.

- Em sentenças intransitivas, por outro lado, há a possibilidade de coocorrência entre prefixos pessoais e pronomes livres, sugerindo que os prefixos podem ser analisados como marcas de concordância (gramaticalizadas no verbo intransitivo).

- Um argumento em favor dessa análise é que há um prefixo correferencial/anafórico nominal de $3^{\mathrm{a}}$ pessoa te-, o qual não ocorre como forma livre e é marca de concordância com sujeito de verbos intransitivos, em sentenças matrizes (ou aparece como possessivo de $3^{\text {a }}$ pessoa de um SN, também ligado a um sujeito $)^{9}$.

A seguir, discutiremos os marcadores verbais de pessoa nas sentenças transitivas e, em seguida, nas sentenças intransitivas.

\subsubsection{Paradigma de pessoa com verbos transitivos}

Os verbos transitivos selecionam dois argumentos. O sujeito pode ser realizado por um nominal livre ou por pronomes pessoais. $\mathrm{O}$ objeto pode ser realizado por um sintagma nominal ou por pronomes cliticizados. A ordem básica é OV. O sujeito pode vir antes ou depois da unidade OV (NOGUEIRA, 2011).

Na língua Wayoro, não há marcadores de caso morfológico nos SNs argumentos (externo e interno). Nos dados abaixo, as sentenças (26a-26b) são compostas pelas mesmas palavras,

\footnotetext{
${ }^{9}$ Nas orações subordinadas, te- ocorre como sujeito do verbo intransitivo correferencial ao sujeito do verbo da matriz, tal como será tratado no Capítulo 5.
} 
porém apresentam interpretações distintas, indicando que a ordem das palavras é relevante para identificarmos qual SN funciona como sujeito e qual funciona como objeto. Note que o SN imediatamente anterior ao verbo ombaa 'bater' funciona como o objeto, amẽko 'onça', em (26a), e ngwendap 'tamanduá', em (26b). Observa-se, comparando-se (26b-26c), que o sujeito, no caso amẽko 'onça', pode estar antes ou depois do sintagma verbal, constituído de objeto e verbo; cf. o sujeito antes de OV em (26b) e depois de OV em (26c).

(26) Ordem dos constituintes SNs em sentenças transitivas

a. ngwendap amẽko ombaat. ngwendap amẽko ombo-a-t tamanduá onça bater/matar-V.T-NFUT

'O tamanduá matou a onça' (PM-2016)

b. amẽko ngwendap ombaat.

amẽko ngwendap ombo-a-t

onça tamanduá bater/matar-V.T-NFUT

'A onça matou o tamanduá.' (PM-2016)

c. aote.ñ̃ etikia amẽko.

aote.nã etiki-a amẽko.

pessoa.?fazer pegar-V.T onça

'A onça pega as pessoas.' (Nogueira, 2011, p. 112)

Dessa forma, os dados (26a-26c) evidenciam o fato de que, em sentenças transitivas, o elemento nominal pré-verbal funciona como objeto do verbo.

Confira, em (27), o paradigma completo de pronomes pessoais usados como argumento sujeito do verbo transitivo (abreviado como argumento A, quando necessário). Note que a marca de pessoa no verbo transitivo não se refere ao sujeito, ou seja, não é uma concordância com o sujeito, mas sim a realização do objeto.

(27) Paradigma de pronomes pessoais usados como sujeito de verbo transitivo (A) [objeto $d j=$ ' 3 a pessoa'; verbo ipitkwa 'jogar'; - $t$ 'não-futuro']
a. on $d j=i p i t k w a \quad$ Eu vou jogar algo.'
b. en dj=ipitkwa 'Você joga algo.'
c. ndeke dj=ipitkwa-t 'Ele jogou algo.'
d. txire dj=ipitkwa-t 'Nós (inclusivo) jogamos (passado) algo.'
e. ote dj=ipitkwa 'Nós (exclusivo) estamos jogando algo.'
f. djat dj=ipitkwa-t 'Vocês jogaram algo.'
g. ndeat dj=ipitkwa-t 'Eles jogaram algo.'

O paradigma em (28) apresenta morfemas pessoais na função de objeto do verbo transitivo. 
(28) Prefixos pessoais argumento O [aramĩra 'mulher'; tigaa 'pintar (o corpo)'; -t 'nãofuturo']
a. aramĩra o=tigaa-t 'a mulher me pintou'
b. aramĩra e=tigaa-t 'a mulher te pintou'
c. aramĩra $\emptyset=$ tigaa-t 'a mulher o/os pintou'
d. aramĩra txi=tigaa-t 'a mulher nos (inclusivo) pintou'
e. aramĩra ote=tigaa-t 'a mulher nos (exclusivo) pintou'
f. aramĩra djat=tigaa-t 'a mulher pintou vocês.'

(PM- 2012, 2014)

Como dissemos anteriormente, na posição de objeto não são encontradas coocorrências entre marcas de pessoa no verbo e pronomes pessoais ou SN correspondente. Observe que, nos dados em (28), o objeto realizado pelos marcadores pessoais não realiza concordância com os pronomes pessoais apresentados em (27).

Podemos hipotetizar que essas marcas de pessoa no verbo transitivo são resultantes de contração obrigatória dos pronomes livres, ou seja, podem ser classificados como clíticos pessoais. Dada a semelhança fonológica entre os marcadores de pessoa verbais e os pronomes pessoais livres, pode-se dizer que tanto os clíticos quanto os prefixos pessoais se desenvolveram a partir dos pronomes livres.

Em (29a) o objeto do verbo ombaa 'bater' é amẽko 'onça, cachorro'. Note que não há prefixo pessoal de $3^{\text {a }}$ pessoa no verbo. Em (29b), o objeto de $3^{\text {a }}$ pessoa é realizado por $y=$ e não há sintagma nominal precedente como objeto do verbo. O dado agramatical em (29c) mostra que o marcador verbal de pessoa objeto e o sintagma nominal objeto se excluem. Assim, podese dizer que os marcadores pessoais na função de objeto estão em distribuição complementar com os sintagmas nominais objetos. Nossa análise para esses fatos é que a marca de pessoa no verbo transitivo, como em (29b), (27) e (28), é o objeto do verbo (pronome cliticizado).

(29) Não há concordância entre pronome ou SN e prefixo pessoal

a. ngwendap amẽko ombaat.

ngwendap amẽko ombo-a-t

tamanduá onça bater-V.T-NFUT

'O tamanduá matou a onça.'

b. ngwendap $y=$ ombaa- $t$

ngwendap $\mathrm{y}=$ ombo-a- $\mathrm{t}$

tamanduá 3=bater-V.T-NFUT

'O tamanduá o/a matou.'

c. *ngwendap améko yombaat.

*ngwendap amẽko $\mathrm{y}=$ ombo-a-t

tamanduá onça 3 =bater-V.T-NFUT 
Os dados em (30) somam-se aos anteriores quanto à impossibilidade de concordância entre SN objeto e marca de pessoa de objeto no verbo (no caso, o verbo amĩa 'espremer'), em uma sentença imperativa (tipo de sentença em que apenas o argumento interno é expresso, em um verbo transitivo).
a. ondoap
amĩa!
o-ndop-a-p
amĩ-a
1SG-deitar-V.T-NMLZ espremer-V.T
'espreme minha rede!' (PM-2008)
b. *ondoap
yamĩa!
*o-ndop-a-p
$\mathrm{y}=\mathrm{amĩ}-\mathrm{a}$
1 SG-deitar-V.T-NMLZ 3=espremer-V.T

Dados registrados com um pronome livre antecedendo o clítico de objeto não apresentam a interpretação de correferência entre pronome livre e marca de objeto no verbo, como se pode observar em (31).

(31) mbogop, ndeke yombaat.

mbogop ndeke $\mathbf{y}=$ ombo-a- $t$

criança ele/a $3=$ bater-V.T-NFUT

'O menino $i$, ele $_{i}$ bateu nele $_{j}$.' (PM-2015)

\subsubsection{Cliticização dos pronomes livres}

O dado em (32) mostra a impossibilidade de se realizar a forma do pronome livre como marca de pessoa na função de objeto do verbo transitivo. Tal dado nos direciona a uma análise de que, em posição de objeto, os pronomes livres ocorrem como formas obrigatoriamente contraídas e presas (clíticos). Nesta subseção, traremos mais argumentos em favor dessa análise.

(32) Cliticização obrigatória: impossibilidade de pronunciar o pronome livre on na posição de objeto

a. Irene otigaat.

Irene $\mathrm{o}=$ tiga-a- $\mathrm{t}$

Irene $1 \mathrm{SG}=$ pintar.corpo-V.T-NFUT

'A Irene me pintou.'

b. *Irene ontigaat

*Irene on=tiga-a-t

Irene $1 \mathrm{SG}=$ pintar.corpo-V.T-NFUT

'Interpretação pretendida: A Irene me pintou.' 
Segundo nossa colaboradora, a frase (32b) "Não pode ser que a Irene me pintou, mesmo se falar devagar". Uma interpretação oferecida foi 'Eu pintei a Irene', em que, entendemos, teria ocorrido uma topicalização do objeto.

Nas línguas da família Tupari, os morfemas pessoais se agrupam em uma série de formas independentes e outra série de marcadores de pessoa no verbo. Note que os marcadores de pessoa no verbo são analisados diferentemente em cada língua. Em Makurap (BRAGA, 2005) e Akuntsu (ARAGON, 2014), as formas dependentes são analisadas como clíticos. Em Tupari, são classificadas como pronomes proclíticos (SINGERMAN, 2018). Em Mekens, são classificadas como prefixo (GALUCIO, 2011).

Em um estudo sobre caso e concordância nas línguas Tupi, Storto (2005, p. 73) afirma que

Karitiana, Mekéns e Karo apresentam prefixos de pessoa de sujeito nos verbos intransitivos e de objeto nos verbos transitivos. Em Karitiana esses prefixos têm o status gramatical de concordância, pois estão associados a movimento verbal e coocorrem com sufixos de tempo. Em Karo, por estarem em distribuição complementar com pronomes livres, eles são pronomes cliticizados. Em Mekéns, eles parecem ser concordância, como veremos abaixo nas sentenças inversas.

Storto (2005) analisa que Mekens está em um estágio intermediário de gramaticalização, apresentando propriedades semelhantes à Karitiana, concordância, e semelhantes à Karo, pronomes cliticizados. Em Galucio (2011), bem como Galucio (2014a), afirma-se que, nas sentenças intransitivas de Mekens, os prefixos de pessoa apresentam concordância de número e pessoa com um SN sujeito, se presente.

Siewierska (2010) menciona a dificuldade em distinguir clíticos de afixos, que são também fonologicamente ligados a uma palavra. Por exemplo, observa Gerlach (2002, p. 25), os clíticos pronominais das línguas românicas têm sido analisados como afixos flexionais (por exemplo, Monachesi (2000)), mas também como clíticos (por exemplo, Vigário (1999)).

Segundo Siewierska (2010), alguns autores distinguem clíticos e afixos em termos de grau de integração fonológica ao radical a que as formas estão ligadas. Para a autora, contudo, a propriedade definitiva de clítico, como oposto ao status de afixo de uma forma pessoal, é a habilidade de um clítico de "ligar-se a múltiplos núcleos, ou, dizendo de outra forma, sua habilidade de ligar-se a sintagmas ou posições sintáticas em oposição a radicais específicos" 10 .

Citando, entre outros autores, Zwicky (1985), Gerlach e Grijzenhout (2001) explicam a diferença feita na literatura entre clíticos simples e clíticos especiais. Entre as propriedades dos

\footnotetext{
10"Clitics are notoriously difficult to distinguish from affixes, which are also phonologically attached to a word. Some scholars distinguish the two in terms of the degree of phonological integration of the relevant stem to which the forms are attached. I, however, will take as definitive of the clitic, as opposed to affix status of a person form, its ability to attach to multiple hosts or, to put it differently, its ability to attach to phrases or syntactic positions as opposed to specific stems" (SIEWIERSKA, 2010).
} 
clíticos especiais, tem-se que "eles podem ou devem ser localizados em uma posição diferente da forma livre [full form], se houver alguma" 11 .

Gerlach e Grijzenhout (2001, p. 28-29) esclarecem que tal cenário pode resultar em uma distribuição complementar entre clíticos especiais e pronomes plenos.

enquanto os clíticos simples têm a mesma distribuição que as formas plenas, os clíticos especiais desenvolvem uma sintaxe especial, o primeiro passo sendo a redução das posições admissíveis nas formas plenas. O resultado então é que as posições que são ocupadas por clíticos não são mais admissíveis para pronomes plenos, de maneira que clíticos e formas plenas subjazem uma distribuição complementar (GERLACH; GRIJZENHOUT, 2001, p. 28-29, tradução nossa). ${ }^{12}$

Vimos, em (29), que, na função de objeto, não podem coocorrer marcador de pessoa no verbo e um SN ou pronome livre. Tal fato sugere que há a referida distribuição complementar entre formas plenas e clíticos mencionada por Gerlach e Grijzenhout (2001). De fato, podemos observar tal distribuição complementar entre formas leves e plenas dos pronomes também na função de sujeito de verbo transitivo, pois, como mencionamos, somente as formas plenas podem aparecer como sujeito de um verbo transitivo.

Seguindo Storto (STORTO, 2005; STORTO, 2014a), o principal argumento para analisar as marcas de pessoa, na função de objeto, como pronomes cliticizados ao verbo (a que chamaremos clíticos de pessoa), em Wayoro, é a distribuição complementar com os SNs ou pronomes livres correferentes - em outras palavras, o marcador pessoal de objeto no verbo transitivo é analisado como o próprio objeto do verbo, e não uma marca de concordância ${ }^{13}$.

Trataremos a seguir dos verbos intransitivos.

\subsection{Verbos intransitivos}

$\mathrm{O}$ argumento sujeito do verbo intransitivo pode ser expresso por um sintagma nominal ou pronome livre que pode ocorrer antes do verbo, como em (33a-b), ou após o verbo, como em $(33 c)$.

(33) Ordem dos constituintes na sentença intransitiva
a. txiewato
Mãkirẽy teatoa,
tet.
txi-ewato
Mãkirẽy te-ato-a
tet
1PL.INCL-avô.INAL Mãkirẽy 3C-banhar.se-V.T ir

\footnotetext{
11 "Simple clitics are different from special clitics in that the latter are not necessarily derived from corresponding full forms in a transparent way and they may or must be placed at a different position than the corresponding full form if there is one"(GERLACH; GRIJZENHOUT, 2001, p. 1).

12 "While simple clitics have the same distribution as their full forms, special clitics develop a special syntax, the first step being a reduction of the positions admissible for the full form. The result then is that positions which are occupied by clitics are no longer admissible for full forms, so that clitic and full form underlie complementary distribution" (GERLACH; GRIJZENHOUT, 2001, p. 28-29).

${ }^{13}$ Veremos, no Capítulo 5, que essa série de clíticos de pessoa é usada para expressar os argumentos pessoais nas orações subordinadas da língua Wayoro, ambiente sintático em que não há concordância.
} 
'Nosso avô Mãkirẽy se banhou, foi embora.' (WYR-20080616-AVG-ANT-Histagua-010)

b. txire txiemẽto eri txiapitngwara

txire txi-emẽto eri txi-apitngwat-a

nós 1PL.INCL-idioma ABL 1 PL.INCL-esquecer-V.T

'Nós esquecemos do nosso idioma.' (WYR-20161007-FN-PM-MA-festa-tradic)

c. tepikãakwa ugu eriat, ngwãngwã poot.

te-pikãy-kwa ugu eriat ngwãngwã poot

3C-bravo-VZR água dono camaleão velho

'O dono da água, o camaleão antigo, se irritou.' (WYR-20080616-AVG-ANT-Histagua-044)

Os prefixos pessoais são obrigatórios em radicais verbais intransitivos pois realizam a função de sujeito do verbo ${ }^{14}$. A ausência dos mesmos resulta em sentenças agramaticais, como vemos em (34).

(34) Verbos intransitivos: ausência de prefixos pessoais é agramatical
a. o-tera-t (on).
o-tet-a-t (on)
1SG-ir-V.T-NFUT eu
'Eu fui.'
b. *terat on.
*tet-a-t on
ir-V.T-NFUT eu
c. mbogop teenunkarat.
mbogop te-e-nun-kara-t
criança 3C-MED-respirar-VZR-NFUT
'A criança respirou.'
d. *mbogop enunkarat.
*mbogop e-nun-kara-t
criança MED-respirar-VZR-NFUT

(NOGUEIRA, 2011, p. 70)

Com verbos intransitivos, os morfemas pessoais livres ou um nominal livre podem ocorrer opcionalmente correferentes com o prefixo pessoal sujeito. Quando presentes, os pronomes

\footnotetext{
${ }^{14}$ Veremos, na seção 2.7, que há ocorrência de formas verbais sem qualquer morfologia verbal, inclusive sem os prefixos pessoais em verbos intransitivos. São casos de construções multiverbais, como ocorre com o verbo tet 'ir' em (33a).
} 
livres podem preceder ou seguir o verbo. Em (35), apresenta-se o paradigma completo de prefixos pessoais usados como sujeito de verbo intransitivo.

(35) Paradigma de prefixos pessoais usados como sujeito do verbo intransitivo (S)
a.
m-engukwa-t
(on)
'Eu estou suando'
b.
e-engukwa-t
(en)
'você está suando'
c. (ndeke)
te-ngunguka-t
'Ele está suando muito'
d. ngwaykup
te-engukwa-t
'O homem suou'
e.
txi-engukwa-t
(txire)
'Nós (incl) estamos suando'
f.
ote-engukwa-t
(ote)
'Nós (excl) estamos suando'
g. (djat)
djar-engukwa-t
'Vocês estão suando'
h. (ndeat)
te-engukwa-t
'Eles suaram'

(PM-2008; PM-2010)

A próxima subseção argumenta em favor da análise de que os prefixos pessoais são morfemas de concordância, uma vez que refletem os traços do sujeito SN ou pronome livre correspondente.

\subsubsection{O morfema te- $3^{\text {a }}$ pessoa anafórica: concordância nos verbos intran- sitivos}

Comparando-se os morfemas pessoais que indicam o argumento sujeito do verbo intransitivo com os que indicam o argumento objeto do verbo transitivo, nota-se que ambos são expressos pela mesma série de prefixos/clíticos pessoais, exceto no que diz respeito à $3^{\mathrm{a}}$ pessoa singular/plural. A Tabela 2.3, abaixo, resume as características da $3^{\mathrm{a}}$ pessoa.

Tabela 2.3: Marcadores verbais de $3^{a}$ pessoa

\begin{tabular}{l|l|l|l}
\hline \multirow{4}{*}{ Munção } & Forma & Exemplo & \\
\hline \hline Objeto & $y=\sim d j=\sim \emptyset=$ & dj=ipitkwa & 'Jogue (algo).' \\
\hline Sujeito do verbo intransitivo & $t e-$ & ndeke te-terat & 'Ele vai.' \\
\hline Possessivo correferencial a sujeito & $t e-$ & te-tak & 'filha dele (mesmo)' \\
\hline Possessivo não correferencial a sujeito & $y-\sim d j-\sim \emptyset-$ & y-engu & 'chicha dela' \\
\hline
\end{tabular}

A $3^{\mathrm{a}}$ pessoa em função de objeto realiza-se como $y=\sim d j=\sim \emptyset=$ ' $3^{\mathrm{a}}$ pessoa'; em função de sujeito do verbo intransitivo é usado o prefixo te-.

O morfema te- é um prefixo anafórico. Argumentaremos, nesta subseção, que a presença de tal morfema nos verbos intransitivos e a sua ausência nos verbos transitivos estão relacionadas ao fato de que os prefixos sujeito de verbo intransitivo se caracterizem como marcadores 
de concordância, diferentemente dos clíticos de pessoa que ocorrem como objeto do verbo transitivo.

Nogueira (2014) mostra que a mesma série de prefixos pessoais é usada em Wayoro com verbos, nomes e adjetivos. O paradigma a seguir (36) ilustra os prefixos pessoais que ocorrem com nomes em construção de posse.

(36) Paradigma de prefixos pessoais em construção de posse

$\begin{array}{ll}\text { o-tak } & \text { 'minha filha (fala masculina)' } \\ \text { e-tak } & \text { 'tua filha', } \\ \text { ndeke-tak } & \text { 'filha dele' } \\ \text { txi-tak } & \text { 'nossa filha (inclusivo)' } \\ \text { ote-tak } & \text { 'nossa filha (exclusivo)' } \\ \text { djat-tak } & \text { 'filha de vocês' } \\ \text { ndeat-tak } & \text { 'filha deles'. }\end{array}$

(NOGUEIRA, 2013, p. 328)

Em adição ao paradigma de prefixos possessivos, o prefixo te- é usado para indicar uma $3^{\mathrm{a}}$ pessoa anafórica a um sujeito, como no dado (37). O morfema te- é correferente ao SN ndop 'pai'.

(37) Prefixo te- $3^{a}$ pessoa anafórica em construção de posse

ndop tetak atinãn.
ndop te-tak atinẽ-a-n
pai 3 C-filha.o' sovinar-V.T-NFUT
'O pai ${ }_{i}$ estava com ciúme [lit. sovinando a] da filha dele ${ }_{i}$.'

Caso semelhante é registrado em outras línguas da família Tupari, como Mekens (GALUCIO, 2001) e Tupari (SINGERMAN, 2018). Em contexto sintático de sentenças intransitivas, a língua Mekens utiliza o prefixo se- de $3^{\mathrm{a}}$ pessoa correferencial e Tupari se vale do prefixo correferencial te- (analisado como reflexivo em Alves (2004)) como sujeito do verbo intransitivo. Comparemos os dados abaixo em (38) (GALUCIO, 2001).

(38) Prefixo correferencial se- Mekens

a. Mekens

kirit se-esoroka

criança 3C-descer

'A criança desceu.'

b. assii se-anip tap sereka naat mãe 3C-cabeça cabelo cortar COP 
'Minha mãe ${ }_{i}$ está cortando seu próprio ${ }_{i}$ cabelo (ela $_{i}$ mesma).' (GALUCIO, 2014, p. 191)

Dados cognatos podem ser encontrados na língua Wayoro, revelando um padrão idêntico ao das línguas irmãs Mekens e Tupari. Abaixo, o morfema te- ocorre como possessivo de SN objeto (39a) e como concordância (39d). Nesses dados, te- é correferente aos SNs Mariazinha e piakarat 'galo/galinha' sujeito da sentença. Para expressar uma terceira pessoa não correferencial se usa $d j$ - (39b), te- não é aceito nesse contexto. O dado em (39c) é apresentado para argumentar que te- é correferente somente a um sujeito de $3^{\mathrm{a}}$ pessoa, o prefixo pessoal de $2^{\mathrm{a}}$ pessoa é usado quando o sujeito correferente é $2^{\mathrm{a}}$ pessoa.

(39) Prefixo te- $3^{a}$ pessoa anafórica/correferencial em construção de posse e em sentença intransitiva

a. Mariazinha teupipe toat.

Mariazinha $_{i}$ te $_{i / * j}$-upipe top-a-t

Mariazinha 3C-porto ver-V.T-NFUT

'Mariazinha ${ }_{i}$ viu o porto dela $i / * j$ ' (PM-2017)

b. en *teldjupipe toat.

en $*$ te/dj-upipe top-a-t

você 3c/3-porto ver-V.T-NFUT

'você viu o porto dela. ${ }^{15}$ ' (PM-2017)

c. en eupipe toat nen?

en e-upipe top-a-t nen

você 2 SG-porto ver-V.T-NFUT INTERR.2

'você viu seu porto?' (PM-2017)

d. enã kerom, piakarat teukarat.

nã k-erom piakarat ${ }_{i} \quad \mathrm{te}_{i / * j}$-ukar-a-t

agora ?-NEG, galo/galinha 3C-chorar-V.T-NFUT

'De madrugada, o galo cantava.' (Lit. 'Não é agora, o galo chorava.') (texto, PM2016)

Avaliamos que o conjunto de dados acima constituem argumento em favor da análise de que o prefixo anafórico de $3^{\mathrm{a}}$ pessoa te- é uma marca de concordância em verbos intransitivos.

\footnotetext{
${ }^{15}$ Compare, ainda, com o seguinte exemplo em que há um nome, Catiúcia, na construção possessiva:
}

(1) Catiúcia upipe toat on.

Catiúcia upipe top-a-t on

Catiúcia porto ver-V.T-NFUT eu

'Eu vi o porto da Catiúcia.' (PM-2017) 


\section{4 homofonia entre prefixo, clítico e pronome livre}

A análise até aqui construída constata três comportamentos sintáticos diferenciados para os morfemas pessoais da língua Wayoro: marcadores de pessoa em função de objeto do verbo transitivo, analisados como clíticos, os quais não configuram concordância com um pronome livre ou nominal livre; marcadores de pessoa em função de sujeito de verbo intransitivo, analisados como prefixos pessoais de concordância com o pronome livre ou nominal livre; pronomes livres, os quais podem ocorrer como sujeito de verbo transitivo e podem coocorrer com os prefixos pessoais sujeito de verbo intransitivo.

Apesar do comportamento sintático diferente, alguns clíticos/prefixos são fonologicamente idênticos aos pronomes livres correspondentes, como evidencia a Tabela 2.4, abaixo.

Tabela 2.4: Homofonia entre marcas de pessoa

\begin{tabular}{l|l|l|l}
\hline & Pron. livre $(\arg$. S e A) & Clíticos $($ arg. O) & Prefixo $(\arg$. S) \\
\hline \hline 1PL.EXCL & ote & ote $=$ & ote- \\
\hline 2PL & djat & djat $=\sim$ djar $=$ & djat $-\sim$ djar- \\
\hline
\end{tabular}

O pronome de $2^{\mathrm{a}}$ pessoa do singular djat será utilizado como exemplo para explicarmos que a distribuição sintática e a função sintática dos morfemas pessoais são diferentes quando usados como clíticos/prefixos e quando usados como pronomes livres, apesar da identidade fonológica.

Note que a consoante final do morfema djat sofre espirantização (ou enfraquecimento) e muda para $[\mathrm{r}$ ] diante de verbos iniciados por vogal, como em (40a), porém se mantém [t], antes de verbo iniciado por consoante, como em (40b).

(40) Espirantização 2PL em posição de sujeito do verbo intransitivo
a. djarepagat djar-e-pag-a-t nen djat?

2PL-MED-acordar-V.T-NFUT INTERR. 2 vocês

'Vocês se acordaram?'

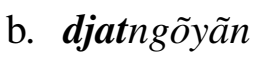

djat-ngõy-ã-n

2PL-sentar-V.T-NFUT

'Vocês sentaram.' (NOGUEIRA, 2011 p. 70)

As formas [nofat-] e [ndjar-] podem ser, portanto, analisadas como alomorfes do prefixo de $2^{\mathrm{a}}$ pessoa do plural djat-. Observe que a $2^{\mathrm{a}}$ pessoa do plural quando usada como objeto do verbo transitivo sofre a mesma alomorfia.

(41) Espirantização 2PL em posição de objeto 
a. djarombokwat on.

djar $=$ ombo-kwa-t on

2PL=bater-ITER-VZR-NFUT eu

'Eu bati em vocês.'

b. ote djattigaat.

ote djat=tiga-a-t

nós.EXCL 2PL=pintar-V.T-NFUT

'Nós pintamos vocês.' (PM-2012)

Vimos que, apesar da identidade fonológica entre prefixos e clíticos pessoais, podemos analisá-los de maneira distinta com base na sua distribuição sintática, especificamente a possibilidade de concordância com um pronome livre ou SN correferente. A $2^{\mathrm{a}}$ pessoa do plural, quando usada como sujeito do verbo intransitivo pode coocorrer com o pronome livre djat, como em (40a); ao passo que, quando funciona como objeto do verbo transitivo, não coocorre com o pronome livre, como em (41).

Tal comportamento nos levou a analisar o marcador de pessoa que indica a $2^{\text {a }}$ pessoa do plural no verbo intransitivo como marca de concordância. Já o elemento que funciona como objeto do verbo transitivo de $2^{\mathrm{a}}$ pessoa do plural foi analisado como clítico de pessoa, resultante da cliticização obrigatória dos pronomes livres quando em função de objeto do verbo transitivo.

Nos exemplos a seguir, observe o uso do pronome livre djat como sujeito de verbo transitivo, além de sujeito do verbo intransitivo - com o qual o prefixo pessoal do verbo intransitivo concordará.

(42) a. Pronome djat 'vocês' como argumento A

$\begin{array}{lll}\text { "ãa! djitogo } & \text { eteia } & \text { djat." } \\ \text { ãa dj-i-togo } & \text { ete-ip-a } & \text { djat }\end{array}$

INTJ 3-OBJ.NMLZ-mascar SOC-vir-V.T vocês

‘(A mulher-caracol disse) “Ah! vocês estão trazendo masca dela/para ela.” (WYR20100326-FN-PM-caracol-17)

b. Pronome djat 'vocês' como argumento $\mathrm{S}$

$\begin{array}{lcc}\text { djarepagat } & \text { nen } & \text { djat? } \\ \text { djar-e-pag-a-t } & \text { nen } & \text { djat } \\ \text { 2PL-MED-acordar-V.T-NFUT INTERR.2 vocês } \\ \text { 'Vocês se acordaram?' }\end{array}$




\subsection{Nota sobre SNs e pronome de $1^{\mathrm{a}}$ pessoa do singular em posição inicial}

Elementos como tópico e foco ocupam tipicamente a primeira posição da sentença (periferia esquerda), nas línguas do mundo (cf. Storto (2014a)). Em Karitiana, conforme Storto (2014a, p. 178) há um tipo especial de mudança de tópico realizada através da repetição do sujeito no final da sentença. O sujeito repetido no final da sentença é que indica o tópico. Tal repetição se dá quando o sujeito não é o tópico do enunciado anterior. O sujeito repetido pode ser pronominal ou não.

Veremos, nesta seção, que, em Wayoro, podem ocorrer em posição inicial, com a semântica de tópico, um sintagma marcado com o morfema de tópico mẽ, um pronome - repetição do sujeito de $1^{\text {a }}$ pessoa do singular para efeito de mudança de tópico - ou um pronome acompanhado dos enfáticos kiet 'um, somente' e/ou emõ 'realmente'.

O morfema mẽ é homófono à posposição mẽ 'para'. Veja um exemplo desse morfema em (43), trecho do texto descritivo sobre o enterro tradicional Wayoro, narrado por um pajé, já falecido, em entrevista gravada por Denny Moore. Ao descrever o enterro tradicional, o texto tem como sujeito uma terceira pessoa indeterminada e há repetição da marca de $1^{\mathrm{a}}$ pessoa do plural inclusiva nas palavras que descrevem os artefatos funerários, por exemplo, "[...] cavam a cova, colocam o nosso pote [funerário] [...]”. Após descrever os tipos de utensílios funerários que podem ser usados no enterro tradicional, o locutor fala sobre o que é inserido dentro desses utensílios - no caso, txiakãra 'nosso osso' é colocado dentro de djaap 'vasilha tradicional' ou do 'uwa 'pote tradicional', por exemplo.

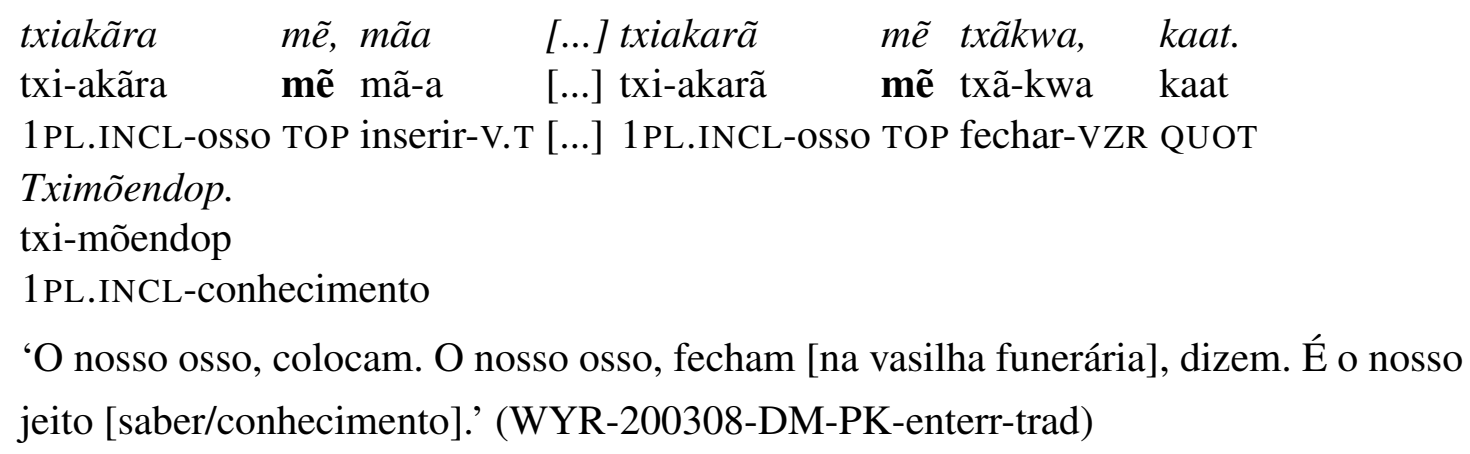

Um exemplo da repetição do pronome de $1^{a}$ pessoa do singular para efeito de tópico pode ser constatado em outro trecho do texto descritivo sobre o enterro tradicional. Como dissemos, nesse texto, o sujeito é uma terceira pessoa indeterminada e há repetição da marca de $1^{\mathrm{a}}$ pessoa do plural inclusiva nas palavras que descrevem os objetos funerários que são inseridos na cova (44a-b). Em uma das sentenças, contudo, o locutor inicia com o pronome de $1^{\text {a }}$ pessoa do singular, on, e faz uma pausa, antes de falar sobre qual será o seu próprio artefato $(44 \mathrm{c})$. A presença do pronome de $1^{\mathrm{a}}$ pessoa no final da sentença, bem como a pausa, indicam que se trata 
de uma repetição, para expressar uma mudança de tópico, dado que as sentenças anteriores expressam a $1^{\mathrm{a}}$ pessoa do plural inclusiva.

a. karemõ txi-kopiip

karemõ txi-kopiip

$m \tilde{a}-a$

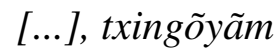

pot

depois 1PL.INCL-forro inserir-V.T [...] 1PL.INCL-sentar-V.T-NMLZ ?

$n \tilde{a}$

nẽ-a

tornar.se-V.T

'Depois, bota o nosso forro, vai ser nossa esteira.'

b. Karemõ txire me

Karemõ txire mẽ

depois nós TOP

'Depois, somos nós [colocados].'

c. on, djaap mbiro kap nã on

on djaap mbiro ?k-a-p nã on

eu vasilha EXIST ?AUX-INF FUT eu

'Lit. Quanto à mim, eu terei vasilha.' (WYR-200308-DM-PK-enterr-trad-1)

Em Karitiana, a quantificação do sintagma nominal por 'somente' ou pitat 'realmente' causa o fronteamento do sujeito na ordem canônica SV (sentença intransitiva). Em Wayoro, o fronteamento de elemento com kiet 'um, apenas' e emõ 'realmente' (ENF) fica claro no seguinte trecho do texto em que um pajé explica o tratamento de uma pessoa enferma (45).

a. kupkuya uurat

kupkuya uut-a-t

on. Okiet

ngut.

raiz.venenosa retirar.doença-V.T-NFUT eu 1 SG-um/apenas PASS.DIST

'Eu curei/retirei o veneno. Eu sozinho, naquele tempo.'

b. Okiet

emõ kap

ndekwat.

o-kiet

emõ kap

ndekwat

1SG-um/apenas ENF PROFORMA INTENS

'Eu mesmo sozinho [fiz] isso bastante.'

c. okiet

emõ djauwat.

o-kiet

emõ $\mathrm{dj}=\mathrm{au}-\mathrm{wa}-\mathrm{t}$

1SG-um/apenas ENF 3=curar-VZR-NFUT

'Eu mesmo sozinho curei/rezei ele.' (WYR-200308-DM-PM-tratamento-paje-01)

Os dados acima mostram o fronteamento de um sintagma topicalizado, a repetição de um pronome em posição inicial para efeito de mudança de tópico, bem como o fronteamento do 
pronome como expressões enfáticas. Vale observar que a repetição de um pronome em posição inicial para efeito de mudança de tópico foi identificada somente com o pronome de $1^{\mathrm{a}}$ pessoa do singular.

\subsection{Verbos auxiliares}

Vejamos, nesta seção, verbos que aparecem após outro verbo, comportando-se de forma semelhante a um núcleo funcional, recebendo os afixos de tempo e a indicação de sujeito. Chamaremos estes itens de verbos auxiliares, os quais foram registrados com as marcas de tempo e com o sufixo de negação -om -rom ou -ap negação do modo irrealis. São itens que não contribuem com o significado da sentença e ocorrem sempre após o verbo (lexical). Essas propriedades estão de acordo com a definição de auxiliares, como proposto em Heine (1993, p. 22-24).

Os auxiliares verbais, em Wayoro, são kara e $n \tilde{a}^{16}$. É possível hipotetizar que kara está relacionado historicamente ao verbo kara que significa ‘cair' (bem como ao verbalizador $k a t$ ), assim como $n \tilde{a}$ pode estar relacionado diacronicamente ao verbo transitivo $n \tilde{a}$ 'tornar-se, fazer' ${ }^{17}$. Atualmente, contudo, observa-se que os auxiliares kara e nã têm significado lexical esvaziado, como atestam os dados em (46) e (47).

\footnotetext{
${ }^{16}$ Analisamos como auxiliar também o verbo mangã 'mandar' usado em construções de causativização analítica (NOGUEIRA, 2011, p. 255), como no exemplo a seguir. São construções diferentes dos auxiliares tratados nesta seção quanto ao verbo lexical, que, na causativização analítica, aparece sem vogal temática e se une ao auxiliar por um morfema de ligação.

a. kap toromangãm nã on, kaat on.

kap top-ro-mang-a-m nã on kaat on

PROFORMA ver-?-AUX-V.T-INF FUT eu DESID eu

'Eu quero mandar olhar isso.' (WYR-200308-DM-PK-tratamento)

${ }^{17}$ Como lembra Anderson (2006, p. 5), é comum, no desenvolvimento das línguas, o seguinte caminho de gramaticalização: verbo lexical $>>$ verbo auxiliar $>>$ afixo. Note que o auxiliar kara é homófono ao verbalizador -kara. Contudo, uma raiz verbalizada com -kara se comportará como verbo típico, por exemplo, terá a negação afixada diretamente ao radical, sem a vogal temática. É o que ocorre com o adjetivo pare ‘bom' que pode ser verbalizado com -kara e então receber o morfema de negação. Confira:
}

a. opare on.

o-pare on

1SG-bom eu

'Eu sou uma boa pessoa [Lit. Eu sou bom].' (PM-2013)

b. oparekarom on.

o-pare-kar-om on

1SG-bom-VZR-NEG eu

'Eu não fiquei bom [da doença].' (PM-2012) 
(46)

$\begin{array}{lllll}\text { yengu } & \text { ate } & k a . & \text { Nderarap } & \text { ere, "eengu } \\ \text { y-engu } & \text { ate } & \text { ko-a } & \text { ndet-ar-a-p } & \text { ere e-engu }\end{array}$

3-chicha.INAL mesmo.assim ingerir-V.T moer-REP-V.T-INF em 2SG-chicha.INAL

korom nãm nã on”.

ko-rom nẽ-Ø-ã-m nã on

ingerir-NEG AUX-VT-INF FUT eu

'Mesmo assim, [as pessoas] estão tomando a chicha dela. Quando ela preparou chicha de novo, [ele disse] "Eu não vou beber tua chicha".' (WYR-20100326-FN-PM-caracol44-45-46)

a. kup mbora, "opiitorom karat on".

kup mbora o-piito e-rom kat-a-t on

pau derrubar 1SG-ar/descanso COP-NEG AUX-V.T-NFUT eu

'(Ele) derrubava árvore, [depois dizia:] "eu estou cansado [Lit. Eu não tenho meu ar/meu descanso]".' (PM-2016-festa-tradicional)

b. Maỹ mé, amboroyom ko karap ne kire.

mayĩ mẽ, amboroyom ko kat-ap nẽ txire

macaxeira TOP farinha comer AUX-NEG IRR nós.INCL

'Quanto à macaxeira, nós não [nunca] comíamos farinha.' (WYR-19900302-DMPM-roca-pesca1)

Os verbos intransitivos usados como auxiliar são tera 'ir' e ia 'vir'. Como auxiliares, esses verbos não utilizam toda a gama de morfemas verbais disponíveis, não aparecem, por exemplo, com morfema causativo. Conforme Heine (1993, p. 23), auxiliares, apesar de terem propriedades verbais, apresentam um comportamento verbal reduzido, "tipicamente, podem ser associados apenas a um espectrum reduzido de distinções de tempo/aspecto e/ou flexões verbais $[\ldots] " 18$.

No dado (48), o auxiliar tera 'ir' aparece após o verbo lexical, ora 'chegar' transitivizado, e seu objeto, 'uwoy 'peixe', na ordem O-V-AUX. O verbo auxiliar recebe o sufixo de negação -rom e a flexão de sujeito $o$ - ' 1 a pessoa do singular'.

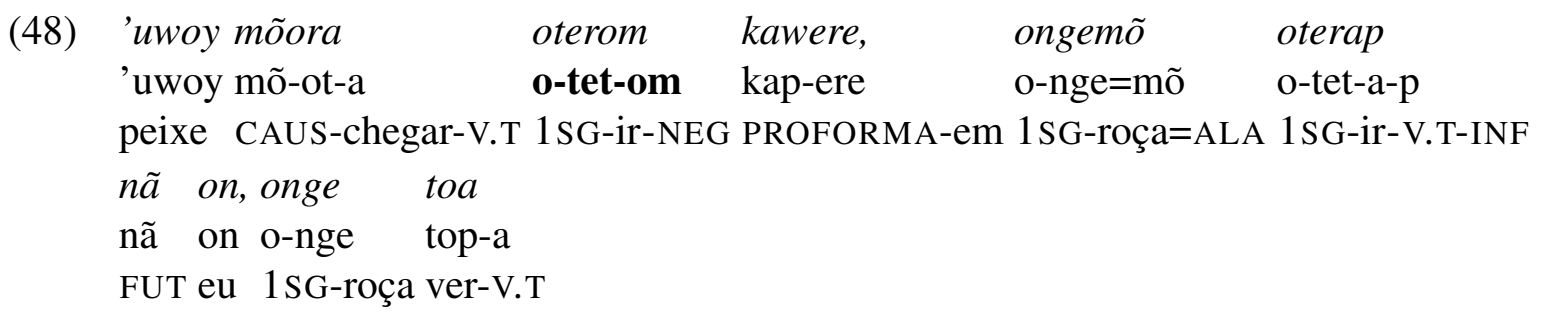

'Se [lit. nisso] eu não for pescar [lit. fazer chegar peixe], eu vou para a minha roça, olhar a minha roça.' (PM-2012)

\footnotetext{
18“'Typically, they may associate only with a restricted spectrum of tense/aspect distinctions and/or verbal inflections [...]" (HEINE, 1993, p. 23).
} 
Em (49), a expressão de futuro aparece no verbo auxiliar ia 'vir' ${ }^{19}$, bem como a marca de pessoa de sujeito. O verbo transitivo lexical toa 'ver' aparece com o clítico de objeto.

$\begin{array}{lllllll}\text { mengu } & \text { nẽrom } & \text { kawere } & \text { etoa } & \text { mbidjap } & \text { nã on. } \\ \text { m-engu } & \text { nẽ-rom } & \text { kap-ere } & \text { e=top-a } & \text { mb-ip-a-p } & \text { nã on. } \\ \text { 1SG-chicha.INAL fazer-NEG PROFORMA-em } & \text { 2SG=ver-V.T } & \text { 1 SG-vir-V.T-INF FUT eu } \\ \text { 'Se [lit. nisso] eu não fizer chicha, eu venho te ver/visitar.' (PM-2012) }\end{array}$

Tanto Galucio (2014a) quanto Singerman (2018) descrevem o sistema de marcação de argumento no verbo auxiliar como nominativo, ou seja, a marca de pessoa se refere sempre ao sujeito. Tal fato também pode ser constatado nos dados acima de Wayoro. Duas formas podem ter o sujeito expresso por um pronome após o auxiliar: o auxiliar nãa, como em (46), e o auxiliar kara, como em (47). Uma situação semelhante é descrita para o auxiliar naat de Mekens, em (GALUCIO, 2001, p. 58-59).

A descrição dos auxiliares é preliminar e são necessários testes de coocorrência com outros morfemas verbais e em outros ambientes sintáticos para dar uma análise detalhada dos mesmos. A marcação de tempo nos auxiliares ocorre também em predicados não verbais ou com raiz verbal sem qualquer morfologia de finitude (sem vogal temática e outros morfemas verbais, como o verbo ko 'comer' em (46)). Outros exemplos de auxiliares serão apresentados no Capítulo 6.

\subsection{Itens com semântica de evento sem morfologia verbal}

Discutiremos nesta seção itens com semântica de evento mas que aparecem sem qualquer flexão verbal. Podemos descrever duas situações diferentes em que isso ocorre: uma em que os itens sem flexão não tem registro de ocorrência com morfemas verbais, como $p u$ 'ir' (50a-b) e põ 'cair' (50b); e outra situação em que os itens são sem dúvida verbos transitivos ou intransitivos, uma vez que são registrados com morfologia verbal em sentenças simples, como tet, em (50a) relacionado ao verbo tera 'ir'. Tratemos, inicialmente, dos itens que não apresentam registro com a flexão verbal.

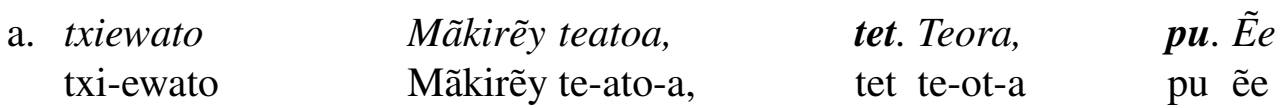

$$
\begin{aligned}
& \text { 1PL.INCL-avô.INAL Mãkirẽy 3C-banhar.se-V.T ir 3C-chegar-V.T ir DEM } \\
& \text { nin pu. Tekuykuya. } \\
& \text { nin pu te-kuy kuy-a } \\
& \text { pequeno ir } 3 \mathrm{C} \text {-terra } \sim \text { terra-V.T }
\end{aligned}
$$

\footnotetext{
${ }^{19}$ A raiz ip 'vir' perde a consoante final diante da vogal temática (cf. outros exemplos de perda dessa consoante na seção 4.1 do capítulo 4). No exemplo, há uma mudança no radical ia 'vir', que se realiza como idja ao receber o prefixo $m b$ - de $1^{\text {a }}$ pessoa singular, tornando a estrutura silábica da palavra CV.CVC. Assim, notamos diferentes alomorfes para o verbo 'vir': ip, ia, idja.
} 
'Nosso avô Mãkirẽy se banhou, foi embora. Chegou e foi. Não demorou, foi. Se sujou [com terra].' (WYR-20080616-AVG-ANT-Hist-agua-010-13)

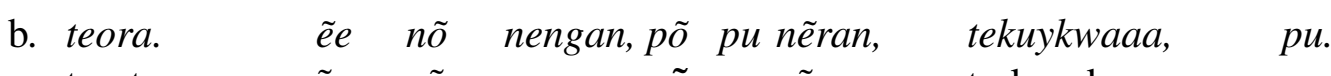
te-ot-a ẽe nõ nengan põ pu nẽran te-kuy-kwaaa pu 3C-chegar-V.T DEM outro SIM cair ir novamente 3C-terra-VZR.ENF ir 'Ele foi. Igual,[fez] isso de novo, foi e caiu de novo, se sujoooou e foi.' (WYR20080616-AVG-ANT-Hist-agua-26-27)

Os itens lexicais sem registro de flexão verbal (cf. Tabela 2.5) são, em sua maioria, monossilábicos, pronunciados com ênfase e podem ter relação sonora com a ideia do evento (alguns de forma mais evidente, como, $p \tilde{o}$ 'cair'). Vamos diferenciá-los de outras onomatopeias que são expressões que se assemelham ao som do referente e que aparecem sempre repetidas (três vezes ou mais) ou prolongadas, imitam, por exemplo, um ser vivo, como o barulho de um pássaro. Os dados em (51) são exemplos de expressões onomatopaicas.

a. kãnkãnkãnkãn pu.

kãnkãnkãnkãn pu

ONTP:canto.pássaro ir

'Foi e [cantou] kãnkãnkãnkãn' (WYR-20080616-AVG-ANT-Hist-agua-077)

b. иииииh uuuuuh arooop

arop

ONTP:chamar.a.distância ONTP:chamar.a.distância coisa.ENF

'[O rapaz chamou] иииии ииииh!. [O outro respondeu de longe:] O que éeeee?' (WYR-20080616-AVG-ANT-Hist-agua-077)

Diferente das onomatopeias, os itens sem flexão em questão têm semântica de evento e ocorrem em construções com outros verbos. Há duas possibilidades de análise para esses itens. Por serem relacionados a uma ideia sonora, podem ser considerados ideofones. Em Karitiana, ideofones são uma classe especial de palavras. Storto (2014b, p. 419-422) distingue ideofones de verbos, usando como evidência o fato de os ideofones não poderem ser flexionados com o morfema de $2^{\mathrm{a}}$ pessoa ou receber o sufixo imperativo. No modo imperativo, os ideofones podem ser usados como complemento do verbo $a$ 'fazer, dizer'. Este é um teste a ser aplicado para uma análise definitiva dos itens aqui discutidos.

Uma outra possibilidade de análise é tratar esses itens não flexionados como uma das classes de verbos da língua, uma classe de verbos não flexionável. Em Mekens, ao lado das classes de verbos transitivos, intransitivos e auxiliares, há os verbos não flexionáveis que expressam, em geral, onomatopeias, enunciação e postura. Tais verbos não flexionam para pessoa, tempo e aspecto; a não ser que sejam verbalizados por processos derivacionais de transitivização e intransitivização (GALUCIO, 2001; GALUCIO, 2014a). 
Tabela 2.5: Possíveis ideofones em Wayoro

\begin{tabular}{ll}
\hline Item - semânt. evento & Significado \\
\hline \hline $\min$ & passar \\
$p u$ & ir \\
$p \tilde{o}$ & cair \\
$k u y$ & pegar \\
ekun & descer \\
\hline
\end{tabular}

Diferentemente dos verbos não flexionáveis de Mekens, que podem receber flexão, após verbalizados, os itens aqui estudados, apesar de terem a semântica de evento, não aparecem em nenhum registro flexionados para pessoa ou para tempo/aspecto. Considerando a verbalização de verbos não flexionáveis proposta por Galucio (2001), poderíamos supor uma relação entre ponga 'partir' e o item não flexionado põ 'caiu' (o sufixo -nga é também um verbalizador; vale ressaltar ainda que a onomatopeia pong 'barulho de coisa que partiu' foi registrada). Para os demais itens, não foram encontrados verbos com semântica relacionada e, portanto, testes deverão evidenciar o comportamento como verbo ou não desses itens.

Consideremos agora os verbos que são claramente transitivos ou intransitivos, mas que também são registrados sem qualquer flexão. Uma primeira observação é que um verbo transitivo ou intransitivo sem flexão aparece sempre em construções com outros verbos, assim como os itens acima ${ }^{20}$. Podem também aparecer repetidos, expressando, por exemplo, uma continuidade do evento ${ }^{21}$. É o caso dos verbos transitivos ngiriira 'rasgar' e mẽengã 'grudar', em (52a-b); e dos verbos intransitivos tera 'ir', no dado (50a), acima mencionado, e ngwea 'subir', em $(52 \mathrm{a})^{22}$.
a. karemõ ekun ngwep endudja
ere meeng, kawere
e tekara
karemõ ekun ngwep endudja
ere meeng kap-ere
ẽe te-kar-a depois descer subir mão.de.pilão em grudar PROFORMA-em DEM 3C-cair-V.T

\footnotetext{
${ }^{20}$ Note que tais registros permitem identificar a raiz verbal, sem a vogal temática $-a$. Por ora, utilizaremos como forma de citação dos verbos o radical verbal (com a vogal temática).

${ }^{21}$ Como apontado de forma preliminar por Nogueira e Costa (2014).

${ }^{22}$ Confira exemplos dos verbos ngiriira 'rasgar', mẽengã 'grudar' e ngwea 'subir' com morfologia verbal:

a. ope ngiriirat on.

o-pe ngiriit-a-t on

1SG-pele rasgar-V.T-NFUT eu

'Eu rasguei minha roupa.' (Nogueira, 2011, p. 111)

b. tura mẽengã, ek teparekarat.

tura mẽeng-ã ek te-pare-kara-t

palha grudar-VZR casa 3C-bom-VZR-NFUT

'Grudaram a palha, a casa ficou pronta.' (PM-2013)

c. mbogop tengweat.

mbogop te-ngwep-a-t

criança 3C-subir-V.T-NFUT

'A criança subiu.'
} 
yãyngu.

yãy-ngu

dente-líquido.INAL

'Então, [a mulher transformada em caracol] subia e descia, grudava-se na mão de pilão (mão do almofariz), então isso caía, o líquido do dente.”

b. ek pe mẽ, ngiriit ngiriit ngiriit, toa.

ek pe mẽ, ngiriit ngiriit ngiriit top-a

casa palha TOP rasgar rasgar rasgar ver-V.T

'A palha da casa, [o rapaz] foi abrindo, abrindo, abrindo, e viu [o que estavam fazendo com os homens].' (WYR-20080627-FN-PM-a-chefe-das-mulheres 40)

Uma hipótese a ser explorada é se tais verbos estão sendo usados de forma ideofônica. Outra questão que se coloca é se fariam parte de uma construção de verbos seriais, pois aparecem em contextos multiverbais. Segundo Haspelmath (2016), os verbos de uma construção de verbos seriais devem ser verbos que, em outros contextos, são independentes; ou seja, devem ser capazes de ocorrer como núcleo de uma oração, sem outros verbos (HASPELMATH, 2016, p. 12). Como vimos, este é o caso de tera 'ir', por exemplo, tornando-o suspeito de fazer parte de uma construção de verbos seriais, quando não flexionado.

Uma das generalizações na literatura sobre as construções de verbos seriais é a seguinte: "todas as CVS [construções de verbos seriais] são pronunciadas com um único contorno entoacional, como uma oração de um único verbo" (HASPELMATH, 2016, p. 308) ${ }^{23}$. Tal generalização não se aplica às construções aqui estudadas. Um exemplo adicional a este fato é oferecido em (53), em que a construção com o verbo não flexionado tet 'ir' tem sua própria unidade entoacional.

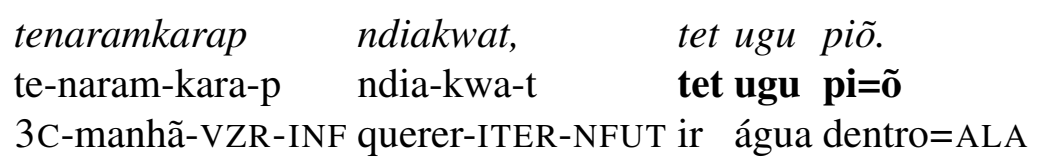

'[Quando] estava querendo amanhecer, ela foi embora para a água.' (WYR-20100326FN-PM-caracol-53)

No exemplo (54), podemos ver que os verbos que podem aparecer sem flexão nem sempre são eventos dinâmicos, como koa 'ficar'. Ainda, tais verbos nem sempre aparecem em adjacência com os demais verbos da construção. No exemplo (54), um sintagma posposicional intervém entre os verbos. Dinamicidade da semântica do verbo e adjacência dos verbos nas construções seriais são outros requisitos para analisá-las como tal (HASPELMATH, 2016, p. 12-14).

\footnotetext{
23“All SVCs are pronounced with a single intonation contour, like single-verb clauses" (HASPELMATH, 2016, p. 308).
} 
(54) kop ndop yindak ere ka.

kop ndop [SPyindak ere] ko-a

ficar deitar noite em ingerir-V.T

'De noite, ele ficou deitado, comendo.' (WYR-200308-DM-PK-origemdomundo-23)

\subsection{Sumarizando os fatos sobre pronomes, prefixos e clíticos}

Em Wayoro, vimos que uma série idêntica de marcadores argumentais verbais (exceto para a terceira pessoa) é usada como argumento objeto do verbo transitivo e como argumento sujeito do verbo intransitivo. Nas sentenças intransitivas, há concordância entre marcadores pessoais e pronomes livres ou nominal livre correferente. Em sentenças transitivas, no entanto, não há concordância entre marcadores pessoais no verbo e pronomes livres ou nominal livre correferente.

Há, portanto, dois paradigmas sentenciais: o de verbo intransitivo, em que há concordância; e o de verbo transitivo, em que não há concordância. Uma das evidências usadas para se constatar tal diferença é a utilização do marcador de $3^{\mathrm{a}}$ pessoa correferencial como correferente ao sujeito do verbo intransitivo.

Consideraremos a concordância como propriedade sintática significativa, dado que nos permite refinar a descrição e análise das sentenças matrizes da língua Wayoro. Assim, classificaremos os marcadores de pessoa no verbo em dois grupos:

- Marcadores clíticos de pessoa (argumento objeto do verbo transitivo): dada a semelhança na identidade fonológica e a impossibilidade de coocorrer com um nominal livre ou pronome correferente, serão analisados como marcadores clíticos de pessoa, cuja cliticização é obrigatória. São, portanto, argumentos cliticizados ao verbo.

- Prefixos pessoais (sujeito do verbo intransitivo): dada a possibilidade de coocorrência com pronomes livres ou SN correferente serão considerados prefixos pessoais de concordância, que refletem os traços do sujeito do verbo intransitivo.

Em outras palavras, nossa análise atual dos marcadores de pessoa no verbo difere da apresentada em Nogueira $(2011,2013,2014)$. Com base na investigação específica sobre concordância nas sentenças matrizes, consideramos que analisar os marcadores de argumento objeto como clíticos captura uma diferença morfossintática relevante na língua, a saber, os diferentes paradigmas sintáticos das sentenças matrizes transitivas e intransitivas.

Verbos com comportamento distinto fazem parte de uma construção verbo + auxiliar ou de construções multiverbais. 


\section{Morfologia verbal: causativo e voz média}

txiewato ẽe, tximõapokaya ẽe.

Esse nosso avô, esse estava fazendo a gente

sair. (Antônio Wajuru)

Neste capítulo, apresentaremos os processos de alteração de valência identificados na língua Wayoro. As seções 3.1 e 3.2 tratam da transitivização/causativização através dos prefixos mõ$\sim \tilde{o}$ - e ete-. Na seção 3.3, apresenta-se dados de intransitivização via prefixo $e$ - de voz média. Por fim, em 3.4, são apresentados dados que têm algum comportamento diverso das análises aqui apresentadas e, portanto, são desafios futuros.

\subsection{Transitivização/causativização via prefixo $m \tilde{\boldsymbol{o}}-\sim \tilde{\boldsymbol{o}}$ -}

Segundo Rodrigues e Cabral (2012, p. 530), em todas as famílias linguísticas Tupi, existe um elemento que deriva verbos transitivos de uma base intransitiva. Tal prefixo é reconstruído para Proto-Tupi como prefixo causativo **mo-. Os autores mencionam ainda a possibilidade de uso deste morfema com bases adjetivais e nominais derivando verbos transitivos. O comportamento do reflexo deste prefixo na língua Wayoro é detalhadamente estudado em Nogueira (2011, 2013, 2014) e, por este motivo, será apresentado de maneira resumida nesse capítulo.

Observe o efeito do prefixo mõ- sobre o verbo apokaya 'sair', atoa 'banhar-se' e ora 'ir', nos seguintes trechos de textos. Note, em (55a), (56a) e (57a), que, como verbos intransitivos, apokaya 'sair', atoa 'banhar-se' e ora 'chegar' apresentam um prefixo pessoal que pode coocorrer com um SN correferencial. Por sua vez, os mesmos verbos, quando transitivizados via prefixo causativo $m \tilde{o}-$, podem receber marcadores clíticos de pessoa que realizam o objeto direto do verbo, no caso $t x i=$ ' 1 a pessoa do plural inclusiva', em $(55 \mathrm{~b} ; 57 \mathrm{~b})$ ou ter um SN objeto como temẽpit 'filho dela', em (56b).

(55) Transitivização do verbo apakaya 'sair'

a. mbogop teapokaya.

mbogop te-apokay-a

criança 3C-sair-V.T 
'A meninada saiu.' (WYR-200308-DM-PK-origemdomundo-51)

b. txiewato $\tilde{e}$ e, tximõapokaya $\tilde{e}$.

txi-ewato ẽe, txi=mõ-apokay-a ẽe

1 PL.INCL-avô DEM 1PL.INCL=CAUS-Sair-V.T DEM

'Esse nosso avô, esse estava fazendo a gente sair.' (WYR-20080616-AVG-ANTHist1-13)

(56) Transitivização do verbo atoa 'banhar-se'

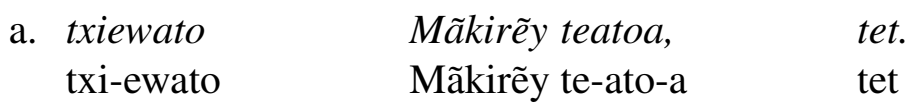

1 PL.INCL-avô.INAL Mãkirẽy 3C-banhar.se-V.T ir

'Nosso avô Mãkirẽy se banhou, foi embora.' (WYR-20080616-AVG-ANT-Histagua-010)

b. temẽpit mõatokwa, pu.

te-mẽpit mõ-ato-kwa pu

3C-filho.o CAUS-banhar.se-ITER ir

'Deu banho na filha dela [lit. fez a filha dela se banhar], foi embora' (WYR20080616-AVG-ANT-Hist-agua-018)

(57) Transitivização do verbo ora 'ir'

a. tetera, teora.

te-tet-a te-ot-a

3C-ir-V.T 3C-chegar-V.T

'Foram e chegaram de novo.' (WYR-20080616-AVG-ANT-Hist-agua-045)

b. tximõoran

txi=mõ-ot-a-t

$\tilde{e} e, \quad$ txiewato

Mãkirẽy.

1 PL.INCL=CAUS-chegar-V.T-NFUT DEM 1PL.INCL-avô.INAL Mãkirẽy

'Esse nos fez chegar, nosso avô Mãkirẽy.' (WYR-20080616-AVG-ANT-Hist1-23)

O prefixo causativo $m \tilde{o}$ - $\sim \tilde{o}$ - é uma ferramenta para identificar a transitividade dos verbos da língua Wayoro. Tal prefixo ocorre somente com verbos intransitivos e causa uma mudança na estrutura argumental, adicionando um argumento sujeito agente ou causa à sentença, ou seja, tornando o verbo transitivo (NOGUEIRA, 2013, p. 329). Vejamos exemplos complementares em (58) e (59). As provas morfossintáticas de que o verbo se transitivizou são a inserção de um SN objeto imediatamente antes do verbo (ordem canônica da língua) (58b) e a realização dos clíticos de pessoa como objeto do verbo (58c; 59b-c).

(58) Transitivização do verbo ngwea 'subir' (GALUCIO; NOGUEIRA, 2014) 
a. mbogop tengweat.

mbogop te-ngwep-a-t

criança 3C-subir-V.T-NFUT

'A criança subiu.'

b. ngwaykup mbogop ongweat.

ngwaykup mbogop õ-ngwep-a-t

homem criança CAUS-subir-V.T-NFUT

'O homem fez o menino subir.'

c. ngwaykup yõngweat.

ngwaykup y=õ-ngwep-a-t

homem $\quad 3=$ CAUS-subir-V.T-NFUT

'O homem o fez subir.' (PM-2010)

(59) Transitivização do verbo era 'dormir'

a. mberat on.

mb-et-a-t on

1SG-dormir-V.T-NFUT eu

'Eu dormi/estou dormindo.' (SANTOS, 2010, p. 78)

b. õn emõeran.

õn $\mathbf{e}=$ mõ-et-a-t

eu $2 \mathrm{SG}=\mathrm{CAUS}$-dormir-V.T-NFUT

'Eu fiz você dormir.'

c. oti omõeran.

o-ti o=mõ-et-a-t

1 SG-mãe $1 \mathrm{SG}=$ CAUS-dormir-V.T-NFUT

'Minha mãe me fez dormir.' (GALUCIO; NOGUEIRA, 2014)

Adicionalmente, note que, em (58a) e (59a), os verbos intransitivos têm uma marca de pessoa como argumento sujeito que é correferente com um nominal livre ou pronome pessoal — ou seja, há concordância nos verbos intransitivos. Quando transitivizados, no entanto, o comportamento é diferente. Veja, comparando (58b-c), que o SN objeto não coocorre com a marca verbal de $3^{\mathrm{a}}$ pessoa objeto $y=$, assim como, em (59b-c), o objeto é realizado unicamente pelos clíticos de pessoa $e=\mathrm{e} o=$. Não há concordância no verbo transitivizado.

Além das características de verbos transitivos acima listadas, as sentenças em que não há SN ou marca de pessoa como objeto antes do verbo transitivizado por mõ- têm o alomorfe zero de objeto como terceira pessoa, tal como ocorre com verbos transitivos iniciados por consoantes, como em (60a). Por outro lado, quando o alomorfe $\tilde{o}$ - é usado, a marca de $3^{\text {a }}$ pessoa deve ser 
explícita $y=$, como em (60b).

(60) Objeto de $3^{\mathrm{a}}$ pessoa com verbos transitivizados

a. mо̃amо̃yãm nã on.

$\emptyset=$ mõ-amõy-ã-m nã on

3=CAUS-dançar-V.T-INF FUT eu

'Eu fiz (alguém) dançar.'

b. yõngwaroa, ndege mõ!

$\mathrm{y}=\tilde{o}-$ ngwaro-a ndege mõ

3=CAUS-moquear-V.T QUANT HORT

'Moqueavam isso [a caça], [chamavam] "vamos todos!"” (WYR-20161007-FNPM-MA-festa-tradic)

Por fim, Nogueira $(2011,2013)$ mostra que o morfema causativo tem comportamento

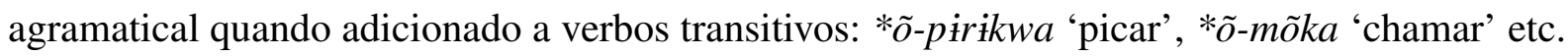
Pode-se dizer, assim, que tal morfema seleciona verbos intransitivos.

\subsection{Prefixo transitivizador ete- 'sociativo'}

Guillaume e Rose (2010, p. 386) lembram que os causativos sociativos são também mecanismos de aumento de valência. Os autores afirmam que um número expressivo de línguas da América do Sul apresenta um contraste claro entre um morfema causativo regular e um morfema causativo sociativo específico (GUILLAUME; ROSE, 2010, p. 390), como em várias línguas Tupi (BIRCHALL, 2014), tais como as línguas da subfamília Tupari (GALUCIO; NOGUEIRA, 2014) ${ }^{1}$.

Galucio e Nogueira (2014) identificam o prefixo causativo sociativo ete- em Wayoro na forma verbal etetera 'levar', cuja base é o verbo intransitivo tera 'ir'. Esta subseção pretende aprofundar a descrição do morfema ete-. Na presente pesquisa, foram registradas ocorrências de ete- com os verbos intransitivos ia 'vir', ndoa 'deitar', além de tera 'ir'. Trechos de textos e dados elicitados através de tradução de português para Wayoro para o estudo destas formas são apresentados a seguir.

As seguintes perguntas foram levantadas: (i) quais são as evidências de que se trata de um prefixo transitivizador e não de uma posposição nominal expressando companhia? (ii) aplicase aos demais verbos intransitivos? Para responder essas perguntas foram realizados testes de

\footnotetext{
${ }^{1}$ Segundo Guillaume e Rose (2010, p. 384), os eventos causativos sociativos podem ser classificados como: ação conjunta, na qual causador e causee realizam a mesma ação (joint-action); assistiva, em que o causador ajuda o causee sem realizar exatamente a mesma ação (assistive); supervisionada, em que o causador meramente supervisiona a ação realizada pelo causee (supervision). Com base em Guillaume e Rose (2010), apontamos a necessidade de descrever as nuances semânticas (ação conjunta, assistiva, supervisionada) das sentenças em que aparece o prefixo causativo sociativo ete-, bem como das sentenças em que ocorre o prefixo causativo $m \tilde{o}-\sim \tilde{o}-$.
} 
julgamento de gramaticalidade com relação à inserção do prefixo a outros verbos intransitivos, testes de uso do prefixo como morfema livre (posposição), bem como a identificação dos prefixos/clíticos pessoais que aparecem no verbo com ete-.

Observe, nos dados que seguem, que os verbos intransitivos com ete-podem ter um objeto de $3^{\mathrm{a}}$ pessoa realizado pelo marcador clítico $d j=(61 \mathrm{a}-\mathrm{b}, 62 \mathrm{~b} ; 63 \mathrm{~b})$; ou o objeto pode ser expresso por um SN pleno como em (61c; 62a; 63c). Trata-se de comportamento esperado para verbos transitivos.

(61) Verbo tera 'ir' com o sociativo ete-

a. Ndeke djetetet, koypet mẽ

Ndeke dj=ete-tet koypet mẽ

ele/a 3=SOC-ir irmã. $o^{7}$ TOP

'Ele a levou, a irmã dele.' (WYR-19900302-DM-PK-cobra-duas-cabecas)

b. djeteterat.

$\mathrm{dj}=$ ete-tet-a-t

$3=$ SOC-ir- - .T-NFUT

'(Ele) levou algo.' (PM-2015)

c. aramira indiakwa etetera tendek mõ.

aramira indiakwa ete-tet-a te-ndek=mõ

mulher comida SOC-ir-V.T 3C-casa=ALA

'A mulher levou comida para a casa dela (mesma).' (GALUCIO; NOGUEIRA, 2014, p. 229)

(62) Verbo ia 'vir' com morfema sociativo ete-

a. kerere aramiraian djitogo eteia.

k-e-rere aramira-ian dj-i-togo ete-ip-a

?-COP-SUB mulher-PL 3-OBJ.NMLZ-mascar SOC-vir-V.T

'Enquanto isso, as mulheres estavam trazendo masca para ela (a chicha).' (WYR20100326-FN-PM-caracol 16)

b. djeteiat.

$\mathrm{dj}=$ ete-ip-a-t

$3=$ SOC-vir-V.T-NFUT

'(Ele) trouxe algo' (PM-2016)

(63) verbo ndoa 'deitar' com o sociativo ete-

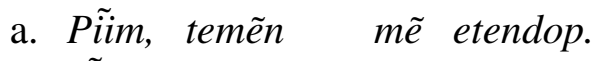

Piim te-mẽn mẽ ete-ndop

escuro 3C-marido TOP SOC-deitar 
'(Quando) escureceu, deitou com (ele), com o marido dela' (WYR-20080627-FNPM-yangwareta-cabeça-se-solta)

b. djetendoat on.

$d j=e t e-n d o p-a-t \quad e u$

3=sOC-deitar-V.T-NFUT eu

'Eu deitei com ele.'

c. omẽpit etendoap nã

o-mẽpit ete-ndop-a-p nã

1 SG-filho. + SOC-deitar-V.T-INF FUT

'Eu deitarei com meu filho.' (PM-2015)

Testamos, ainda, a aplicação do prefixo com outros verbos intransitivos. Note em (64) que o verbo intransitivo atoa 'banhar-se' foi julgado agramatical com o prefixo ete-

(64) Verbo intransitivo atoa testado e julgado agramatical com ete- (PM-2015)

a. teatoat.

te-ato-a-t

3C-banhar.se-V.T-NFUT

'Ele tomou banho.'

b. *djeteatoat.

$*$ dj=ete-ato-a-t

3=sOC-banhar.se-V.T-NFUT

É interessante notar que, quando o colaborador julgou o verbo atoa com o prefixo sociativo acima, apresentou como sentença gramatical correspondente uma sentença com o elemento posposicional eremõ que indica companhia, como vemos em (65).

(65) Posposição de companhia eremõ

a. omẽpit eremõ mbatoa.

o-mẽpit eremõ mb-ato-a

1SG-filho.q com 1SG-banhar.se-V.T

'Eu estou tomando banho com meu filho.'

b. omẽn eremõ mbatoa.

o-mẽn eremõ mb-ato-a

1SG-marido com 1SG-banhar.se-V.T

'Eu estou tomando banho com meu marido.' (PM-2015) 
A posposição comitativa eremõ tem claramente em sua estrutura a marca de caso $-m \tilde{o}$ 'instrumental/alativo'. A forma ere pode ter tido origem na posposição Tupi $* * e^{j} o \sim e \Gamma^{j} e$ 'associative'2.

Vale observar ainda que há semelhança fonológica entre ete- 'sociativo', $e$ - 'voz média' e $t e-3^{a}$ pessoa correferencial. É possível, inclusive, imaginar que ete- é constituído por e-te 'MED-3C'. Investigações diacrônicas poderão explicar tal relação. Sincronicamente, contudo, a interpretação de ete- 'sociativo' como constituído por $e$-te 'MED-3C' não é plausível, uma vez que em dados atuais tais morfemas coocorrem na ordem contrária te-e 'MED-3C'.

Vimos que há verbos intransitivos que não aceitam a prefixação de ete-. É interessante notar que semelhante restrição de uso do prefixo causativo sociativo (também denominado comitativo, na literatura, como em Rodrigues (1953)) é descrita para a língua Munduruku (subfamília Mundurukú, Tupi) (GOMES, 2014, p. 257); bem como para a língua Guajá (subfamília TupiGuarani, Tupi), em que as ocorrências de formação de verbos transitivos com o prefixo causativo comitativo $r$ - são analisadas como lexicalizações (MAGALHÃES, 2014, p. 74).

Apesar do pequeno número de verbos registrados com o morfema sociativo em Wayoro, trata-se de um dos morfemas gramaticais produtivos na língua. No seguinte dado, o morfema sociativo ete- ocorre após um verbo transitivo ter sido intransitivizado pela marca de voz média e-. Como se observa, em (66a), o verbo ngwara 'afastar-se' é biargumental. Em (66b), este verbo transitivo recebe o morfema $e$ - tornando-se intransitivo, engwara 'fugir', o que podemos concluir pela presença do morfema de $3^{a}$ pessoa correferencial. $\mathrm{O}$ dado (66c) mostra que o verbo em questão pode se tornar novamente transitivo através do uso do prefixo sociativo ete-, eteengwara 'fugir com'. Note em (66c), que eteengwara é biargumental, tendo o SN txikut nin 'nossas crianças pequenas' como objeto e ngwerep 'não indígena' 3 como sujeito.

(66) ngwara 'afastar-se' coocorrência entre voz média $e$ - e ete- 'sociativo'

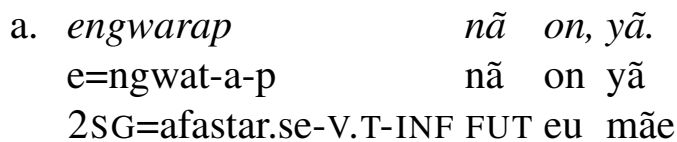

'Eu vou deixar você, mamãe.' (conversa, MJ-2010)

b. aramira teengwarat.

aramira te-e-ngwat-a-t

mulher 3C-MED-afastar.se-V.T-NFUT

'A mulher fugiu.' (PM-2017)

\footnotetext{
${ }^{2}$ Segundo Rodrigues e Cabral (2012, p. 531), tal posposição pode estar relacionada ao prefixo causativocomitativo de forma fonológica idêntica $\left(* * e \Gamma^{j} \boldsymbol{O} \sim e \boldsymbol{r}^{j} e\right.$ 'associative') que "deriva verbos transitivos de verbos intransitivos e cujo causee deve desempenhar simultaneamente os papéis de agente e paciente (coadjuvantes) de um processo verbal" (RODRIGUES; CABRAL, 2012, p. 531, tradução nossa).

${ }^{3} \mathrm{O}$ termo usado, na TI Rio Guaporé, em português, para se referir aos não-indígenas é ere [ع.'rع].
} 


\section{c. kawere txikut nin eteengwarat

kap-ere txi-kut nin ete-e-ngwat-a-t

PROFORMA-em 1PL.INCL-sêmen pequeno SOC-MED-afastar.se-V.T-NFUT

ngwerep.

ngwerep

não.indígena

'Então (nisso), os brancos carregaram/roubaram (lit. fugiram com) as nossas crianças pequenas.' (texto, ANT-2008)

Nogueira (2011) atesta que o morfema transitivizador $m \tilde{o}$ - $\sim \tilde{o}$ - pode ser aplicado a um verbo intransitivizado de forma semelhante ao processo observado em (66) com o morfema sociativo ete-. Em (67a) podemos constatar que o verbo ngennga 'engolir' é biargumental ${ }^{4}$. O dado (67b) mostra o referido verbo com o morfema de voz média $e$ - e com o prefixo de $3^{\text {a }}$ pessoa correferencial, ou seja, comportando-se como verbo intransitivo, traduzido como 'afundar'. Em (67c), a forma intransitivizada de ngennga recebe o prefixo transitivizador mõ- 'causativo', mõengennga.

(67) a. ngwaykup 'uwoy ngenngat. ngwaykup 'uwoy ngen-nga-t

homem peixe engolir-VZR-NFUT

'O homem engoliu o peixe.'

b. kupe teengenngat.

kupe te-e-ngen-nga-t

canoa 3C-MED-engolir-VZR-NFUT

'A canoa afundou.'

c. ngwaykup kupe mõengenngat.

ngwaykup canoa mõ-e-ngen-nga-t

homem canoa CAUS-MED-engolir-VZR-NFUT

'O homem afundou a canoa.' (NOGUEIRA, 2011, p. 192)

\subsection{Voz média via prefixo $e$ -}

O prefixo reflexivo ${ }^{* *}$ we- do Proto-Tupi teve como reflexo nas línguas da família Tupi diferentes tipos de valores gramaticais, a saber, prefixos recíprocos, prefixos reflexivos, prefixos

\footnotetext{
${ }^{4} \mathrm{~A}$ raiz ngen ocorre sem flexão verbal no seguinte trecho.

a. ẽete emõ yãy pãrangãn, ngen. ẽete emõ yãy pãrang-ã-n ngen DEIT ENF dente quebrar-VZR-NFUT engolir 'aqui mesmo no dente acertaram, [ela] afundou.' (WYR-20080627-FN-PM-a-chefe-das-mulheres 71)
} 
de voz média e prefixos de passiva (RODRIGUES; CABRAL, 2012, p. 527-529). Na língua Wayoro, o prefixo $e$ - 'voz média' está relacionado historicamente com tal proto-morfema.

Segundo Nogueira $(2011,2013)$, do ponto de vista morfossintático, as sentenças cujo núcleo são verbos com prefixo $e$ - são claramente construções intransitivas. Com relação aos marcadores de pessoa verbal, tais verbos exigem apenas um argumento indicado pelos prefixos pessoais absolutivos. Vimos, no Capítulo 2, que a $3^{\text {a }}$ pessoa de verbos intransitivos é expressa pelo prefixo correferencial te-, evidenciando a concordância entre SN sujeito e verbo. Os dados em (68a) e (69a) mostram que os verbos puruga 'furar' e kowa 'esconder' são biargumentais. Nas sentenças em (68b) e (69b-c), os verbos aparecem com o prefixo $e$ - e o morfema de $3^{\mathrm{a}}$ pessoa te- e $1^{\text {a }}$ pessoa $o-$, respectivamente, concordam com o sujeito.

(68) Intransitivização do verbo puruga 'furar': interpretação reflexiva
a. opurukwat
ẽete awape akara.
$\mathrm{o}=$ puru-kwa- $\mathrm{t}$
ẽete awape akara
$1 \mathrm{SG}=$ furar-ITER-NFUT DEIT barata grande

'A barata grande me mordeu aqui [na cintura].' (WYR-201512-FN-ANI-vocab-102)

b. Pororoka teepurugat.

Pororoka te-e-puru-ga-t

Pororoka 3C-MED-furar-VZR-NFUT

'Pororoka se furou (com flecha).' (conversa, MJ-2010)

(69) Intransitivização do verbo kowa 'esconder': interpretação reflexiva

a. tut kowat on.

terçado esconder-V.T-NFUT eu

'Eu escondi o terçado.' (PM-2012)

b. en eri mbekowat on.

en eri mb-e-kow-a-t on

você ABL 1SG-MED-esconder-V.T-NFUT eu

'Eu me escondi de você.' (PM-2012)

c. "mbekowap nã on".

mb-e-kow-a-p nã on

1SG-MED-esconder-V.T-INF FUT eu

“"Eu vou me esconder.”' (WYR-20100326-FN-PM-caracol-27)

Outra evidência morfossintática da intransitivização advém do fato de que os verbos com prefixo $e$ - podem coocorrer com o prefixo causativo/transitivizador $m \tilde{o}-\sim \tilde{o}$ - e, como verbo 
transitivizado, podem receber os marcadores clíticos de pessoa na função de objeto. Abaixo, observe que o verbo ngennga 'engolir' torna-se monoargumental, com a adição do prefixo $e$ (70b-c). Como verbo intransitivizado pode, então, ser transitivizado por mõ-. O marcador clítico de objeto evidencia que o processo de transitivização ocorreu (70c).

(70) Intransitivização do verbo ngẽnga 'engolir/afundar': leitura anticausativa (NOGUEIRA, 2011, p. 192-193)

a. ngwaykup 'uwoy ngenngat.

ngwaykup 'uwoy ngen-nga-t

homem peixe engolir-VZR-NFUT

'O homem engoliu o peixe.'

b. 'uwoy teengenngat.

'uwoy te-e-ngen-nga-t

peixe 3C-MED-engolir-VZR-NFUT

'O peixe afundou.'

c. omõengenngat.

$\mathrm{o}=$ mõ-e-ngen-nga-t

$1 \mathrm{SG}=\mathrm{CAUS}-\mathrm{MED}-\mathrm{engolir}-\mathrm{VZR}-\mathrm{NFUT}$

‘(Alguém) me afundou.' (NOGUEIRA, 2011, p. 193)

Há, ainda, verbos em que o morfema $e$ é inerente à raiz verbal (71). São verbos intransitivos cujo radical não ocorre como forma livre na língua, ou seja, não apresentam uma versão biargumental ou monoargumental correspondente.

(71) Verbo emean 'conversar/combinar de fazer algo' e epũiwã 'anoitecer': leitura média

a. tuero nderere, ngwandap teemẽan.

tuero ndet-ere ngwandap te-emẽ-a-n

chicha moer-SUB cacique 3C-MED.conversar-V.T-NFUT

'Enquanto preparavam chicha, o cacique se combinava [com os demais].' (WYR20161007-FN-PM-MA-festa-tradic)

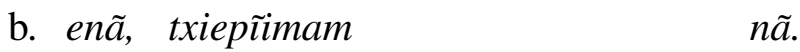

enã txi-epĩim-a-m nã

agora 1PL.INCL-MED.escuridão-V.T-INF FUT

“'Agora, nós vamos anoitecer” [disse o dono da noite, uuy poot].' (WYR-200308-

DM-PK-diaenoite)

Nogueira (2013) conclui que, do ponto de vista semântico, tais construções com prefixo $e$ podem ser analisadas como: 
- Anticausativas: em que o objeto torna-se sujeito do verbo intransitivizado (e não há indicação do sujeito do verbo transitivo original), como em (70);

- Reflexivas: em que sujeito e objeto são correferenciais e que, segundo Kemmer (1993), descrevem eventos que, na forma não derivada, são geralmente direcionados a outro participante, como em (68). Em Nogueira (2011) e Nogueira (2013, p. 335), mencionamos que outra via para a construção de sentenças reflexivas é o uso dos clíticos de objeto como correferentes ao sujeito do verbo transitivo;

- Médias: verbos com sujeito [- animado] com leitura de evento espontâneo, bem como verbos com morfema $e$ inerente, os quais fazem parte de situações médias propostas por Kemmer, como em (71).

Assim, em Wayoro, os verbos intransitivizados por meio do prefixo $e$ - podem apresentar valor anticausativo, reflexivo e de voz média (eventos espontâneos, eventos naturalmente recíprocos etc.). Considerando que são semânticas relacionadas à voz média, de maneira geral, tal como identificado em Nogueira (2013), glosaremos o prefixo $e$ - como voz média ${ }^{5}$ (cf. análise semelhante em Aragon (2014) para a língua Akuntsú).

Neste trabalho, identificamos outro morfema com valor recíproco, o prefixo ege- $\sim e w e-{ }^{6}$. Como exemplo, veja a adição deste prefixo ao verbo poanã 'substituir', em (72) ${ }^{7}$. Em (72a) podemos observar que o verbo poanã é um verbo transitivo, pois tem o clítico de $2^{\mathrm{a}}$ pessoa do plural como objeto e o sujeito on de $1^{\text {a }}$ pessoa do singular. Tal verbo pode ser intransitivizado pelo recíproco ege- e, assim, ser usado com o prefixo de terceira pessoa correferencial (72b) ou $1^{\text {a }}$ pessoa do plural inclusiva txi- (72c) como sujeitos.

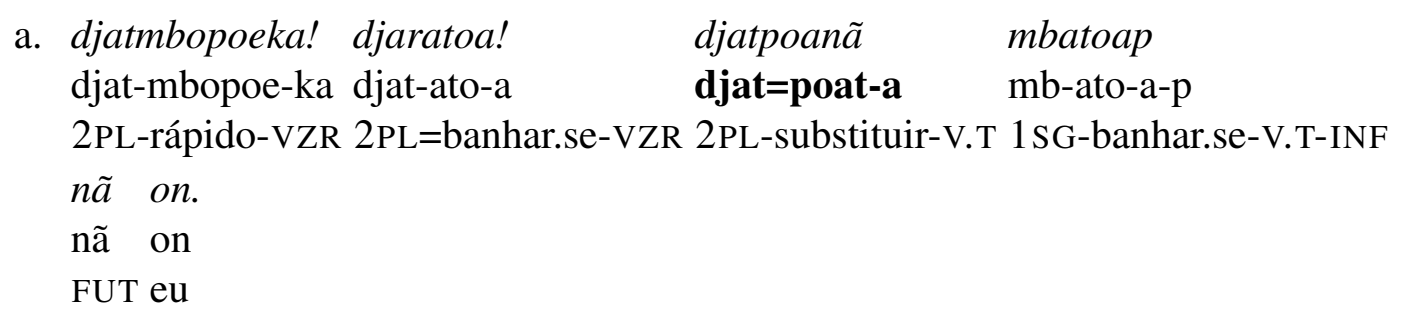

'Sejam rápidos vocês! Tomem banho! [depois] eu vou tomar banho no lugar de vocês [lit. substituir vocês].' (PM-2017)

b. teegepoatkarat.

te-ege-poat-kara-t

3C-RECP-substituir-VZR-NFUT

'Ele faleceu [Lit. Ele se substituiu].' (PM-2012)

\footnotetext{
${ }^{5}$ Agradeço a sugestão ao professor Dr. Denis Creissels durante minha apresentação de trabalho no Laboratório Dynamique Du Langage (DDL), Lyon, França, em 27 de abril de 2018.

${ }^{6}$ Variação semelhante é encontrada nas palavras com o fone $\left[\mathrm{gg}^{w}\right]$, como em $\left[\mathrm{gg}^{w}\right.$ iri] $\sim$ [ßiri] 'açaí', o que aparentemente se relaciona a uma variação dialetal.

${ }^{7}$ Em Tupari, o morfema recíproco é eue- (SINGERMAN, 2018).
} 


\section{c. kap, txiegepoatkatkwap ere [...] \\ kap txi-ege-poat-kat-kwa-p ere [...] \\ PROFORMA 1PL.INCL-RECP-substituir-VZR-ITER-INF em [...]}

'[Sobre] isso, [sobre] quando nós falecemos [ele quer saber].' (WYR-200308-DMPK-enterr-trad)

\subsection{Desafios futuros}

Segundo Galucio e Nogueira (2014), embora seja um verbo transitivo, é possível utilizar o verbo toa 'ver' com o morfema causativo õ-. O sentido da forma resultante $\tilde{o}$-toa é 'mostrar' A estrutura com o verbo causativizado $\tilde{o}$-toa apresenta um terceiro argumento oblíquo, acompanhado pela posposição mẽ (73a), mas que pode também não ser realizado fonologicamente (opção indicada pelos parênteses). Os dados em (73b-c) mostram que é possível acrescentar os marcadores clíticos de pessoa na função de objeto do verbo.

(73) verbo ôtoa 'mostrar' (NOGUEIRA, 2011)
a. ngwaykup mbogop ôtoat
(dj-ewato mẽ)
ngwaykup mbogop õ-top-a-t
(dj-ewato mẽ)
homem criança CAUS-ver-V.T-NFUT 3-avô.INAL para
'O homem mostrou a criança para o avô dela.'

b. ngwaykup yõtoat.

ngwaykup $\mathrm{y}=\tilde{0}-$ top-a-t

homem $3=$ CAUS-ver-V.T-NFUT

'O homem o mostrou (para alguém).'

c. ngwaykup txiôtoat.

ngwaykup txi=õ-top-a-t

homem 1PL.INCL=CAUS-ver-V.T-NFUT

'O homem nos mostrou (para alguém).' (PM-2010)

O verbo ôtoa se comporta de maneira semelhante ao verbo bitransitivo yõa 'dar', que também tem um argumento oblíquo opcional, como se observa em (74).

a. temen uwape yõa.

te-men uwape yõm-a

3C-marido chicha dar-V.T

'[A mulher] deu chicha do marido dela/para o marido dela.' (WYR-20080627-FN-

PM-yangwareta-cabeça-se-solta)

b. ngwaykup 'uwoy tũkwap ngwaykup 'uwoy tũy-kwa-p

$$
\begin{array}{ll}
\text { yõan } & \text { (on mẽ). } \\
\text { yõm-a-n } & \text { on mẽ }
\end{array}
$$

homem peixe ?chupar-VZR-NMLZ dar-V.T-NFUT eu para 
'O homem (me) deu uma malhadeira/rede.pesca [instrumento de pesca].' ((NOGUEIRA, 2011, p. 2010))

Em estudo sobre mudança de valência em Tsez (família Daghestanian, localizada no Cáucaso) Comrie (2007, p. 368) nota que "outra complicação que precisa ser considerada é que alguns verbos causativos em Tsez foram aparentemente lexicalizados." Em Tsez, a palavra egi-r 'enviar', com o sufixo causativo - $r$, parece ser o causativo de egi- que atualmente significa 'desaparecer'. Conforme Comrie (2007, p. 369), “se um verbo foi lexicalizado sua valência não reflete mais a do verbo causativo derivado produtivamente" 8 . Segundo o autor, trata-se de um fator adicional que resulta em comportamento diferenciado de verbos aparentemente causativizados.

Vejamos alguns casos atestados de lexicalização do causativo em línguas Tupi. Cruz (2011, p. 287) mostra que, na língua Nheengatú (subfamília Tupi-Guarani), o prefixo causativo $m u$ é utilizado para aumentar a valência de verbos intransitivos. Há, no entanto, verbos transitivos em que o prefixo $m u$ - pode ser reconhecido, mas que perderam sua contraparte intransitiva; por exemplo, mbeu 'cortar', mbue 'ensinar', munuka 'cortar', mukuna 'engolir' e mukamẽ 'mostrar' (CRUZ, 2011, p. 294).

Magalhães (2014, p. 78) também menciona casos de lexicalização com o morfema causativo direto, em Guajá (subfamília Tupi-Guarani).

Singerman (2018, p. 124-125) analisa dados cognatos como ôtop 'mostrar' como casos que aparentam ser causativização fossilizada ou lexicalizada. Uma evidência dessa lexicalização é que ôtop pode receber o prefixo intransitivizador $e$-. Em geral, o prefixo intransitivizador $e$ é mais próximo da raiz verbal que o causativo $\tilde{o}_{-}^{-}$, sugerindo que ôtop é uma unidade lexical atualmente.

Em Wayoro, assim como o verbo õtoa, nos verbos ombaa 'bater, matar' e ôka 'alimentar', também podemos, em princípio, identificar o prefixo causativo. Seriam, assim, verbos derivados historicamente de ambitransitivos que perderam a versão intransitiva. Testes de coocorrência com outros morfemas devem contribuir para uma análise definitva sobre tais verbos.

\footnotetext{
8"If a verb has been lexicalized, its valency may no longer reflect that of productively derived causatives, and this might be an additional factor leading to differential behaviour of what are apparently causatives of affective verbs"(COMRIE, 2007, p. 369).
} 


\section{Tempo e aspecto, tipos sentenciais, modalidade e polaridade}

kawere, ugu poret, ugu poret iih, teatoa. Poret ugu kerewa pu. [...] Mãkirẽy ugu nãn. Agora tem água, agora tem água! Tomam banho. Agora buscam água. Mãkirẽy fez [surgir] a água. (Antônio Wajuru)

Conforme Timberlake (2007, p. 283), ao usar distinções de tempo, as línguas podem indicar se a ocasião contextual e o evento reportado ocorreram antes, simultaneamente ou depois do aqui-e-agora da fala. O tempo é, portanto, um operador dêitico que localiza eventos com respeito ao momento de fala. As distinções amplamente estudadas na literatura são passado, presente e futuro. $\mathrm{O}$ aspecto, por sua vez, se relaciona com as diferenças de situações que os predicados apresentam (TIMBERLAKE, 2007, p. 284). Seguindo a literatura (MÜLLER, 2013; TIMBERLAKE, 2007), aspecto deve ser entendido como a característica interna do evento ou o ponto de vista das ações. Alguns exemplos são perfectivo, imperfectivo, habitual, iterativo.

De acordo com Müller (2013, p. 70), na América do Sul, a indicação gramatical de futuro e passado é bastante difundida, ou seja, ocorre em uma região muito ampla do território. A distinção de presente, no entanto, é escassa e efetivamente ausente ao longo da cordilheira dos Andes.

Em trabalhos anteriores, temos glosado o morfema - $t$ como 'passado' (NOGUEIRA, 2011, 2012, 2013, 2014). Argumentaremos, neste capítulo, que a língua Wayoro pode ser melhor analisada como língua que distingue morfologicamente futuro vs. não-futuro. Quanto a distinções de aspecto, dois sufixos de aspecto foram registrados, - $k w a$ 'iteratividade/pluracionalidade' usado para indicar intensificação e repetição do evento e -rara -ara 'repetição/habitual'.

Outro objetivo deste capítulo é descrever os tipos sentenciais. A identificação das propriedades dos tipos sentenciais pode fornecer ferramentas para distinguir sentenças subordinadas de sentenças principais. Alcázar e Saltarelli (2014, p. 6), por exemplo, apontam restrições sintáticas relacionadas aos imperativos e aos hortativos, tais como interpretação temporal irrealis (*let 
them go yesterday) e resistência em funcionar como uma oração dependente (*John ordered let them go!).

A identificação de marcas de modalidade e polaridade é de igual importância para a comparação de sentenças independentes vs. dependentes, uma vez que uma das características das sentenças subordinadas é que as mesmas têm, em geral, menos possibilidades flexionais que as sentenças matrizes (van GIJN, GALUCIO, NOGUEIRA, 2015, p. 304).

Antes da apresentação dos dados cabe uma nota quanto à metodologia de coleta. Para investigação sobre tempo, aspecto e tipos sentenciais foram realizadas sessões de elicitação direcionadas ao tema e elicitação associada com a transcrição de textos. Por outro lado, com relação à modalidade e à polaridade, nossa análise se baseia majoritariamente nos elementos identificados em transcrições de textos.

\subsection{Tempo e Aspecto}

\subsubsection{Verbalizadores e vogal temática}

Nogueira (2011) descreve o radical verbal Wayoro como constituído por uma raiz (nome, adjetivo ou acategorial/categoria não identificada), mais um verbalizador e a vogal temática - $a$. Após a vogal temática, morfemas de aspecto e tempo podem ser acrescidos. Os verbalizadores propostos em Nogueira (2011) (-k; -g; -ng; -kat ; -0; -kw) fazem parte tanto de radicais transitivos quanto de intransitivos (com exceção do verbalizador -kat registrado apenas em verbos intransitivos) e, portanto, não estão associados com a seleção de uma única estrutura argumental - diferentemente de verbalizadores de outras línguas Tupari, como Akuntsú (ARAGON, 2014), Makurap (BRAGA, 2005) e Mekens (GALUCIO, 2001).

Veremos, nesta seção, que a complexidade morfológica interna do verbo Wayoro ainda deve ser melhor entendida - especificamente qual contribuição semântica de verbalizadores e da vogal temática. Explicaremos aqui a revisão de alguns tópicos, que motivam segmentações/glosas diferentes das que estavam sendo utilizadas em trabalhos anteriores, como Nogueira (2011).

Compare os verbos munnga 'soltar', em (75), ngennga 'engolir/afundar', em (76), e ndera 'pronunciar/dar nome, em (77). Observa-se que a vogal temática se encontra no mesmo paradigma que o verbalizador -nga. Dessa maneira, os verbalizadores propostos em Nogueira (2011) serão revisados como -ka, - ga, -nga $a^{1}$, -kara, -kwa. Podemos, ainda, abandonar a hipótese de um verbalizador zero (NOGUEIRA, 2011), proposto para os casos em que a vogal temática se une diretamente à raiz, como ndera 'pronunciar/dar nome', cuja raiz é ndet 'nome'.

$$
\begin{aligned}
& \text { a. ongõ munnga. } \\
& \text { o-ngõ mun-nga }
\end{aligned}
$$

\footnotetext{
${ }^{1}$ Os segmentos [g] e [ng] são alofones do mesmo fonema, [g] ocorre em ambiente intervocálico, entre vogais orais; [ng] em início de palavra ou onset silábico diante de vogal oral, bem como após vogal nasal e diante de vogal oral. Dessa maneira, os verbalizadores -nga e - ga são alomorfes, condicionados fonologicamente.
} 
'Estão soltando meu bichos de criação.' (PM-2008)

b. Karemõ dja mun tet nẽran, tetera.

Karemõ dja mun tet nẽran te-tet-a

depois cabeça soltar ir novamente 3C-ir-V.T

'Depois, a cabeça ia e soltava de novo, ia embora.' (WYR-20080627-FN-PMyangwareta-cabeça-se-solta-6)

(76) a. 'uwoy teengenngat.

'uwoy te-e-ngen-nga-t

peixe 3C-MED-engolir-VZR-NFUT

'O peixe afundou.'

b. ẽete emõ yãy pãrangãn, ngen.

ẽete emõ yãy pãrang-ã-n ngen

DEIT ENF dente quebrar-V.T-NFUT engolir

'aqui mesmo no dente acertaram, [ela] afundou.' (WYR-20080627-FN-PM-achefe-das-mulheres 71)

(77) a. aramĩra Paulina ndera.

aramĩra Paulina ndet-a

mulher P. nome-V.T

'A mulher pronunciou o nome Paulina.'

b. txindetngap mbiroap ne.

txi=ndet-nga-p mbiro-ap nẽ

1PL.INCL=nome-VZR-NMLZ EXIST-NEG IRR

'Nós ainda não existíamos [Lit. Ainda não havia nos dado/pronunciado nosso nome].' (WYR-200308-DM-PK-origemdomundo 005)

c. ondetngat.

$\mathrm{o}=$ ndet-nga- $\mathrm{t}$

$1 \mathrm{SG}=$ nome-VZR-NFUT

'[Ele] falou meu nome.' (PM-2010)

Note, contudo, que o significado associado ao verbalizador e à vogal temática é difícil de ser identificado com base nas traduções. Em Makurap, $-n g$ é analisado como morfema de 'efetividade'. Braga (2005, p. 73, tradução nossa) explica que "a essência da noção de efetividade é o grau de afetação e de implicação do participante objeto no predicado transitivo"2.

\footnotetext{
2“L'essence de la notion d'effectivité est le degré d'affectation et d'implication du participant objet dans le prédicat transitif” (BRAGA, 2005, p. 73)
} 
Tal noção é baseada em Queixalós (1998), por exemplo. Em Sikuani, Queixalós (1995, p. 249) explica que o morfema auxiliar de efetividade indica, entre outras características, maior afetação (plus affectant). Um exemplo dado é a distinção entre uku-ta (plus affectant) 'cortar - de uma só vez' e $u k u$-ba 'cortar - por partes'.

Noções de aspectualidade devem ser investigadas em busca de uma explicação para o valor gramatical dos verbalizadores e da vogal temática. Isso também vale para os verbalizadores -kwa e -kara. Tampouco podemos afirmar que estes sufixos representam o conjunto total de verbalizadores Wayoro. Por exemplo, outro sufixo suspeito de ser verbalizador é -wa, em auwa 'curar/rezar' cuja raiz verbal é $a u$. No entanto, temos somente esse registro de uso de -wa como verbalizador, necessitando-se, assim, de mais ocorrências para se confirmar como morfema separado da raiz.

Outra complicação é que, em geral, raízes verbais terminadas por vogal arrendondada ou consoante bilabial perdem esses segmentos ao receber a vogal temática. Isso ocorre, por exemplo, com os verbos $k a$ 'ingerir'/ raiz ko e ndoa 'deitar'/ raiz ndop. Veja exemplos da raiz do verbo $n d o a$ 'deitar' em (78a-b). Note em (78c) que a consoante bilabial é também perdida ao se acrescentar o sufixo de repetição.

a. Pĩim, temẽn mẽ etendop. pĩim te-mẽn mẽ ete-ndop escuro 3C-marido TOP SOC-deitar

'(Quando) escureceu, deitou com (ele), com o marido dela.' (WYR-20080627-FNPM-yangwareta-cabeça-se-solta)

b. djetendoat on.

$\mathrm{dj}=$ ete-ndop-a- $\mathrm{t} \quad \mathrm{eu}$

$3=$ SOC-deitar-V.T-NFUT eu

'Eu deitei com ele.'

c. ondorarap na on.

o-ndop-rara-p nã on

1SG-deitar-REP-INF FUT eu

'Eu vou deitar de novo.' (PM-2016)

O condicionamento para esta perda da consoante bilabial ou da vogal arredondada diante da vogal temática é misterioso, pois nem sempre ocorre. Note, nos dados em (79), que há raízes em que a consoante bilabial final se mantém após o acréscimo da vogal temática, como tuuwa 'dar à luz'/ raiz tuup.

a. yindopeõ, tuup koypet nerro pegat.

yindopeõ tuup koypet nẽro peg-a-t

atrás dar.à.luz irmã. ơ DEM DESID.IRR-V.T-NFUT 
'Atrás, nasceu aquela que seria a irmã deles.' (WYR-19900302-DM-PK-cobraduas-cabecas)

b. kopit tekut tuupkwat.

kopit te-kut tuup-kwa-t

queixada 3-esperma/filho dar.à.luz-VZR-NFUT

'O porco-do-mato (queixada) teve o filho dele.' (PM-2010)

c. aramĩra mbogop ndurut tuuwat.

aramĩra mbogop ndurut tuup-a-t

mulher criança dois dar.à.luz-V.T-NFUT

'A mulher teve gêmeos.' (PM-2010)

\subsubsection{Análise do sufixo - $t$ como "não-futuro"}

Vimos que, na subfamília linguística Tupari, a vogal - $a$ é analisada como sufixo temático de verbos nas línguas Mekens ou Sakurabiat, Tupari, Akuntsú e Wayoro. Na língua Makurap, tal vogal é analisada como aspecto imperfectivo e sua ausência como aspecto perfectivo (GALUCIO 2001, p. 88; ALVES 2004, p. 69; ARAGON, 2008, p. 110; BRAGA, 2005, p. 53; NOGUEIRA, 2011, p. 82). Há, nessa subfamília linguística, auxiliares e partículas para a expressão de tempo e aspecto (GALUCIO, 2001; ALVES, 2004; ARAGON, 2008).

Em Wayoro, após a vogal temática pode ser afixado o morfema - $t \sim-n,[\mathrm{t}]$ após segmento oral e [n] após segmento nasal. Os dados de contraste, em Nogueira (2011), entre a presença deste sufixo de tempo e sua ausência, sugeriam, em sua maioria, um contraste entre passado e não-passado (NOGUEIRA, 2011, p. 76). No entanto, Nogueira (2011, p. 83) assinala que há registros do morfema $-t \sim-n$ em "referência ao tempo passado e em alguns casos ao progressivo"3.

Bowern (2008, p. 87) enfatiza que em sessões de elicitação, mesmo que o consultor seja fluente na duas línguas, é muito comum que forneça um tempo diferente do que foi pedido. Segundo a autora, trata-se de uma consequência inevitável do método de elicitação e uma boa razão para não usar exclusivamente esse método. ${ }^{4}$

No prosseguimento da pesquisa, confirmou-se que o morfema $-t \sim-n$ pode ser traduzido de diferentes maneiras, exceto como futuro. É possível notar que o morfema $-t \sim-n$ pode ser traduzido como presente e passado contínuo, em (80), e como passado, em (81).

(80) Morfema $-t \sim-n$ com valor de presente e passado contínuo

\footnotetext{
${ }^{3}$ Agradeço à professora Dra. Ana Suelly Arruda Cabral por reforçar a necessidade de revisão da análise deste morfema, durante o IV Encontro Internacional sobre Línguas e Culturas Tupí, realizado na Universidade de Rondônia (UNIR), Campus de Ji-Paraná, entre os dias 10 a 12 de dezembro de 2013.

4 "Even if your consultants are fully fluent in both languages, it is very easy to switch participants, or give a different tense from what is asked. Don't think of these as 'errors'; they are the inevitable consequence of this method, and a very good reason for not using it exclusively." (BOWERN, 2008, p. 87)
} 


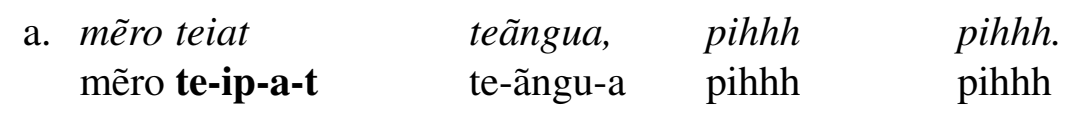

DEIT 3C-vir-V.T-NFUT 3C-entrar-V.T ONMT.pássaro ONMT.pássaro

'Aquele já vinha entrando, pihhh pihhh.' (WYR-20080616-AVG-ANT-Hist-agua087)

b. "Kerom, okwa korom ote, ate itoagat ote." K-e-rom okwa ko-rom ote ate itoak-a-t ote ?-COP-NEG irmão.९ comer-NEG 1PL.EXCL somente chorar-V.T-NFUT 1PL.EXCL 'Não, nós não comemos nosso irmão, estamos só chorando por ele.' (WYR20080627-FN-PM-a-chefe-das-mulheres-62)

c. txiporẽto mãyãn, enã ãam, txato.

txi-porẽto mãy-ã-n enã ãam txato

1 PL.INCL-história contar-NFUT hoje NEG.EXIST acabar

'Contavam nossas histórias, agora não há, acabou.' (WYR-20161007-FN-PM-MAfesta-tradic)

(81) Morfema $-t \sim-n$ com valor de passado

a. oyõ engu pawakat on. o-yõ engu pawa-ka-t on

1SG-língua líquido.INAL seco-VZR-NFUT 1SG

'Eu já sequei minha língua [líquido da minha língua].' (WYR-20100326-FN-PMmulher-estrela-17)

b. djatpagat nen djat?

djat-pap-ga-t nen djat

2PL-embriagar.se-VZR-NFUT INTERR. 2 vocês

'Vocês se embriagaram?' (NOGUEIRA, 2013, p. 330)

c. Mãkirẽy ugu nãn.

Mãkirẽy ugu nẽ-a-n

Mãkirẽy água fazer-V.T-NFUT

'Mãkirẽy fez [surgir] a água.' (WYR-20080616-AVG-ANT-Hist-agua-107)

Pode-se notar que tanto as traduções de sentenças elicitadas quanto de textos podem variar. É necessário, assim, encontrar ferramentas dentro da língua Wayoro para se testar o valor gramatical de tal morfema. Um teste importante é a possibilidade de coocorrência com outros elementos indicadores de tempo na sentença, como proposto, por exemplo, por Bowern (2008, p. 98-99) e Comrie e Smith (1977).

Nos dados em (82), o morfema $t$ é apresentado relacionado ao advérbio de tempo po- 
ret 'agora/já' e ndaikut 'amanhã'. Observe, em (82a), que o sufixo -t pode aparecer em uma sentença com o advérbio poret 'agora'. No entanto, a coocorrência de - $t$ com o advérbio indicador de tempo futuro ndaikut 'amanhã' foi rejeitada em teste de julgamento de gramaticalidade, como mostra do dado (82b-c).

(82) Coocorrência de $-t$ como advérbios de tempo

a. poret, en eiat.

poret en e-ip-a-t

agora você 2 SG-vir-V.T-NFUT

'Agora que você veio!' (PM-2012)

b. ndaikut ngwaykup teterap nã

ndaikut ngwaykup te-tet-a-p nã

amanhã homem 3C-ir-V.T-INF FUT

'O homem vai amanhã.' (NOGUEIRA, 2011, p. 84)

c. *ndaikut ngwaykup teterat.

*ndaikut ngwaykup te-tet-a-t

amanhã homem 3C-ir-V.T-NFUT

Neste sentido, vamos propor que a distinção temporal relevante indicada por - $t \sim-n$ é a indicação de que o evento reportado ocorreu antes ou simultaneamente ao momento da fala, mas não depois. Adotaremos, assim, a glosa de ‘não-futuro' para o referido morfema.

\subsubsection{Morfema $n \tilde{a}$ 'futuro'}

Nogueira (2011, p. 84) descreve a indicação de futuro na língua Wayoro como sendo realizada através do "uso de uma consoante - $p$ após a vogal temática seguida pelo morfema $n \tilde{a}[\ldots]$. Estas construções também apresentaram interpretação progressiva." Nesta seção, retomaremos a definição de que a construção com $-p \sim-m+n a \tilde{a}$ está relacionada à indicação de futuro de um evento.

A ocorrência de nã como indicador de futuro é comum em textos. Observe os exemplos em (83).

(83) Trechos de textos com o morfema nã 'futuro'

a. toa-p na.

$\emptyset=$ top-a-p nã

3=ver-V.T-INF FUT

'Eles vão descobrir [as plantas].' (WYR-200308-DM-PK-origemdomundo-028)

b. djauwap

nã, djauwap

mõendop mãyã.

dj=au-wa-p nã, $d j=a u-w a-p \quad$ mõendop mãy-ã

$3=$ curar-VZR-INF FUT 3=curar-VZR-NMLZ conhecimento narrar/ensinar-V.T 
'Vou rezar/curar isso, ensinar o conhecimento da cura disso.' (WYR-20080616AVG-ANT-Hist-agua-022)

Diferentemente do comportamento observado com o morfema - $t$ 'não futuro', a construção $-p \sim-m+n \tilde{a}$ pode coocorrer com o advérbio ndaikut 'amanhã', como em (84a-c).

(84) Coocorrência do morfema nã com o advérbio ndaikut 'amanhã'

a. ndaikut ngwaykup teterap nã

ndaikut ngwaykup te-tet-a-p nã

amanhã homem 3C-ir-V.T-INF FUT

'O homem vai amanhã.' (NOGUEIRA, 2011, p. 84)

b. ndaikut djauwap ñ̃ on

ndaikut $d j=a u-w a-p \quad$ nã on

amanhã $3=$ rezar/curar-VZR-INF FUT eu

'Amanhã, eu vou curar/rezar ele.' (PM-2016)

c. ndaikut mõ txiamõyãm nã.

ndaikut mõ txi-amõy-ã-m nã

amanhã HORT 1PL.INCL-dançar-V.T-INF FUT

'Amanhã, vamos dançar.' (PM-2015)

É importante questionar se é possível ocorrer algum item lexical entre - $p \sim-m$ e o morfema de futuro nã para averiguar se se trata de um só morfema, uma vez que ocorrem geralmente juntos. Até o momento não temos registro de elementos entre os morfemas em questão.

Veremos, agora, que há um verbo nã , o qual é homófono ao morfema de futuro. O verbo nã 'fazer, transformar-se' tem comportamento sintático diferente do morfema na 'futuro'. O verbo $n \tilde{a}$ exige dois argumentos e pode receber afixos verbais, tal como o morfema - $t$ 'não-futuro', como em (85).

(85) Verbo nã 'fazer': biargumental e passível de receber afixos verbais
a. minẽ rom
nãn
en.
m-i-nẽ-rom
nẽ-a-n
en

1SG-FOC.OBJ-fazer-NEG fazer-V.T-NFUT você

'(Isso) eu nunca fiz, você fez.' (PM-2015)

b. Mãkirẽy ugu nãn.

Mãkirẽy ugu nẽ-a-n

Mãkirẽy água fazer-V.T-NFUT

'Mãkirẽy fez [surgir] a água.' (WYR-20080616-AVG-ANT-Hist-agua-107) 


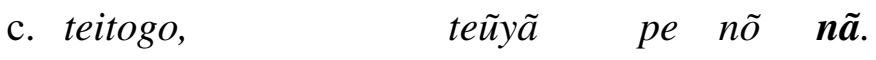

te-i-togo te-ũyã pe nõ nẽ-a

3C-OBJ.NMLZ-mascar 3C-caracol pele outro fazer-V.T

'O caracol dela [Lit. sua pele de caracol] fazia mais masca para ela mesma (chicha dela).' (WYR-20100326-FN-PM-caracol 22)

d. on om̃̃y nãn.

on omõy nẽ-a-n

eu beiju fazer-V.T-NFUT

'Eu fiz pamonha.' (PM-201312)

e. ongora ñ̃n on.

1SG-música fazer-V.T-NFUT eu

'Eu estou cantando [lit. fazendo minha música].' (PM, 2010)

Os dados de (86) mostram que o verbo nã com sentido 'transformar-se' apresenta comportamento idêntico: exige dois argumentos e pode receber sufixo - $t$ 'não-futuro'.

(86) Verbo nã 'fazer' com sentido 'transformar-se, tornar-se': biargumental e passível de receber afixos verbais

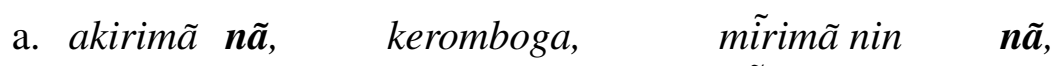

akirimã nẽ-a k-e-romb-oga mirimã nin nẽ-a

saca.saia fazer-V.T ?-COP-NEG-FRUST mosca pequeno fazer-V.T

keromboga.

k-eromb-oga

?-COP-NEG-FRUST

'(Ele) se transformava em formiga, mas não era, se transformava em mosca, mas não era.' (WYR-200308-DM-PK-origemdomundo-30)

b. auwat nãn ndeke.

auwat nẽ-a-n ndeke

pajé fazer-V.T-NFUT ele

'Ele se tornou pajé.' (PM-2013)

c. ndeke ngwendap nãn.

ndeke ngwendap nẽ-a-n

ele cacique fazer-V.T-NFUT

'Ele se tornou cacique.' (PM-2013)

Dessa maneira, nota-se que $n \tilde{a}$, em Wayoro, não pode ser analisado como uma posposição 'translativa', como proposto para Proto-Tupi (RODRIGUES; CABRAL, 2012). Trata-se de 
verbo transitivo com sentido 'transformar-se, tornar-se' e 'fazer'.

Nos dados em (87), observe que o morfema $n \tilde{a}$ 'futuro' pode também ocorrer em sentenças com o verbo $n \tilde{a}$ (raiz $n \tilde{e}+a$ V.T) 'fazer, transformar-se' (cf. na seção 5.2 do capítulo 5 uma hipótese de explicação diacrônica para esta identidade fonológica).

(87) Coocorrência do morfema $n \tilde{a}$ com o verbo $n \tilde{a}$

a. on, omõy nãm nã on.

on omõy nẽ-a-m nã on

eu pamonha fazer-V.T-INF FUT eu

'Quanto a mim, eu vou fazer pamonha.' (PM-2013)

b. tengora nãm nã.

te-ngora nẽ-a-m nã

3C-música fazer-V.T-INF FUT

'Ele vai cantar.' (PM- 2010)

c. ndeke ngwendap nãm na

ndeke ngwendap nẽ-ã-m nã

ele cacique fazer-V.T-INF FUT

'Ele vai se tornar cacique.' (PM-2013)

Algumas construções podem ser consideradas suspeitas de serem constituídas por um verbalizador -nã (como ocorre em Tupari e Mekens), pois são sempre precedidas por um elemento nominal específico, como em (88) com os verbo ngora nã 'cantar, fazer música', ukap nã 'tocar/fazer taboca' e mbo nã 'ajudar/fazer mão'.

(88) Construções $\mathrm{SN}+n \tilde{a}$

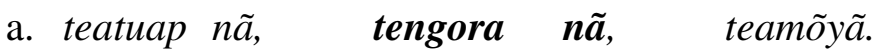

te-atuap nẽ-a te-ngora nẽ-a te-amõy-ã

3C-festa fazer-V.T 3C-música fazer-V.T 3C-dançar-V.T

'Eles faziam festa, eles cantavam e dançavam.' (WYR-20161007-FN-PM-MAfesta-tradic)

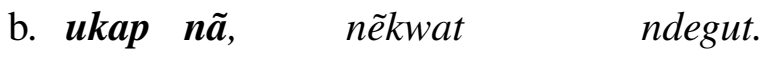

ukap nẽ-ã nẽkwat nde-ngut

taboca fazer-V.T AUX-ITER-NFUT ?-PASS.DIST

'(Eles) tocavam [lit. faziam taboca], era assim antigamente.' (WYR-20161007-FN-

PM-MA-festa-tradic)

c. djitogo togoa, aramira-ian mbo nã .

dj-i-togo togo-a aramira-ian mbo nẽ-a

3-OBJ.NMLZ-mascar mastigar-V.T mulher-PL mão fazer-V.T 
'Mastigaram masca para ela, as mulheres estavam ajudando.' (WYR-20100326-FNPM-caracol-6-7)

No entanto, em (89), mostra-se que a construção ngora nã 'cantar/fazer música' não é uma unidade inseparável pois pode ser intercalada por outros elementos.

(89) Teste de inseparabilidade da construção SN+nã

$\begin{array}{llr}\text { engora toapndia nã } & \text { on. } \\ \text { e-ngora toapndia nẽ-a on } & \text { on } \\ \text { 2SG-música bonita fazer-V.T eu }\end{array}$

'Eu cantei tua música bonita/música bonita para você.' (PM-2013)

Dessa forma, não é possível afirmar que há um morfema -nã verbalizador, com relação ao verbo ngora nã. As demais construções suspeitas de conterem um verbalizador deverão ser testadas da mesma maneira para que tenhamos uma análise definitiva.

\subsubsection{Aspecto repetitivo/habitual e iterativo (intensificação e pluraciona- lidade do evento)}

Os morfemas aspectuais identificados até o momento são: -rara $\sim$-ara ${ }^{5}$ para indicar repetição e habitualidade; e - $k w a$ para indicar iteratividade (pluracionalidade do evento). Veja exemplos do morfema de repetição com verbos transitivos $k a$ 'ingerir', em (90), e ndera 'moer', em (91). Observe, em (91b-c), que tais morfemas aspectuais coocorrem com os morfemas - $t$ 'não-futuro' e - $p+n \tilde{a}$ de futuro, evidenciando que existe, na língua Wayoro, a diferença gramatical entre aspecto e tempo.

(90) Uso de morfema de aspecto com verbo transitivo $k a$ 'ingerir'

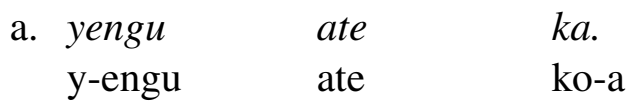

3-chicha.INAL mesmo.assim ingerir-V.T

'Assim mesmo (as pessoas) estão tomando a chicha dela.' (WYR-20100326-FNPM-caracol)

b. tekerewa, tuero korara.

te-kerew-a tuero ko-rara

3C-chegar-V.T chicha ingerir-REP

'Eles chegavam, bebiam chicha de novo.' (WYR-20161007-FN-PM-MA-festatradic)

(91) Uso de morfemas de aspecto com verbo transitivo ndera 'moer'

\footnotetext{
${ }^{5}$ Os alomorfes se distribuem da seguinte maneira: /-rara/ ocorre após vogal e /-ara/ é usado após consoante.
} 
a. on atiti nderap nã on.

on atiti ndet-a-p nã on

eu milho moer-V.T-INF FUT eu

'Quanto a mim, eu vou moer milho.' (NOGUEIRA, 2011, p. 137)

b. tuero nderarap nã on.

tuero ndet-ara-p nã on

chicha moer-REP-INF FUT eu

'Eu vou moer chicha (bebida fermentada) de novo.' (PM-2012)

c. aramiraian atiti ndetkwat.

aramira-ian atiti ndet-kwa-t

mulher-PL milho moer-ITER-NFUT

'As mulheres estão moendo demais milho [pluracionalidade do evento].' (NO-

GUEIRA, 2011, p. 137)

Exemplo de morfema de aspecto repetitivo com verbo intransitivo é apresentado em (92) para o verbo ia 'vir'. Exemplos do morfema de aspecto iterativo - $k w a$ são apresentados em (93) e (94) para os verbos intransitivos atoa 'banhar-se' e pikãya 'irritar-se'.

(92) Morfema de aspecto com verbo intransitivo ia 'vir'

a. kerere aramĩaian djitogo eteia.

k-e-rere aramĩra-ian dj-i-togo ete-ip-a

?-COP-SUB mulher-PL 3-OBJ.NMLZ-mascar SOC-vir-V.T

'Enquanto isso, as mulheres estavam trazendo masca para ela (a chicha).' (WYR20100326-FN-PM-caracol-16)

b. aramĩraian itogo eteirara.

aramĩra-ian i-togo ete-ip-rara

mulher-PL OBJ.NMLZ-mascar SOC-vir-REP

'As mulheres traziam masca de novo.' (WYR-20100326-FN-PM-caracol-X)

(93) Morfema de aspecto - $k w a$ com verbo intransitivo atoa 'banhar'

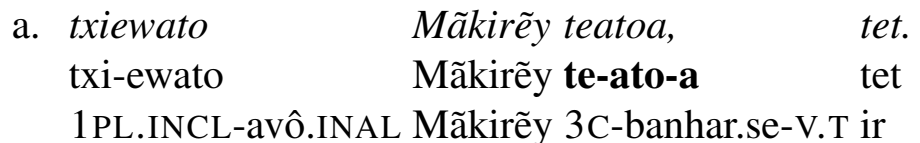

'Nosso avô Mãkirẽy se banhou, foi embora.' (WYR-20080616-AVG-ANT-Histagua-010)

b. temẽpit mõatokwa, pu.

te-mẽpit mõ-ato-kwa pu

3C-filho.o CAUS-banhar.se-ITER ir 
'Deu banho na filha dela [lit. fez a filha dela se banhar], foi embora' (WYR20080616-AVG-ANT-Hist-agua-018)

(94) Morfema de aspecto - $k w a$ com verbo intransitivo pikãyã 'irritar-se'

a. tepikãyã, toa.

te-pikãy-ã top-a

3C-bravo-V.T ver-V.T

'Ficou bravo, viu.' (WYR-20080616-AVG-ANT-Hist-agua-41)

b. tepikãykwa ugu eriat, ngwãngwã poot.

te-pikãy-kwa ugu eriat ngwãngwã poot

3C-bravo-ITER água dono camaleão velho

'O dono da água, o camaleão antigo, se irritou ainda mais.' (WYR-20080616-AVG-

ANT-Hist-agua-44)

Outro mecanismo usado em Wayoro para indicar intensificação do evento é a duplicação total ou parcial da raiz verbal (NOGUEIRA, 2011). Veja um exemplo com o verbo transitivo atinã 'ter ciúmes/sovinar', em (95), e com o verbo intransitivo kuykwa 'sujar-se com terra', em (96).

a. ndop tetak atinãn.

ndop te-tak atin-ã-n

pai 3C-filha. ${ }^{\top}$ sovinar-V.T-NFUT

'O pai estava com ciúme [lit. sovinando a] da filha dele.' (PM-2012)

b. mbogop atinẽtinẽkat.

mbogop atinẽ $\sim$ tinẽ-ka-t

criança sovinar $\sim$ RED-VZR-NFUT

'(Ele) estava com muito ciúme da filha [lit. sovinando a criança dele]' (WYR200308-DM-PM-tratamento-paje-21)

(96) a. teora. $\tilde{E} e$ no nengan, põ punerran, tekuykwaaa, pu. te-ot-a ẽe nõ nengan põ pu nẽran te-kuy-kwaaa pu 3C-chegar-V.T DEM outro SIM cair ir novamente 3C-terra-VZR.ENF ir 'Ele foi. Igual, [fez] isso de novo, foi e caiu de novo, se sujoooou e foi.' (WYR20080616-AVG-ANT-Hist-agua-26-27)

b. txiewato

Mãkirẽy teatoa,

tet. Teora,

pu. $\tilde{E} e \quad$ nin

txi-ewato

Mãkirẽy te-atoa,

tet te-ot-a

pu ẽe nin

1PL.INCL-avô.INAL Mãkirẽy 3C-banhar.se ir 3C-chegar-V.T ir DEM pequeno pu. Tekuykuya.

pu te-kuy $\sim$ kuy-a

ir $3 \mathrm{C}$-terra $\sim$ terra-V.T 
'Nosso avô Mãkirẽy se banhou, foi embora. Chegou e foi. Não demorou, foi. Se sujou mais [com terra].' (WYR-20080616-AVG-ANT-Hist-agua-010-13)

\subsubsection{Sumarizando os fatos sobre morfemas de tempo e aspecto}

Wayoro apresenta afixos verbais de tempo e aspecto. Além desses afixos, morfemas livres realizam também indicação de tempo e aspecto da sentença, como os advérbios de tempo poret 'agora/já' e ndaikut 'amanhã', em (97), e de repetição do evento, como nẽran 'novamente', em $(98)^{6}$.

a. kawere, ugu poret, ugu poret iih, teatoa. Poret ugu kerewa pu. kap-ere ugu poret ugu poret iih te-ato-a poret ugu kerewa pu PROFORMA-em água agora água agora INTJ 3C-banhar-se agora água buscar ir 'Agora tem água, agora tem água! Se banham. Agora vão buscar água.' (WYR20080616-AVG-ANT-Hist-agua-103-104)

b. ndaikut, en emen ombaa.

ndaikut en e-men ombo-a

amanhã você 2 SG-marido bater-V.T

“"Amanhã, você mata seu marido".' (WYR-20080627-FN-PM-a-chefe-dasmulheres-03)

(98) tuero ndera neran, tembopoe puga. tuero ndet-a nẽran te-mbopoe pug-a chicha moer-V.T novamente 3C-rápido cozinhar-V.T

'(A mulher-caracol) fazia chicha de novo, ela cozinhava rápido.' (WYR-20100326-FNPM-caracol-30)

Em Mekens, "tempo, aspecto, modo e polaridade são expressos através de partículas pósverbais, exceto o tempo passado, o modo repetitivo e um tipo de negação, que são marcados por sufixos verbais" (GALUCIO, 2014b, p. 165, tradução nossa). De acordo com Galucio (2001, p. 91), em Mekens, o sufixo /-ra/ 'repetitivo' ocorre após o radical verbal, ou seja, após a vogal temática. O dado em (99) apresenta um exemplo das possibilidades de afixos de tempo, modo e polaridade, em Mekens.

(99) Mekens: sufixo de modo repetitivo $\{$-ra $\}$, tempo passado $\{-t\}$ e polaridade $\{$-ap $\}$ 'negação'

a. se-e-pibor-a-ra-r-ap

3C-INTR-chegar-V.T-REP-PASS-NEG

'Ele não chegou ainda [de novo]' (GALUCIO, 2014, p. 165)

\footnotetext{
${ }^{6}$ Provavelmente, tal advérbio apresenta em sua morfologia interna o morfema de repetição -ara.
} 
Vimos que Wayoro apresenta um comportamento muito semelhante a Mekens: o tempo nãofuturo, o aspecto repetitivo e de pluracionalidade (bem como negação verbal, como veremos adiante) podem ser expressos por afixos verbais.

A Tabela 4.1 apresenta os afixos de tempo e aspecto identificados até o momento em Wayoro.

Tabela 4.1: Morfemas de tempo e aspecto em Wayoro

\begin{tabular}{lll}
\hline Expressão de tempo & Significado & Glosa \\
\hline \hline$-t \sim-n$ & indicação de não-futuro & NFUT \\
$-p \sim-m+n \tilde{a}$ & indicação de 'futuro' & -INF+FUT \\
\hline
\end{tabular}

\begin{tabular}{lll} 
Expressão de Aspecto & Significado & Glosa \\
\hline \hline$-k w a$ & intensificação/pluracionalidade do evento & ITER \\
$-r a r a \sim-a r a$ & repetição/habitual & REP \\
\hline
\end{tabular}

\subsection{Investigação sobre tipos sentenciais: declarativo, impera- tivo, hortativo}

Os três tipos de sentenças mais estudados nas línguas do mundo são declarativo, interrogativo e imperativo. Segundo König e Siemund (2007, p. 281), os dispositivos usados nas línguas para diferenciar os tipos de sentenças básicos incluem aqueles geralmente considerados parte do sistema gramatical: entoação, flexão (mais especificamente adição ou omissão de afixos flexionais), ordem de palavras, adição, omissão ou substituição de constituintes. De acordo com os autores, a entoação tem um papel claramente especial.

König e Siemund (2007, p. 285) explicam que as sentenças declarativas são as sentenças não marcadas por várias razões: as sentenças declarativas são o tipo de sentença mais frequente; a ordem de constituintes exibida nas sentenças declarativas é geralmente considerada a ordem básica da língua; declarativas exibem um paradigma completo das combinações de tempoaspecto disponíveis na língua, em contraste com imperativas.

Vejamos as características dos tipos sentenciais declarativo, imperativo e hortativo em Wayoro.

A língua Wayoro não apresenta elemento gramatical para indicar o tipo sentencial declarativo, tal como o faz a língua Karitiana, por exemplo. Em Karitiana, o modo declarativo é, em (100a), indicado pelo alomorfe ta-, ao passo que, em Wayoro, não há qualquer morfema relacionado ao tipo sentencial declarativo (100b).

(100) Marca verbal para indicação de modo declarativo em Karitiana e ausência de marca de declarativo em Wayoro 
a. Karitiana

Yn aj-ta-ahoj- $\phi \quad$ ajxa

Eu 2PL-DECL-rir-NFUT vocês

'Eu ri de vocês.' (STORTO, 2008, p. 186, tradução nossa)

b. Wayoro

$e=$ ngway- $a$ on.

$2 \mathrm{SG}=$ rir-V.T eu

'Eu estou rindo de você.' (MJ-2010)

Veremos que o que define os tipos sentenciais declarativo, imperativo e hortativo é o comportamento de um conjunto de propriedades sintáticas e morfossintáticas em cada tipo sentencial.

\subsubsection{Declarativo e imperativo}

Comecemos pelas diferenças com relação a sentenças imperativas e declarativas observadas em Wayoro. Constatamos que há um comportamento sintático diferente com relação aos morfemas pessoais (pronomes livres e prefixos/clíticos) nos tipos declarativo e imperativo.

Segundo Nogueira (2014, p. 246), a coocorrência ou não de pronomes livres e de prefixo/clítico pessoal evidencia diferenças entre os tipos sentenciais imperativo e declarativo. No modo imperativo dos verbos intransitivos, na $2^{\mathrm{a}}$ pessoa do singular, ocorre apenas o prefixo pessoal $e$-, enquanto que no modo declarativo ocorrem o prefixo pessoal $e$ - e o pronome pessoal en. Observe esse fato comparando (101a-b) com (102a-b). No imperativo de verbos transitivos, quanto à expressão de argumentos, há possibilidade de representação somente do clítico de pessoa objeto (101c-d) ou do sintagma nominal objeto (101e). Em um verbo transitivo no modo declarativo, por sua vez, ocorre um pronome sujeito, on ' 1 a pessoa do singular', como se pode notar em (102c-d).

(101) Imperativo: prefixo pessoal e marcador clítico de pessoa

a. eatoa!

e-ato-a

2SG-banhar.se-V.T

'Toma banho!' (PM-2013)

b. eamõyã!

e-amõy-ã

2SG-dançar-V.T

'Dança!' (PM-2013) 
c. djipitkwa!

$\mathrm{dj}=\mathrm{ipit}-\mathrm{kwa}$

$3=$ jogar-VZR

'Joga algo!' (PM-2013)

d. $m \tilde{a} a !$

$\emptyset=$ mã-a

$3=$ inserir $-\mathrm{V} . \mathrm{T}$

'Coloca!' (PM-2012)

e. yerra ande ipitkwa!

yẽra ande ipit-kwa

carne podre jogar-VZR

'Joga a carne podre!' (PM-2013)

(102) Declarativo: prefixo pessoal e pronome pessoal

a. en eatoa.

en e-ato-a

você 2SG-banhar.se-V.T

'Você está tomando banho.' (PM-2013)

b. en eamõya.

en e-amõy-ã

você $2 \mathrm{SG}$-dançar-V.T

'Você está dançando.' (PM-2013)

c. on djipitkwa.

on dj=ipit-kwa

eu 3=jogar-VZR

'Eu vou jogar algo.' (PM-2013)

d. kopit mãan on ngwãe pi.

kopit mã-a-n on ngwãe pi

queixada inserir-V.T-NFUT eu panela dentro

'Eu coloquei a queixada dentro da panela.' (PM-2012)

Com relação à entoação, podemos afirmar, preliminarmente, que a sentença imperativa apresenta padrão entoacional diferente dos demais tipos sentenciais, com características próprias de frequência fundamental e intensidade da sílaba final. Não identificamos, em Wayoro, morfema específico relacionado ao imperativo. Descreveremos em trabalhos futuros correlatos acústicos relacionados à análise entoacional que podem diferenciar os tipos sentenciais em Wayoro, tais como frequência fundamental, intensidade, duração. Aikhenvald (2010, p. 18) enfatiza 
que sentenças imperativas frequentemente se diferenciam dos demais tipos sentenciais por seu padrão entoacional. Conforme Aikhenvald (2010, p. 89), a entoação pode ser o único meio de distinguir tipos sentenciais em línguas que não tem morfema específico para marcar uma sentença imperativa, como na língua Lote (Papua-Nova Guiné).

Uma vez que os pronomes livres são opcionais em sentenças intransitivas declarativas, podese dizer que a entoação típica das sentenças imperativas estabelece o contraste entre os tipos sentenciais em dados como (101a) e (102a).

\subsubsection{Hortativo}

Vejamos, agora, outro tipo sentencial em Wayoro, o hortativo, indicado por mõ.

Segundo Andrews (2007, p. 207, tradução nossa):

A forma verbal usada para o imperativo não é restrita ao uso imperativo. Ao invés disso, tal forma é usada em uma gama de construções que expressam um desejo de que algo aconteça, chamada 'hortativo' se o sujeito é a $1^{a}$ pessoa do plural e 'optativo' se o sujeito é a primeira pessoa do singular' .

Aikhenvald (2010, p. 224), ao discutir significados relacionados a uso de imperativos, afirma que "convites e sugestões podem ter uma expressão especial, frequentemente apenas para a

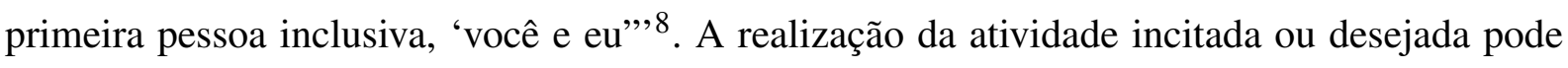
ser de maneira exclusiva (sem o ouvinte) ou inclusiva (com o ouvinte) (AIKHENVALD, 2010, p. 48).

Em Wayoro, é possível identificar o tipo sentencial hortativo, observando-se o valor semântico do morfema $m \tilde{o}^{9}$, em sentenças cujo sujeito é a $1^{\text {a }}$ pessoa do plural inclusiva $t x i$-. Como ilustração, considere o contraste no par de sentenças em (103).

(103) Declarativo vs. hortativo

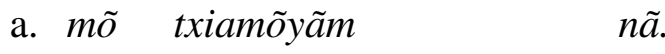

mõ txi-amõy-ã-m nã

HORT 1PL.INCL-dançar-V.T-INF FUT

'Vamos dançar!' (hortativo)

b. txiamõyãm nã.

txi-amõy-ã-m nã

1 PL.INCL-dançarV.T-INF FUT

'Nós vamos dançar.' (declarativo)

\footnotetext{
7 "The verb form used for imperatives is not restricted to imperative usage. It is rather used in a range of constructions expressing a desire that something happen, called 'hortatives' if the subject is first person plural, and 'optative' if the subject is first person singular."

8"Invitations and suggestions may have a special expression, often just for first person inclusive, 'you and me"'(AIKHENVALD, 2010, p. 224).

${ }^{9}$ Trata-se de uma forma claramente relacionada à raiz do verbo mõka 'chamar'.
} 
Segundo descrição da colaboradora, "para chamar [convidar] é preciso usar Mõ txiamõyãm $n \tilde{a}$ '.

Há agramaticalidade da construção hortativa, quando o verbo é flexionado para não-futuro (104).

(104) Agramaticalidade da construção hortativa com sufixo - $t$ 'não-futuro'

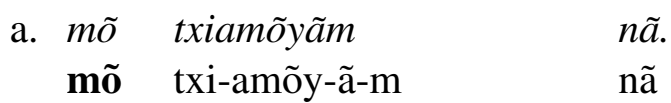

HORT 1PL.INCL-dançar-V.T-INF FUT

'Vamos dançar!' (hortativo)

b. *mõ txiamõyãn.

*mõ txi-amõy-ã-n

HORT 1PL.INCL-dançar-V.T-NFUT

Com advérbios temporais, a construção hortativa é possível com morfema de tempo futuro e com advérbios de presente e futuro, mas não com advérbio de passado, como se pode observar em (105a-d). Os dados em (105e-f) mostram que o uso de mõ 'hortativo' isoladamente também é possível, mas sua coocorrência com a expressão ndaikut ega usada para ‘ontem’ é agramatical.

(105) Construção hortativa e advérbios de tempo

a. eñ̃ txiamõyãm nã.

enã txi-amõy-ã-m nã

hoje 1 PL.INCL-dançarV.T-INF FUT

'Nós vamos dançar hoje.' (declarativo)

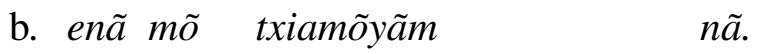

enã mõ txi-amõy-ã-m nã

hoje HORT 1PL.INCL-dançar-V.T-INF FUT

'Vamos dançar hoje!' (hortativo)

c. ndaikut mõ txiamõyãm nã

ndaikut mõ txi-amõy-ã-m nã

amanhã HORT 1PL.INCL-dançar-V.T-INF FUT

'Amanhã, vamos dançar!' (hortativo)

d. *ndaikut ega mõ txiamõyãm nã.

*ndaikut ega mõ txi-amõy-ã-m nã

amanhã FRUST HORT 1 PL.INCL-dançar-V.T-INF FUT

e. ndaikut mõ!

ndaikut mõ

Amanhã HORT

'Amanhã, vamos!' 


\section{f. *ndaikut ega mo \\ *ndaikut ega mõ \\ amanhã FRUST HORT}

Os dados expostos até o momento apresentam construções hortativas com verbo intransitivo. Em (106), podemos ver que mõ também ocorre com verbos transitivos.

(106) Construção hortativa com verbo transitivo

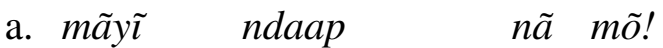
mãyĩ nda-a-p nã mõ
macaxeira plantar-V.T-INF FUT HORT
'Vamos plantar macaxeira!' (PM-2012)
b. nge pokwap nã mõ!
nge po-kwa-p nã mõ
roça queimar-VZR-INF FUT HORT
'Vamos queimar roça!' (WYR-20161007-FN-PM-MA-festa-tradic)

Vale notar a localização do morfema hortativo mõ dentro da sentença. Em sentenças intransitivas, sem advérbio, mõ ocorre no início da sentença, cf. dado (104) acima. Em sentenças intransitivas, com advérbio, mõ ocorre após o advérbio, cf. (105). Em sentenças transitivas, $m \tilde{o}$ ocorre em posição final, cf. (106). Será interessante comparar, em pesquisas futuras, os dados de sentenças hortativas transitivas com advérbio para averiguar a posição do morfema hortativo. A localização do morfema hortativo em sentenças transitivas e intransitivas, com e sem advérbio, poderá fornecer evidência sobre a estrutura sintática das sentenças.

\subsubsection{Sumarizando os fatos sobre tipos sentenciais declarativo, impera- tivo e hortativo}

Vimos um conjunto de características específicas de cada tipo sentencial. Os itens abaixo fazem um resumo das propriedades de cada tipo sentencial.

- O tipo sentencial declarativo pode fazer uso das possibilidades de expressão de tempo e pessoa disponíveis na língua.

- O tipo sentencial imperativo tem uso restrito de marcas de pessoa, expressando, nos verbos intransitivos, somente o prefixo de $2^{\text {a }}$ pessoa do singular ou do plural, não há concordância com os pronomes livres; no verbo transitivo, expressando apenas o clítico de objeto do verbo ${ }^{10}$.

- O tipo sentencial hortativo, indicado por $m \tilde{o}$, expressa somente a $1^{\text {a }}$ pessoa do plural inclusiva em um verbo intransitivo, e o objeto, em um verbo transitivo. Com respeito à morfologia verbal, ocorre com morfema de futuro e apresenta semântica de convite.

\footnotetext{
${ }^{10}$ Não há indicação de morfema de tempo 'não futuro' nas sentenças imperativas. A presença de um morfema de tempo tem interpretação declarativa, como se pode notar no seguinte par de exemplos:
} 


\subsection{Distinções de Modalidade e Polaridade}

Descreveremos, a seguir, elementos cujo valor gramatical está relacionado à modalidade. A construção frustrativa (ke)romboga expressa que o evento anteriormente mencionado não ocorreu. Os elementos ngwat, pega e pare indicam que o evento é irrealis. O morfema emõ 'enfático' é usado para expressar semântica deôntica. Os morfemas kaat e tika expressam a semântica desiderativa. O item nengan 'similativo' é utilizado tanto para comparação a um SN, equivalente a expressões como 'igual, como' ou like em inglês (TREIS; VANHOVE, 2017), quanto para um evento irrealis, como no trecho ongwãyomkarat nengan "como se eu estivesse febril".

\subsubsection{Frustrativo}

De acordo com Longacre (2007, p. 385), a noção chave para a frustração é a mudança de expectativa. Há uma ação, evento ou estado que implica em outra ação, evento ou estado como sua continuação ou consequência. Há uma circunstância ou consideração que resulta em um valor oposto (negativo ou positivo) do valor pretendido. Conforme Aikhenvald (2009, p. 140), na língua Manambu (família Ndu, Nova Guiné), a modalidade frustrativa indica que uma atividade foi em vão.

Campbell (2012, p. 291) aponta que um número significativo de línguas sul-americanas tem um morfema verbal frustrativo, incluindo várias línguas Tupi-Guarani (Tupi).

Em Mekens, de acordo com Galucio (2014b, p. 165), a partícula frustrativa etaop adiciona a semântica específica de frustração ou a ideia de que não foi obtido o resultado esperado da proposição. Tal partícula pode ocorrer em uma sentença declarativa independente, como mostra o dado (107).

(107) Modalidade epistêmica em Mekens: etaop 'frustrativo'

o-po-ãkã kora etaop.

$1 \mathrm{SG}-\mathrm{mão}$-osso procurar FRUST

'Ele/Ela procurou meu bracelete em vão/Ele/Ela procurou meu bracelete, mas não o encontrou.' (GALUCIO, 2014b, p. 169)

a. eekoya!

e-e-koy-a

2SG-MED-afastar.se-V.T

'Afaste-se!'

b. eekoyat.

e-e-koy-a-t

2SG-MED-afastar.se-V.T-NFUT

'Você se afastou.' (PM-2013) 
A partícula frustrativa (e)taop tanto pode se relacionar a apenas uma sentença, quanto expressar valor semântico de oposição entre duas sentenças independentes. Vejamos dados relacionados em Wayoro (NOGUEIRA, FREITAS, 2014) ${ }^{11}$.

A construção -romb+-oga 'negação+frustrativo' foi registrada em orações da língua Wayoro expressando, em geral, uma mudança de expectativa. Tal construção ocorre após um radical verbal. Compare a sentença declarativa negativa em (108b) com a construção frustrativa em (108c). Note que a construção frustrativa não introduz uma negação ao evento, mas sim um valor oposto ao esperado. Um exemplo adicional de construção frustrativa ligada diretamente ao verbo é oferecido em (109).

(108) Construção frustrativa: verbo tatankwa 'correr atrás de'

a. on piakarat tatankwat.

on piarakarat tatan-kwa-t

eu galinha correr.atrás-VZR-NFUT

'Eu corri atrás da galinha' (NOGUEIRA, 2011, p. 103)

b. tatankwarom.

tatan-kwa-rom

correr.atrás-VZR-NEG

'Ela não foi atrás.'

c. tatankwa-romb-oga

tatan-kwa-rom-oga

correr.atrás-VZR-NEG-FRUST

'Ela foi atrás mas não alcançou.' (PM-2015)

(109) Construção frustrativa: verbo ngora 'procurar'

a. iko ngora [...]

iko ngora-a $[\ldots]$

caça procurar-V.T [...]

'Procuravam caça.' (WYR-20161007-FN-PM-MA-festa-tradic)

b. ngwatoa, poko, ngoraromboga, ngoraromboga, 'ãam. ngwato-a, poko, ngora-rom-oga 'ãam esperar-V.T sair procurar-NEG-FRUST procurar-NEG-FRUST NEG.EXIST '(Ele) esperou, saiu, procurou, não encontrou, procurou de novo, não encontrou. Não havia' (WYR-200308-DM-PK-origemdomundo-43)

O dado em (110a) mostra que o verbo transitivo toa 'ver' seguido do elemento frustrativo pode aparecer com o objeto realizado por um clítico, tal como em uma sentença simples (110b).

\footnotetext{
${ }^{11}$ Comunicação apresentada no IV Encontro Internacional sobre Línguas e Culturas Tupí, realizado na Universidade de Rondônia (UNIR), Campus de Ji-Paraná, entre os dias 10 a 12 de dezembro de 2013.
} 
(110)

a. otoromboga, ugu eriat emõ toa

[o=top-rom-oga ] ugu eriat emõ top-a

1SG-ver-NEG-FRUST água dono ENF ver-V.T

'Iriam me ver, mas não viram, viram só o dono da água.' (WYR-20080616-AVG-

ANT-Hist-agua-66-67)

b. ngwaykup otoat.

ngwaykup o=top-a-t

homem $1 \mathrm{SG}=$ ver-V.T-NFUT

'O homem me viu' (NOGUEIRA, 2011, p. 159)

Testes sobre a natureza do morfema -oga 'frustrativo' evidenciaram que o mesmo não tem comportamento de morfema livre. Testes de oga quanto à coocorrência com morfemas verbais mostraram que este item não flexiona para pessoa e não pode ocorrer sem o morfema de negação que o precede. Os únicos morfemas verbais registrados na construção frustrativa foram o sufixo iterativo - $k w a$ 'intensificação/pluracionalidade' (111a) e os morfemas de não-futuro (111b) e de futuro (111c). Tais propriedades aproximam oga de um verbo auxiliar.

a. omẽpiriat mõendop mãyrombokwa.

o-mẽpit-iat mõendop mãy-rom-o.kwa

1SG-filho.Q-PL conhecimento contar/ensinar-NEG-FRUST.ITER

'Eu quero ensinar minhas filhas o conhecimento, mas elas não aprendem mesmo.'

b. "aramíra ndekwat ngwat miõkop,

aramira ndekwat ngwat m-i-õ-kop

mulher corpo ESPEC 1SG-FOC.OBJ-CAUS-ficar/estar

kerombogat on kawete."

k-e-rom-oga-t on kawete

?-COP-NEG-FRUST-NFUT eu CONJ

"'Parecia que eu estava morando com mulher verdadeira [corpo de mulher], mas eu não estava."' (WYR-20100326-FN-PM-caracol-42)

c. Kerombogap nã on.

k-e-rom-oga-p nã on

?-COP-NEG-FRUST-INF FUT eu

'Eu ia fazer, mas não fiz.' (PM-2016)

Além do uso de -romboga após um verbo, é frequente em textos a construção keromboga relacionada a uma ideia oposta à ideia pretendida pelo evento de uma construção anterior. Tal construção ocorre geralmente em posição final, mas pode ser seguida pelo sujeito da sentença. $\mathrm{Na}$ oração antecedente, ocorre um verbo em forma finita (flexionado para pessoa e tempo), tal como se observa nos dados em (112). 
No exemplo (112a), ocorre o prefixo pessoal absolutivo de $1^{\text {a }}$ pessoa do singular $o$ - e, no dado (112b), o verbo recebe o prefixo de $3^{\mathrm{a}}$ pessoa correferencial te-. Em (112c), o argumento do verbo intransitivo é a $2^{\text {a }}$ pessoa do singular $e$-. O verbo pode ocorrer com morfema de nãofuturo (112a) ou com morfema de 'futuro' (112c). Como dissemos, a sentença com a qual a construção frustrativa keromboga se relaciona apresenta o verbo na forma finita.

A construção frustrativa pode estar relacionada a uma sentença declarativa afirmativa ou negativa (112b), bem como a uma sentença interrogativa (112c).

(112) Construção frustrativa

a. otandjorat o-tandjot-a-t

ngwat kerombogat

ngwat k-e-romb-oga-t

1SG-engravidar-V.T-NFUT ESPEC ?-COP-NEG-FRUST-NFUT eu

'Eu pensei que eu estava grávida, mas não estava.' (PM-2012)

b. Juca tetandjorom

ngwat kerombogat

Juca te-tandjot-om

ngwat k-e-romb-oga-t

on, kawate

Juca 3C-engravidar-NEG ESPEC ?-COP-NEG-FRUST-NFUT eu CONJ

tetandjorat.

te-tandjot-a-t

3C-engravidar-V.T-NFUT

'Eu pensei que a Juca não estava grávida, mas ela estava.' (PM-2012)

c. eterap

e-tet-a-p

nã kerombogat

nen?

2SG-ir-V.T-INF FUT ?-COP-NEG-FRUST-NFUT INTERR.2

'Você já ia?' (PM-2012)

Podemos resumir o comportamento da construção frustrativa keromboga da seguinte maneira: a construção frustrativa está relacionada uma oração sintaticamente independente, expressando o valor oposto (negativo ou positivo) da continuação ou consequência esperada do evento dessa oração independente anterior.

Sobre a constituição de keromboga devemos considerar que erom existe isoladamente como forma de negação nominal. Veremos, no Capítulo 6, que o morfema de negação ocorre afixado ao verbo cópula $e$-, nos predicados não verbais. Em Wayoro, a negação verbal é realizada através dos sufixos -om -rom, com a seguinte distribuição: /-om/ após raízes que terminam em consoante, como em te-tandjor-om 'Ela não engravidou', e /-rom/ após raízes finalizadas por vogais, como em tatankwa-rom '(Ela) não correu atrás'. Portanto, é possível sugerir uma segmentação em que temos $e$ - 'cópula' + -rom 'negação' em k-e-romb-oga.

A forma kerom foi registrada isoladamente em texto como negação. A segmentação $k$-e-rom, possivelmente tem o sentido 'não é isso'. A pergunta feita em (113a) é respondida com a forma kerom em (113b). 
a. Djarokwa korom ne djat?

djar-okwa ko-rom nẽ djat

2PL-irmão. ingerir-NEG INTERR 2PL

'Vocês não comeram o irmão de vocês?'

b. "Kerom, okwa korom ote, ate itoagat ote."

k-e-rom okwa ko-rom ote ate itoak-a-t ote

?-COP-NEG irmão.९ comer-NEG 1PL.EXCL somente chorar-V.T-NFUT 1PL.EXCL

'Não, nós não comemos nosso irmão, estamos só chorando por ele.' (WYR20080627-FN-PM-a-chefe-das-mulheres-61-62)

A forma keromboga pode ser considerada uma construção especializada com a semântica frustrativa, uma vez que há um verbo cópula envolvido ${ }^{12}$.

\subsubsection{Especulativo ngwat}

O valor especulativo está associado ao item ngwat, como podemos notar nos dados em (114). Observe que o verbo da sentença apresenta suas propriedades de finitude. Quando o verbo é transitivo, como auwa 'rezar/curar', em (114a), pode-se expressar um SN sujeito e um objeto clítico de pessoa, como $y=3^{\mathrm{a}}$ pessoa. Um verbo intransitivo aparecerá com o prefixo pessoal obrigatório, como te - $3^{\mathrm{a}}$ pessoa correferencial, em (114b). Note, ainda que o verbo pode apresentar morfema de não-futuro - $t$ (114a-b). Vale observar que a sentença com o elemento especulativo pode ser seguida pela oração frustrativa keromboga, como se observa em (114c).

(114) Morfema especulativo $n g w a t$

a. ondaup Patoringwat djauwat.

o-ndaup Patori ngwat $\mathrm{dj}=\mathrm{au}-\mathrm{wa}-\mathrm{t}$

1SG-filho. $0^{7}$ P. ESPEC 3-rezar/curar-VZR-NFUT

'Acho que meu filho Patori rezou/curou ele.' (WYR-200308-DM-PM-tratamentopaje-34)

b. Fernanda teorat

ngwat. $^{13}$

Fernanda te-ot-a-t

ngwat

F. 3C-chegar-V.T-NFUT ESPEC

'Parece que a Fernanda chegou.' (PM-2015)

\footnotetext{
${ }^{12} \mathrm{Em}$ Mekens, o elemento ke é utilizado como uma proforma que pode substituir qualquer trecho de discurso ( sintagma nominal, sintagma verbal ou até uma sentença inteira). Tal elemento é analisado, preliminarmente, como um verbo sem flexão (GALUCIO, 2019, comunicação pessoal).
} 
c. "aramira ndekwat ngwat miõkop, aramira ndekwat ngwat m-i-õ-kop mulher realmente ESPEC 1SG-FOC.OBJ-CAUS-ficar/estar kerombogat on kawete." k-e-romb-oga-t on kawete ?-COP-NEG-FRUST-NFUT eu CONJ

"'Parecia que eu estava morando com mulher verdadeira, mas eu não estava." (WYR-20100326-FN-PM-caracol-42)

\subsubsection{Elemento pega 'irrealis' e pare 'irrealis negativo'}

A forma pega ocorre como resposta 'sim/eu gostaria' de uma pegunta polar (115a-b). A mesma forma com o sufixo de negação verbal, pegom, corresponde à resposta negativa 'não/não gostaria', como se observa em (115c).

(115) Exemplo de pega 'desiderativo irrealis'

a. Pergunta

$\begin{array}{ll}\text { etigaap } & n \tilde{a} ? \\ \text { e-tiga-a-p } & \text { nã } \\ \text { 2sG-pintar.corpo-V.T-INF FUT }\end{array}$

'Você quer (vai) se pintar?'

b. Resposta afirmativa

$\begin{array}{ll}\text { pegat } & \text { on. } \\ \text { peg-a-t } & \text { on } \\ \text { IRR-V.T-NFUT eu }\end{array}$

'Sim [lit. Eu gostaria].'

Resposta negativa

c. pegom on.

peg-om on

IRR-NEG eu

'Não quero [lit. eu não gostaria].'

$\mathrm{O}$ item pega comporta-se como verbo transitivo, podendo expressar um SN objeto e um pronome sujeito tal como se observa em (116). Em Mekens o elemento cognato pegat é glosado como futuro irrealis e como condicional. Podemos observar, em (115-116), que pega em Wayoro está associado com uma ideia de desiderativo irrealis (115-116a) ou apenas irrealis (116b).

\footnotetext{
${ }^{13} \mathrm{O}$ presente dado evidencia que o verbo intransitivo ora pode concordar com um SN singular. Nogueira (2011) analisou erroneamente o verbo ora 'ir (plural)' como forma supletiva plural de tera 'ir (singular)'.
} 
a. ngoyoto pegat on.

ngoyoto peg-a-t on

feijão IRR-V.T-NFUT eu

'Eu queria/gostaria de feijão.' (PM-2012)

b. yindopeõ, tuup koypet nẽro pegat.

yindopeõ tuup koypet nẽro peg-a-t

atrás dar.à.luz irmã.ơ DEM IRR-V.T-NFUT

'Atrás, nasceu aquela que seria a irmã deles.' (WYR-19900302-DM-PK-cobraduas-cabecas)

Outra maneira de responder de forma negativa é usar o item pare, que se assemelha a uma modalidade irrealis negativa, como em (117).

(117) pare 'irrealis negativo'

a. Pergunta

$$
\begin{aligned}
& \text { etigaap nã? } \\
& \text { e-tiga-a-p nã } \\
& \text { 2sG-pintar.corpo-V.T-INF FUT } \\
& \text { 'Você quer (vai) se pintar?' }
\end{aligned}
$$

b. Resposta

$$
\begin{aligned}
& \text { pare on. } \\
& \text { pare on } \\
& \text { IRR.NEG eu } \\
& \text { 'Não [lit. não irei].' }
\end{aligned}
$$

A semântica de modalidade irrealis negativa é corroborada pelo trecho de texto em (118).

(118) pare 'irrealis negativo'

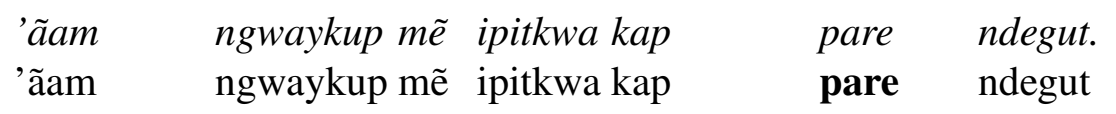

NEG.EXIST homem TOP jogar PROFORMA IRR.NEG PASS.DIST

'O homem não existiria, se não fosse isso, jogar [o veneno], naquele tempo.' (WYR200308-DM-PM-tratamento-paje-46)

\subsubsection{Enfático emo}

O elemento emõ nemõ é traduzido com o advérbio 'mesmo, realmente'. Note, em (119), que o valor gramatical de modalidade 'ter que' pode estar associado com o item emõ. Em (119a), esse morfema é usado para expressar que, uma vez que nos tempos antigos não havia água, as 
pessoas eram obrigadas/tinham que se banhar com urina. De maneira semelhante, em (119b), ao narrar sobre o tempo em que não existiam os frutos cultivados hoje, era necessário comer pouco e comer apenas os caules das plantas.

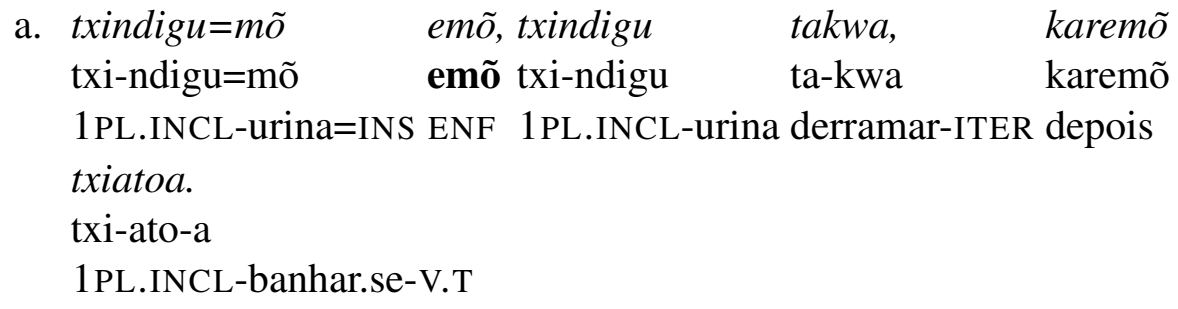

O valor gramatical de modalidade deôntica, expresso através do enfático emõ , é evidenciado no par de dados em (120).

a. indiakwa pugap nã.

indiakwa puga-a-p nã

comida cozinhar-V.T-INF FUT

'(Ele) vai cozinhar comida.'

b. indiakwa emõ pugap nã on

indiakwa emõ puga-a-p nã on

comida ENF cozinhar-V.T-INF FUT eu

'Eu tenho que cozinhar comida/Eu vou cozinhar comida mesmo.' (PM- 2010)

O elemento enfático/assertivo de Mekens ebõ pode ser considerado cognato ao enfático emõ $\sim$ nemõ de Wayoro.

\subsubsection{Partícula kaat 'quotativo'}

Como se observa em (121), em Wayoro, o morfema kaat tem valor semântico quotativo. 
a. kap toromangãm nã on, kaat on.

kap top-ro-mang-a-m nã on kaat on

PROFORMA ver-?-AUX-V.T-INF FUT eu QUOT eu

'Eu quero mandar olhar isso.' (WYR-200308-DM-PK-tratamento)

b. ndeke "ẽe kupkuya ẽe" kaat, Durafogo djauwap ere.

ndeke ẽe kupkuya ẽe kaat Durafogo dj=au-w-a-p ere

ele DEM raiz/veneno DEM QUOT D. 3=curar/rezar-VZR-V.T-INF em

'Quando Durafogo o rezou, ele falou/contou "É veneno isso, é isso".' (WYR200308-DM-PK-tratamentodetertuliano)

c. kaarigit

kaat-igit

QUOT-?

'Contavam assim.' (NOGUEIRA; MACURAP; WAJURU, 2019, p. 355)

O elemento cognato kaat é analisado como morfema desiderativo em Mekens.

\subsubsection{Elemento tika 'desiderativo'}

O item tika é um elemento desiderativo, como se constata nos exemplos em (122).
a. kukuya uraap, yimãyãm $\quad$ eroa tika.
kukuya uraa-a-p y-i-mãy-ã-m eroa tika

raiz.venenosa retirar.doença-V.T-NMLZ 3-FOC.OBJ-contar-V.T-NMLZ DEM DESID

'A cura/sugamento do veneno, ele quer que conte aquilo para ele.' (WYR-200308-

DM-PK-tratamento)

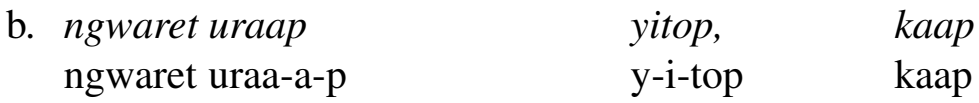

doença retirar.doença-V.T-NMLZ 3-FOC.OBJ-ver?

yimãyãm êroa tika.

y-i-mãy-ã-m ẽroa tika

3-FOC.OBJ-contar-V.T-NMLZ DEM DESID

'A cura/sugamento da doença, ele viu, ele quer que conte aquilo para ele.' (WYR200308-DM-PK-tratamento)

\subsubsection{Similativo nengan}

O morfema similativo nengan 'também, como, igual' em Wayoro é cognato ao morfema 'similativo' de Mekens.

Nos dados em (123), o elemento similativo aparece após sintagmas nominais, ndeke ' 3 a pessoa do singular' (123a) e omõy 'pamonha' (123b). 
a. kuy piora [...] ndeke nẽngara.

kuy pi-ot-a [...] ndeke nẽngan-a

terra dentro-ir-V.T [...] ele SIM-ENF

'[sobre o enterro tradicional], cava-se a terra [...] como ele mesmo ${ }^{14}$.' (WYR200308-DM-PK-enterr-trad)

b. omõy nengan emõ omõy mboa.

omõy nengan emõ omõy mbo-a

pamonha SIM ENF pamonha distribuir-V.T

'Pamonha mesmo também, distribuíam pamonha.' (WYR-20161007-FN-PM-MAfesta-tradic)

Nos dados em (124), o similativo ocorre após uma construção nominalizada (124a) e após uma oração finita (124b), conferindo um valor irrealis à mesma.

a. ngwerep agopkap kup mbutngap nengan, kap.

ngwerep agopkap kup mbut-nga-p nengan kap

não.indígena fogo/lenha pau acender-VZR-NMLZ SIM PROFORMA

‘É como o acender de fósforo do branco, isso' (WYR-200308-DM-PK-fogo)

b. ongwãyomkarat nengan kap nã on.

o-ngwãyom-kara-t nengan kap nã on

1SG-estar.febril-VZR-NFUT SIM PROFORMA fazer eu

'Eu faço isso, como se eu estivesse com febre.' (WYR-20080627-FN-PM-a-chefedas-mulheres-25)

\subsection{Polaridade negativa: sufixo -ap}

O sufixo -ap -am é cognato ao sufixo de negação -ap da língua Mekens que ocorre com nomes, adjetivos e verbos (GALUCIO, 2001, p. 92).

A negação -ap -am de Wayoro ocorre após o radical verbal, acompanhada de nẽe, expressando a negação de um evento irrealis.

Em Mekens, ne e na são descritos como "partículas invariantes que servem para marcar um predicado não prototípico como capaz de funcionar como predicado e ocorrer com partículas modais que marcam tempo, aspecto e/ou modo na língua"15. A partícula ne ocorre com sintagmas nominais, sintagmas adposicionais e sintagmas adverbiais. A partícula na ocorre

\footnotetext{
${ }^{14} \mathrm{O}$ morfema final da palavra nẽngan- $a$, deste exemplo, é glosado com base no sufixo cognato - $o$ enfático da língua Karitiana Storto (2014a, p. 171), considerando a mudança vocálica em sentido anti horário das línguas Tupi para Karitiana (STORTO; BALDI, 1994).

15 “....] an invariant particle that serves to mark a non-prototypical predicate as able to function as a predicate and occur with modal-like particles marking tense, aspect, and for mode in the language" (GALUCIO, 2001, p. 184).
} 
apenas com sintagmas nominais (GALUCIO, 2001). Em Galucio (2011, p. 33, 39), ne é glosado como 'cópula' e na como 'verbalizador'.

Em Wayoro, as construções que usam o elemento ñe 'irrealis' não podem substituí-lo por nã morfema de futuro, como se observa em (125). O verbo mbiro recebe o sufixo de negação -ap. Tal verbo é claramente biargumental, porém não recebe vogal temática e marcas de tempo, de forma que pode ser analisado como verbo irregular, como veremos no Capítulo 6.

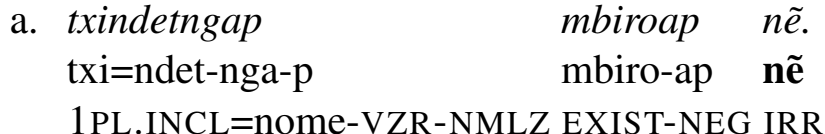

'Nós ainda não existíamos [Lit. Ainda não havia nos dado/pronunciado nosso nome].' (WYR-200308-DM-PK-origemdomundo 005)

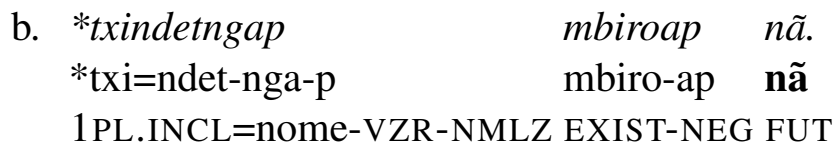

Provavelmente, também em Wayoro, nẽ é utilizado em "predicados não prototípicos”, como descrito por Galucio para a língua Mekens, tal como no modo irrealis. Glosaremos nẽ como 'irrealis'.

Mais exemplos de negação por meio de $-a p+n \tilde{e}$ com valor irrealis/condicional estão listados em (126).

(126) Negação via -ap+ne 'irrealis'

a. awariat ngora nãram nẽ.

awat-iat ngora nẽ-a-r-am nẽ

espírito-PL música fazer-V.T-NFUT-NEG IRR

'Música de espíritos, ninguém [pode] cantar' (WYR-200308-DM-PK-canto-paje)

b. txiyẽpot nõnõam ne atiti, aragwi, ngoyoto,

txi-yẽpot nõ nõ-a-r-am nẽ atiti aragwi ngoyoto

1 PL.INCL-plantas outro outro-V.T-NFUT-NEG IRR milho amendoim feijão/fava

agwa.

agwa

cará

'As nossas plantas não poderiam ser outras: milho, amendoim, feijão, cará.' (WYR-

200308-DM-PK-origemdomundo)

\subsection{Considerações finais}

Neste capítulo, apresentamos uma análise provisória para morfemas relacionados a tempo, aspecto, tipos sentenciais, modalidade e polaridade, com o intuito de: (i) identificar o maior número possível de núcleos funcionais relacionados à finitude das sentenças matrizes para, 
no Capítulo 5, comparar tais propriedades com as sentenças subordinadas/nominalizadas; (ii) apresentar glosas hipotéticas para unidades gramaticais identificadas, especialmente, na análise de textos. A Tabela 4.2 retoma os morfemas identificados.

Tabela 4.2: Morfemas de tempo, aspecto, modalidade e polaridade em Wayoro

\begin{tabular}{|c|c|c|}
\hline Expressão de tempo & Significado & Glosa \\
\hline$-t \sim-n$ & indicação de não-futuro & NFUT \\
\hline$-p \sim-m+n \tilde{a}$ & indicação de 'futuro' & -INF FUT \\
\hline Expressão de Aspecto & Significado & Glosa \\
\hline$-k w a$ & intensificação/pluracionalidade do evento & ITER \\
\hline -rara $\sim$-ara & repetição/habitual & REP \\
\hline Expressão de Modalidade & Significado & Glosa \\
\hline (ke)romboga & frustrativo & FRUST \\
\hline ngwat & especulativo & ESPEC \\
\hline pega; pare & irrealis; irrealis negativo & IRR; IRR.NEG \\
\hline emo & enfático & ENF \\
\hline kaat & quotativo & QUOT \\
\hline tika & desiderativo & DESID \\
\hline nengan & similativo & SIM \\
\hline Expressão de polaridade & Significado & Glosa \\
\hline$-a p+n \tilde{e}$ & negação irrealis & NEG IRR \\
\hline
\end{tabular}

Rodrigues e Cabral (2012) propõem que as línguas Tupi, em geral, tendem a expressar tempo e aspecto através de partículas e/ou auxiliares. Vimos que na língua Wayoro foram identificados como afixos de tempo - $t$ 'não-futuro' e de aspecto -rara -ara 'repetição/habitual' e - $k w a$ 'pluracionalidade/intensificação' do evento.

Dentre as distinções de modalidade apresentadas em Galucio (2014b, p. 169) para a língua Mekens, há elementos que correspondem a morfemas de valor gramatical idêntico ou aproximado na língua Wayoro. Confira esses elementos na Tabela 4.3, a seguir.

Tabela 4.3: Morfemas de modalidade em Mekens (GALUCIO, 2014b) e Wayoro

\begin{tabular}{|c|c|c|c|}
\hline Mekens & Significado & Wayoro & Significado \\
\hline (e)taop & frustrativo & (ke)romboga & frustrativo \\
\hline kêra & especulativo, não-assertivo & ngwat & especulativo \\
\hline pegat & condicional; irrealis & pega; pare & irrealis; irrealis negativo \\
\hline$e b \tilde{o}$ & assertivo, marca enfática & emó & enfático \\
\hline$k o t=k a a t$ & desiderativo & tika & desiderativo \\
\hline nẽ $\tilde{a} t$ & similativo & nengan & similativo \\
\hline
\end{tabular}

A descrição dos tipos sentenciais/modo e modalidade é importante para a identificação de elementos gramaticais relacionados à asserção pragmática. Sentenças matrizes são ambientes que apresentam asserção pragmática. As sentenças subordinadas, por outro lado, são 
construções pragmaticamente não-assertivas (CRISTOFARO, 2005, p. 30), de forma que se pressupõe que as sentenças subordinadas não devem ter, em geral, marcas de modo/modalidade.

Veremos que nas orações subordinadas infinitivas podem ocorrer morfemas de aspecto rara -ara 'repetição/habitual' e - $k w a$ 'iterativo'. Não são registrados morfemas de tempo nem morfemas de modalidade, estudados neste capítulo.

Vale ressaltar, por fim, que a descrição dos itens de modalidade evidencia que o que é expresso através de oração subordinada em uma língua pode corresponder a construções de natureza diversa em outra língua. Por exemplo, verbos que podem ter uma oração como complemento em português, como 'parecer', 'ter que', correspondem a itens não verbais em Wayoro, como mostra a comparação em (127).

(127) Verbos que podem ter complemento oracional (subordinadas) em Português são itens não verbais em Wayoro

$\begin{array}{lll}\text { Português } & \text { Wayoro } & \\ \text { Parecer } & \text { ngwat } & \text { 'especulativo' } \\ \text { Ter que } & \text { emõ } & \text { 'enfático' } \\ \text { Querer } & \text { tika } & \text { 'desiderativo' } \\ \text { Dizer } & \text { kaat } & \text { 'quotativo' }\end{array}$




\title{
Nominalização, Subordinação e Finitude
}

\author{
Uyã iperiat, tuero nderap eriat. A Dona é o \\ caracol fêmea. (Ela) é a dona do preparo da \\ chicha. (Paulina Macurap)
}

A seção 5.1, deste capítulo, esclarece a terminologia sob enfoque (nominalização, subordinação e finitude). Em seguida, na seção 5.2, traz-se um breve diálogo dos dados de Wayoro com o tema da gramaticalização. Os diagnósticos morfossintáticos que permitem diferenciar construções nominalizadas de orações subordinadas infinitivas são discutidos nas seções 5.3, 5.4 e 5.5. A seção 5.6 mostra que alguns verbos que tomam oração complemento em outras línguas correspondem a recursos gramaticais não verbais em Wayoro. A seção 5.7 apresenta resultados da investigação sobre movimento de constituintes de dentro das construções com o sufixo - $m \sim-p$. Apoiando-se em Comrie e Thompson (2007), a seção 5.8 discute de forma sucinta a produtividade e previsibilidade semântica de cada construção aqui estudada. Na seção 5.9, veremos características de outro tipo de oração subordinada, a subordinada imperfectiva.

\subsection{Nominalização, subordinação e finitude}

Para o desenvolvimento deste capítulo, será necessário delimitar o sentido do termo nominalização que vamos empregar (ou seja, se o termo será usado como se referindo a um processo sincrônico ou a um processo diacrônico). Ainda, será útil evidenciar a relação entre os termos nominalização, subordinação e finitude.

Givón (2016, p. 272-273) define nominalização como "um processo diacrônico, pelo menos inicialmente, através do qual uma oração verbal finita - que pode ser tanto uma oração completa quanto uma oração sem sujeito — é convertida em um sintagma nominal" ". Uma oração verbal é nominalizada em um contexto sintático em que ocupa, dentro de outra oração, a função ou posição prototípica de um nome, ou seja, sujeito, objeto direto, objeto indireto ou predicado nominal. Por esse motivo, a nominalização sinaliza subordinação ou complexidade

\footnotetext{
1 "Nominalization is, at least initially, a diachronic process via which a finite verbal clause either a complete clause or a subject-less verb phrase is converted into a noun phrase” (GIVÓN, 2016, p. 272).
} 
sintática. $\mathrm{O}$ fator de comparação entre uma oração verbal finita e uma nominalização (menos finita ou não-finita) é a finitude, vista como uma escala de propriedades oracionais. Givón (Ibid., p. 272) explica que as propriedades das orações principais-declarativas-afirmativas-ativas são tomadas como protótipo de orações verbais finitas, ou seja, o modelo a partir do qual orações não-finitas se diferenciarão ou irão variar. A escala de finitude, reproduzida na Tabela 5.1, com exemplos de gradação em inglês, é apresentada por Givón (Ibid., p. 274).

Most non-finite (nominalized)

a. [Her good knowledge of math] surely helped

b. [Her knowing math well] surely helped

c [For her to know math so well] surely helped

d. She wanted [to know math well]

e. [Knowing math well], she then...

f. [Having known math well since highschool], she...

g. [that she knew math well] was great help

h. She knew math well

Most finite

Tabela 5.1: Escala de finitude

Observa-se, assim, que o termo nominalização refere-se a um processo no qual as propriedades sintáticas de uma oração ou finitude se tornam menos parecidas ao protótipo mais finito, ou seja, se tornam menos finitas e mais parecidas com nomes. Entre os extremos desse processo, contudo, há vários tipos de orações, que, segundo o autor, "exibem graus intermediários de finitude ou nominalização" ${ }^{2}$. Note que dentro da escala estão orações infinitivas e na extremidade menos finita a nominalização lexical, knowledge.

Esta terminologia é utilizada em grande parte da literatura sobre nominalizações, tal como em Gijn, Haude e Muysken (2011a). De acordo com Gijn, Haude e Muysken (2011b, p. 1011) a nominalização é "provavelmente a estratégia de subordinação mais comum nas línguas sul-americanas"3. A nominalização, em geral, abrange os seguintes tipos: participant nominalization, aquela que funciona como orações relativas; event nominalization, usadas para complementação, mas também para relações adverbiais e relativas; e participial nominalization em que o nominalizador também codifica uma propriedade verbal. Como exemplo de nominalizações de evento que funcionam como complemento são citadas as línguas Pilagá (Guaycuru), dado reproduzido em (128a), e Huallaga Quechua, dado reproduzido em (128b).

(128) Sentenças complemento analisadas como nominalizações

a. Pilagá (Guaycuru) $)^{4}$

se-take da' y-onta-naYak

1-querer CMP 1 POSS-trabalhar-NMLZ

\footnotetext{
2"But many clause-types fall in-between, and thus exhibit intermediate degrees of finiteness or nominalization" Givón (2016, p. 274).

3 "Probably the most common subordination strategy in South-American languages is nominalization" (GIJN; HAUDE; MUYSKEN, 2011b, p. 10-11).
} 
'Eu quero trabalhar' (VIDAL, 2001, p. 356 apud van GIJN, HAUDE; MUYSKEN, 2011, p. 12)

b. Huallaga Quechua (Quechua)

mucha-y-ta muna-:

beijar-INF-ACC querer-1

'Eu quero beijar ela.' (WEBER, 1989, p. 289 apud van GIJN, HAUDE; MUYSKEN, 2011, p. 12)

Note que, em Quechua, há o morfema -y glosado e traduzido como 'infinitivo' e a oração é analisada como uma nominalização de evento.

Gijn, Haude e Muysken (2011b, p. 13) explicam que a nominalização de evento na América do Sul frequentemente permite a retenção de morfologia verbal no predicado nominalizado. Note, em (129), que a construção subordinada de Mapuche ou Mapudungun pode apresentar morfemas característicos de sentenças, como - $k a$ 'factivo' e $-f u$ 'impeditivo', indicadores de modalidade.

(129) Mapuche ou Mapudungun (Araucanian)

Chew mün ngilla-ka-pe-fu-ye-m fende-nge-y- $\phi$

Onde 2PL.POSS comprar-FAC-PROX-IPD-CONST-IVN sell-PASS-IND-3

'[O lugar] onde você costumava fazer suas compras foi vendido' (Smeets 2007, p. 207 apud van GIJN, HAUDE; MUYSKEN, 2011, P. 13)

Segundo os autores, a nominalização através de formas verbais participiais pode também codificar categorias verbais, em particular, tempo. Os autores explicam que, no dado de Aymara, em (130), o nominalizador infinitivo -nya pode introduzir uma interpretação de tempo futuro.

Aymara (Aymara)

yati-qa-nya-taki-w hut-ta

saber-para.baixo-INF-BEN-AFF vir-1SG

'Eu vim para aprender' (ADELAAR; MUYSKEN, 2004, p. 289 apud van GIJN, HAUDE; MUYSKEN, 2011, p. 13)

Assim, dentro da perspectiva tipológica, a subordinação pode ser realizada através de nominalização. Podemos ver que é possível que uma oração infinitiva complemento de verbo também seja analisada como nominalização.

\footnotetext{
${ }^{4}$ Glosas dos dados extraídos de van Gijn, Haude e Muysken (2011): $\mathrm{cmp}=$ complementizador; $\mathrm{pl}=$ plural; poss = possessivo; fac $=$ factivo; prox $=$ proximidade $;$ ipd $=$ impeditivo $;$ const $=$ traço constante $;$ ivn $=$ inversa; pass = passiva; ind = indicativo; ben = benefactivo; aff = afirmativo; inf = infinitivo; acc $=$ acusativo; $\mathrm{nmlz}=$ nominalizador
} 
Com relação à finitude verbal, vimos que as nominalizações eventivas e participais permitem "a retenção de morfologia verbal". De acordo com Cristofaro (2005, p. 18), orações subordinadas podem exibir formas verbais reduzidas (não finitas) não marcadas para categorias como tempo, aspecto, modo ou pessoa, dependendo, nestes casos, da oração principal para a interpretação dessas categorias. Igualmente, para Gijn, Galucio e Nogueira (2015, p. 304), frequentemente, o predicado dependente ou subordinado tem menos possibilidades flexionais que o predicado independente.

Com o objetivo de investigar comparativamente as estratégias de subordinação na família Tupi, Gijn, Galucio e Nogueira (2015) compararam construções atestadas nas línguas filhas em que há relação entre dois eventos. Para os autores, a nominalização e as orações não-finitas podem ser diferentes estratégias de subordinação. Gijn, Galucio e Nogueira (2015) tratam a subordinação de um ponto de vista semântico, entendo-a como a expressão da relação entre dois eventos. Nessa perspectiva, construções de natureza morfossintática muito diversas podem expressar a relação entre dois eventos, a saber, combinação de sentenças, construções verbais seriais, construções com verbos auxiliares, compostos verbo-verbo e afixos derivacionais (tais como desiderativos e causativos), além da nominalização e das orações não-finitas.

Com relação à finitude, na identificação de subordinadas, Gijn, Galucio e Nogueira (2015, p. 304) propõem a investigação de propriedades verbais que podem ocorrer independentemente no evento subordinado, tais como concordância de sujeito e objeto, aspecto, tempo, modalidade de evento e modalidade epistêmica/evidencialidade. Com relação à nominalização, os autores propõem investigar quão semelhantes as subordinadas são dos sintagmas nominais, características relevantes são a possibilidade de apresentar marcas/adposições de caso, codificação de sujeito ou objeto como possuidor, modificação por um determinante ou demonstrativo atributivo, número nominal, desencadeamento de concordância em outras palavras (GIJN; GALUCIO; NOGUEIRA, 2015, p. 304).

\subsubsection{Nominalização em Proto-Tupi e na subfamília Tupari}

Rodrigues e Cabral (2012, p. 533) propõem quatro afixos nominalizadores para ProtoTupi: **-at 'nome de agente', **pit 'nome de paciente', **-ap 'nome de circunstância' e **mi- 'nome de objeto'. Conforme os autores, Proto-Tupi utilizava as nominalizações em uma variedade de contextos sintáticos, incluindo aqueles em que poderiam corresponder a orações complemento, relativas e adverbiais. É interessante notar que a língua Karitiana (subfamília Arikém) diferencia morfologicamente um nominalizador - $p a$ de um sufixo - $p$ infinitivo (SILVA, 2016). Os morfemas de Karitiana sugerem que as propriedades gramaticais de nominalização e de subordinação infinitiva são relacionadas a morfemas cognatos na família Tupi. De fato, a palavra ewapap 'olho', em Wayoro, parece ter, em sua etimologia, um morfema -pa e um morfema - $p$. É possível depreender ewa 'luz', presente em mbo-ewa [mão-luz] 'lâmpada' (Lit. 
'luz de mão'). Há também o verbo transitivo ewaka [luz-verbalizador] 'acender'5. A palavra ewapap é um item lexical usado como nome, atualmente. Até o momento, contudo, não temos evidências sincrônicas de que há um nominalizador - $p a$ em Wayoro.

Seguindo Shibatani e Makhashen (2009), Galucio (2011) descreve a língua Mekens (subfamília Tupari) como constituída por dois tipos de nominalização: nominalização gramatical de evento e nominalização lexical. Dentre as nominalizações lexicais, há o nominalizador circunstancial -ap que se refere a nomes instrumentais e a nomes locativos, como em (131):

(131) Nominalização lexical em Mekens (subfamília Tupari, Tupi)

a. otat poka-ap

fogo queimar/iluminar-NMLZ

'Fósforo ou isqueiro [lit. instrumento (para) iluminar o fogo].'

b. iki ekwe-ap

água correr-NMLZ

'corredeira [lit. parte de um rio onde a corrente é rápida].'

c. o-to-ap i-pagop

1SG-deitar-NMLZ 3SG-novo

'Minha rede é nova.' (GALUCIO, 2011, p. 239)

Neste tipo de estrutura, o prefixo pessoal funciona no nome derivado (sintagma) como o possuidor da nominalização (GALUCIO, 2011, p. 243). Tal como ocorre com o prefixo o-, em (131c). Por sua vez, na nominalização de evento, o nominalizador circunstancial se combina com posposições, resultando em um sintagma posposicional que codifica uma modificação adverbial (GALUCIO, 2011, p. 239-245). Em (132), a nominalização funciona como objeto do sintagma posposicional, nucleado pela posposição $e$ se.

(132) Nominalização de evento em Mekens

[o-ib-ra-ab=ese] tabir=eri ka ki-po-e-mot-kwa

$1 \mathrm{SG}$-vir-REP-NMLZ=LOC campo=ABL ir 1 PL.INCL-mão-INTR-fazer-TR

'Quando eu voltar do campo, nós vamos trabalhar. [ Lit. Na minha volta do campo, nós vamos trabalhar]' (GALUCIO, 2011, p. 243)

De acordo com Galucio (2011, p. 244), há diferenças morfológicas relacionadas à nominalização lexical e à nominalização eventiva. Na nominalização lexical, o morfema -ap se afixa diretamente à raiz verbal, como nos dados em (131). Na nominalização eventiva, o

\footnotetext{
${ }^{5}$ Outra palavra suspeita de ser constituída por um nominalizador - pa diacronicamente é kawap 'cuia'. A forma $k a$ 'ingerir' é um verbo transitivo. Assim, kawap 'cuia' poderia ter sido constituída historicamente como segue: ka-pa-p.
} 
sufixo - ap ocorre após a vogal temática e/ou outros morfemas flexionais, como o morfema -ra 'repetição/habitual' em (132) 6 .

Quanto à estrutura argumental dos verbos com -ap, Galucio afirma que as nominalizações eventivas "mantêm as propriedades sintáticas do verbo", ao passo que as nominalizações lexicais mantêm apenas uma associação morfológica e semântica com a raiz verbal.

\subsubsection{Nominalização vs. subordinação em Wayoro}

Adotaremos uma perspectiva estritamente sintática (e não semântica ou comparativa tipológica) para a análise do conjunto de dados a ser apresentado de Wayoro e argumentaremos que as nominalizações eventivas são melhor analisadas como orações subordinadas uma vez que têm propriedades sentenciais — as quais nominalizações (lexicais), por sua vez, não permitem. Utilizando como ferramenta apenas propriedades sintáticas e morfossintáticas internas à língua Wayoro, mostraremos que há distinção entre nominalização via - $p \sim-m$ vs. subordinação via - $p \sim-m$. Ou seja, há dois tipos de construções envolvendo - $p \sim-m$ : uma que tem propriedades de sintagmas nominais e outra que tem propriedades de orações.

Dessa forma, neste capítulo, apresentaremos argumentos para:

- Considerarmos como nominalização a construção com - $p$ - $m$ que se comporta sintaticamente como sintagma nominal ${ }^{7}$, com respeito a (i) funcionar como objeto de determinados verbos; (ii) funcionar como objeto de uma posposição; (iii) poder ser modificada por um adjetivo ou outro SN; (iv) não permitir o uso de afixos verbais. Note, em (133), que a nominalização é objeto do verbo transitivo e ocorre modificada por um nome, ngwerep 'não indígena' .

- Considerarmos como orações subordinadas (especificamente, infinitivas) construções com $-p \sim-m$ que funcionam como complemento de um verbo e que permitem diferentes afixos verbais, tais como (i) transitivizadores $m \tilde{o}-\sim \tilde{o}$ - 'causativo' e ete- 'sociativo', (ii) indicadores de aspecto, -rara -ara 'repetição/habitual' e - $k w a$ 'iterativo/pluracionalidade', mas não ocorrem com morfema -t〜-n 'não-futuro' e não permitem concordância nas orações intransitivas subordinadas. Note, em (134a), que a construção com $-p \sim-m$ permite o uso do morfema -rara -ara 'repetição/habitual'.

(133) Nominalização lexical via - $p$

$\begin{array}{lll}\text { ngwerep } & \text { [ndoap] } & \text { emõ ponã } \\ \text { ngwerep } & \text { [ndop-a-p] } & \text { emõ ponẽ-a } \\ \text { não.indígena } & \text { deitar-V.T-NMLZ } & \text { ENF usar-V.T }\end{array}$

\footnotetext{
6"In the lexical nominalizations, the nominalizer morpheme -ap directly follows the verb root, while in event nominalizing [...], the nominalizer appears after the thematic vowel and other inflectional morphemes. Furthermore, the event nominalization maintains the syntactic properties (specifically the argument structure) of the verb, while the lexical nominalization holds only a morphological and semantic association to the verb root" (GALUCIO, 2011, p. 244)

${ }^{7}$ Como definido por Muysken (1993, p. 2811) "Sintactically, nominalizations are constructions that have properties of noun phrases but are headed by an element that is to some extent verbal".
} 
‘(As mulheres) só usam a rede do branco.' (WYR-20100326-FN-PM-confeccao-rede22)

(134) Subordinada via - $p$ (nominalização eventiva, em uma perspectiva comparativa tipológica)

a. [endorarap] toat on

[e-ndop-rara-p] top-a-t on

2SG-deitar-REP-INF ver-V.T-NFUT eu

'Eu vi você deitar de novo.' (PM-2016)

b. ndeke “ẽe kupkuya ẽe" kaat, [Durafogo djauwap ere].

ndeke ẽe kupkuya ẽe kaat Durafogo dj=au-w-a-p ere

ele DEM raiz/veneno DEM QUOT D. $\quad 3=$ curar/rezar-VZR-V.T-INF em

'Quando Durafogo o rezou, ele falou/contou "É veneno isso, é isso".' (WYR200308-DM-PK-tratamentodetertuliano)

Veremos que o sufixo $-p \sim-m$ de Wayoro é cognato ao sufixo -ap de Mekens e pode estar relacionado historicamente ao morfema **-ap 'nome de circunstância' do Proto-Tupi. Em uma perspectiva comparativa tipológica, tal morfema pode ser analisado tanto como uma nominalização locativa ou instrumental — como ndoap 'rede (lugar para deitar)' (133) e toap 'espelho (instrumento de ver)' - quanto como uma nominalização de evento usada como complemento de verbo, como em (134a), além de modificação adverbial (tal como em Mekens), em (134b).

\subsection{Nota sobre Gramaticalização envolvendo construções com $-p \sim-m$}

Salta aos olhos a igualdade fonológica entre três morfemas Wayoro: $-p \sim-m$ 'nominalizador de lugar ou instrumento'; - $p \sim-m$ infinitivo e a construção $-p \sim-m$ seguido de $n \tilde{a}$ utilizada para expressar o futuro.

Devemos lembrar que as construções com $-p \sim-m$ aqui analisadas como infinitivo são descritas como nominalização de evento em Mekens (GALUCIO, 2011) e como nominalizações de ação e circunstância em Makurap (BRAGA, 2005, p. 72-73). Tal correspondência formal do morfema infinitivo com o morfema nominalizador de instrumento ou lugar, bem como o comportamento de construções cognatas como nominalização de ação ou evento em outras línguas Tupi sugere uma relação histórica. De fato, é reconstruído para proto-Tupari um elemento nominalizador *-ap (GALUCIO; NOGUEIRA, 2011) e também é reconstruído para proto-Tupi **-ap 'nome de circunstância' (RODRIGUES; CABRAL, 2012). Não há morfema 
reconstruído como infinitivo. Considerando que as construções nominalizadas seriam mais antigas, vale perguntar: como teriam surgido as construções infinitivas em Wayoro?

Como vimos, Givón (2016) descreve a nominalização como um processo diacrônico através do qual uma oração verbal finita é transformada em sintagma nominal. Analisando dados da língua Ute (família Uto-Aztecan), classificada como língua extremamente nominalizadora, o autor identifica uma marca de aspecto $k w a$ 'anterior' dentro da oração subjetiva nominalizada e a marca de aspecto vaa 'irrealis' dentro da oração completiva do verbo mày 'contar'. Confira em (135):

a. 'uru ta'wachi 'uway yoghovu-chi pakha-kwa-kwa-na tut-'ay that/OBJ man/GEN the/GEN coyote/OBJ kill-go-ANT-NMLZ good-IMM 'It is good that the man killed the coyote [lit. 'The man's killing (of) the coyote is good']' (GIVÓN, 2016, p. 375)

b. mamachi 'u na'acichi 'uway tнkuavi 'uru tzka-vaa-ku woman/sUJ the/SUJ girl/OBJ the/OBJ meat/OBJ the/OBJ eat-IRR-NMLZ/SUJ.DIF máy-puga.

tell-REM

'The woman told the girl to eat the meat.' (GIVÓN, 2016, p. 376)

Elementos da estrutura finita presentes dentro das orações nominalizadas são explicadas pelo autor da seguinte maneira: "De fato, muitos tipos oracionais que foram historicamente nominalizados em Ute talvez são refinitizados dessa forma"8.

A presença de sufixos de aspecto - $k w a$ 'iterativo/pluracionalidade' e -rara $\sim$-ara 'repetição/habitual' nas orações infinitivas de Wayoro com $-p \sim-m$ poderia estar relacionada a um processo de refinitização das construções nominalizadas com $-p \sim-m$. Assim, a noção de refinitização é um caminho a ser explorado em relação às construções nominalizadas e infinitivas da língua.

Segundo Gildea (2008, p. 12), nominalizações podem ainda servir de input para o processo histórico de surgimento/renovação de expressões de tempo e aspecto, permitindo que a gramática da nominalização se manifeste como orações principais ${ }^{9}$.

Outro tema apontado por Givón (2016) que pode dialogar com os dados aqui estudados é o tema da dessubordinação (de-subordination). Trata-se de um processo diacrônico em que "uma oração subordinada antiga — frequentemente nominalizada ou não-finita — torna-se uma oração principal.” Givón considera a dessubordinação como um subproduto da gramaticalização de verbos matrizes como marcas de tempo, modo e aspecto estabelecida por Gildea (1994).

\footnotetext{
8"Indeed, many clause-types that were historically nominalized in Ute are perhaps re-finitized in this way" (GIVÓN, 2016, p. 276).

9“[...] in these languages nominalizations serve as the input to the historical process of tense-aspect renewal. This allows the grammar of nominalizations to surface into main clauses, generally with an auxiliary, but sometimes not, especially in those languages that do not require a copula for all forms of nonverbal predication"(GILDEA, 2008, p. 12).
} 
Segundo Givón (2016, p. 284), “quando a antiga oração subordinada se torna a oração principal, sua morfossintaxe não finita é simplesmente transferida para a nova oração principal" ${ }^{10}$.

Um exemplo desse processo na língua Ute ocorreu com a gramaticalização da marca de passado remoto - puga REM. Tal morfema é resultante da combinação do verbo irregular de incorporação de objeto - $g a$ - 'ter' e o morfema nominalizador - $p$, como podemos observar em (136).

a. tuka-pu-ga-y eat-NMLZ-have-IMM

'(s/he) has food.'

b. tuka-puga

eat-REM

'(s/he) ate.' (GIVÓN, 2016, p. 285)

Vimos que a indicação de futuro em Wayoro se dá através de construção - $p$ 〜 $m$ 'infinitivo' seguido de nã. Vimos também que há, em Wayoro, o verbo nã 'fazer' ou 'translativo'. Argumentamos que se trata de um verbo transitivo, pois tem comportamento biargumental e pode receber morfema - $n$ 'não-futuro'. Com base nas propostas de Gildea e Givón, podemos problematizar se $-p \sim-m$ 'infinitivo' $n \tilde{a}$ seria resultante da gramaticalização de $n \tilde{a}$ 'fazer' combinado com uma nominalização com $-p$. Dessa forma, $-p \sim-m+n \tilde{a}$ usado para futuro teria sido derivado de uma construção como em (137).

(137) Hipótese para origem de $-p \sim-m+n \tilde{a}$ como expressão de futuro

a. Possível origem: combinação de nã 'fazer' ou 'transformar-se' com construção nominalizada

$\begin{array}{lrl}\text { ondoap } & \text { ñ̃ } & \text { on. } \\ \text { o-ndop-a-p } & \text { nã } & \text { on } \\ \text { 1 SG-deitar-V.T-NMLZ fazer eu } & \end{array}$

'Eu vou deitar.' [Hipotético: eu faço meu deitar]

b. Interpretação com $n \tilde{a}$ 'futuro' sincrônica

$\begin{array}{lll}\text { ondoap } & \text { nã } & \text { on. } \\ \text { o-ndop-a-p } & \text { nã } & \text { on }\end{array}$

1SG-deitar-V.T-INF FUT eu

'Eu deitarei/vou deitar' (PM-2016)

Sincronicamente, o elemento nã que ocorre nessa construção é de fato nã 'futuro' e não o verbo nã 'fazer'. Uma nominalização não permite que o verbo da construção com $-p$ tenha

\footnotetext{
10"When the erstwhile subordinate clause becomes the main clause, its non-finite morpho-syntax is simply transferred to the new main clause"(GIVÓN, 2016, p. 284)
} 
indicação de aspecto. As construções sob análise, no entanto, permitem que o verbo tenha morfema de aspecto -rara -ara 'repetição/habitual' (138a) ou - $k w a$ 'iterativo/pluracionalidade' (138b).

(138) Evidências de que construções com $-p \sim-m+n a \tilde{a}$ não são [NMLZ+V] sincronicamente

a. ondorarap nã on.

o-ndop-rara-p nã on

1SG-deitar-REP-INF FUT eu

'Eu vou deitar de novo.' (PM-2016)

b. etopkwap nã on.

e=top-kwa-p nã on

2SG=ver-ITER-INF FUT eu

'Eu vou te olhar/visitar todo dia'

c. kap toromangãm nã on, kaat on.

kap top-ro-mang-a-m nã on kaat on

PROFORMA ver-?-AUX-V.T-INF FUT eu QUOT eu

'Eu quero mandar olhar isso.' (WYR-200308-DM-PK-tratamento)

Quanto à estrutura argumental, as nominalizações admitem que o verbo intransitivo nominalizado não apresente o prefixo pessoal obrigatório, por exemplo, ndoap 'rede'. Contudo, em (138a), observa-se que o verbo aparece com o prefixo pessoal obrigatório. Em (138b), o verbo aparece com clítico de pessoa como objeto, tal como previsto para verbos transitivos.

Em (138c), podemos ver a presença do verbo auxiliar de causativização analítica mangã 'mandar', na construção com - $m$. Tal verbo auxiliar não foi registrado nas nominalizações. Outra evidência de que os dados em (138) não são sincronicamente nominalizações seguidas de $n \tilde{a}$ 'fazer' é que o elemento nã não aparece com morfema - $n$ 'não-futuro' e outros morfemas verbais, tal como seria previsto caso se tratasse de $n \tilde{a}$ verbo transitivo.

Assim, sincronicamente, não podemos afirmar que as construções nominalizadas são parte da expressão de tempo futuro. Contudo, com base em Gildea e Givón, é possível hipotetizar que nominalização e tempo futuro estejam relacionados no desenvolvimento histórico da língua.

\subsection{Nominalização de sintagma verbal (SV) via sufixo $-p \sim-m$}

Apresentaremos, nesta seção, paradigmas em que os verbos com sufixo - $p \sim-m$ apresentam comportamento de sintagma nominal. Contudo, inicialmente, provaremos que os verbos testados são, de fato, verbos, ou seja, têm comportamento morfossintático verbal esperado, no sentido de que exigem prefixos pessoais obrigatórios e permitem transitivização (se intransitivos), têm estrutura argumental, aceitam morfema de tempo e aspecto. Em seguida, mostraremos que 
o mesmo verbo, quando nominalizado via - $p \sim-m$, tem comportamento de um sintagma nominal, pois pode funcionar como objeto de outro verbo ou de uma posposição, pode ser modificado por um adjetivo ou por outro SN e é agramatical quando testado com afixos verbais.

Em (139), o verbo ngõyã 'sentar' apresenta propriedades de um verbo intransitivo, em sentença independente. Note que o verbo ngõya 'sentar' ocorre com prefixo pessoal te' 3 a pessoa correferencial' (139a) e permite os sufixos de aspecto e tempo -rara (139b) 'repetição/habitual' e -t〜-n 'não-futuro' (139a-c). Além disso, como previsto para verbos in-

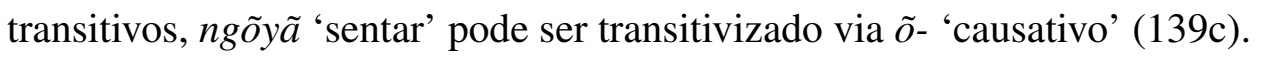

(139) Verbo ngõya 'sentar': comportamento intransitivo

a. Afixo te- $3^{\mathrm{a}}$ correferencial e sufixo - $n$ 'não-futuro'

mbogop tengõyãn.

mbogop te-ngõy-ã-n

criança 3C-sentar-V.T-NFUT

'A criança sentou.' (NOGUEIRA, 2011, p. 141)

b. Sufixo -rara 'repetição/habitual'

$\begin{array}{lll}\text { tengõyraran } & \text { ongõyãm } & \text { tere. } \\ \text { [te-ngõy-rara-n] } & \text { o-ngõy-ã-m } & \text { tere }\end{array}$

3C-sentar-REP-NFUT 1SG-sentar-V.T-NMLZ acima

'(Ele) sentou de novo na minha esteira [lit. onde se senta/para sentar].' (PM-2016)

c. Prefixo transitivizador $\tilde{o}-\sim m \tilde{o}-$

ndeke eõngõyãn.

ndeke e=õ-ngõy-ã-n

ele $2 \mathrm{SG}=\mathrm{CAUS}-$ sentar-V.T-NFUT

'Ele te sentou.' (PM-2016)

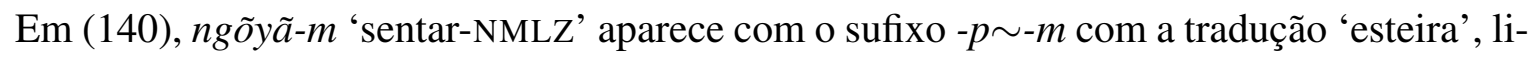
teralmente 'lugar para/onde se sentar'. Observe que ngõyãm apresenta as propriedades sintáticas e morfossintáticas de nome, podendo ocorrer como argumento objeto de verbo transitivo (140a), em uma construção possessiva (140b), como objeto de uma posposição (140c) e ser modificado por um adjetivo (140d).

(140) Verbo ngõã 'sentar' nominalizado: comportamento morfossintático de nome

a. Argumento objeto de verbo transitivo

$\begin{array}{llll}\text { ngõyãm } & \text { ningãm } & \text { nã } & \text { on. } \\ \text { [sNngõy-ã-m] } & \text { ning-ã-m } & \text { nã } & \text { on } \\ \text { sentar-V.T-NMLZ tecer-V.T-INF FUT } & \text { eu }\end{array}$

'Eu vou tecer esteira.' (MA-2015) 
b. Construção possessiva

engõyãm

e-ngõy-ã-m

2SG-sentar-V.T-NMLZ

'tua esteira' (PM-2016)

c. Argumento objeto de posposição

\begin{tabular}{|c|c|}
\hline $\begin{array}{l}\text { tengõyraran } \\
\text { te-ngõy-rara-n }\end{array}$ & 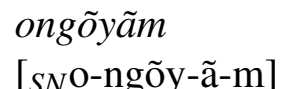 \\
\hline
\end{tabular}

3C-sentar-REP-NFUT 1SG-sentar-V.T-NMLZ acima

'Ele sentou de novo na minha esteira.' (PM-2016)

d. Modificação por um adjetivo

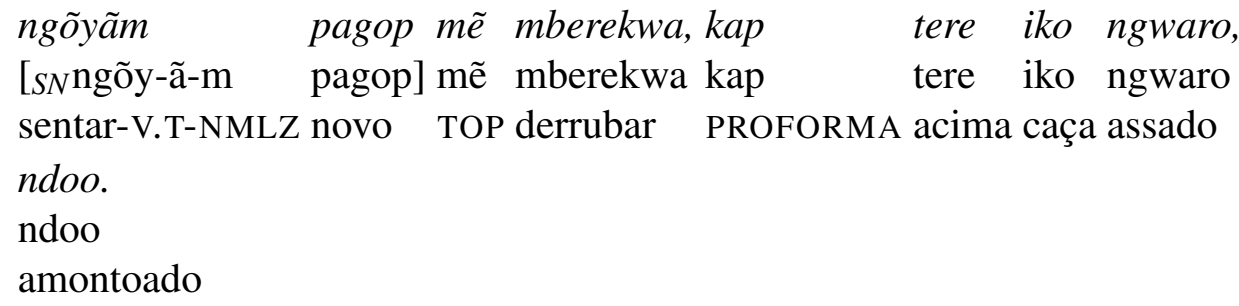

'A esteira nova, estendiam [lit. derrubavam], amontoavam a caça assada/moqueada em cima dela.' (WYR-20161007-FN-PM-MA-festa-tradic-01)

Vimos, em (139b-c), que o verbo ngõya 'sentar' permite, como previsto para verbos, o sufixo de aspecto -rara 'repetição/habitual', bem como o prefixo transitivizador $\tilde{o}$-. No entanto, os dados agramaticais em (141) e (142) mostram que, quando nominalizado, ngõyã-m 'sentarNMLZ' não aceita a inserção dos afixos verbais de aspecto e de alteração de valência.

(141) Verbo ngõyã 'sentar' nominalizado: teste de inserção de afixo verbal -rara 'repetição/repetição/habitual'
a. engõyrara e-ngõy-rara
ngõyãm
tere
2SG-sentar-REP sentar-V.T-NMLZ acima

'Senta de novo na esteira!' (PM-2016)
b. *engõya ngõyraram tere
*e-ngõy-a ngõy-rara-m tere
2SG-sentar-V.T sentar-REP-NMLZ acima

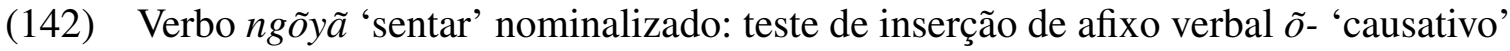
a. $e-n g \tilde{o} y \tilde{a}-m$
e-ngõy-ã-m
pagop
2SG-sentar-V.T-NMLZ novo

'Tua esteira nova' (PM-2016) 


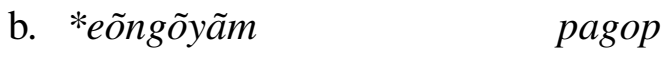

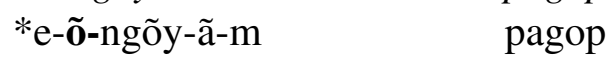

$$
\begin{aligned}
& \text { 2SG-CAUS-sentar-V.T-NMLZ novo }
\end{aligned}
$$

Comportamento semelhante pode ser observado com o verbo intransitivo ndoa 'deitar'. Em (143a-c), podemos ver que o verbo exige apenas um argumento realizado por prefixos pessoais. Os dados $(143 \mathrm{a}, \mathrm{c})$ mostram que esse verbo pode receber o sufixo de aspecto -rara 'repetição/habitual'. Os dados (143b-c) mostram que o verbo indica tempo através de $-t$ 'nãofuturo' e da construção $-p \sim-m+n \tilde{a}$ 'futuro'.

(143) Verbo ndoa 'deitar': comportamento morfossintático de verbo intransitivo

a. endorara.

e-ndop-rara

2SG-deitar-REP

'Deita de novo!' (PM-2016)

b. endoat nen?

e-ndop-a-t nen

2SG-deitar-V.T-NFUT INTERR.2

'Você está deitado?' (PM-2008)

$\begin{array}{ll}\text { c. } \begin{array}{l}\text { ondorarap } \\ \text { o-ndop-rara-p }\end{array} & \text { nã on } \\ \text { 1 SG-deitar-V.T-REP-INF } & \text { FUT eu }\end{array}$

'Eu vou deitar de novo.' (PM-2016)

Quando nominalizado, por sua vez, ndoa-p 'deitar-NMLZ' é traduzido como 'rede', literalmente 'lugar onde se dorme/para dormir'. Em (144a), ndoa-p ocorre como argumento objeto de verbo transitivo e em uma construção possessiva. Em (144b), ndoa-p 'deitar-NMLZ' ocorre como argumento objeto da posposição pi 'dentro'. Em (144c-d), ndoa-p ocorre modificado por um adjetivo e por outro $\mathrm{SN}$, respectivamente.

(144) Verbo ndoa 'deitar' nominalizado: comportamento morfossintático de nome

a. Argumento objeto de verbo transitivo e construção possessiva

$$
\begin{array}{ll}
\text { ondoap } & \text { eteia! } \\
{\left[S N^{\mathrm{O}-\text { ndop-a-p] }}\right.} & \text { ete-ip-a } \\
\text { 1SG-deitar-V.T-NMLZ } & \text { SOC-Vir-V.T }
\end{array}
$$

'Traz a minha rede!' (PM-2016)

b. Argumento objeto de posposição

$$
\begin{array}{lcl}
\text { ondoap } & \text { pi } & \text { tendorarat } \\
\text { [SNO-ndop-a-p] } & \text { pi } & \text { te-ndop-rara-t } \\
\text { 1SG-deitar-V.T-NMLZ dentro } & \text { 3C-deitar-REP-NFUT }
\end{array}
$$


'Deitaram na minha rede de novo!' (PM-2016)

c. Modificação por um adjetivo

ondoap txuир.

[SNO-ndop-a-p] txuup

1SG-deitar-V.T-NMLZ molhado

'Minha rede está molhada.' (PM-2016)

d. Modificação por um nome

$\begin{array}{lll}\text { endoap } & \text { yam toat } & \text { on } \\ \text { [SNe-ndop-a-p } & \text { yam] top-a-t } & \text { on } \\ \text { 2SG-deitar-V.T-NMLZ corda ver-V.T-NFUT eu } & \end{array}$

'Eu vi a corda da tua rede' (PM-2016)

Tal como ocorreu com o verbo ngõyã 'sentar', o teste de gramaticalidade de inserção de afixos verbais à construção nominalizada ndoa-p teve resultados agramaticais. Em (145), observa-se que ndoa-p não permite o sufixo de aspecto -rara quando usada como objeto da posposição. Em (145c-d), nota-se que ndoa-p também não admite o sufixo de aspecto -rara quando modificada por um adjetivo.

(145) Verbo ndoa 'deitar' nominalizado: teste de inserção de afixo verbal -rara 'repetição/habitual'

a. ondoap pi tendorarat!

o-ndop-a-p pi te-ndop-rara-t

1 SG-deitarV.T-NMLZ dentro 3C-deitar-REP-NFUT

'Deitaram na minha rede de novo!' (PM-2016)

b. *ondorarap pi tendoat.

*o-ndop-rara-p pi te-ndop-a-t

1SG-deitar-REP-NMLZ dentro 3C-deitar-V.T-NFUT

c. ondoap txuиp.

o-ndop-a-p txuup

1 SG-deitarV.T-NMLZ molhado

'Minha rede está molhada.' (PM-2016)

d. *ondorarap txuир.

*o-ndop-rara-p txuup

1SG-deitar-REP-NMLZ molhado

Vejamos, agora, dois casos de verbos transitivos nominalizados, taara 'ralar'/ taarap 'ralador' e toa 'ver' / toap 'espelho'. 
Confira, em (146), que o verbo taara 'ralar' tem dois argumentos e que pode receber morfemas de aspecto e tempo.

(146) Verbo taara 'ralar': comportamento morfossintático de verbo transitivo

atiti taararat on omõy nã nẽran.

atiti taat-ara-t on omõy nẽ-ã nẽran

milho ralar-REP-NFUT eu pamonha fazer-V.T novamente

'Eu estou ralando milho de novo para fazer pamonha de novo.' (PM-2016)

Observa-se, em (147), que a forma nominalizada não admite morfema de aspecto. O prefixo pessoal é interpretado como possessivo.

(147) Verbo taara 'ralar' nominalizado: teste de inserção de afixo verbal -rara 'repetição/habitual'
a. etaarap
toat
on.
$\left[{ }_{S N}\right.$ e-taat-a-p]
top-a-t
on
2sG-ralar-V.T-NMLZ ver-V.T-NFUT eu

'Eu vi teu ralador.' (PM-2016)
b. *etaararap toat on.
*e-taat-ara-p top-a-t on
2SG-ralar-REP-NMLZ ver-V.T-NFUT eu

Resultados semelhantes são obtidos com o verbo toa 'ver' e sua forma nominalizada toap 'espelho'. Em (148), o verbo toa apresenta comportamento transitivo, com clítico de pessoa como objeto e possibilidade de expressão de aspecto e tempo.

(148) Verbo toa 'ver': comportamento morfossintático de verbo transitivo

$\begin{array}{lll}\text { etorarap } & n \tilde{a} & \text { on. } \\ \text { e=top-rara-p } & \text { nã } & \text { on } \\ \text { 2sG=ver-REP-INF } & \text { FUT eu }\end{array}$

'Eu vou te ver/visitar ${ }^{11}$ de novo.' (PM-2016)

A forma nominalizada, no entanto, não permite a inserção de morfema de aspecto, como se pode observar em (149).

(149) Verbo toa 'ver' nominalizado: teste de inserção de afixo verbal -rara 'repetição/habitual'
a. etoap toat nen?
$[s N$ e-top-a-p] top-a-t nen
2SG-ver-V.T-NMLZ ver-V.T-NFUT INTERR. 2
'Você viu seu-2SG espelho?' (PM-2016)

\footnotetext{
${ }^{11} \mathrm{O}$ significado ‘visitar' para o verbo toa ‘ver' é resgistrado também em Mekens, cf. Galucio (2011, p. 33).
} 
b. etoap torarap na on.

$\left[{ }_{S N} \mathrm{e}\right.$-top-a-p] top-rara-p nã on

2SG-ver-V.T-NMLZ ver-REP-INF FUT eu

'Eu vou ver teu espelho de novo.' (PM-2016)

$$
\begin{aligned}
& \text { c. *etorarap toap nã on. } \\
& \text { [ }{ }_{S N} \text { e-top-rara-p] top-a-p nã on } \\
& \text { 2SG-ver-REP-NMLZ ver-V.T-INF FUT eu }
\end{aligned}
$$

Dessa forma, podemos ver que a construção com $-p \sim-m$ nominaliza o verbo e o argumento interno (objeto do verbo transitivo e sujeito dos verbos intransitivos, os quais são inacusativos, cf. Nogueira (2011)). Pode-se dizer que a nominalização afeta o sintagma verbal (SV), uma vez que núcleos funcionais acima do mesmo na estrutura sintática não são possíveis nas construções nominalizadas, tais como morfemas causativos/transitivizadores $\mathrm{S} v$, responsável pela inserção de argumento externo (sujeito de verbo transitivo) e núcleos de aspecto/tempo.

Os dados em (150) reforçam a ideia de que um objeto, como tuero 'chicha' e ugu 'água', em (150a-b), pode aparecer nas construções nominalizadas.
a. ugu auwap mõendop mãyã.
[sNugu au-wa-p] mõendop mãy-ã
água curar/rezar-VZR-NMLZ conhecimento contar/ensinar-V.T
'Ensinar o conhecimento de cura da água.' (WYR-20080616-AVG-ANT-Hist-agua- 023)

b. Uyã iperiat. Tuero nderap eriat.

Ũyã ip-eriat $\left[s_{N}\right.$ tuero nder-a-p] eriat

caracol ?F-dono chicha moer-V.T-NMLZ dono

'A Dona era o caracol fêmea. (Ela) é a dona do preparo da chicha.' (WYR20100326-FN-PM-caracol-02-03)

\subsubsection{Nominalização como modificador de nome inalienável}

Veremos, nesta seção, outra evidência de que a nominalização se comporta como um sintagma nominal, a saber, a nominalização pode modificar outro nome, como qualquer SN.

Segundo Nogueira (2015, p. 245), "há, na língua Wayoro, nomes obrigatoriamente possuídos ou inalienáveis, os quais sempre ocorrem precedidos por prefixo pessoal ou sintagma nominal, em relação de posse". Algumas palavras apresentam uma forma livre fonologicamente semelhante, como é o caso de ape ‘caminho' (forma presa, inalienável) e pe 'caminho' (forma livre) (151).

(151) Nomes inalienáveis: ape 'caminho'

a. Forma livre

pe 'caminho' 
b. Forma inalienável

mb-ape 'meu caminho'
1SG-caminho
*ape 'caminho'

A palavra $u g u$ 'líquido, água, rio, chuva' (152a) aparece como ngu quando em construção possessiva. Isso pode ser observado no dado (152b), em que $n g u$ é modificado pelo SN o-mãyi 'minha macaxeira'. Em (152c), verificamos que a forma inalienável $n g u$ pode ser modificada igualmente pelo verbo transitivo tuuwa 'dar à luz' nominalizado por - $p \sim-m$. A agramaticalidade em (152d) deve-se ao fato de $u g u$, quando núcleo de um sintagma nominal, dever ocorrer na forma inalienável $n g u$. Esse conjunto de dados mostra que tanto um SN não derivado, como $o$ mãa $\tilde{i}$ 'minha macaxeira', quanto um SN resultante de nominalização, $e=t u u w a-p$ 'onde deram à luz você', podem ocorrer como modificador de um nome, no caso ngu 'líquido.INAL'.

(152) Nominalização como modificador de nome inalienável: ngu 'líquido, água' (PM-2008, 2015)

a. Forma livre

Ugu 'líquido, rio, água, chuva'

b. Forma inalienável ${ }^{12}$

$\begin{array}{lll}\text { omayingu } & \text { djati, } & \text { djati. } \\ \text { [o-mayi-ngu] } & \text { dj-ati } & \text { dj-ati }\end{array}$

1SG-macaxeira-líquido.INAL 3-ardido 3-ardido

'Minha chicha [bebida fermentada] de macaxeira está azeda, está azeda.' (PMmúsica)

c. Nominalização como modificador de $n g u$

Mãkenẽan ugu ndet? [...] etuuwapngu [...]

Mãkenẽan ugu ndet [...] [e=tuup-a-p-ngu $] \quad[\ldots]$

QU.como água nome [...] 2SG=dar.à.luz-V.T-NMLZ-líquido.INAL [...]

‘Como é o nome do igarapé, o igarapé onde deram à luz você?' (WYR-19900302-

DM-PK-vida-maloca-2)

d. Agramaticalidade de $u g u$ como núcleo do sintagma possessivo

$\begin{array}{lc}* \text { Etuuwap } & \text { ugu } \\ \text { *E=tuup-a-p } & \text { ugu } \\ \text { 2SG=dar.à.luz-V.T-NMLZ líquido }\end{array}$

\footnotetext{
${ }^{12} \mathrm{~A}$ forma $n g u$ aparece ainda nos nomes dos igarapés do território tradicional Wayoro, como Ndooyangu, Perangu, Djawangu, bem como em penengu 'igapó [região da floresta amazônica que permanece alagada mesmo na estiagem dos rios (HOUAISS; VILLAR; FRANCO, 2001)]'.
} 
Vejamos como se comporta tuuwa quanto ao teste de inserção de morfema de aspecto 'repetição/habitual'. Inicialmente, devemos notar que, em (153a), tuuwa 'dar à luz' comportase como verbo transitivo biargumental. Em (153b), tal verbo ocorre com - $p$, tuuwa- $p$, nominalizado. Como vimos anteriormente, a nominalização não permite a inserção de afixos verbais, como -rara 'repetição/habitual'. O dado (153c) evidencia que a construção nominalizada tuuwa-p é agramatical quando testada com o afixo verbal -rara.

(153) Nominalização como modificador da forma inalienável $n g u$

a. tuuwa 'dar à luz': verbo transitivo

$\begin{array}{ll}\text { ngwaykup tuuwararat } & \text { on. } \\ \text { ngwaykup tuup-a-rara-t } & \text { on } \\ \text { homem dar.à.luz-V.T-REP-NFUT eu }\end{array}$

'Eu tive filho homem de novo.' (PM-2015)

b. tuuwa 'dar à luz' nominalizado via -p

Ngorip tuuwapngu

Ngorip tuup-a-p-ngu

N. dar.à.luz-V.T-NMLZ-líquido.INAL

‘água/rio onde deram à luz Ngorip’ (PM-2015)

c. Agramaticalidade da inserção de afixo verbal -rara à nominalização

*ngwaykup tuuwararapngu

*ngwaykup tuup-a-rara-p-ngu

homem dar.à.luz-V.T-REP-NMLZ-líquido.INAL

'água/rio onde deram à luz o homem.' (PM-2015)

\subsection{Subordinação via sufixo $-p \sim-m$}

O objetivo desta seção é mostrar que as formas que aparecem na construção com $p \sim-m$ complemento são itens verbais que permitem, como núcleos funcionais, sufixo de aspecto - $k w a$ 'iterativo, pluracionalidade', -rara -ara 'repetição/habitual', bem como prefixos transitivizadores $m \tilde{o}-\sim \tilde{o}$ - 'causativo' 13 e ete- 'sociativo'.

\footnotetext{
${ }^{13}$ Há línguas, como algumas línguas Tupi e Macro-Jê (como, Apinajé), que derivam um verbo intransitivo a partir da afixação de morfema causativo a adjetivos e nomes, cf. Rodrigues e Cabral (2012, p. 530-531) quanto às línguas Tupi e Oliveira (2003) sobre Apinajé — agradeço essa observação a um parecerista anônimo da proposta submetida ao Workshop on Tenselessness, University of Greenwich, 05-06 de outubro de 2017. Se este fosse também o caso em Wayoro, o morfema causativo não poderia ser considerado um argumento para distinguir nominalização de oração subordinada, pois seria uma propriedade compartilhada por verbos e nomes. Contudo, Nogueira (2011) mostra que o morfema transitivizador é de uso exclusivo de verbos intransitivos, permitindo que o sujeito se torne objeto da versão transitivizada. Consideraremos $m \tilde{o}-\sim \tilde{o}$ - 'causativo' como um núcleo funcional da oração.
} 
Os verbos identificados que tomam construções com - $p \sim-m$ como complemento, em nosso banco de dados são:

(154) Verbos registrados no corpus tomando uma oração complemento

$\begin{array}{ll}\text { Wayoro } & \text { Português } \\ \text { ndia } & \text { querer } \\ \text { toa } & \text { ver } \\ \text { ngwaynga } & \text { começar }\end{array}$

Inicialmente, mostraremos que o núcleo das construções com -p - $m$ são verbos, com estrutura argumental biargumental ou monoargumental, passíveis de serem transitivizados (se intransitivos) e de indicarem tempo e aspecto.

Notamos, em (155), que o verbo amõya 'dançar' tem comportamento de verbo intransitivo na língua, a saber, ocorre com prefixo pessoal obrigatório (155a), com morfema de aspecto (155b) e pode ser transitivizado pelo morfema causativo (155c).

(155) Verbo intransitivo amõyã 'dançar': sentença matriz (NOGUEIRA, 2011)

a. Verbo com prefixo pessoal obrigatório

mamõyãn.

m-amõy-ã-n

1SG-dançar-V.T-NFUT

'Eu dancei.'

b. Verbo com morfema de aspecto

$\begin{array}{lc}\text { mamõykwat } & \tilde{o n} . \\ \text { m-amõy-kwa-t } & \tilde{\text { onn }} \\ \text { 1 SG-dançar-ITER-NFUT eu }\end{array}$

'Eu estou dançando rápido.'

c. Verbo transitivizado

aramira mbogop mõamõyãn.

aramïra mbogop mõ-amõy-ã-n

mulher criança CAUS-dançar-V.T-NFUT

'A mulher fez a criança dançar.'

Observamos, em (156a), que, o verbo amõyã 'dançar', em contexto de oração encaixada, tem propriedades morfossintáticas semelhantes às das orações matrizes. Nota-se que o prefixo pessoal é obrigatório, tal como evidenciado pelo dado agramatical em que o prefixo pessoal está ausente (156b). Em (156c), observa-se que, em contexto de encaixamento, também é possível flexionar o verbo para aspecto repetição/habitual, via sufixo -rara -ara.

(156) Verbo intransitivo amõya 'dançar': sentença encaixada 
a. Verbo com prefixo pessoal obrigatório

on, [mamõyãm] ndiarom on

on [m-amõy-ã-m] ndia-rom on

1SG 1SG-dançar-V.T-INF querer-NEG eu

'Eu, eu não quero dançar.' (PM-2105)

b. Agramaticalidade da ausência de prefixo pessoal obrigatório

*on [amõyãm] ndiarom on

*on [amõy-ã-m] ndia-rom on

$1 \mathrm{SG}$ dançar-V.T-INF querer-NEG eu

c. Verbo com morfema de aspecto

$\begin{array}{lcc}\text { mamõyãraram } & \text { ndiarom } & \text { on. } \\ \text { [m-amõy-ã-rara-m] } & \text { ndia-rom } & \text { on } \\ \text { 1 SG-dançar-V.T-REP-INF querer-NEG eu }\end{array}$

'Eu não quero dançar de novo.' (PM-2105)

O verbo apokaya 'sair' comporta-se como verbo intransitivo: ocorre com prefixo pessoal obrigatório (157a) e com morfema transitivizador mõ- 'causativo' (157b).

(157) Verbo intransitivo apokaya 'sair': sentença matriz

a. Verbo com prefixo pessoal obrigatório

mbogop teapokaya.

mbogop te-apokay-a

criança 3C-sair-V.T

'A criança saiu.' (WYR-200308-DM-PK-origemdomundo-051)

b. Verbo transitivizado

$\begin{array}{llll}\text { txiewato } & \tilde{e} e, & \text { tximõapokaya } & \tilde{e} e . \\ \text { txi-ewato } & \tilde{e} \mathrm{e} & \text { txi-mõ-apokay-a } & \tilde{e} \mathrm{e} \\ \text { 1PL.INCL-avô DEM } & \text { 1PL.INCL-CAUS-sair-V.T DEM }\end{array}$

'Esse nosso avô, esse fez a gente sair.' (WYR-20080616-AVG-ANT-Hist1-13)

Note, em (158), que, em contexto de encaixamento, o verbo intransitivo apokaya 'sair' também pode ser transitivizado via prefixo causativo $m \tilde{o}-\mathrm{e}$, assim, pode receber clíticos de pessoa que realizam o objeto direto do verbo. Portanto, os verbos das subordinadas podem ter as mesmas possibilidades de aumento de valência que os verbos das orações matrizes.

(158) Verbo intransitivo apokaya 'sair': sentença encaixada
a. tximõapokayap
toat
on.
[txi-mõ-apokay-a-p]
top-a-t on
1 PL.INCL-CAUS-sair-V.T-INF ver-V.T-NFUT eu

'Eu vi/sei.sobre nos fazer sair.' (WYR-20080616-AVG-ANT-Hist1-02) 
Outro transitivizador da língua Wayoro é ete- 'sociativo'. Observe, em (159a), que o verbo ia 'vir' ocorre com prefixo pessoal, obrigatório em verbos intransitivos, e pode receber sufixo de tempo. Em (159b), nota-se que o verbo ia 'vir' pode ser transitivizado por ete- 'sociativo', comportando-se, então, como verbo biargumental.

(159) Verbo intransitivo ia 'vir': sentença matriz

a. Verbo com prefixo pessoal obrigatório e com morfema de tempo

poret en eiat.

poret en e-ip-a-t

agora você 2 SG-vir-V.T-NFUT

'Agora que você veio!' (PM-2012)

b. Verbo transitivizado

$\begin{array}{lll}\text { "ãa! djitogo } & \text { eteia } & \text { djat!" } \\ \text { ãa dj-i-togo } & \text { ete-ip-a } & \text { djat }\end{array}$

ITNJ 3-OBJ.NMLZ-mascar SOC-vir-V.T vocês

'[A mulher-caracol disse] "Ah! vocês estão trazendo masca [da macaxeira] dela/para ela [a chicha]!"' (WYR-20100326-FN-PM-caracol-17)

$\begin{array}{lll}\text { euwape } & \text { eteiat } & \text { on. } \\ \text { e-uwape } & \text { ete-ip-a-t } & \text { on } \\ \text { 2SG-chicha } & \text { SOC-vir-V.T-NFUT eu }\end{array}$

'Eu trouxe tua chicha (bebida fermentada)/chicha para você.' (PM-2013)

Em (160), observamos que o verbo ia 'vir' pode ocorrer em oração encaixada. Note que o verbo está transitivizado por ete- 'sociativo'. Como verbo transitivo, ete-ia 'trazer' (lit. 'vir com') recebe clítico de objeto.

(160) Verbo intransitivo ia 'vir': sentença encaixada e transitivizado por ete- sociativo

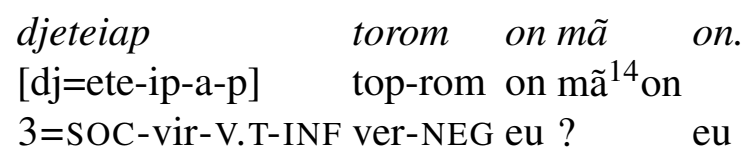

'Eu não vi (ele) trazer isso.' (WYR-200308-DM-PK-tratamentodetertuliano)

Vimos que ndoa 'deitar' é um verbo intransitivo. Como tal, recebe prefixos pessoais obrigatórios e pode indicar aspecto repetitivo e tempo futuro através da construção $-p \sim-m+n \tilde{a}$ ‘futuro', como em (161).

(161) Verbo intransitivo ndoa 'deitar': sentença independente com prefixo pessoal obrigatório e com morfemas de aspecto e tempo

\footnotetext{
${ }^{14} \mathrm{Em}$ Akuntsu, mã é descrito como partícula epistêmica com o valor de certeza (certainty) (ARAGON, 2014).
} 
$\begin{array}{lcc}\text { ondorarap } & \text { na } & \text { on. } \\ \text { o-ndop-rara-p } & \text { nã } & \text { on } \\ \text { 1 SG-deitar-REP-INF } & \text { FUT eu }\end{array}$

'Eu vou deitar de novo.' (PM-2016)

Observe, em (162), que o verbo ndoa 'deitar' como complemento do verbo toa 'ver' ocorre com os prefixos pessoais obrigatórios (162a-b) e pode receber a inserção de afixo de aspecto -rara 'repetição/habitual' (162b).

(162) ndoa 'deitar': sentença encaixada

a. Verbo com prefixo pessoal obrigatório

$\begin{array}{lll}\text { endoap } & \text { toat } & \text { on } \\ \text { [e-ndop-a-p] } & \text { top-a-t } & \text { on }\end{array}$

'Eu vi você deitar.' (PM-2016)

b. Verbo com prefixo pessoal obrigatório e com morfema de aspecto

$\begin{array}{lll}\text { endorarap } & \text { toat } & \text { on } \\ \text { [e-ndop-rara-p] } & \text { top-a-t } & \text { on } \\ \text { 2SG-deitar-REP-INF } & \text { ver-V.T-NFUT eu }\end{array}$

'Eu vi você deitar de novo.' (PM-2016)

Até o momento, vimos o comportamento dos verbos intransitivos (amõya 'dançar', apokaya 'sair', ia 'vir' e ndoa 'deitar) em contexto de oração encaixada. Em nosso banco de dados, foram registrados três verbos transitivos em construção com - $p$ - $m$ como oração complemento de outro verbo, (i) ngwíringã 'tecer/rolar' 15 como complemento do verbo transitivo ngwaynga 'começar', (ii) toa 'ver/visitar' e (iii) taara 'ralar' como complementos do verbo transitivo toa 'ver'. Os exemplos que seguem trazem tais verbos transitivos em contexto de oração subordinada. Vejamos as propriedades verbais desses itens em oração independente, para, em seguida, visualizar sua ocorrência em contexto sintático subordinado.

Em (163), observamos que o verbo ngwiring a 'tecer/rolar' é biargumental e que pode aparecer com o sufixo de tempo -n 'não-futuro'.

(163) Verbo transitivo ngwiringa 'tecer/rolar': sentença matriz
tipap nãn
$\tilde{e}$ e, Txuirika emõ ororo
ngwĩringãn
tipap nẽ-a-n
ẽe Txuirika emõ ororo ngwĩring-ã-n
avó fazer-V.T-NFUT DEM T.
ENF algodão tecer/rolar-V.T-NFUT

'Essa sogra [lit. que se tornou avó], somente Txuirika tecia mesmo [linha de] algodão.' (WYR-20100326-FN-PM-confeccao-rede-19)

\footnotetext{
${ }^{15}$ Verbo também utilizado para descrever a forma de fazer fogo no modo tradicional, rolando um pedaço de madeira com as duas mãos.
} 
Em (164), o verbo transitivo ngwĩing ã 'tecer/rolar' ocorre como núcleo do complemento do verbo ngwaynga 'começar'. Note que ocorre na sentença encaixada o SN ororo 'algodão', objeto direto do verbo ngwĩringã 'tecer/rolar'. O sujeito da sentença subordinada é correferencial ao sujeito da matriz (controlado pelo sujeito da matriz).

(164) Verbo transitivo ngwĩing ã 'tecer.algodão': sentença encaixada

$\begin{array}{llll}\text { ndeke ororo } & \text { ngwĩringãm } & \text { ngwayngap } & \text { nã. } \\ \text { ndeke [ororo } & \text { ngwining-ã-m] } & \text { ngwayng-a-p } & \text { nã } \\ \text { ele } & \text { algodão tecer/rolar-V.T-INF começarV.T-INF FUT }\end{array}$

'Ela vai começar a tecer linha de algodão/fazer linha de algodão.' (PM-2012)

Comportamento semelhante pode ser observado com o verbo transitivo taara 'ralar'. Observe, em (165a), que taara 'ralar' pode ter SN como objeto e pronome livre como sujeito. Em (165b), nota-se que, tal como os demais verbos transitivos iniciados por consoante, o objeto pode não ser realizado fonologicamente. Além disso, veja que o verbo pode receber morfema de aspecto e tempo.

(165) Verbo transitivo taara 'ralar': sentença matriz

a. atiti taarat on.

atiti taar-a-t on

milho ralar-V.T-NFUT eu

'Eu estou ralando milho.' (PM-2016)

b. taararat on.

$\emptyset=$ taat-ara- $\mathrm{t} \quad$ on

$3=$ ralar-REP-NFUT eu

'Eu estou ralando algo de novo.' (PM-2016)

O verbo taara 'ralar' como complemento oracional do verbo toa 'ver' permite a expressão do argumento objeto atiti 'milho' (166a) e a inserção de afixo de aspecto -ara 'repetição/habitual' (166b). Vale observar, em (166b-c), que o teste com a presença de pronome sujeito/argumento externo na encaixada obteve julgamento agramatical.

(166) Verbo transitivo taara 'ralar': sentença encaixada

a. Verbo com argumento objeto

$\begin{array}{lll}\text { atiti taarap toat } & \text { on } \\ \text { [atiti taar-a-p] top-a-t } & \text { on } \\ \text { milho ralar-V.T-INF ver-V.T-NFUT eu }\end{array}$

'Eu vi (você) ralando milho.' (PM-2016)

b. Verbo com morfema de aspecto 
$\begin{array}{llll}\text { atiti taararap } & \text { toat } & \text { on } \\ \text { [atiti taar-ara-p] } & \text { top-a-t } & \text { on } \\ \text { milho ralar-REP-INF } & \text { ver-V.T-NFUT eu }\end{array}$

'Eu vi (você) ralando milho de novo.' (PM-2016)

c. Agramaticalidade da presença de pronome sujeito/argumento externo da encaixada *en atiti taararap toat on.

[*en atiti taar-ara-p] top-a-t on

você milho ralar-REP-INF ver-V.T-NFUT eu

O verbo toa 'ver' também foi registrado em contexto de subordinação. Em (167), pode-se ver que, como verbo biargumental, toa 'ver' apresenta dois argumentos, o sujeito é realizado por um pronome pessoal livre e o objeto por clítico de pessoa. Além disso, o verbo pode receber morfema de aspecto - $k w a$ 'iterativo/pluracionalidade' e pode indicar tempo futuro pela expressão $-p \sim-m+n \tilde{a}$.

(167) Verbo transitivo toa 'ver': sentença matriz

$\begin{array}{lcc}\text { etopkwap } & \text { na } & \text { on. } \\ \text { e=top-kwa-p nã } & \text { on } \\ \text { 2SG=ver-ITER-INF } & \text { FUT eu }\end{array}$

'Eu vou te olhar todo dia.' (PM-2016)

Em (168), o verbo toa 'ver' ocorre como complemento do verbo ndia 'querer' e toa 'ver'. Em (168a, c), toa 'ver' tem o mesmo sujeito da sentença matriz e o objeto não é realizado fonologicamente, tal como previsto para verbos transitivos iniciados por consoante (NOGUEIRA, 2011). Em (168b), o sujeito da subordinada é o mesmo da oração matriz e o objeto é a $2^{\text {a }}$ pessoa do singular, indicada pelo clítico de pessoa $e=$. Observa-se que a estrutura argumental prevista para verbos transitivos se mantém nas orações subordinadas, com o objeto expresso por clíticos pessoais, como estudado no Capítulo 2. Em (168d), observa-se que o verbo transitivo na subordinada também pode ser usado com morfema de aspecto. Além disso, nota-se que o sujeito da subordinada em (168d) é diferente da sentença principal, uma terceira pessoa indeterminada.

(168) Verbo transitivo toa 'ver': oração subordinada
a. on toap ndiarom ndekwat. on $[\emptyset=$ top-a-p] ndia-rom ndekwat eu 3=ver-V.T-INF querer-NEG INTENS

'Eu não quero nem ver isso.' (PM-2012)

b.
etoap
ndiakwat
on.
[e=top-a-p]
ndia-kwa-t
on
$2 \mathrm{SG}=$ ver-V.T-INF querer-ITER-NFUT eu 
'Eu quero [?muito] te ver.' (PM-2016)

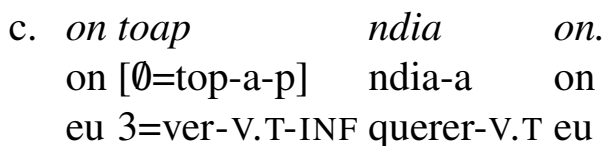

'Eu quero vê-la.' (SANTOS, 2010, p. 102)

d. otopkwap toap nã on.

[o=top-kwa-p] top-a-p nã on

$1 \mathrm{SG}=$ ver-ITER-INF ver-V.T-INF FUT eu

'Eu vou ver (quem) me visita [?muito].' (PM-2016)

A Tabela 5.2 resume o comportamento do morfema -rara -ara REP em construções com - $p \sim-m$ em contexto sintático de subordinação (em relação aos verbos matrizes ndia/toa/ngwaynga'querer/ver/começar') e em contexto de nominalização.

Tabela 5.2: morfema -rara -ara REP e verbos em subordinação e em nominalização

\begin{tabular}{|c|c|c|}
\hline & $\begin{array}{c}\text { REP E SUBORDINAÇ̃̃̃O(INF) } \\
\text { COMPL de V }\end{array}$ & $\begin{array}{c}\text { REP E NOMINALIZAÇÃO } \\
\text { COMPL de V, P/ ADJUNTO de SN }\end{array}$ \\
\hline VINTR-p (ndoa 'deitar') & Sim & Não \\
\hline VTR-p (taara 'ralar') & Sim & Não \\
\hline VTR-p (toa 'ver') & Sim & Não \\
\hline
\end{tabular}

\section{$5.53^{\mathrm{a}}$ pessoa correferencial: distinção entre orações comple- tivas dos verbos ndia 'querer' e toa 'ver'}

Nesta seção, descreveremos outro recurso que pode ser usado como teste de identificação de orações dependentes (infinitivas), a saber, $3^{a}$ pessoa correferencial te-. Há restrições de uso entre $3^{\mathrm{a}}$ pessoa correferencial e não-correferencial em verbos intransitivos que são núcleos de orações dependentes dos verbos ndia 'querer' e toa 'ver'.

Observe, a seguir, que a forma nominalizada do verbo intransitivo atoa 'banhar-se' com o sufixo - $p$ permite a ocorrência tanto do prefixo de $3^{a}$ pessoa não correferencial $y$-, como em (169), quanto da $3^{\mathrm{a}}$ pessoa correferencial te-, como em (170).

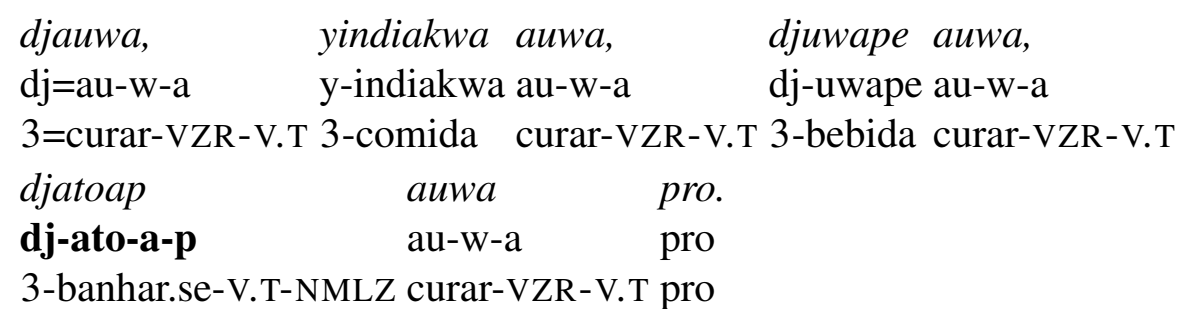


'(Ele [o marido]) está rezando/curando isso, curando a comida para ela/dela, curando a bebida dela, curando o banho dela.' (WYR-20100326-FN-PM-mulher-estrela-12)

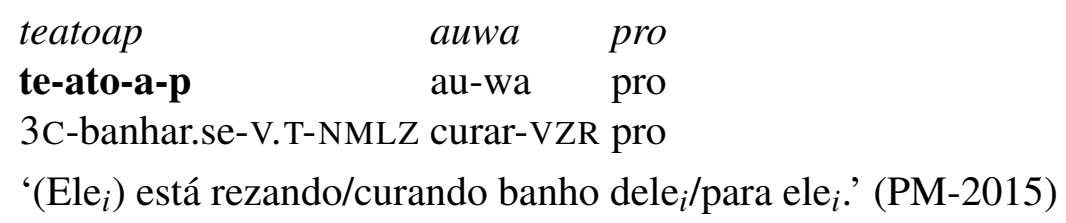

Comportamentos distintos com relação à $3^{\text {a }}$ pessoa correferencial são identificados quando a construção entre colchetes é objeto dos verbos ndia 'querer', como em (171), e toa 'ver', como em $(172)^{16}$.
Djeopõri [teatoap]
ndiakwat
Djeopõri te-ato-a-p
ndia-kwa-t
D. 3C-banhar.se-V.T-INF querer-ITER-NFUT

'Djeopõri quer tomar banho.' (PM-2017)
a. Djeopõri [djatoap]
toat.
Djeopõri dj=ato-a-p
top-a-t
D. $\quad 3$ =banhar.se-V.T-INF ver-V.T-NFUT

'Djeopõri ${ }_{i}$ viu ele $_{* i / j}$ tomando banho.' PM-2017)
b. *Djeopõri [teatoap] toat.
Djeopõri te-ato-a-p top-a-t
D. 3C-banhar.se-V.T-INF ver-V.T-NFUT

Tanto em SNs quanto em orações completivas, o prefixo de $3^{\mathrm{a}}$ pessoa correferencial teé utilizado somente como uma anáfora, coindexado a um sujeito (cf. morfema cognato em Karitiana (STORTO, 2007), em Mekens (GALUCIO, 2014a) e em Tupari (SINGERMAN, 2018)). Veremos, contudo, que, quando usado com uma oração completiva, te- apresenta restrições relacionadas ao verbo da oração matriz ${ }^{17}$. De forma resumida, temos o seguinte cenário:

- Quando o verbo da matriz é ndia 'querer', a oração completiva requer um sujeito correferencial. Assim, quando o verbo da subordinada é intransitivo, na $3^{a}$ pessoa, teé obrigatório.

- Por outro lado, quando o verbo da matriz é toa 'ver', a oração completiva requer um sujeito não-correferencial. Com um verbo intransitivo como núcleo da subordinada, na $3^{\mathrm{a}}$ pessoa, o uso de te-é agramatical.

\footnotetext{
${ }^{16}$ As sentenças gramaticais correspondentes apresentam orações coordenadas ou o auxiliar mangã 'mandar, pedir, fazer', como veremos adiante.

${ }^{17}$ Agradecemos à Profa. Dra. Esmeralda Vailati Negrão (USP) pela sugestão de investigação da presente temática, na ocasião da avaliação do Relatório de Qualificação da tese.
} 
- te-, quando afixado a um sintagma nominal/nominalização, não apresenta restrições de uso como anáforico coindexado a um sujeito.

Confira o comportamento correferencial da $3^{\mathrm{a}}$ pessoa te- como morfema possuidor em sintagma genitivo, comparando os prefixos da palavra engu 'chicha/bebida fermentada (termo inalienável)' nos exemplos (173) e (174). O uso não correferencial é indicado por $y$-, realçado no trecho do texto em (173a).
a. Yengu
ate
$k a$
pro
y-engu
ate
ko-a pro

3-chicha.INAL mesmo.assim ingerir-V.T pro

'Assim mesmo (as pessoas ${ }_{i}$ ) estão tomando a chicha dela ${ }_{j}$.'
b. Nderarap ere, "eengu korom nãm nã on". ndet-ara-p ere e-engu ko-rom nẽ-ã-m nã on moer-REP-INF em 2SG-chicha.INAL ingerir-NEG AUX-V.T-INF FUT eu 'Quando (ela) preparou (chicha) de novo, (ele disse) "Eu não vou beber tua chicha”.' (WYR-20100326-FN-PM-caracol)

Os dados em (174), por sua vez, mostram que te- é o morfema de $3^{\mathrm{a}}$ pessoa usado para indicar a correferência do objeto do verbo ou da posposição com o sujeito da sentença.

a. Raquel Gleice, ndaikut ega, teengu nderat.

Raquel Gleice ndaikut ega te-engu ndet-a-t

Raquel Gleice amanhã FRUST 3C-chicha.INAL moer-V.T-NFUT

'Raquel e Gleice prepararam a chicha delas $_{i}$, ontem.' (PM-2013)

b. Ivan tendek pi koap.

Ivan te-ndek pi kop-a-p

Ivan 3C-casa dentro ficar/estar-V.T-?

'Ivan ${ }_{i}$ está na casa dele $e_{i}$ ' (PM-2010)

Tanto Galucio (2014a) quanto Singerman (2018) argumentam que a $3^{\mathrm{a}}$ pessoa correferencial é necessariamente coindexada a um elemento nominal sujeito.

Sobre a língua Tupari, Singerman (2008, p. 46) afirma que os proclíticos $i-\sim y-\sim s-\sim \emptyset$ - não são correferenciais com o sujeito da oração, enquanto que o proclítico te- marca o argumento verbal ou possuidor nominal correferente com o sujeito de $3^{\mathrm{a}}$ pessoa ${ }^{18}$.

Quanto à distribuição da $3^{\mathrm{a}}$ pessoa, Galucio (2014a, p. 384-387) explica que, em Mekens, apesar de nas orações simples os verbos intransitivos sempre usarem a $3^{a}$ pessoa correferencial

\footnotetext{
18“"The proclitics $i-\sim y-\sim s-\sim \emptyset$ - mark nominal possessors/verbal arguments that are not co-referent with the subject of the clause; these are glossed here as ' 3 '. The proclitic te-, meanwhile, marks nominal possessors/verbal arguments that are coreferent with the third person subject" (SINGERMAN, 2018, p. 46).
} 
se-, quando há uma relação entre uma sentença dependente e independente, a $3^{\text {a }}$ pessoa não correferencial $i-\sim s$ - é usada com verbo intransitivo para indicar que os sujeitos das duas orações relacionadas não são idênticos. O prefixo se- é empregado quando há sujeitos idênticos. Tal estratégia é também registrada nos verbos auxiliares de Mekens ${ }^{19}$. Confira o funcionamento desse mecanismo na língua Mekens com o seguinte exemplo:

(175) Mekens

se-i-a te ikão i-et-a i-to-a pe=o-met.

3C-vir-V.T FOC DEM 3SG-dormir-V.T 3SG-AUX.deitado-IPFV.PASS OBL=1 SG-marido

'Ele ${ }_{j}$ veio na hora em que ele ${ }_{i}$ estava dormindo, meu marido $i$.' (GALUCIO, 2014a, p. 387)

Veremos, a seguir, que os dados de infinitivas de Wayoro corroboram a observação feita por Galucio de que a distinção entre $3^{\mathrm{a}}$ pessoa correferencial e não-correferencial é relevante em verbos intransitivos que são núcleos de orações dependentes. Tal distinção pode ser usada como recurso para identificação de orações infinitivas de controle.

\subsubsection{Verbo toa 'ver' com sintagma nominal e com orações como comple- mento}

Note que ambos os prefixos de $3^{\mathrm{a}}$ pessoa, correferencial te- e não coorreferencial $d j$-, são possíveis quando o verbo toa 'ver' toma um sintagma nominal como complemento, como se pode observar em (176).

$\begin{array}{ll}\text { a. [Catiúcia/djupipe] toat } & \text { on } \\ \text { Catiúcia/dj-upipe top-a-t } & \text { on } \\ \text { C./3-porto } & \text { ver-V.T-NFUT eu }\end{array}$

'Eu vi o porto dela/da Catiúcia.'

b. Mariazinha [teupipe] toat.

Mariazinha te-upipe top-a-t

M. 3C-porto ver-V.T-NFUT

'Mariazinha ${ }_{i}$ viu o porto dela $i / * j$ '. (PM-2017)

Vejamos como se comporta o verbo toa 'ver' quando toma um verbo transitivo e um verbo intransitivo nas sentenças encaixadas.

\footnotetext{
19 "the distribution of third person markers with transitive and intransitive verbs in simple clauses is distinct. Intransitive verbs always take the se- prefix indexing their argument, whereas transitive verbs take the $i-/ s$ - prefix. For transitive verbs and also for possessive nouns, there is always a choice between the non-coreferential and the coreferential third person forms, which is regulated by reference to the subject of the clause where the possessive noun and the pronominal object occur. For intransitive verbs, it is only in the dependent/independent clause relation that the distinction between coreferential ( $s e-)$ and non-coreferential (i-/s-) third person markers becomes relevant [grifo nosso]" (GALUCIO, 2014a, p. 387).
} 
Quando temos um verbo transitivo/transitivizado na encaixada é possível a marcação de objeto do verbo da subordinada e o sujeito da mesma é interpretado como indeterminado, como em (177).

[txi=mõ-apokay-a-p] top-a-t on

1 PL.INCL=CAUS-Sair-V.T-INF ver-V.T-NFUT eu

'Eu vi/sei.sobre nos fazer sair.' (WYR-20080616-AVG-ANT-Hist1-02)

b. otopkwap toap nã on.

[o=top-kwa-p] top-a-p nã on

$1 \mathrm{SG}=$ ver-ITER-INF ver-V.T-INF FUT eu

'Eu vou ver (quem) está me olhando/visitando sempre.' (PM-2016)

Vale lembrar que os dados com um verbo transitivo como complemento do verbo toa 'ver' também podem apresentar uma interpretação nominalizada do complemento. Dados anteriormente mencionados estão reproduzidos em (178). Será necessário investigar se é possível interpretar o prefixo pessoal como objeto do verbo da subordinada, ou seja, eu vou ver de novo (quem) visita você (178a) e eu vi (quem) ralar você (178b).

$$
\begin{aligned}
& \text { a. etoap torarap nã on. } \\
& \text { [SNe-top-a-p] top-rara-p nã on }
\end{aligned}
$$

'Eu vou ver teu espelho de novo.' (PM-2016)

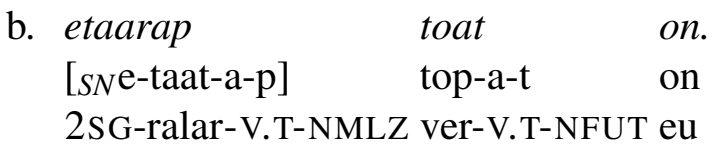

'Eu vi teu ralador.' (PM-2016)

A seguir, vejamos o comportamento do verbo intransitivo na encaixada. Note que há obrigatoriedade da estrutura argumental e impossibilidade de expressão da $3^{\text {a }}$ pessoa correferencial.

O elemento que está imediatamente antes do verbo encaixado é interpretado como sujeito do verbo encaixado, em (179), o que corrobora a hipótese de exigência de indicação da estrutura argumental nas encaixadas infinitivas ${ }^{20}$.

$$
\begin{array}{ll}
\text { a. Djeopõri [ngwaykup atoap] } & \text { toat. } \\
\text { Djeoporri ngwaykup ato-a-p } & \text { top-a-t } \\
\text { D. homem banhar.se-V.T-INF ver-V.T-NFUT }
\end{array}
$$

'Djeopõri viu o homem tomando banho.'

\footnotetext{
${ }^{20}$ Os dados com o verbo toa têm a limitação de não terem sido coletados com o morfema de aspecto repetição/habitual (outro teste usado para identificar uma infinitiva). Contudo, a referida exigência de expressão da estrutura argumental nos inclina a ver tais dados como exemplos de infinitivas.
} 
b. Djeopõri [mbatoap] toat.

Djeopõri mb-ato-a-p top-a-t

D. $1 \mathrm{SG}-$ banhar.se-V.T-INF ver-V.T-NFUT

'Djeõpõri me viu tomando banho.' (PM-2017)

c. eorap torom on.

[e-ot-a-p] top-rom on

2SG-chegar-V.T-INF ver-NEG eu

'Eu não vi você chegar.' (PM-2012)

O contexto apresentado para testar a $3^{a}$ pessoa correferencial foi: "Djeopõri está se vendo (no reflexo do rio) tomar banho". Como resultado, podemos ver que o uso de $3^{\text {a }}$ pessoa correferencial é agramatical, ao passo que o uso da $3^{\text {a }}$ pessoa não correferencial é possível como sujeito da subordinada.

a. *Djeopõri teatoap

toat.

Djeopõri te-ato-a-p

top-a-t

D. 3C-banhar.se-V.T-INF ver-V.T-NFUT

'Interpretação pretendida: Djeopõri viu ele mesmo tomando banho.'

b. Djeopõri [djatoap] toat.

Djeopõri dj=ato-a-p top-a-t

D. $\quad 3$ =banhar.se-V.T-INF ver-V.T-NFUT

'Djeopõri ${ }_{i}$ viu ele ${ }_{* i / j}$ tomando banho.' (PM-2017)

A construção fornecida como correspondente à tradução Wayoro solicitada apresenta duas sentenças coordenadas, cada uma com verbo flexionado.
Djeopõri teatoa,
kawere
ugu piri
tendaop toat.
Djeopõri te-ato-a
kap-ere
ugu pi=eri
te-ndaop top-a-t

D. 3C-banhar.se-V.T PROFORMA-em água dentro-ABL 3C-reflexo ver-V.T-NFUT

'Djeopõri estava se banhando, então ele viu a imagem dele na água.' (PM-2017)

Veremos que as infinitivas complementos do verbo toa 'ver' se comportam de maneira diferente das infinitivas complemento do verbo ndia 'querer'. Note que as construções aqui discutidas não admitem o prefixo de $3^{\text {a }}$ pessoa correferencial te-. $\mathrm{O}$ sujeito de $3^{\mathrm{a}}$ pessoa de um verbo intransitivo pode se manifestar como $d j=$, resultando em uma leitura não-correferencial. Esta restrição necessita mais investigação. Vimos que o verbo toa 'ver' aceita uma oração infinitiva (com morfema de repetição), quando os sujeitos são diferentes. ${ }^{21}$

\footnotetext{
${ }^{21}$ Repetimos aqui um dos dados relacionados a esta afirmação:
} 


\subsubsection{Verbo ndia 'querer' com sintagma nominal e com orações como complemento}

$\mathrm{O}$ verbo ndia 'querer' pode ter um sintagma nominal com $3^{\mathrm{a}}$ pessoa correferencial e não correferencial como complemento, como se nota em (182).

a. amẽko [djuwape] ndia.

amẽko dj-uwape ndia

cachorro 3-bebida querer

'O cachorro $i$ quer água dele ${ }_{j}$.'

b. amẽko [teuwape] ndiakwat.

amẽko te-uwape ndia-kwa-t

cachorro 3C-bebida querer-ITER-NFUT

'O cachorro está com sede [Lit. O cachorro $_{i}$ quer muito água dele ${ }_{i}$.].' (SANTOS, 2010, p. 105)

Com um verbo transitivo na oração encaixada, como toa 'ver', em (183), é obrigatória a interpretação de sujeito correferencial ao sujeito da matriz e é possível indicar o objeto através dos clíticos de pessoa.

$$
\begin{array}{lll}
\text { [etoap] } & \text { ndiakwat } & \text { on } \\
\text { e=top-a-p } & \text { ndia-kwa-t } & \text { on } \\
\text { 2SG=ver-V.T-INF } & \text { querer-ITER-NFUT eu } \\
\text { 'Eu quero te ver.' } & (P M-2016)
\end{array}
$$

Se o verbo da encaixada é intransitivo, como amõya 'dançar', em (184), o sujeito é correferencial ao sujeito da matriz e, portanto, na $3^{\text {a }}$ pessoa, o prefixo correferencial é obrigatório, como em (184) e (185).
on, [mamõyãm]
ndiarom on.
on [m-amõy-ã-m] ndia-rom on
eu 1 SG-dançar-V.T-INF querer-NEG eu
'Eu não quero dançar.' (PM-2016)

(185) Djeopõri [teatoap]

ndiakwat

Djeopõri te-ato-a-p

ndia-kwa-t

D. 3C-banhar.se-V.T-INF querer-ITER-NFUT

'Djeopõri quer tomar banho.' (PM-2017)

a. endorarap toat on.

[e-ndop-rara-p] top-a-t on

2SG-deitar-REP-INF ver-V.T-NFUT eu

'Eu vi você deitar de novo.' (PM-2016) 
Sujeitos da oração subordinada não-correferenciais com o sujeito da matriz resultaram em dados agramaticais. As sentenças oferecidas para expressar 'Djeopõri quer que ele/eu tome banho' apresentam o verbo auxiliar mang a 'mandar, pedir'. Veja um dos dados oferecidos em (186).
Djeopõri dj/mbatoromangã
mbopoe emõ.
Djeopõri $\mathrm{dj} / \mathrm{mb}=$ ato-ro-mangã mbopoe emõ
D. $\quad 3 / 1 \mathrm{sG}=$ banhar.se-?-AUX rápido ENF
'Djeopõri está mandando ele/eu tomar banho rápido mesmo.' (PM-2017)

O conjunto de dados discutidos nessa seção mostra que, tanto em SNs quanto em orações complemento, o prefixo de $3^{\mathrm{a}}$ pessoa correferencial te- é utilizado tão somente como uma anáfora, indexado a um sujeito. Vimos que, quando usado com uma oração completiva, teapresenta restrições relacionadas ao verbo da oração matriz.

A multifuncionalidade dos morfemas pessoais - a mesma série de prefixos pessoais marca argumento absolutivo e argumento possuidor de $\mathrm{SN}$ - pode tornar construções com $-p \sim-m$ ambíguas entre nominalizadas e construções infinitivas. Contudo, quando o prefixo pessoal é usado como argumento absolutivo sujeito de oração complemento infinitiva, há restrições de uso na $3^{\text {a }}$ pessoa correferencial (conforme seleção do verbo da matriz), ao passo que tais restrições não são encontradas nos prefixos pessoais usados como possuidores de SN.

A seguinte tabela resume as propriedades dos verbos ndia 'querer' e toa 'ver', quanto ao controle do sujeito com relação ao verbo da oração subordinada.

Tabela 5.3: Controle com os verbos matrizes ndia e toa

\begin{tabular}{l|l|l}
\hline & ndia 'querer' (MATRIZ) & toa 'ver' (MATRIZ) \\
\hline \hline SUB núcleo V trans & controle de sujeito da matriz & Não controle de sujeito da matriz \\
\hline SUB núcleo V intrans & controle de sujeito da matriz & Não controle de sujeito da matriz \\
\hline SUB. te- 3C no V intrans. & gramatical & agramatical \\
\hline
\end{tabular}

\subsection{Verbos que exigem uma oração complemento em diversas línguas}

Verbos identificados em Wayoro com orações complemento fazem parte das seguintes classes semânticas propostas por Noonan (2007): toa 'ver/saber' - de conhecimento (knowledge) e percepção imediata (immediate perception); ndia 'querer' - desiderativo (desiderative); ngwaynga 'começar' - fasais (phasal). Apresentaremos, nesta seção, diferentes estratégias morfossintáticas de Wayoro que correspondem a verbos que tomam oração como complemento em inglês ou português. 
As classes semânticas de verbos que exigem complemento frequentemente encontradas na literatura são (termos originais): utterance predicates; propositional attitude predicates; pretence predicates; commentative predicates (factives); predicates of knowledge and acquisition of knowledge; predicates of fearing; desiderative predicates; manipulative predicates; modal predicates; achievement predicates; phasal predicates (aspectuals); immediate perception predicates; negative predicates; conjunctive predicates (NOONAN, 2007, p. 121-145).

Os registros em narrativas, em (187), dos verbos mãya 'contar/ensinar' (verbo de enunciação, utterance) e ngwaktoa 'ouvir/saber/descobrir' (verbo de conhecimento e perceptivo) ocorrem com SNs como complemento que especificam seu sentido. A construção mãyã mõendop é usada para 'ensinar (lit.contar conhecimento)' e mãyã porẽto para 'narrar (lit. contar história/acontecimento)'. O significado 'saber' é ainda obtido pelo uso do SN mõendop 'conhecimento', em construção não verbal.
a. oti
omõendop
mãyã.
o-ti o-mõendop
mãy-a

1 SG-mãe 1 SG-conhecimento contar/ensinar-V.T

'Minha mãe me ensinou.' (WYR-20100326-FN-PM-confeccao-rede-02)
b. kat nẽkwat ndengut oporẽto mãyã
kat nẽ-kwa-t nde-ngut, o-porẽto mãy-ã
PROFORMA AUX-ITER-NFUT ?-PASS.DIST 1SG-história contar/ensinar-V.T
$y \tilde{a}$.
yã
mamãe

'Aquilo [as festas antigas] era assim antigamente, mamãe contava isso [história] para mim.' (PM-festa-tradicional)

c. “[...] txiporẽto

ngwaktoa?"

[...] txi-porẽto

ngwakto-a

[...] 1PL.INCL-história/acontecimento ouvir-V.T

“"[Quem] vai escutar/descobrir o que está acontecendo para nós?” (WYR20080627-FN-PM-a-chefe-das-mulheres-22)

d. kũo ngura omõendop.

kũo ngut-a o-mõendop

tucum tirar-V.T 1SG-conhecimento

'Tirar tucum, eu sei [lit. tenho/é meu conhecimento].' (WYR-20100326-FN-PMconfeccao-marico-03)

O verbo apitngwara 'esquecer' (de atitude proposicional) se comporta como verbo intransitivo, o que pode ser conferido em (188): 
a. txire txiemẽto eri txiapitngwara

txire txi-emẽto eri txi-apitngwat-a

nós 1PL.INCL-idioma ABL 1PL.INCL-esquecer-V.T

'Então nós esquecemos do nosso idioma.' (WYR-20161007-FN-PM-MA-festatradic)

b. mbapitngwarat on.

mb-apitngwar-a-t on

1SG-esquecer-V.T-NFUT eu

'Eu me esqueci.' (PM-2015)

Cada classe semântica de verbos proposta por Noonan (2007) corresponde aos verbos mais frequentes nas línguas da literatura consultada pelo autor. Contudo, cada língua apresenta suas especificidades em relação a essas classes. Por exemplo, com relação aos verbos de enunciação, Noonan (Ibid., p. 122) afirma que nem todas as línguas empregam citações indiretas, ou que elas são usadas raramente apenas ${ }^{22}$. As línguas Agta, Punjabi e Shina são citadas como exemplos. Vimos, em (187), que, em Wayoro, os registros do verbo mãya 'contar/ensinar' tem um SN como complemento. Além disso, Wayoro utiliza para citações diretas o morfema quotativo kaat, como em (189), também registrado na língua Mekens (GALUCIO, 2014b, p. 175) (Akuntsu apresenta a partícula reportativa ndap (ARAGON, 2014, p. 253)).

$$
\begin{array}{llll}
\text { ndeke “ẽe kupkuya } & \tilde{e} e \text { " } & \text { kaat, Durafogo djauwap } & \text { ere. } \\
\text { ndeke ẽe } & \text { kupkuya ẽe kaat Durafogo dj=au-w-a-p } & \text { ere }
\end{array}
$$

ele DEM raiz/veneno DEM QUOT D. $\quad 3=$ curar/rezar-VZR-V.T-INF em

'Quando Durafogo o rezou, ele falou/contou "É veneno isso, é isso".' (WYR-200308DM-PK-tratamentodetertuliano)

Como apresentado na seção 4.3.4, do capítulo 4, a semântica relacionada ao verbo modal 'ter que' é obtida através do uso do elemento enfático emõ nemõ, traduzido como o advérbio 'mesmo, realmente', como em (190).

(190) Enfático emõ 'mesmo, realmente'

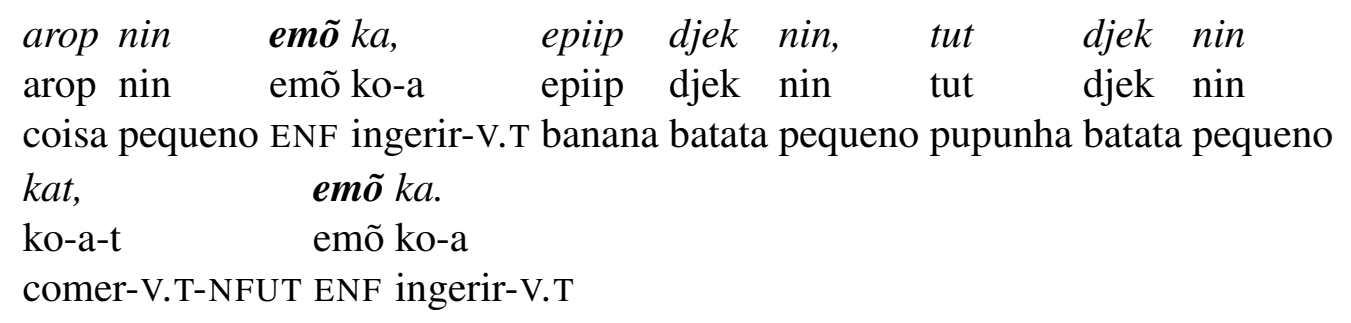

\footnotetext{
22"Not all languages employ indirect quotes, or, if they are used, they may be used only infrequently"(NOONAN, 2007, p. 122).
} 
'[Quando não existiam nossas plantas](nós) comíamos pouquinho mesmo [Lit. tínhamos que comer pouca coisa], ficávamos comendo batatinha de banana, batatinha de pupunha, tínhamos que comer.' (WYR-200308-DM-PK-origemdomundo-14)

Adicionalmente, compare o par de sentenças em (191):
a. indiakwa puga-p nã. indiakwa puga-a-p nã comida cozinhar-V.T-INF FUT

'(Ele) vai cozinhar.'
b. indiakwa emõ puga-p nã on indiakwa emõ puga-a-p nã on comida ENF cozinhar-V.T-INF FUT eu

'Eu tenho que cozinhar/Eu vou cozinhar comida mesmo.' (PM- 2010)

Dentre os elementos que expressam a semântica desiderativa, identificamos tika (seção 4.3.6, capítulo 4), o qual não foi registrado com qualquer morfema flexional e, por isso, não é classificado como verbo.
kupkuya
uraap,
yimãyãm
erroa tika.
kupkuya
uraa-a-p
y-i-mãy-ã-m
eroa tika
raiz.venenosa retirar.doença-V.T-NMLZ 3-FOC.OBJ-contar-V.T-NMLZ DEM DESID
'A cura/sugamento do veneno, ele quer que conte aquilo para ele.' (WYR-200308-DM-
PK-tratamento)

Em várias línguas, são atestadas diferenças de comportamento das orações completivas de verbos como 'parecer' (verbo de alçamento) e como 'tentar' (verbo de controle), cf. Davies e Dubinsky (2004) e Landau (2013). Assim, elicitamos a tradução para Wayoro de sentenças em que aparecem os verbos 'parecer' e 'tentar'. Os resultados obtidos mostram que elementos não verbais (ngwat 'especulativo', keromboga 'construção frustrativa') ou outro verbo do mesmo campo semântico (paretoa 'testar/experimentar') expressam o significado correspondente.

Observa-se que o morfema ngwat 'especulativo' ocorre em sentenças matrizes como elemento de modalidade epistêmica traduzido como 'parecer'. Em (193), o verbo da sentença aparece em uma construção de foco do objeto.

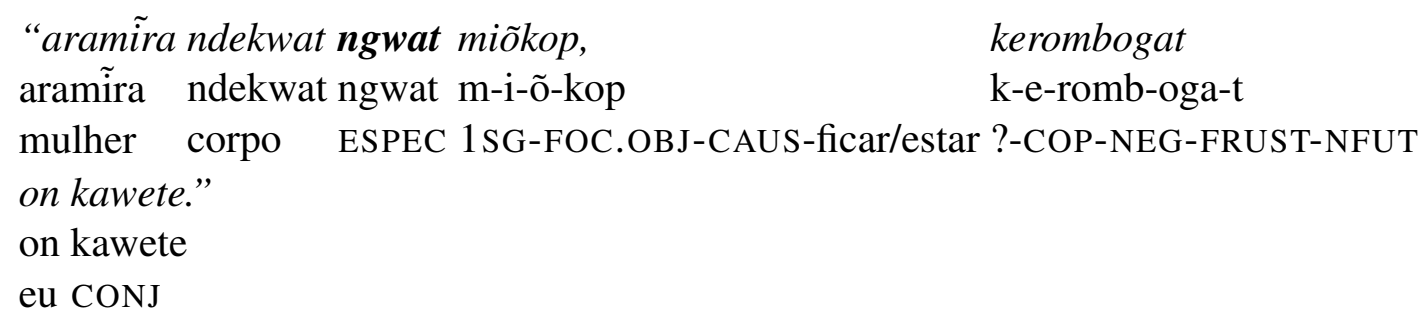


“"Parecia que eu estava morando com mulher verdadeira [corpo de mulher], mas eu não estava."” (WYR-20100326-FN-PM-caracol-42)

Morfema verbais de tempo, aspecto e o prefixo causativo são agramaticais com ngwat. Nas sentenças com ngwat, o verbo intransitivo aparece com o prefixo pessoal obrigatório e pode receber o morfema - $t$ 'não-futuro', como em (194). O verbo transitivo ocorre com SN sujeito, como Mário, em (194), e SN objeto, txi-emẽto 'nosso idioma' e pode aparecer com morfema de futuro.

(194) Elemento ngwat 'especulativo' traduzido como 'parecer'

a. Aramira teorat ngwat aramira te-ot-a-t ngwat

mulher 3C-chegar-V.T-NFUT ESPEC

'Parece que a mulher chegou' (PM-2017)

b. Txiemẽto nãm nã kaat ngwat Mário.

Txi-emẽto nẽ-a-m nã kaat ngwat Mário

1PL.INCL-idioma tornar.se/fazer--INF FUT QUOT ESPEC M.

'Mário parece que quer falar nossa língua.' (PM-2015)

Em (195), há um par mínimo em que se evidencia a diferença e o valor especulativo de ngwat.

(195) Contraste entre sentenças via adição de ngwat 'especulativo'

a. kap na on

kap nẽ-a on

PROFORMA fazer eu

'Eu vou fazer isso.' (PM-2015)

b. kap nã ngwat on

kap nẽ-a ngwat on

PROFORMA fazer ESPEC eu

'Eu acho que vou fazer isso.' (PM-2015)

O verbo 'tentar', por sua vez, foi traduzido tanto pela construção frustrativa especializada keromboga quanto pela expressão paretoa 'testar/experimentar' (cuja morfologia interna pode ser complexa, irrealis+ver/saber), como em (196) .

(196) keromboga 'frustrativo' e paretoa 'testar/experimentar' traduzidos como 'tentar'
a. Txiemẽto
nãm
txi-emẽto
nẽ-a-m
nã keromboga
nã k-e-rom-oga

1 PL.INCL-idioma tornar.se/fazer-INF FUT ?-COP-NEG-FRUST 
'(Ele) está tentando falar nossa língua [Lit. Ele vai fazer/tornar-se nosso idioma, mas não consegue].' (PM-2015)

b. memẽto paretoat on

m-emẽto pareto-a-t on

1 SG-idioma testar/experimentar-V.T-NFUT eu

'Eu estou tentando falar [Lit. Eu estou testando/experimentando meu idioma].]'

(PM-2015)

c. omõendop paretoa, omõendop paratoa, omõendop

o-mõendop pareto-a o-mõendop pareto-a o-mõendop

1SG-conhecimento testar-V.T $1 \mathrm{SG}$-conhecimento testar-V.T $1 \mathrm{SG}-$ conhecimento

parekara.

pare-kar-a

bom-VZR-V.T

'(Eu) tentava [lit. experimentava meu conhecimento], tentava [lit. experimentava meu conhecimento], até que aprendi [lit. meu conhecimento ficou bom].' (WYR20100326-FN-PM-confeccao-rede-05-06)

Dessa forma, nota-se que a elicitação de verbos cuja diferença é fundamental na literatura de Controle ('parecer') vs. Alçamento ('tentar') resultaram em sentenças traduzidas por morfemas de modalidade, construção especializada frustrativa ou por outros verbos. Será interessante coletar futuramente outros verbos de controle para comparar com ndia 'querer' 23 .

\subsection{Construções interrogativas com $-m \sim-p$}

A descrição das estratégias interrogativas da língua Wayoro é importante para a elaboração de testes que envolvem movimento de constituintes de dentro das construções com o sufixo - $m \sim-p$ quando são complementos de verbos transitivos. Até o presente, os diagnósticos de subordinação em Wayoro são exclusivamente morfossintáticos: presença de morfemas de aspecto -rara -ara 'repetição/habitual' e - $k w a$ 'iterativo/pluracionalidade'; presença de transitivizadores causativo $m \tilde{o}$ - $\sim \tilde{o}$ - e sociativo ete-; estrutura argumental e comportamento da $3^{\text {a }}$ pessoa correferencial.

É necessário combinar tais fatos com outros diagnósticos tais como os testes de extração de dentro de uma subordinada e a identificação de outros elementos (como escopo de advérbios) que possam excluir a possibilidade de se tratar de uma nominalização mais alta — ou seja, nominalização do sintagma aspectual (dada a presença de morfemas de aspecto) contendo o

\footnotetext{
${ }^{23}$ Agradeço a sugestão ao professor Dr. Marcello Modesto (USP), na ocasião de minha apresentação no XXI Encontro dos Alunos de Pós-Graduação em Semiótica e Linguística Geral, na USP, em 07 de novembro de 2018. Uma lista de verbos relacionados à distinção entre verbos de controle exaustivo e verbos de controle parcial é oferecida por Landau (2013, p. 158) e pode ser futuramente trabalhada em pesquisa de campo.
} 
$\mathrm{S} v$ (dada a presença de morfemas transitivizadores) ${ }^{24}$ e o SV (estrutura argumental do verbo) ${ }^{25}$. Para tanto, inicialmente, apresentaremos uma descrição preliminar das expressões interrogativas identificadas. Em seguida, discutiremos os resultados obtidos a partir de testes de movimento de constituintes das construções com $-m \sim-p$, focalizando a dificuldade de elicitação de sentenças bioracionais (interrogativas e declarativas).

\subsubsection{Expressões interrogativas}

Os dados em que os morfemas interrogativos nen e nẽ aparecem são construções interrogativas polares (Yes/No questions), como se observa em (197). Quando a interrogativa se refere a uma segunda pessoa, a forma nen é usado.
a. Awat ugu nen
eipait
$[\ldots]$ ?
awat ugu nen
e-i-pai-it
$[\ldots]$

vovô água INTERR.2 2SG-FOC.OBJ-encontrar-RES

‘A água do vovô [Mãkirẽy], você encontrou [Lit. foi encontrada por você]?' (WYR20080616-AVG-ANT-Hist-agua)

b. djarokwa korom nen djat?

djar-okwa ko-rom nen djat

2PL-irmão.q ingerir-NEG INTERR. 2 vocês

'Vocês não comeram o irmão de vocês?' (WYR-20080627-FN-PM-a-chefe-dasmulheres-62)
c. teatuat $\boldsymbol{n} \tilde{\boldsymbol{e}}$ ?
te-atua-t nẽ
3C-engordar-NFUT INTERR
'Ela engordou?' (PM-2013)

É provável que nen tenha relação diacrônica com o morfema de $2^{\mathrm{a}}$ pessoa do singular en, mas, sincronicamente, ocorre como marca interrogativa de $2^{\mathrm{a}}$ pessoa plural ou singular (ou seja, não marcada para número). Os dados em (198) mostram que (i) os dois morfemas, en e nen, coocorrem e (ii) nen não é obrigatório em perguntas direcionadas à segunda pessoa.

$$
\begin{aligned}
& \text { a. en endoat nen? } \\
& \text { en e-ndop-a-t nen } \\
& \text { você 2SG-deitar-NFUT INTERR.2 } \\
& \text { 'Você está deitado?' (SANTOS, 2010, p. 80) }
\end{aligned}
$$

\footnotetext{
24 "The causative component is represented by an abstract verb, little v, whose specifier is the CAUSER argument [...]" (HAEGEMAN, 2006, p. 701).

${ }^{25}$ Agradeço a sugestão ao professor Dr. Jairo Nunes (comunicação pessoal, 2017), na ocasião de minha apresentação no XX Encontro de Estudantes de Linguística da USP-ENAPOL.
} 
$\begin{array}{ll}\text { b. } & \text { etigaap } \\ \text { e=tiga-a-p } & \text { nã? } \\ \text { 2SG=pintar.corpo-V.T-INF FUT } \\ \text { 'Você vai se pintar?' (PM-2013) }\end{array}$

Nas sentenças interrogativas sobre argumentos do verbo, como em (199) registramos a expressão especializada aropkwaat para questionar argumentos objeto não humanos e apokwaat ${ }^{26}$ para questionar argumento sujeito e objeto (de posposição) humano (distribuição idêntica a das expressões interrogativas cognatas arop e apo do dialeto Guaratira, da língua Mekens, conforme Galucio (2001, p. 167)).

a. apokwaat keytoniarom, tauroti eri?

apokwaat key-to-ndia-rom tauroti eri

quem rir-?-querer-NEG jovem. $\sigma^{\prime} \mathrm{ABL}$

'Quem é que é sério [lit. não gosta de rir], desses rapazinhos?' (WYR-20080627-

FN-PM-a-chefe-das-mulheres-21)

b. Aropkwaat ugu, ugu pi etuuwap [...]

aropkwaat ugu ugu pi e=tuup-a-p pro

QU água água dentro $2 \mathrm{SG}=$ dar.à.luz-V.T-?INF pro

‘Qual é o igarapé, dentro de qual igarapé deram à luz você?' (WYR-19900302-DM-

PK-vida-maloca-1)

Interrogativas de objeto diferem das de sujeito pelo comportamento morfossintático do verbo. Em uma interrogativa de sujeito de verbo intransitivo ou transitivo e de adjunto, o verbo apresenta vogal temática e, portanto, pode ter morfemas de tempo.

a. Apokwaat teerat?

apokwaat te-et-a-t

quem 3C-dormir-V.T-NFUT

'Quem é que dormiu?' (PM-2017)

\footnotetext{
como em (a). A palavra kwaa é registrada como verbo 'parecer, ser como’, em (b). Essas expressões interrogativas são, portanto, construções complexas cuja sintaxe e morfologia deverão ser objeto de investigação aprofundada. Como tradução hipotética teríamos, mais literalmente, aropkwaat 'parece o que/qual que' e apokwaat 'parece quem que'.

a. [...] arop $\operatorname{nin}$ emõ ka.

[...] arop nin emõ ko-a

[...] coisa pequeno ENF ingerir-V.T

‘[Nós] comíamos pouca coisa.' (WYR-200308-DM-PK-origemdomundo-013)

b. on mbogop kwaat.

on mbogop kwaa-a-t

eu criança parecer-V.T-NFUT

'Eu pareço criança.' (PM-2010)
}

${ }^{26}$ Dessas duas expressões interrogativas, registramos arop como palavra isolada com sentido de 'algo, coisa', 
$\begin{array}{lll}\text { b. Apokwaat mboeri } & \text { Raquel 'uwoy djarap? } & \text { Apokwaat 'uwoy } \\ \text { apokwaat mbo=eri } & \text { Raquel 'uwoy djar-a-p } & \text { apokwaat 'uwoy }\end{array}$ quem mão=ABL R. peixe receber-V.T-?INF quem peixe yõan? yõm-a-n dar-V.T-NFUT

'Da mão de quem é que a Raquel recebeu o peixe? Quem é que deu peixe?' (PM2017)

c. Aropkwaap ere eiap nã?

Aropkwaa-p ere e-ip-a-p nã QU-?NMLZ em 2SG-vir-V.T-INF FUT

'Quando é que você vai vir?' (PM-2012)

Uma sentença interrogativa de objeto, por outro lado, tem o verbo sem vogal temática. Além disso, o prefixo $i$ - é usado para indicar o deslocamento do objeto da posição fixa Objeto-Verbo. Temos glosado o prefixo $i$ - como ‘foco do objeto' (cf. Galucio e Nogueira (2018) para uma explicação sobre o desenvolvimento histórico dessa construção). O prefixo pessoal que aparece no verbo transitivo com o prefixo $i$ - corresponde, semanticamente, ao sujeito da sentença. Lembre-se que, em uma construção não foco, os únicos prefixos/clíticos de pessoa no verbo são o objeto do verbo transitivo e o sujeito do verbo intransitivo, e não o sujeito do verbo transitivo, como observado por Galucio (2001) para a língua Mekens e Storto (2005) para outras línguas Tupi.

a. Aropkwaat e-i-top

ega?

Aropkwaat e-i-top

(ndaikut).ega

QU

2SG-FOC.OBJ-ver/saber/acontecer amanhã.FRUST

'O que é que você fez/aconteceu ontem?' (PM-2012)

b. Aropkwaat indiakwa eipek?

Aropkwaat indiakwa e-i-pek

QU comida 2SG-FOC.OBJ-querer

'Qual é a comida que você quer?' (PM-2013)

Galucio (2001, p. 169) explica tais distinções morfossintáticas relacionadas a questões de foco de objeto e de sujeito com base na ordem e nas propriedades do sintagma verbal de Mekens. A autora explica que o deslocamento do objeto para a posição inicial de pergunta violaria a restrição de adjacência e ordem linear do sintagma verbal (OV), enquanto que construções de pergunta sobre o sujeito não violariam. 


\subsubsection{Movimento de constituinte de oração completiva e a dificuldade em elicitar sentenças bioracionais}

A literatura em linguística formal prevê que o resultado do movimento para uma posição

qu$^{27}$ de um constituinte que está dentro do complemento de um nome é agramatical (compare He made the claim [that he has met Subcomandante Marcos] e *[Who] $]_{i}$ did he make the claim [that he has met $t_{i}$ ]?, exemplo extraído de Santorini e Kroch (2007)).

Nesse sentido elaboramos contextos, com base em eventos reais ocorridos na estadia em campo, para elicitar perguntas sobre constituintes que estão dentro da construção com $-p \sim-m$. Se a construção com - $p \sim-m$ for uma nominalização a extração de elementos de dentro dela será agramatical. Procedemos da seguinte maneira. Primeiro, solicitamos a tradução para Wayoro das orações declarativas correspondentes. Então, solicitamos a sentença interrogativa.

Um dos contextos criados foi:

Contexto: Djeopõri deu uma tipoia [carregador de bebê] para a filha dele. Um homem viu essa situação. Como você diria em Wayoro: 'O homem viu Djeopõri dando/dar a tipoia para a filha dele'.

As orações declarativas correspondentes a tal situação obtidas foram:

a. Djeopõritetak yam yõan.

Djeopõri te-tak yam yõm-a-n

D. 3C-filha.o' tipoia dar-V.T-NFUT

'Djeopõri deu a tipoia da/para a filha dele.' (PM-2017)

b. ngwaykup Djeopõritetak yam yõam toat.

ngwaykup Djeopõri [te-tak yam yõm-a-m] top-a-t

homem D. 3C-filha.o' tipoia dar-V.T-INF ver-V.T-INF

'O homem viu Djeopõri dar uma tipoia da/para a filha dele.' (PM-2017)

Tentou-se, então, obter a seguinte pergunta: 'Para quem o homem viu Djeopõri dar a tipoia?', com deslocamento do modificador (tetak 'filha dele') do objeto (yam 'tipoia') do verbo ( $y \tilde{a} a$ 'dar') da construção com -p - $m$. A sentença interrogativa fornecida, contudo, não apresentou oração completiva:

(203) Apokwaat mẽ Djeopõri yam yõam?

apokwaat mẽ Djeopõri yam yõm-a-m

quem para D. tipoia dar-V.T-?INF

'Para quem é que Djeopõri deu a tipoia?' (PM-2017)

\footnotetext{
27 "Wh-movement (wh-fronting or wh-preposing) is used to refer to a transformational rule which moves a whphrase (wh-XP) to initial position in the sentence" (CRYSTAL, 2008, p. 520).
} 
Outro contexto foi criado com o verbo djara 'receber' que tem como argumento indireto $X$ mboeri 'da mão de X (alguém)'. A situação foi criada a partir de uma situação real em que uma mulher recebeu peixe de seu irmão, veja:

Contexto: Raquel recebeu peixe de seu irmão Henrique. Também estava presente, no momento, um homem (que não mora na aldeia) e viu a situação. Como você diria: 'O homem viu Raquel receber o peixe do irmão dela.'

O dado declarativo obtido, apresentado em (204), envolve duas sentenças coordenadas, em que os argumentos mencionados na primeira oração são omitidos na segunda oração. A segunda oração apresenta como objeto uma construção com - $p \sim-m$. Vale observar que o argumento indireto teokwa mboeri 'da mão do irmão dela' se encontra na periferia direita da sentença:

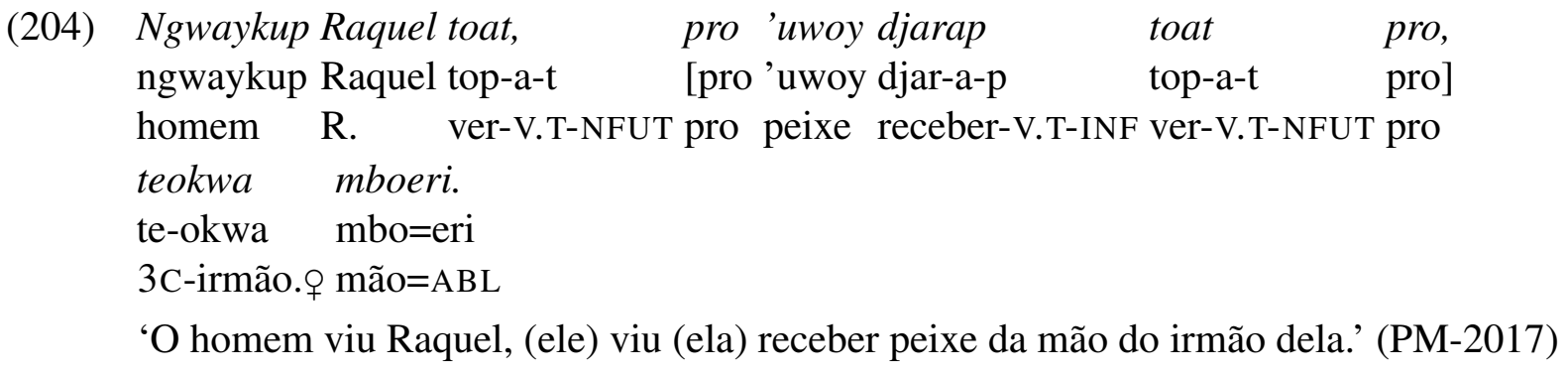

De forma semelhante aos resultados obtidos para o contexto anterior, a elicitação da interrogativa do argumento indireto resultou em sentenças interrogativas coordenadas, como se pode ver em (205).

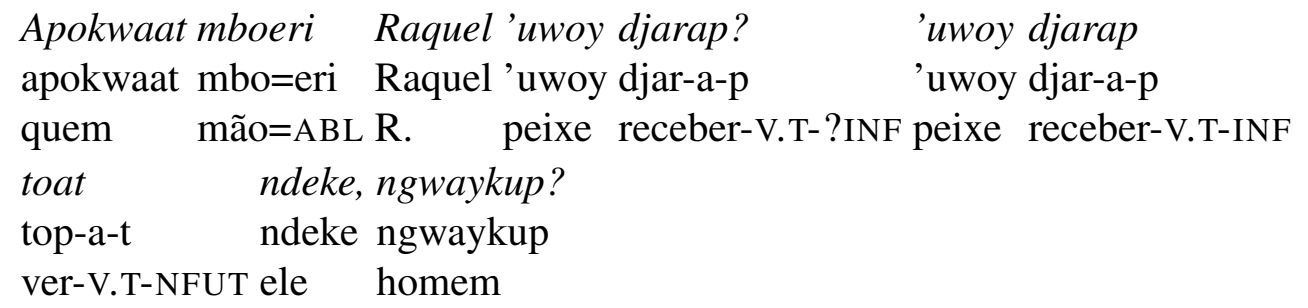

'De quem é que a Raquel recebeu o peixe? Ele, o homem, viu (ela) receber o peixe?' (PM-2017)

Dentre os problemas que podem ocorrer em uma sessão de elicitação, Bowern (2008, p. 87) menciona que é muito comum que os consultores troquem as traduções de primeira e segunda pessoas, uma vez que os referentes para 'eu' e 'você' dependem de quem está falando. Outro problema comum ocorre com a elicitação de perguntas, as quais são frequentemente respondidas, ao invés de traduzidas ${ }^{28}$.

\footnotetext{
28 "It's very common for consultants to switch first- and second-person translations. Those pronouns are shifters, the referent of ' $\mathrm{I}$ ' or 'you' is different depending on who is speaking. [...] Another common 'shifter' problem occurs with imperatives and questions. Questions are often answered rather than translated (so make it clear that you want to know how to ask questions, rather than the answers).” (BOWERN, 2008, p. 87)
} 
Com base nos resultados da aplicação de experimentos realizados para elicitação de perguntas qu- de longa distância da língua Karitiana, Vivanco (2019) alerta para dois tipos de problemas que o pesquisador pode ter para obter este tipo de dado. Um dos problemas é o fato de a sentença alvo se tratar de uma pergunta. $\mathrm{O}$ outro problema mencionado tem a ver com o fato de serem sentenças interrogativas bioracionais. Reportando-se a estudos realizados com diferentes línguas (como Mithun () para as línguas Mohawk, Gunwinggu e Kathlamet; e Legate (2011) para a língua Warlpiri), Vivanco mostra que a há uma tendência para a produção de sentenças curtas.

Ao elicitar perguntas de longa distância para a língua Wayoro, pudemos observar os dois problemas apontados por Bowern (2008) e por Vivanco (2019). Note, no dado (206), oferecido espontaneamente durante a elicitação da sentença 'Para quem o homem viu Djeopõri dar a tipoia?', que a colaboradora produz duas orações interrogativas diferentes, uma delas é uma pergunta direta a uma $2^{\mathrm{a}}$ pessoa, utilizando a marca interrogativa $n e n$.

$\begin{array}{lllll}\text { Apokwaat mẽ } & \text { teiropkwa yõam? } & \text { yõam } & \text { toat } & \text { nen? } \\ \text { Apokwaat mẽ } & \text { te-iropkwa yõm-a-m? } & \text { yõm-a-m } & \text { top-a-t } & \text { nen }\end{array}$
quem para 3C-coisas dar-V.T-?INF dar-V.T-INF ver-dar-V.T-NFUT INTERR.2 'Para quem ela deu as coisas dela? Você viu ela dar?' (WYR-201711-FN-PM-falaespontânea-5)

Vale ressaltar que os problemas apontados por Vivanco (2019), especialmente, a divisão de uma sentença bioracional em duas orações independentes, foram notados também durante a elicitação de sentenças bioracionais declarativas.

Durante a sessão de elicitação de sentenças complementos do verbo ndia 'querer', a seguinte situação foi dada:

Contexto: Chegaram pessoas desconhecidas, sujas, e pediram para tomar banho.

Djeroinĩka queria fazer as suas tarefas e queria que os homens tomassem banho rápido. Nesse contexto, como você diria: 'Djeroinika quer que os homens tomem banho rápido, 29 .

Nesse caso, a colaboradora fornece uma frase imperativa e uma sentença em primeira pessoa, com se estivesse dialogando com interlocutores. Veja:

(207) Ngwaykuwiat, djatmbopoeka, djaratoa! Ngwaykup-iat djat-mbopoe-ka djat-ato-a ongwãekut piokwap homem-PL 2PL-rápido-VZR 2PL-banhar.se-V.T 1SG-prato dentro-lavar-V.T-INF nã on. nã on FUT eu

\footnotetext{
${ }^{29} \mathrm{O}$ objetivo desta elicitação, além de verificar o complemento do verbo ndia 'querer', foi investigar o advérbio 'rápido' com escopo sobre o verbo da subordinada. O resultado, no entanto, foi uma oração, mbopoeka 'ser rápido', e não um uso como advérbio modificando a subordinada.
} 
'Homens, tomem banho, sejam rápidos! Eu quero/vou lavar meus pratos.' (PM-2017)

Mudou-se o teste para o sujeito que fala ser uma $3^{\text {a }}$ pessoa, Djeopõri. Ainda assim, a resposta foi dada em primeira pessoa, como se fosse Djeopõri falando. Por fim, realizamos a elicitação da sentença na língua Wayoro produzida por nós, para, em seguida, pedir o julgamento de gramaticalidade, sempre solicitando para a colaboradora repetir a sentença na língua Wayoro.

Na bibliografia sobre a temática é mencionada uma variação quanto à aceitabilidade dos dados de qu- de longa distância. Tal variação é demonstrada através da inclusão de uma interrogação no início da sentença trabalhada. É o que podemos observar em Adger (2003, p. 324), ao tratar da possibilidade de alçamento da qu- de objeto, em 'I asked which city which king invaded' e '? Which city did you ask which king invaded'. O autor afirma que o dado citado de qu- de objeto é considerado 'ligeiramente degradado' ${ }^{30}$ para a maioria dos falantes. O mesmo tipo de reserva pode ser notado em análises de dados de qu- de longa distância do português, como o dado '?Que poesia a Ana perguntou quando o Pedro declamou' de Marchesan (2014a, p. 85$)^{31}$.

\subsection{Produtividade e Previsibilidade Semântica}

Com respeito aos processos de formação de nomes, segundo Comrie e Thompson (2007, p. 342), as línguas tipicamente apresentam baixa previsibilidade de forma e de sentido quanto aos nomes derivados. Em Zulu, por exemplo, apesar de muitos verbos formarem nomes agentivos, como -lima 'cultivar' / um-lim-i 'agricultor', certos verbos não podem formar nomes dessa maneira (KUNENE 1974, p. 120-121 apud COMRIE; THOMPSON, 2007, p. 342).

Além disso, Comrie e Thompson (2007, p. 357) afirmam que "semanticamente, é muito comum encontrar um nome deverbal tomando significados não previsíveis e especiais pois se trata de um nome e é tão suscetível à mudança semântica idiossincrática quanto qualquer outro item lexical" 32 .

Seguindo Comrie e Thompson (2007), faz-se necessário investigar a produtividade e a previsibilidade semântica de cada construção com $-p \sim-m$. Como processo derivacional, espera-se que as nominalizações com $-p \sim-m$ tenham aplicação mais restrita que as orações subordinadas com $-p \sim-m$. Como processo sintático, espera-se que haja nas subordinadas previsibilidade semântica, ao passo que nomes deverbais podem apresentar significado imprevisível.

A lista na Tabela 5.4 mostra o verbo intransitivo, a nominalização e seu significados.

\footnotetext{
30"This example is, for most speakers slightly degraded, but it contrasts dramatically with examples where we try to move the embedded wh-subject" (ADGER, 2003, p. 324).

${ }^{31} \mathrm{O}$ uso de estímulos, como figuras (BOWERN, 2008) e encenações com fantoches (CRAIN; THORNTON, 2000), é importante para esclarecer o contexto e poderá ser aplicado em trabalhos futuros.

32 "Semantically, it is very common to find a deverbal noun taking special and unpredictable meanings precisely because it is a noun and as susceptible to idiosyncratic semantic change as any other lexical item" (COMRIE; THOMPSON, 2007, 357).
} 
Tabela 5.4: Exemplos de verbos intransitivos nominalizados em Wayoro

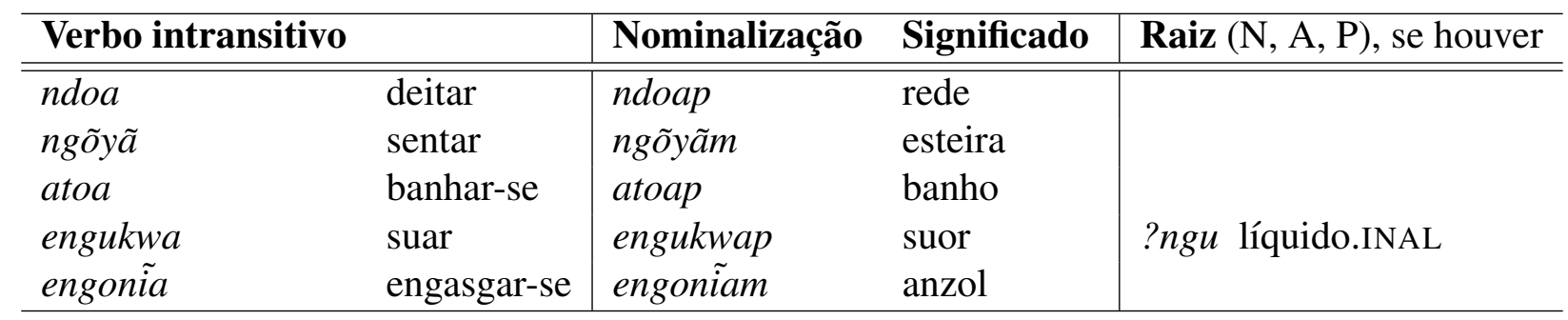

Na Tabela 5.5, há uma lista de nominalizações e seus significados, bem como os verbos transitivos com semântica correspondente ou aproximada.

Tabela 5.5: Exemplos de verbos transitivos nominalizados em Wayoro

\begin{tabular}{ll|ll|l}
\hline Verbo transitivo & & Nominalização & Significado & Raiz (N, A, P), se houver \\
\hline \hline tigaa & pintar.corpo & tigaap & genipapo & ?tiktik'cor escura' \\
kokaa & despejar & kokaap & peneira & \\
toa & ver & toap & espelho & \\
puruga & furar & purugap & furador & \\
taara & ralar & taarap & ralador & \\
uura & curar/sugar.doença & uurap & remédio & \\
\hline
\end{tabular}

Há palavras terminadas por -ap cuja raiz semanticamente correspondente (verbal ou não) não foi identificada — veja, como exemplo, ukap 'flauta' ${ }^{33}$ — ou é identificada apenas em parte com um significado aparentemente relacionado - nĩam 'tornozeleira' (?ania 'atar [rede]'), kuwoap 'machado de pedra [tradicional]' (?kup-mbo-a-p 'árvore-mão-VZR-NMZL'). Outros casos, tem uma relação semântica apenas suspeita, atua 'engordar' e atuap 'festa [?lugar/para engordar) ${ }^{34}$.

Comparemos os dados acima com o significado dos verbos nas construções com $-p \sim-m$ em ambiente subordinado ao verbo toa 'ver', na Tabela 5.6.

Tabela 5.6: Verbos testados como complemento de toa 'ver' em Wayoro

\begin{tabular}{ll|ll}
\hline Verbo & & SUB ao toa 'ver' & Significado \\
\hline \hline apokaya & sair & apokayap & sair \\
ia & vir & iap & vir \\
ndoap & deitar & ndoap & deitar \\
taara & ralar & taarap & ralar \\
toa & ver & toap & ver/visitar \\
uura & curar/sugar.doença & uurap 35 & curar \\
punkwa & atirar & punkwap & atirar \\
\hline
\end{tabular}

Observa-se que os significados dos verbos se mantêm nas construções subordinadas e se alteram nas nominalizações. Tal fato corrobora a distinção proposta entre construções com -

\footnotetext{
${ }^{33}$ Conforme Galucio (2019, comunicação pessoal), em Mekens, $u$ significa 'garganta'.

${ }^{34}$ Contraste esses dados com djap 'gordura' e djapnga 'fritar'.

${ }^{35}$ Os testes com os verbos uura 'sugar/doença' e punkwa 'atirar' são apresentados a seguir:
} 
$p \sim-m$ que resultam em SN e construções com - $p \sim-m$ oração infinitiva. No entanto, dado o fato de que a língua não mais é usada, é difícil fazer qualquer afirmação sobre o tema produtividade.

\subsection{Subordinador imperfectivo -ere}

O subordinador imperfectivo -rere -ere é claramente relacionado à posposição ere 'em' - note que a posposição pode tomar nomes, nominalizações e infinitivas como complemento. No entanto, tal posposição tem a forma invariável ere independente se o segmento final do seu complemento é uma vogal, como em Coca ere 'na Coca (aldeia)', ou uma consoante, como em ndek ere 'na casa'. O subordinador -rere - -ere, por outro lado, tem alomorfes que dependem do segmento final da raiz verbal (-rere após vogal, como em (209) e -ere após consoante, como em (210)). Este subordinador é afixado à raiz verbal diretamente, sem vogal temática para expressar relações temporais traduzidas como 'enquanto' (simultaneamente) ou 'quando', ou seja, um subordinador aspectual imperfectivo. É o que podemos constatar com o verbo intransitivo atoa 'banhar-se' (compare (208) com (209)), ndera 'moer, preparar chicha' (210) e mborekwaa 'cortar (plural)' (211).

(208) kawere ugu poret, ugu poret iih! teatoa.

kap-ere ugu poret ugu poret iih te-ato-a

PROFORMA-em água agora água agora INTJ 3C-banhar.se-V.T

'Então agora tem água, agora tem água! Eles tomam banho.' (WYR-20080616-AVGANT-Hist-agua)

(209) mbatorere, omẽpit toa.

mb-ato-rere o-mẽpit top-a

1 SG-banhar.se-SUB 1 SG-filho.

'Enquanto eu tomo banho, cuida [Lit. olha a] da minha filha.' (PM-2012)

(210) tuero nderere, ngwandap teemẽan.

tuero ndet-ere ngwandap te-emẽ-a-n

chicha moer-SUB cacique 3C-MED.conversar-V.T-NFUT

'Enquanto preparavam chicha, o cacique se combinava [com os demais].' (WYR20161007-FN-PM-MA-festa-tradic)

a. djuurarap toat ndeke.

$\mathrm{dj}=$ uut-ara-p top-a-t ndeke

$3=$ retirar.doença-REP-INF ver-V.T-NFUT ele

'Ele viu (alguém) curando/rezando ele outra vez.' (PM-2016)

b. epunkwap toat on.

$\mathrm{e}=$ punkwa-rara-p top-a-t ndeke

3=atirar-REP-INF ver-V.T-NFUT eu

'Eu vi atirarem em você [lit. te atirarem] outra vez.' (PM-2016) 
(211) on epiip mborekwarere, omẽpit teengu ndera.

on epiip mborekwa-rere o-mẽpit te-engu nder-a

eu banana cortar.PL-SUB 1SG-filho. 9 C-chicha moer-V.T

'Enquanto eu estou apanhando banana, minha filha está fazendo a chicha dela.' (PM2012)

Os dados acima evidenciam que uma oração subordinada imperfectiva preserva a estrutura argumental do verbo, ou seja, expressa o único argumento do verbo intransitivo, como se pode notar em (209); bem como os argumentos do verbo transitivo, como em (210) e (211), podendo inclusive expressar o argumento externo neste último exemplo (na ordem SOV).

Além da estrutura argumental, note que o morfema de negação pode ocorrer na subordinada imperfectiva. Em (212), note que o verbo toa 'ver' aparece na forma negada. Utiliza-se o alomorfe -rom de negação verbal, da mesma forma que se constrói a negação de verbos em sentenças matrizes, cf. (212b).

a. torom=ere, auwat nẽrom.

top-rom=ere auwat nẽ-rom

ver-NEG=SUB pajé tornar.se-NEG

'Quando [o aspirante] não vê [em sonhos], não se torna pajé.' (WYR-19900302-

DM-PK-aprend-paje-2)

b. endek mõ eorap torom on.

e-ndek mõ e-or-a-p top-rom on

2SG-casa ALA 2SG-ir-V.T-INF ver-NEG eu

'Eu não vi você ir para sua casa.' (PM-2012)

Trata-se, portanto, de uma oração subordinada de comportamento morfossintático distinto das orações subordinadas infinitivas, portanto, vamos manter glosas separadas, $-p \sim-m$ INF para subordinadas infinitivas e -rere $\sim$-ere SUB para subordinadas imperfectivas.

\subsection{Comparação entre propriedades de Nominalização e Subordinação (infinitivas)}

Assim, os verbos que aparecem nas construções com - $p \sim-m$ como complemento de outros verbos apresentam propriedades oracionais da língua Wayoro. Com relação à estrutura argumental, quando o núcleo da construção com $-p \sim-m$ é verbo intransitivo, ocorre obrigatoriamente o sujeito realizado por prefixo pessoal. Tais prefixos pessoais, diferentemente das sentenças matrizes, não se comportam como concordância, uma vez que não coocorrem com pronomes livres; são os próprios pronomes sujeitos cliticizados. Com relação aos afixos de tempo e aspecto, os verbos da oração subordinada não foram registrados com morfemas que 
indicam tempo - $t \sim-n$ 'não-futuro' e - $p \sim-m+n \tilde{a}$ 'futuro'. No entanto, podem receber sufixos de aspecto - $k w a$ 'iterativo/pluracionalidade' e -rara -ara 'repetição/habitual'. Os verbos intransitivos podem, ainda, ser transitivizados via prefixos mõ- $\sim \tilde{o}-$ 'causativo' e ete- 'sociativo', tal como nas sentenças matrizes.

As construções com - $p \sim-m$, com verbo intransitivo como núcleo, que ocorrem como $\mathrm{SN}$, se comportam de maneira diferente: não ocorrem sujeitos pronominais cliticizados, nem morfema de aspecto e transitivizadores. É possível que ocorra um pronome de pessoa possessivo. As Tabelas 5.7 e 5.8, a seguir, comparam as propriedades citadas.

Tabela 5.7: Verbos intransitivos em sentença matriz, em subordinada e em nominalização

\begin{tabular}{l|l|l|l}
\hline & VINTRANS sentença matriz & [VINTRANS- $\boldsymbol{p} \sim-\boldsymbol{m}$ ] como SUB & [VINTRANS- $\boldsymbol{p} \sim-\boldsymbol{m}$ ] como SN \\
\hline \hline Concordância & $\operatorname{Sim}$ & Não & Não \\
\hline Morfema de tempo & Sim & Não & Não \\
\hline Morfema de aspecto & $\operatorname{Sim}$ & Sim & Não \\
\hline Transitivizador & Sim & Sim & Não \\
\hline Estrutura argumental & Sim & Sim (suj. pronom.cliticizado) & Opcional (possuidor) \\
\hline
\end{tabular}

Tabela 5.8: Verbos transitivos em sentença matriz, em subordinada e em nominalização

\begin{tabular}{l|l|l|l}
\hline & VTRANS sentença matriz & [VTRANS- $\boldsymbol{p} \sim-\boldsymbol{m}$ ] como SUB & [VINTRANS- $\boldsymbol{p} \sim-\boldsymbol{m}$ ] como SN \\
\hline \hline Concordância & Não & Não & Não \\
\hline Morfema de tempo & Sim & Não & Não \\
\hline Morfema de aspecto & Sim & Sim & Não \\
\hline Transitivizador & Sim & Sim & Não \\
\hline Estrutura argumental & Sim & Sim (argumento interno) & Opcional (possuidor) \\
\hline
\end{tabular}

Consideramos que, de uma perspectiva sintática, há propriedades que nos permitem analisar as construções com $-p \sim-m$ que funcionam como complemento de verbo diferentemente das construções com - $p \sim-m$ que ocorrem como um SN. Tal diferença é capturada em Mekens, por GALUCIO (2011), pela distinção entre nominalização locativa e instrumental e nominalização de evento. Com base nos dados apresentados, analisaremos que nominalização difere de subordinação, da seguinte maneira:

- Oração subordinadas (infinitivas): construções com - $p$ - $m$ que funcionam como complemento de verbo, as quais permitem a ocorrência de propriedades oracionais, tais como núcleos de aspecto, morfema de transitivização e expressão de sujeito pronominal cliticizado ou não pronominal.

- Nominalização: construções com - $p \sim-m$ que funcionam como sintagma nominal, ou seja, podem funcionar como objeto de verbo e de uma posposição, podem modificar outro SN ou ser modificadas por um adjetivo ou outro $\mathrm{SN}$, não permitem o uso de afixos verbais e os prefixos pessoais são opcionais (e quando ocorrem são interpretados como possuidor). 
Tratamos as subordinadas com $-p \sim-m$ aqui estudadas como orações infinitivas, uma vez que elas têm propriedades oracionais, no entanto tais possibilidades são reduzidas (por exemplo, ausência de indicação de tempo). Além disso, vimos que o verbo ndia 'querer' exige que o sujeito da subordinada seja igual ao da oração matriz. Situação descrita na literatura como infinitivas de controle. 


\section{Parte II}

\section{Predicação não verbal}




\section{Predicação não verbal}

Txiiaropkwa 'aam, ngwerep iaropkwa eriat

erom. [...] kawere ngwãngwã poot ugu eriat.

Nossas coisas não existiam, mas os brancos

não são os donos das coisas. [...] Então, o

(espírito) dono da água é o camaleão antigo.

(Antônio Wajuru)

Vimos que há registros de verbos em forma nua, sem vogal temática, como ocorre em construções multiverbais e nas subordinadas imperfectivas, cf. o verbo tera 'ir' que aparece sem vogal temática em construção multiverbal em (213a) e na oração subordinada imperfectiva em (213b). A descrição e análise de dados empreendida neste capítulo nos ajudará a elucidar a seguinte questão: por que raízes verbais nuas não seriam nomes uma vez que a predicação não verbal não apresenta cópula na língua ${ }^{1}$ Nossa argumentação se baseia nas propriedades das categorias gramaticais e da cópula presente na negação em Wayoro.

a. txiewato

\section{Mãkirẽy teatoa,}

tet.

txi-ewato

Mãkirẽy te-ato-a

tet

1PL.INCL-avô.INAL Mãkirẽy 3C-banhar.se- ir

'Nosso avô Mãkirẽy se banhou, foi embora.' (WYR-20080616-AVG-ANT-Histagua-010)

b. ngemõ oterere, ombonẽrere, omẽpit indiakwapuga nge=mõ o-tet-ere, o-mbonẽ-rere, o-mẽpit indiakwa pug-a roça=ALA 1SG-ir-SUB 1 SG-trabalhar-SUB 1SG-filho.o comida cozinhar-V.T kwap.

kwap

?

'Enquanto eu vou para minha roça, enquanto eu estou trabalhando, minha filha cozinha comida.' (PM-2012)

\footnotetext{
${ }^{1} \mathrm{~A}$ mesma questão vale para as orações subordinadas infinitivas: não seriam nominalizações em predicação não verbal sem cópula? Agradeço, especialmente, à Dra. Katharina Haude, pela sugestão de desenvolvimento da temática, durante o estágio no CNRS, SeDyl, Paris-França.
} 
Dessa forma, trataremos aqui de descrever as diferenças entre verbos e as demais categorias, bem como a expressão da predicação não verbal.

Tomando como análise a amostra de dados a seguir — (214)-(217) —, poderíamos concluir que a justaposição, sem a presença de qualquer outra morfologia, é, de maneira generalizada, a estratégia sintática usada para expressar as funções semânticas de identificação/categorização, propriedade/atributo, posse e localização (também denominadas relações semânticas, em Dixon (2010)).

\section{(214) Identificação/Categorização}

a. apokwaat ngwandap? apokwaat ngwandap

QU.quem cacique

'Quem é o cacique?'

b. ndeke ngwandap.

ndeke ngwandap

ele cacique

'Ele é o cacique.' (PM-2017)

\section{(215) Propriedade/atributivo}

ugu ngwetok ondek eri.

ugu ngwetok o-ndek eri

água longe $1 \mathrm{SG}$-casa $\mathrm{ABL}$

'O igarapé é longe da minha casa.' (PM-2013)

(216) Posse

ekupe.

e-kupe

2SG-canoa

‘Sua canoa/A canoa é sua.' (PM-2013)

\section{(217) Localização}

awõpe paut ere.

awõpe paut ere

banco terreiro em

'O banco está no terreiro.' (PM-2013)

Overall, Vallejos e Gildea (2018, p. 20, tradução nossa) alertam que 
quando a justaposição é deixada de lado na expressão da predicação (não verbal), contudo, marcações de TAM podem ser exigidas. Não é surpreendente, dessa forma, que construções de justaposição frequentemente alternem com construções verbais de cópula, tipicamente condicionadas por configuração de TAM [tempo, aspecto e modo] tal como tempo não presente ou polaridade negativa. $^{2}$

Veremos que, em Wayoro, ao lado da justaposição nos predicados não verbais afirmativos, as funções/relações semânticas mencionadas fazem uso, na sentença negativa, de cópula (cobrindo as funções semânticas de identificação, propriedade e posse) ou verbo (irregular) especial, o existencial negativo (cobrindo a semântica de posse, existencial e localização). Apenas as funções semânticas de posse e existência apresentam morfologia nas sentenças afirmativas, que são expressas via o verbo irregular mbiro. A Tabela 6.1 resume tais estratégias sintáticas.

Tabela 6.1: Funções semânticas e morfemas característicos

\begin{tabular}{c|rcccc}
\hline & Identificação/categorização & Propriedade & Posse & Existencial & Localização \\
\hline \hline Afirmativa & & & mbiro & \\
\hline Negativa & $e-$ & \multicolumn{2}{c}{ '̃am } & \\
\hline & & & &
\end{tabular}

Os três morfemas identificados comportam-se como verbos irregulares, no sentido de que nunca ocorrem com vogal temática e, portanto, não recebem afixos verbais de tempo e aspecto. Ainda, não são capazes de receber morfemas de pessoa como clíticos ou prefixos. A evidência de que são verbos vem unicamente dos seus significados e do morfema de negação: $e$ - tem a semântica de 'ser, ter' e ocorre somente nas sentenças negativas, recebendo o mesmo sufixo de negação de um verbo regular (-rom); mbiro tem a semântica de 'ter, existir', ocorre nas afirmativas, e pode ser negado com -ap, morfema dedicado ao modo irrealis marcado por $n \tilde{e}$; 'ãam tem a semântica de 'negação existencial, não ter', funciona como um predicado completo e tem forma invariável ${ }^{3}$. Veremos que os verbos mbiro e 'ãam apresentam ainda comportamento e semântica de posposição (tradução aproximada como com e sem, respectivamente) e, portanto, poderiam ser vistos como verbos (irregulares) deposposicionais.

Na seção 6.1, apresentaremos evidências sintáticas da existência da cópula, seção 6.1.1, apesar do processo de assimilação regressiva total que ela pode sofrer, como será mostrado na seção 6.1.2. Procederemos da seguinte forma: primeiramente, mapearemos os tipos de

\footnotetext{
2"When juxtaposition is coopted to express (nonverbal) predication, however, TAM marking may be required. It is unsurprising, then, that juxtaposition constructions frequently alternate with verbal copular constructions, typically conditioned by TAM configurations such as non-present tenses or negative polarity"

${ }^{3}$ A negação existencial é descrita como uma forma de predicado especial em Overall, Vallejos e Gildea (2018) e há línguas em que é classificada como uma partícula, como em Hup, cf. Epps (2008, 737-741). Como explicitado em Payne (1997, p. 117, tradução nossa) algumas línguas fazem uso na construção nominal de uma partícula invariável. "Esta partícula pode derivar de um verbo ou de um pronome, mas se é invariável, ou seja, se se mantém a mesma independente da pessoa/número/gênero do sujeito, ou do tempo/aspecto da oração, então, esta forma deve ser denominada uma partícula.” Definição semelhante de partícula é oferecida em Crystal (2008, p. 352), ou seja, item invariável, com função gramatical, que, especialmente, não se encaixa facilmente nas partes do discurso padrão. Nosso argumento para tratar 'ãam como verbo tem a ver com sua semântica posposicional, sem, possivelmente sua base de formação.
} 
construções sintáticas usados para cada função/relação semântica (Identificação/Categorização na seção 6.1.3, Posse, na seção 6.1.4, Propriedade, em 6.2, Existencial, em 6.3 e Localização e Negação Existencial, em 6.4). Por fim, discutiremos em que medida o estudo de cópula e negação fornece pistas para a distinção entre nominalização e subordinação (seção 6.5).

\subsection{Predicação negativa com cópula $e$ -}

Overall, Vallejos e Gildea (2018) sugerem em seu questionário para o estudo do tema predicação não verbal, no item sobre predicação copular versus predicação não copular, que se atente para a possibilidade de, no tempo presente, não haver cópula, em contraste com a realização de cópula nos tempos passado, futuro e em sentenças negativas. Os dados em (218) mostram que a presença dos adjuntos adverbiais de tempo passado distante nẽkwat ngut ${ }^{4}(218 \mathrm{a})$, passado ndaikut ega 'ontem' (218b) e futuro nã (218c) não requer cópula para expressar a função semântica de identificação/categorização e atributo. Como previsto, no tempo presente 5 (218d) também não há cópula.

a. ndeke ngwandap nẽ kwat

ngut.

ndeke ngwandap nẽ-kwa-t ngut

ele cacique AUX-ITER-NFUT PASS.DIST

'Ele era cacique, antigamente.'

b. ndaikut ega, endukat djot.

$\begin{array}{lll}\text { ndaikut } & \text { ega } & \text { endukat djot } \\ \text { amanhã } & \text { FRUST } & \text { cocho cheio }\end{array}$

\footnotetext{
${ }^{4}$ A expressão ngut (que ocorre também como ndengut) é o marcador de passado distante (cognato a kut 'ancient past' de Tupari, cf. Singerman (2018)). Tal morfema ocorre após nẽkwat. Dessa forma, a expressão para passado distante é complexa. Apesar de não estudada em profundidade, vemos as seguintes semelhanças com outros

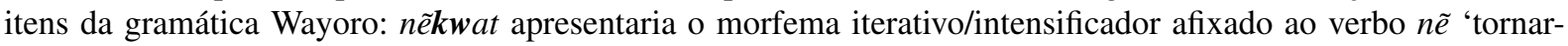
se' que funciona como verbo auxiliar para a afixação de tempo passado. nẽkwat (nde)ngut é a expressão usada nas narrativas com o sentido "antigamente, era assim" ou equivalentes (cf. exemplo (a)). Vale ressaltar, ainda, a semelhança formal e semântica com o morfema similativo nẽngan. Uma evidência de seu comportamento como verbo auxiliar é a coocorrência com a cópula, na negação, e a lenição da consoante final quando seguida por pronome iniciado por vogal (cf. exemplo (b)):
}

a. kat nẽengut oporẽto mãyã yã kat nẽ-kwa-t nde-ngut, o-porẽto mãyã yã PROFORMA AUX-ITER-NFUT ?-PASS.DIST 1SG-história contar/ensinar mamãe

'Aquilo [as festas antigas] era assim antigamente, mamãe contava isso [história] para mim.' (PM-festatradicional)

b. ondek erom nẽkwat on ngut.

$\begin{array}{ll}\text { o-ndeg=e-rom } & \text { nẽ-kwa-r=on } \quad \text { ngut } \\ 1 \mathrm{SG}-\mathrm{casa}=\mathrm{COP}-\mathrm{NEG} & \text { AUX-ITER-NFUT=eu PASS.DIST }\end{array}$

'Naquele tempo, eu ainda não tinha casa [quando cheguei na aldeia Ricardo Franco].' (PM-2013-fala espontânea)

\footnotetext{
${ }^{5}$ Devemos investigar, futuramente, nas expressões enã 'hoje' e ndaikut ega 'ontem (amanhã FRUST)', se a cópula $e$ - se faz presente.
} 
'Ontem, o cocho estava cheio.'

c. mbogop ti nãm nã .

mbogop ti nẽ-a-m nã

criança mãe AUX-V.T-INF FUT

'[Ela] vai ser mãe da criança.' (PM-2017)

d. Eñ̃a, endukat djot.

enã endukat djot

hoje cocho cheio

'Hoje, o cocho está cheio.' (PM-2013)

Por outro lado, quando o predicado não verbal está na negativa, ocorre um morfema $e$ regular, ao qual o morfema de negação é afixado (alomorfe -rom usado após raízes verbais finalizadas por vogal). É o que pode ser constatado nos dados em (219), nas funções semânticas de identificação/categorização (219a), propriedade (219b-c) e posse (219d).

a. ndeke ngwandap erom nẽkwat ngut.

ndeke ngwandap e-rom nẽ-kwa-t ngut

ele cacique COP-NEG AUX-ITER-NFUT PASS.DIST

'Ele não era cacique, antigamente.'

b. upipe ngwetok erom nẽkwat ngut.

o-upipe ngwetok e-rom nẽ-kwa-t ngut

1SG-porto distante COP-NEG AUX-ITER-NFUT PASS.DIST

'Meu porto não era longe, antigamente.'

c. ndaikut ega, ondoap tхиир erom.

ndaikut ega o-ndo-a-p txuup e-rom

amanhã FRUST 1 SG-deitar-V.T-NMLZ molhado COP-NEG

'Ontem, minha rede não estava molhada.' (PM-2013)

d. Adão tum ndet erom.

A. tum ndet e-rom

A neto. $0^{\top}$ nome COP-NEG

'A neta do Adão [ainda] não tem nome.' (PM-2012)

\subsubsection{A cópula $e$-: evidência sintática}

Os predicados não verbais formados por cópula $e^{-}$, bem como por justaposição e por verbo irregular, podem ocorrer com um verbo auxiliar capaz de se flexionar para tempo. Em (220), o predicado atributivo formado por justaposição, em que o adjetivo kam 'comprido' modifica uma 
nominalização, pode ser seguido por um verbo auxiliar para expressar o futuro, assim como o verbo irregular mbiro 'ter, existencial', em (221).

$\begin{array}{lllll}\text { ekoap } & \text { kam } & \text { nãm } & \text { ñ̃ } & \text { nen? } \\ \text { e-koa-p } & \text { kam } & \text { nẽ-a-m } & \text { nã } & \text { nen } \\ \text { 2SG-ficar/estar-NMLZ comprido AUX-V.T-INF FUT INTERR.2 }\end{array}$

'Quanto tempo você vai ficar? [Lit.Será longa a tua estadia?]' (PM-2012-falaespontânea)

a. Adão tum ndet erom.

A. tum ndet e-rom

A neto. $0^{\top}$ nome COP-NEG

'A neta do Adão [ainda] não tem nome.'

b. ndet erom, ndet mbiro nãm nã.

ndet e-rom, ndet mbiro nẽ-a-m nã

nome COP-NEG nome EXIST tornar.se-VT-INF FUT

'(Ela) não tem nome, [ainda] vai ter nome.' (PM-2010)

Em (222), a negação aparece ligada ao nome piito 'ar, descanso'. Ocorre uma assimilação completa da cópula e após a negação -rom aparece o verbo auxiliar kara com a marca de tempo não-futuro - $t$.

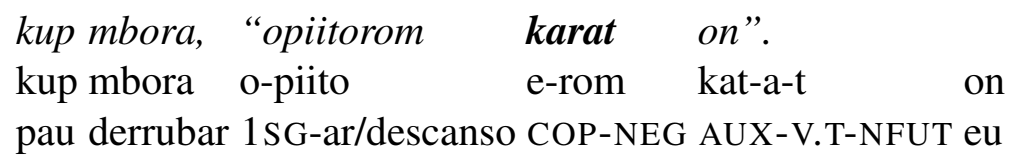

'(Ele) derrubava árvore, [depois dizia:] "eu estou cansado [Lit. Eu estou sem meu ar]”.' (PM-2016-festa-tradicional)

O dado em (222) mostra que a expressão de tempo nessa construção requer um auxiliar, distanciando-se das características da predicação verbal, que pode receber flexão de tempo na raiz verbal (assim como a impossibilidade de receber marcas de pessoa típicas de verbo também distancia o elemento $e$ - da categoria de verbos).

Overall, Vallejos e Gildea (2018, p. 4-5) enfatizam que um predicado com uma cópula verbal não cria um predicado verbal típico. Ao revisar a literatura sobre predicação não verbal, os autores reforçam a afirmação de Dixon de que o complemento de uma cópula não pode ser realizado por pronomes presos. Além disso, adicionam os autores, os complementos de cópula diferem dos argumentos nominais regulares por serem realizados abertamente por sintagmas adjetivais, adverbiais e adposicionais ${ }^{6}$. Vimos que, em Wayoro, os pronomes presos realizam o argumento absolutivo. A cópula $e$ - não ocorre com os prefixos pessoais. Compare os predicados

\footnotetext{
${ }^{6}$ Vale observar o desafio analítico à noção de predicação a que nos remete o tema da predicação não verbal, uma vez que se realizam como argumentos de predicado sintagmas que são adjuntos adverbiais e adposicionais.
} 
de posse e identificação afirmativos (223a, c) e negativos em (223b, d), os quais mostram que temos sempre sintagmas nominais como argumento da cópula.

a. ndeke ẽe mbarop.

ndeke ẽe mb-arop

3SG DEM 1SG-coisa

'Isso é meu. [Lit. Isso (aî) é minha coisa.]' (PM-2008)

b. mbarop erom.

mb-arop e-rom

1 SG-coisa COP-NEG

'Não é meu [lit. Não é minha coisa].' (PM-2013)

c. on ekip.

on e-kip

eu 2SG-irmão.mais.novo. $0^{\top}$

'Eu sou seu irmão mais novo.' (WYR-19880520-DM-PM)

d. ngwãiko on erom!

ngwãiko on e-rom

espírito eu COP-NEG

'Eu não sou bicho (espírito maligno)!' (PM-2016-fala-espontânea, em relação ao fato de algumas pessoas evitarem passar pelo caminho da casa da colaboradora.)

Optaremos por tratar $e$ - como cópula pelos seguintes motivos:

- tem o valor semântico 'ter, ser' descrito na literatura como geralmente associado a uma cópula. Segundo Dixon (2010, p. 61), "uma cópula irá sempre cobrir as relações A1, de Identidade, e/ou A2, Atribuição; frequentemente também A3, Posse, e A4, Benefactiva."

- ocorre em ambientes sintáticos previstos em Overall, Vallejos e Gildea (2018) como propícios à ocorrência de cópula.

- a expressão de tempo nessa construção requer um auxiliar, distanciando-se das características de verbos regulares, que podem receber flexão de tempo na raiz verbal.

- A cópula $e$ - não ocorre com os prefixos pessoais.

\subsubsection{A cópula $e$-: processos morfofonológicos}

Todas as consoantes finais de palavra em Wayoro podem sofrer lenição quando diante de palavra iniciada por vogal, como apresentado em Nogueira (2011). Quanto às vogais, Nogueira (2015) descreve um processo de dissimilação da vogal / $/$ / (que muda para /a/) diante de morfemas iniciados por /i/ e / $\mathfrak{t} /$. Nesta seção, descrevemos outros casos de morfofonológicos, os processos de assimilação completa envolvendo a vogal /o/ (diante de morfema iniciado por 
/o/ ou /u/), dado (224), e a vogal / $/ \varepsilon /$ diante de morfema iniciado por $/ \varepsilon /$ ou / $/ \tilde{\varepsilon} /$ ), dados em (225). Os dados estão transcritos foneticamente.

a. ӧmba:!

о̃-õmbo-a

1 SG-bater-V.T

'Me bate!' (WYR-19880629-DM-PK)

b. jõmba:t $\tilde{\text { on }}$.

n-õmbo-a-a-t õn

3-bater-V.T-?-NFUT eu

'Eu bati nele.'

c. нріре

o-upipe

$1 \mathrm{SG}-$ porto

'meu porto'

d. dzнріре

$\mathrm{d} 3$-шpipe

3-porto

'porto dela/dele/delas/deles' (PM-2017)

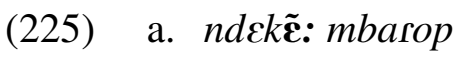

ndeke $\tilde{\varepsilon}$ : mb-arop

3SG DEM 1SG-coisa

'Isso é meu [Lit. Isso é minha coisa].'

b. ndekere

ndeke $\quad \varepsilon r \varepsilon$

$3 \mathrm{SG} \quad \mathrm{em}$

'nela [Trecho de texto: mordeu a avó dela, mordeu [aqui] nela]' (PM-2017)

A cópula $e$-, fonologicamente $/ \varepsilon /$, também sofre um processo de assimilação regressiva (processo semelhante afeta o enclítico nominativo fraco de terceira pessoa /e/ na língua Tupari Singerman (2018, p. 33)). Em (226), a cópula se assimila à vogal /ع/, em (227a), à vogal /i/, e, em (228a), à vogal posterior /o/ (Os itens b de cada exemplo mostram a realização da palavra sem assimilação).

a. $a н \beta a r=\varepsilon г \tilde{m}$, $\mathrm{a} u-\beta \mathrm{a}-\mathrm{t}=\varepsilon-\mathrm{rõm}$

paгего̃m.

curar-VZR-AG.NMLZ=COP-NEG bom COP-NEG

'Não tem pajé, não tem bom (pajé).' (WYR-19900302-DM-PK-aprend-paje-1) 

b. $m \tilde{a} k \varepsilon n \tilde{\varepsilon} \tilde{a} n[k i \ldots]$ außat
pare $n \tilde{a}$

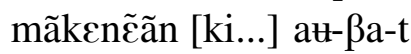
pare nã
QU.como ?
curar-VZR-AG.NMLZ bom FUT
'Como se torna um pajé excelente?' (WYR-19900302-DM-PM-aprend-paje-1)

Em Wayoro, ao que os dados (227b) e (228b) indicam, trata-se de um processo opcional.

$$
\begin{array}{ll}
\text { a. } & \text { oticoßõn } \\
\text { o-ti } \quad \text { E-rom=õn } \\
\text { 1 SG-mãe COP-NEG=eu }
\end{array}
$$

'Eu não tenho mãe.'

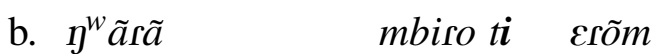

jwãrã mbiro ti $\quad \varepsilon$-rõm

listrado.horizontal com mãe COP-NEG

'A paca [Lit. a que tem listra horizontal] é órfã [Lit. não tem mãe].' (SANTOS, 2010, p. 125)

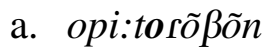

$$
\begin{array}{ll}
\text { o-pi:to } & \varepsilon \text {-rõm=õn } \\
\text { 1 SG-respiração } & \text { COP-NEG=eu }
\end{array}
$$

'Eu estou ficando cansado [Lit. não estou respirando normal].'

b. $\tilde{\sigma \eta \tilde{o}} \quad \varepsilon \varepsilon \tilde{\sigma} \beta \tilde{o}$

$\tilde{\mathrm{o}}-\mathrm{\eta} \tilde{\mathrm{o}} \quad \varepsilon$-rõm=õn

$1 \mathrm{SG}-$ criação COP-NEG=eu

'Eu não tenho minha criação.' (PM-2013)

\subsubsection{Identificação/Categorização e Negação de Identificação}

Em geral, predicados não verbais de identificação e categorização são expressos através da mesma construção (PAYNE, 1997; OVERALL; VALLEJOS; GILDEA, 2018), não havendo, por exemplo, nenhuma língua sul americana descrita como dispondo de construções diferentes para essas duas funções semânticas, como afirmam Overall, Vallejos e Gildea (2018, p. 7). Os predicados de categorização são denominados por Payne (1997) como proper inclusion. Payne (Ibid., p. 114, tradução nossa) explica que nos predicados de inclusão propriamente dita (proper inclusion) afirma-se "que uma entidade específica faz parte da classe de itens especificados no predicado nominal". Overall, Vallejos e Gildea (2018) lembram que a única diferença estaria na definitude do SN predicado: "o predicado de identificação é definido/referencial, enquanto que o predicado de categorização é indefinido/não-referencial"(Ibid., p. 7, tradução nossa).

Os exemplos abaixo mostram dados em que ocorrem as funções semânticas de identificação e categorização (ou Proper Inclusion), em sentença afirmativa e negativa. 
(229) Identificação

kawere ngwãngwã poot ugu eriat

kap-ere camaleão velho água dono

PROFORMA-em camaleão velho água dono

'Então, o [espírito] dono da água é o camaleão velho.' (WYR-20080616-AVG-ANTHist-agua)

(230) Categorização (Proper Inclusion)

awi kupndiiriat

awi kupndiit-iat

pai mato-PL

'Papai é do subgrupo dos Kupndiiriat.' (Pk-2003-casamentos)

Se os exemplos na afirmativa não apresentam qualquer morfologia entre os elementos, os exemplos em (231) e (232) mostram que, na negativa, os predicados não verbais de Identificação/Categorização requerem a cópula $e$ -

\section{(231) Negação de identificação}

a. $\operatorname{txin\tilde {o}}$ erom

txi-nõ e-rom

1 PL.INCL-outro COP-NEG

'Não é nosso parente (em referência aos grupos Wari').' (PM-2012)

b. aipoy erom

e-ipoj e-rom

2SG-tia.INAL COP-NEG

‘(Ela) não é sua tia.' (WYR-20080617-FN-MA-PM-fala-espontânea)

(232) Negação de Categorização

kawate aramira erom poren.

kap-ate aramira e-rom pot=en

CONJ mulher COP-NEG ?PEJORATIVO=você

‘(Ele disse:) “Mas você não é uma mulher”.' (WYR-20100326-FN-PM-caracol-48)

\subsubsection{Posse e Negação da Posse}

Um sintagma nominal possessivo é construído a partir da justaposição de nomes Possuidor+Possuído. O prefixo de pessoa funciona como possuidor nos sintagmas nominais possessivos. Um SN possessivo pode funcionar como objeto de um verbo transitivo, como o SN emen 
'seu marido', objeto do verbo ombaa 'matar', em (233a), mas também como um predicado completo, como em (233b).

a. ndaikut, en emen ombaa.

ndaikut, en e-men ombo-a-a

amanhã, você 2sG-marido bater/matar-V.T-?

'Amanhã, você mata seu marido.'

b. ekupe.

e-kupe

2sG-canoa

'A canoa é sua/Sua canoa.' (PM-2013)

Note, nos dados em (234), que, na negação de um SN possessivo, a cópula $e$ - aparece com o sentido 'ser, ter'.
a. emen erom?
e-men e-rom
2SG-marido COP-NEG
'Você não tem marido?'

b. omen erom on

o-men e-rom on

$1 \mathrm{SG}-$ marido COP-NEG eu

'Eu não tenho marido.' (WYR-20080617-FN-MA-PM fala-espontânea)

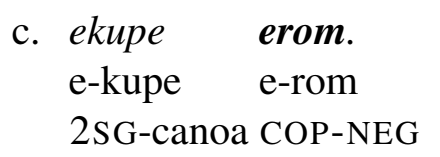

'A canoa não é sua.' (PM-2013)

\subsection{Propriedade e Negação de Propriedade: Adjetivo vs. Nome vs. Verbo}

Em Wayoro, a morfologia verbal é rica e por si só é capaz de distinguir verbos de nomes e adjetivos (NOGUEIRA, 2015). Por outro lado, há poucos morfemas usados exclusivamente com nomes, como o morfema de plural -iat e o quantificador pite. Tal quantificador ocorre como um modificador de nomes, tanto aqueles semanticamente massivos, quanto aqueles semanticamente contáveis ${ }^{7}$. Os dados em (235) mostram o comportamento de pite com nome

\footnotetext{
${ }^{7}$ Informação baseada nos dados coletados no âmbito do projeto A typology of count, mass and number in brasilian languages, organizado por Suzi Lima e Susan Rothstein.
} 
(no caso, um nome inalienável), (235a), e com nominalização (235b). O dado agramatical, em (235c) reforça a diferença entre nomes e adjetivos. Para intensificação de um adjetivo usado como predicativo é utilizada a expressão especializada ndekwat (que também expressa 'realmente, verdadeiramente').

a. mengu pite.

m-engu pite

1SG-chicha.INAL QUANT

'Minha chicha é/tem muita ou Tem/é muita chicha.' (PM-2013)

b. ombo nãm pite.

o-mbo nẽ-a-m pite

1 SG-mão fazer/tornar.se-V.T-NMLZ QUANT

'Eu tenho muito trabalho.' (PM-2013)

c. mbakara *pite/ndekwat

mb-akara *pite/ndekwat

1SG-grande QUANT/INTENS

'Eu sou/estou muito gorda.' (PM-2013)

Quanto ao comportamento de pronomes e prefixos/clíticos pessoais com nomes e adjetivos, observamos padrões que ora se assemelham ora se diferenciam, em construções afirmativas e negativas. Tais diferenças, contudo, evidenciam a existência das categorias de adjetivos, nomes e verbos.

As palavras adjetivais são um pequeno grupo ${ }^{8}$. Uma lista de adjetivos (não exaustiva) é apresentada na Tabela $6.2^{9}$.

Vale acrescentar que há adjetivos cujo sentido contrário é realizado lexicalmente, como akara 'largo, gordo' e anõakup 'magro', e há aqueles cujo sentido antônimo é obtido através da negação, como ngwetok 'longe' e ngwetok e-rom 'perto [longe COP-NEG]'.

\footnotetext{
oração complemento, marcada com o infinitivo - $p$, como se observa nas glosas dos exemplos.

a. pakori djut aramira toap.ndia. pakori djut aramira top-a-p.ndia lua nova mulher ver-V.T-INF.querer 'Lua nova é mulher bonita.' (WYR-20100326-FN-PM-mulher-estrela-01)

b. paokwap toap.ndia. abanador top-a-p.ndia abanador ver-V.T-INF.querer 'abanador bonito/Quer-se ver o abanador.' (NOGUEIRA, 2015, p. 241)
}

${ }^{8} \mathrm{Em}$ adição aos itens da lista, trataremos a palavra toap.ndia 'bonito' (bem como kap.ndia 'gostoso') como uma única forma por ocorrer como modificador de nome, como no exemplo (a-b). São necessários, contudo, testes de inseparabilidade para que essa análise se mantenha, pois tal forma é constituída por um verbo principal e uma

${ }^{9}$ Há itens dessa lista que apresentam cognatos em várias línguas Tupi, por exemplo 'quente', 'frio', 'pequeno', 'seco', cf. Galucio et al. (2015). 


\begin{tabular}{l|l} 
Akara & largo, grande, gordo \\
Akop & quente \\
Anõakup & magro \\
Ati & ardido, doloroso \\
Atiget & feio, amedrontador \\
Atik & liso \\
Kam & comprido \\
Kodji & velho. \\
Kun & reto \\
Ngwem & ruim \\
Ngwetok & distante, longe \\
Nun & estreito \\
Pagop & novo \\
Pare & bom \\
Pawa & seco \\
Pitiik & frio \\
Poot & velho. ${ }^{7}$ \\
Pooti & pesado \\
Tiap & feliz, alegre \\
Txuup & molhado \\
Yãngã & ativo
\end{tabular}

Tabela 6.2: Lista não exaustiva de adjetivos em Wayoro

\subsubsection{Adjetivos vs. Nomes}

Nosso principal argumento para distinguir nomes e adjetivos como duas categorias gramaticais é a referida distribuição de pronomes e clíticos/prefixos com cada uma delas. Os testes sobre categorias gramaticais aqui apresentados foram baseados nas generalizações sobre as diferenças entre as categorias gramaticais atestadas em outras línguas da subfamília Tupari, especialmente em Mekens (GALUCIO, 2001). Assim, uma maneira de distinguir nomes e adjetivos é a possibilidade de coocorrência com pronomes livres: adjetivos permitem tal coocorrência (236a), ao passo que os nomes não a permitem ${ }^{10}$, como em (236b-c).

$$
\begin{aligned}
& \text { a. etxuup (en). } \\
& \text { e-txuup en } \\
& \text { 2sG-molhado você } \\
& \text { 'Você está molhado.' (PM-2008) }
\end{aligned}
$$

\footnotetext{
${ }^{10} \mathrm{~A}$ ocorrência de pronomes livres junto com nomes em sintagma possessivo foi registrada exclusivamente com esses pronomes na primeira posição. Elementos como tópico e foco ocupam a primeira posição e são típicos de ocorrerem na periferia esquerda, nas línguas do mundo (cf. Storto (2014a)). É interessante notar ainda que tais dados tem o NP modificado por um quantificador (geralmente usado de forma enfática, com entonação ascendente).
}

(1) on, omẽpit pite.

on o-mẽpit pite

eu $1 \mathrm{SG}$-filho.? QUANT

'Quanto a mim, eu tenho muitos filhos!' (PM-2010) 
b. eapitep

e-apitep

2sG-orelha

'tua orelha.'

c. *eapitep en

e-apitep en

2sG-orelha você

'Interpretação pretendida: tua orelha.' (NOGUEIRA, 2015, p. 249)

Outra afirmação que pode ser feita com relação à distinção entre nomes e adjetivos é o fato de adjetivos não poderem ser núcleo de argumento de verbo. Veja, em (237), que o adjetivo akara 'largo, grande' pode ser núcleo de um predicado atributivo. Em (238), vemos esse mesmo adjetivo usado como modificador (adjunto) de um nome. O dado (238d) mostra que akara 'grande' não é aceito isoladamente como argumento do verbo transitivo panga 'cortar'.

(237) nge nin k-e-rom, nge akara.

nge nin k-e-rom nge akara

roça pequeno ?-COP-NEG roça grande

'A roça não é pequena, a roça é grande.' (PM-festa-tradicional)

(238) a. ugu akara oop

ugu akara oop

água grande DEIT

'[... Chegaram] aqui no rio (Lit. água grande).' (WYR-20080616-AVG-ANT-Histagua)

b. opurukwat ẽete awape akara.

$\mathrm{o}=$ puru-kwa-t ẽete awape akara

$1 \mathrm{SG}=$ morder-VZR-NFUT DEIT barata grande

'A barata grande me mordeu aqui [na cintura].' (WYR-201512-FN-ANI-vocab-1-

02)

c. on tokaap akara pangat.

on tokaap akara pang-a-t

eu cipó grande cortar-V.T-NFUT

'Eu cortei o cipó grosso.' (PM-2010)

d. *on akara pangat

on akara pang-a-t

eu grande cortar-V.T-NFUT

Interp. Pret.: Eu cortei [algo] grosso.(PM-2010) 
Nogueira (2015) mostrou que adjetivos requerem sempre um complemento (argumento interno), SN ou prefixo de pessoa. Isso pode ser constatado nos dados em (239). Raízes adjetivais iniciadas por vogal, como akara 'grande' e ati 'ardido', requerem um SN ou o alomorfe de $3^{\mathrm{a}}$ pessoa objeto $d j$-. Essa situação é semelhante à alomorfia que ocorre nos verbos transitivos iniciados por vogal (o alomorfe zero é usado como $3^{\mathrm{a}}$ pessoa objeto de raízes verbais transitivas e adjetivais que iniciam por consoante). Tal exigência não é constatada nos SNs (tal como em Mekens como mostrado por Galucio (2001)).

a. apet nin, angup akara. Djakara poot angup.

apet nin angup akara dj-akara poot angup

ninfa.de.piolho pequeno piolho grande 3-grande velho piolho

'A ninfa é pequena [piolhinho], o piolho é grande. É grande e velho o piolho.' (WYR-201512-FN-ANI-vocab-1-01)

b. odja ati ndekwat

o-dja ati ndekwat

1 SG-cabeça ardido INTENS

'Minha cabeça está doendo demais.' (PM-2013)

$\begin{array}{lll}\text { c. } o \text {-mayĩngu } & \text { djati, } & \text { djati. } \\ \text { o-mayi-ngu } & \text { dj-ati } & \text { dj-ati }\end{array}$

1SG-macaxeira-líquido.INAL 3-ardido, 3-ardido

'Minha chicha de macaxeira está azeda, está azeda.' (PM-música)

\subsubsection{Adjetivos e Verbos: Negação e $3^{a}$ pessoa}

A possibilidade de coocorrência entre pronomes livres e prefixos pessoais, como em (240), se, por um lado, distingue nomes de adjetivos, por outro, aproxima os adjetivos de verbos intransitivos que permitem concordância entre o prefixo pessoal e o SN ou pronome correferente $^{11}$.

\footnotetext{
${ }^{11}$ Veremos, contudo, que um adjetivo para ser usado como verbo intransitivo precisa receber os verbalizadores ou a vogal temática. Por exemplo, o adjetivo tхиир 'molhado', citado em (236a), pode receber o prefixo de voz média $e$ - (que ocorre em verbos intransitivos ou intransitivizados) e o verbalizador $-k w a$, e, assim, comportar-se como verbo intransitivo. Veja:

a. mbetxuupkwat on. mb-e-txuup-kwa-r=on

1 SG-MED-molhado-VZR-NFUT=eu

'Eu me molhei.' (PM-2008)

Outros adjetivos verbalizados através de vogal temática/verbalizadores, bem como morfema de voz média $e$ são: tiap 'feliz' / etiawa 'alegrar-se'; akop 'quente' / akowa 'esquentar'; pare / parega 'melhorar/ficar bom'; pawa 'seco'/ epawaka 'secar'; kodji 'velha/idosa' / kodjikara 'envelhecer.o’; djira 'claro' / endjiraka 'clarear'.
} 
a. ah! opitiik on, ongwãyomkarat on

ah o-pitiik on o-ngwãyom-kara-t on

INTJ 1SG-frio eu 1SG-febre-VZR-NFUT eu

'Eu estou com frio, estou ficando com febre.' (WYR-20080627-FN-PM-a-chefedas-mulheres-33)

b. aramira (dj)akara

aramira (dj-)akara

mulher (3-)grande

'A mulher (ela) é gorda.' (PM-2010)

Na forma negativa é também possível essa coocorrência entre SN e prefixo correferencial.

(241) ndeke yengu djatirom.

\begin{tabular}{|c|c|}
\hline ke & y-engu dj-ati e-rom \\
\hline
\end{tabular}

'A chicha dela não azedou.' (PM-2013)

Note, no exemplo (241), assim como em (242), que há a assimilação de /e/ à vogal da palavra precedente.

Os dados em (242) apresentam o adjetivo yangã 'ativo (trabalhador, no sentido adjetival)' como predicado de um SN (242a) e do pronome de $3^{\text {a }}$ pessoa (242b-c). Comparando-se tais dados, podemos ver que, interessantemente, é impossível o uso de $3^{\text {a }}$ pessoa correferencial te- no sintagma adjetival (242d). Tal paradigma pode estar relacionado ao fato de este prefixo poder ser usado em um domínio mais finito ou infinitivo, mas não nos domínios menos finitos da língua como as construções de cópula ou predicação não verbal.

a. djikey

emõ yangã, kupi

yangãrom.

dj-ikey

emõ yangã $\emptyset$-kupi

yangã =e-rom

3-irmã.mais.velha.

'A irmã mais velha dela é trabalhadora/ativa mesmo, a irmã mais nova dela não é trabalhadora/ativa. ${ }^{12}$, (PM-2013

b. ndeke yangã ndekwat

ndeke yangã ndekwat

ele/a ativo INTENS

'Ela é muito ativa.'

c. ndeke yangãrom

ndeke yangã e-rom

ele ativo COP-NEG

\footnotetext{
${ }^{12} \mathrm{~A}$ tradução livre dessa sentença corresponde à comparativa 'a irmã mais velha dela é mais trabalhadora que a irmã mais nova dela'.
} 
'Ela é preguiçosa (não ativa).'

d. *ndeke teyangã ndekwat

ndeke te-yangã ndekwat

ele 3C-ativo INTENS

(PM-2014)

Observemos o comportamento dos verbos com relação à negação. A negação de verbos é afixada diretamente à raiz verbal (que é o núcleo do predicado).
"Kerom,
okwa korom
ote,
ate
itoagat
ote."
K-e-rom okwa ko-rom ote
ate itoak-a-t
ote
?-COP-NEG irmão.o comer-NEG 1 PL.EXCL somente chorar-V.T-NFUT 1PL.EXCL
'Não, nós não comemos nosso irmão, estamos só chorando por ele.' (WYR-20080627-
FN-PM-a-chefe-das-mulheres-62)

Dessa forma, para expressar o futuro nas construções verbais negativas, faz-se necessário que outro elemento verbal, um auxiliar, receba os núcleos funcionais de tempo, como em (244).
(244) yengu
ate
$k a$.
ko-a
Nderarap
ere, "eengu
y-engu
3-chicha.INAL mesmo.assim ingerir-V.T moer-REP-V.T-INF em 2SG-chicha.INAL
ndet-ar-a-p
ere e-engu

$\begin{array}{llll}\boldsymbol{k} \text { korom } & \text { nãm } & n \tilde{a} & \text { on } \\ \text { ko-rom } & \text { nẽ- } \emptyset \text {-ã-m } & \text { nã } & \text { on } \\ \text { ingerir-NEG } & \text { AUX-V.T-INF } & \text { FUT } & \text { eu }\end{array}$
'Mesmo assim, [as pessoas] estão tomando a chicha dela. Quando ela preparou chicha de novo, [ele disse] "Eu não vou beber tua chicha".' (WYR-20100326-FN-PM-caracol- 44-45-46)

Note que as construções negativas verbais não apresentam vogal temática (compare o verbo $k a$ 'ingerir', no primeiro período, com korom 'não ingerir' em (244)). A vogal temática está diretamente ligada à possibilidade de um verbo se flexionar para aspecto e tempo. Assim, dada a ausência de vogal temática, e, em consequência, dada a impossibilidade de flexão de tempo/aspecto as construções negativas expressam tempo em um verbo auxiliar. Tanto no exemplo (243) quanto no dado (244), observamos que as sentenças negativas mantém a estrutura argumental do verbo, expressando sujeito e objeto, em ordem OV, como um verbo típico.

$\mathrm{O}$ verbo intransitivo, ao ser negado, também mantém sua estrutura argumental e sua propriedade de permitir concordância entre prefixo e pronome/SN correferencial (como veremos, apenas nas construções que não são $3^{\text {a }}$ pessoa). Veja exemplos com o verbo intransitivo tera 'ir', em (245).

$$
\begin{array}{ll}
\text { a.erat } & \text { on. } \\
\text { o-ter-a-t } & \text { on } \\
\text { 1SG-ir-V.T-NFUT eu }
\end{array}
$$


'Eu fui.' (NOGUEIRA, 2011, p. 70)

b. oterom on.

o-ter-om on

1 SG-ir-NEG eu

'Eu não fui.' (PM-2012)

No entanto, nas orações negativas intransitivas, a $3^{\text {a }}$ pessoa correferencial te- não ocorre, semelhantemente ao padrão descrito para os adjetivos, em (242). Este fato pode ser observado nos exemplos (246), (247) e (248), em que é possível comparar uma intransitiva negativa com uma intransitiva afirmativa. Como podemos constatar, te- é agramatical no contexto sintático de verbo intransitivo negado.

(246) a. ngwaykup terom.

ngwaykup tet-om

homem ir-NEG

'O homem não foi.' (PM-2010)

b. tetera mberu ngo

te-tet-a mberu ngõ

3C-ir-V.T macaco.prego criação

'O macaco de criação foi embora.' (ANT-2008-hist-lua)

(247) a. djeraorom.

dj-eraot-om

3-aparecer-NEG

'Não apareceu.' (PM-2015)

b. ongõ teeraorat.

o-ngõ te-eraot-a-t

1 SG-criação 3C-ir-V.T-NFUT

'Meus bichos de criação apareceram.' (PM-2010)

(248) a. $(* t e) /$ djepagom.

(*te)/dj-epag-om

$(* 3 \mathrm{C}) / 3$-acordar-NEG

'Não acordou.' (PM-2015)

b. teepagat.

te-epag-a-t

3C-acordar-V.T-NFUT

'Ele acordou.' (PM-2015) 
Singerman (2018, p. 195) relata que em Tupari o verbo cognato tet 'ir.sg' não aceita a terceira pessoa correferencial te-. A explicação de Singerman é de que há razões fonológicas para isso, ou seja, haplologia. Os dados de Singerman estão em sentenças afirmativas. Em Wayoro, por sua vez, a agramaticalidade parece ter motivação sintática, uma vez que ocorre apenas em negativas intransitivas (compare a negativa e afirmativa dos verbos tera 'ir', em (246) e (247)). Além disso, esse julgamento agramatical também se dá diante de verbos iniciados por sílabas diferentes de /te/, como em (248) (não justificando assim uma explicação em termos de haplologia).

Os verbos transitivos parecem se comportar de maneira distinta de verbos intransitivos e adjetivos por aceitar o morfema de $3^{\text {a }}$ pessoa correferencial, em sentenças reflexivas negativas, como em (249). Tal dado pode estar relacionado ao fato de uma sentença reflexiva não ser necessariamente intransitiva. Como cita Cyrino (2015, p. 34-35), em georgiano e italiano, por exemplo, "há fatos empíricos a favor de uma análise transitiva de verbos reflexivos".

(249) aramira teetigarom.

aramira te-e-tiga-rom.

mulher 3C-MED-pintar.corpo-NEG

'A mulher não se pintou.' (PM-2013)

Sumarizando as diferenças de comportamento entre adjetivos e verbos intransitivos, podemos dizer que um adjetivo, ao ser usado como verbo, receberá um verbalizador ou vogal temática. Após formado o radical verbal, a palavra pode receber a gama de morfemas verbais disponível na língua. Veja como exemplo o verbo pikãykwa 'irritar-se' formado a partir do adjetivo pikãy 'bravo', em (250).

a. aote pikãy.

aote pikãy

gente bravo

'gente brava/violenta.' (PM-2010)

b. tepikãykwa ugu eriat, ngwãngwã poot.

te-pikãy-kwa ugu eriat ngwãngwã poot

3C-bravo-VZR água dono camaleão velho

'O dono da água, o camaleão antigo, se irritou.' (WYR-20080616-AVG-ANT-Histagua-044)

Quanto às marcas de pessoa, é o comportamento da $3^{\mathrm{a}}$ pessoa correferencial nas sentenças afirmativas que se torna relevante para distinguir tais categorias. Predicados de propriedade não aceitam prefixo de pessoa correferencial tanto nas afirmativas quanto nas negativas, ao passo que verbos intransitivos rejeitam tal morfema apenas na negativa, como mostra a Tabela 6.3. 


\begin{tabular}{|c|c|c|}
\hline & Pred. Propriedade & Verbos intransitivos \\
\hline Afirmativa (Não3 ${ }^{\mathrm{a}}$ pess.) & $\begin{array}{c}\text { o-tiap on } \\
1 \mathrm{SG}-\mathrm{feliz} \text { eu } \\
\text { 'Eu estou feliz' }\end{array}$ & $\begin{array}{c}o \text {-ter-a-t on } \\
\text { 1 SG-ir-V.T-NFUT eu } \\
\text { 'Eu fui' }\end{array}$ \\
\hline Afirmativa (3C) & $\begin{array}{c}\text { *te-yãngã } \\
\text { 3C-ativo } \\
\text { (Inter. Pret.'Ele é ativo'.) }\end{array}$ & $\begin{array}{c}\text { te-ter-a-t } \\
\text { 3C-ir-V.T-NFUT } \\
\text { 'Ele foi.' }\end{array}$ \\
\hline Negativa (Não3 ${ }^{\mathrm{a}}$ pess.) & $\begin{array}{c}\text { o-tiap e-rom on } \\
\text { 1 SG-feliz COP-NEG eu } \\
\text { 'Eu estou triste' }\end{array}$ & $\begin{array}{l}\text { o-ter-om on } \\
\text { 1SG-ir-NEG eu } \\
\text { 'Eu não fui'. }\end{array}$ \\
\hline Negativa (3C) & $\begin{array}{c}\text { ndeke (*te-)yãngã-rom } \\
\text { ele (*3C-)ativo-NEG } \\
\text { 'Ele não é ativo' }\end{array}$ & $\begin{array}{l}\text { ngwaykup (*te-)ter-om } \\
\text { homem (*3C-)ativo-NEG } \\
\text { 'O homem não é ativo.' }\end{array}$ \\
\hline
\end{tabular}

Tabela 6.3: Exemplos de marcas de pessoa em Predicados de Propriedade e SVs intransitivos

\begin{tabular}{l|l|l} 
& Predicado Propriedade & SV Intr. \\
\hline Afirmativa (Pron. e Pref. Não3 ${ }^{\text {a }}$ pess.) & Sim & Sim \\
\hline Afirmativa (Pron. e Pref. 3C.) & Não & Sim \\
\hline Negativa (Pronome e Pref. Não3 ${ }^{\text {apess.) }}$ & Sim & Sim \\
\hline Negativa (Pron. e Pref. 3C) & Não & Não \\
\hline
\end{tabular}

Tabela 6.4: Marcas de pessoa em Predicados de propriedade e SVs intransitivos

Pela tabela 6.4, podemos notar que, no que concerne às marcas de pessoa, adjetivos e verbos intransitivos se diferenciam (apenas) quanto ao uso do prefixo de $3^{\text {a }}$ pessoa correferencial nas afirmativas. Tal prefixo não ocorre com adjetivos.

Note que, nas afirmativas, a diferença entre as categorias é clara devido, por um lado, à presença de vogal temática e marcas de tempo/aspecto nos verbos intransitivos e, por outro lado, à impossibilidade de ocorrência de $3^{\text {a }}$ pessoa correferencial nos adjetivos. Nas negativas, no entanto, certas configurações fonológicas podem levar à ambiguidade. Os verbos intransitivos, nas negativas, ocorrem sem vogal temática e o morfema de negação se liga diretamente à raiz. Vimos que, devido a um processo de assimilação regressiva opcional, a cópula vocálica do predicado não verbal pode não ser pronunciada, fazendo com que uma raiz adjetival possa se ligar diretamente ao alomorfe verbal de negação -rom. Este é o alomorfe verbal usado com raízes terminadas por vogais. Assim, em (251a), o verbo intransitivo nía 'envergonhar-se', na forma negativa (251b), é ambíguo entre uma estrutura de predicado nominal (se considerarmos que a cópula $e$ foi apagada) ou verbal .

$$
\begin{array}{ll}
\text { a. kawere, } & \text { tenĩa. } \\
\text { kap-ere } & \text { te-nĩ-a }
\end{array}
$$

PROFORMA-em 3C-vergonha-V.T

'Então, ela ficou com vergonha.' (WYR-20100326-FN-PM-caracol-50) 
b. nirom.

$\emptyset$-ni-rom

3-vergonha-NEG

'[Ele] é sem vergonha/[Ele] não se envergonhou.' (PM-2008)

\subsubsection{Duplicação e categorias gramaticais}

Nogueira (2011, p. 120) descreve a duplicação de raízes verbais em Wayoro como processo morfológico regular que tem como efeito a semântica de intensificação do evento da raiz verbal. Como sugere Aikhenvald (2007), bem como Dixon (2010, p. 87), a duplicação é um dos recursos que pode permitir visualizar diferenças entre as categorias gramaticais de uma língua. Podemos identificar nomes inerentemente duplicados em Wayoro, ou seja, nomes cuja forma não duplicada (semanticamente relacionada) não é atestada. Esses nomes fazem parte, principalmente, dos campos semânticos de fauna, plantas e instrumentos, como podemos observar na Tabela 6.5.

\begin{tabular}{l|l} 
Fauna & \\
\hline kupkup & coruja grande \\
tutuut & coruja pequena \\
kotkoriip & gavião \\
aeae & espécie de sapo (onomatopeia) \\
ndatkãkã & cobra cascavel (onomatopeia) \\
ngongorã & cigarra \\
ngwangwã & camaleão \\
Plantas & \\
\hline $\begin{array}{l}\text { atiti } \\
\text { ororo }\end{array}$ & milho (empréstimo) \\
Instrumentos & algodão \\
\hline $\begin{array}{l}\text { mbokiki } \\
\text { ngungup }\end{array}$ & tornozeleira (instrumento musical) \\
\end{tabular}

Tabela 6.5: Nomes inerentemente duplicados

Dentre os nomes duplicados, mberambera 'borboleta' e mẽpirẽpit 'neto (fala feminina)' apresentam raiz atestada, mberaka 'abrir-se' e mẽpit 'filho (fala feminina)', respectivamente ${ }^{13}$. Os nomes apresentados na Tabela 6.5 corroboram a afirmação de Gomez e Voort $(2014$, p. 4) de que a duplicação inerente ou lexical é encontrada "especialmente em formas onomatopaicas ou simbólicas", tal como em Hup.

Adjetivos que expressam cores e disposição de listras (vertical ou horizontal) são atestados na forma não reduplicada. Os dados em (252) mostram que a forma ngopngop 'vermelho' ocorre com prefixos pessoais e pronomes livres e com a cópula na forma negativa, tal como

\footnotetext{
${ }^{13}$ Note que a duplicação nominal/adjetival é produtiva nas línguas Mekens e Akuntsu, da mesma subfamília linguística, nas quais está relacionada à pluralidade e à aspecto, conforme Aragon (2014) e Galucio (2001).
} 
esperado para adjetivos. A forma não duplicada é atestada como modificador do nome amẽko 'onça' em (252c).

a. ongopngop on.

o-ngop $\sim$ ngow $=$ on

$1 \mathrm{SG}-$ vermelho $\sim$ vermelho

'Eu estou vermelho (de urucum).'

b. ondek ngopngop erom.

o-ndek ngop ngop e-rom

1 SG-casa vermelho vermelho COP-NEG

'Minha casa não é vermelha.' (WYR-19880520-DM-PM)

c. amẽko ngop, ngwendap mbiro.

amẽko vermelho ngwendap mbiro

onça vermelho tamanduá EXIST

'Tem onça vermelha, tamanduá.' (WYR-20151204-FN-ANI-vocab)

Note, em (253), que o uso da forma adjetival duplicada ngopngop 'vermelho' como verbo é possível mediante adição da vogal temática que permitirá ao verbo formado ngopngowa flexionar-se para tempo.

(253) ndeat tengopngowat ${ }^{14}$.

ndeat te-ngop $\sim$ ngop-a-t

eles 3C-vermelho vermelho-V.T-NFUT

'Eles estão vermelhos [Lit. Eles avermelharam].' (WYR-19880520-DM-PM)

Dados semelhantes foram constatados em Nogueira (2011, p. 102, 106) com os adjetivos ngwãrãngwãrã 'listrado (horizontalmente)' e puurupuuru 'listrado (verticalmente)'. Essa forma duplicada aparece como modificador de um nome. A forma não duplicada é atestada na raiz dos verbos transitivos formados pela adição do verbalizador - $k w a$, são eles ngwãrã $k w a$ 'listrar (horizontalmente)' e puurukwa 'listrar (verticalmente)'.

A duplicação em adjetivos foi atestada na classe semântica de cores ${ }^{15} /$ disposição de listras. Vimos que, em relação ao item ngopngop 'vermelho', tanto a forma duplicada como a base são adjetivais (a forma duplicada ocorre como núcleo do predicado não verbal e a base como modificador nominal) e a diferença de sentido não é óbvia. Faz-se necessário mais investigação com o objetivo de elucidar ao valor gramatical/regularidades associadas a estes dados.

\footnotetext{
${ }^{14}$ É necessário verificar se o verbo é iniciado pelo morfema de voz média $e$-. Isso pode ser averiguado com a $1^{\mathrm{a}}$ pessoa do singular. Caso o verbo tenha uma vogal $e$ - inicial selecionará o alomorfe $m b$ - ' 1 a pessoa singular' usado diante de raízes iniciadas por vogal.

${ }^{15}$ Especificamente, nas palavras para as cores ngopngop 'vermelho' e tiktik 'escuro'.
} 


\subsubsection{Adjetivos e morfemas de mudança de categoria}

Se, por um lado, nominalizadores e verbalizadores são evidentes em Wayoro, como mencionado em Nogueira (2015), morfemas de mudança de categoria relacionados a adjetivos não o são. GALUCIO (2011, p. 240) descreve o morfema adjetivizador -ipit - pit da língua Mekens, que forma radicais (a partir de verbos transitivos e intransitivos) com todas as propriedades de adjetivos da língua. A autora enfatiza que o "radical derivado corresponde ao estado resultante do evento descrito no verbo e se refere ao paciente afetado pelo evento" (GALUCIO, 2011, p. 240 , tradução nossa) ${ }^{16}$.

Wayoro apresenta morfema verbal claramente cognato -it. Confira exemplo do uso desse morfema com os verbos poora 'varrer' e ndera 'moer', em (254). Tais construções tem sido traduzidas como sequência de eventos.

a. monaum poorit ipitkwa.

monaum poor-it ipitkwa

lixo varrer-RES jogar

'Juntei o lixo e joguei [Lit. O lixo ajuntado, joguei.]' (PM-2012)

b. nderit parekarap ndiakwa.

nder-it pare-kar-a-p ndia-kw-a

moer-RES bom-VZR-V.T-INF querer-ITER-V.T

'Moeu e já estava ficando pronto [Lit. O que foi moído queria aprontar.' (WYR20100326-FN-PM-caracol-36)

Pelo fato de, em Wayoro, o morfema -it parecer selecionar apenas verbos transitivos, vamos manter a glosa como resultativo e não como adjetivizador (já que não mudaria uma categoria como um todo). Contudo, é possível visualizar um uso como modificador do nome mõnaum 'lixo', em (254a). Note que a semântica resultativa é também descrita para as construções cognatas em Mekens.

Em outra mudança de categoria envolvendo adjetivos, suspeita-se que adjetivos tornam-se advérbios, embora sem morfologia explícita ${ }^{17}$. É o que podemos notar com o adjetivo kam

\footnotetext{
16"The derived stem corresponds to the resulting state of the event described in the base verb, and refers to the patient affected by that event."

${ }^{17}$ Advérbios temporais funcionam como adjuntos e tem distribuição bastante livre na sentença, sendo sua inserção impossível apenas entre objeto e verbo transitivo, veja:

a. Raquel Gleice ndaikut ega teengu nderat.

Raquel Gleice ndaikut ega te-engu nder-a-t

R. G. amanhã FRUST 3C-chicha.INAL moer-V.T-NFUT

'Raquel e Gleice fizeram a chicha delas ontem.'

b. Raquel Gleice teengu nderat ndaikut ega

Raquel Gleice te-engu nder-a-t ndaikut ega

R. G. 3C-chicha.INAL moer-V.T-NFUT amanhã FRUST

'Raquel e Gleice fizeram a chicha delas ontem.'
} 
'comprido' no seguinte conjunto de dados. Note, em (255), que, como esperado para adjetivos, kam 'comprido' modifica um nome e pode ser negado através da cópula. O dado (256) mostra que o adjetivo também pode modificar uma nominalização.

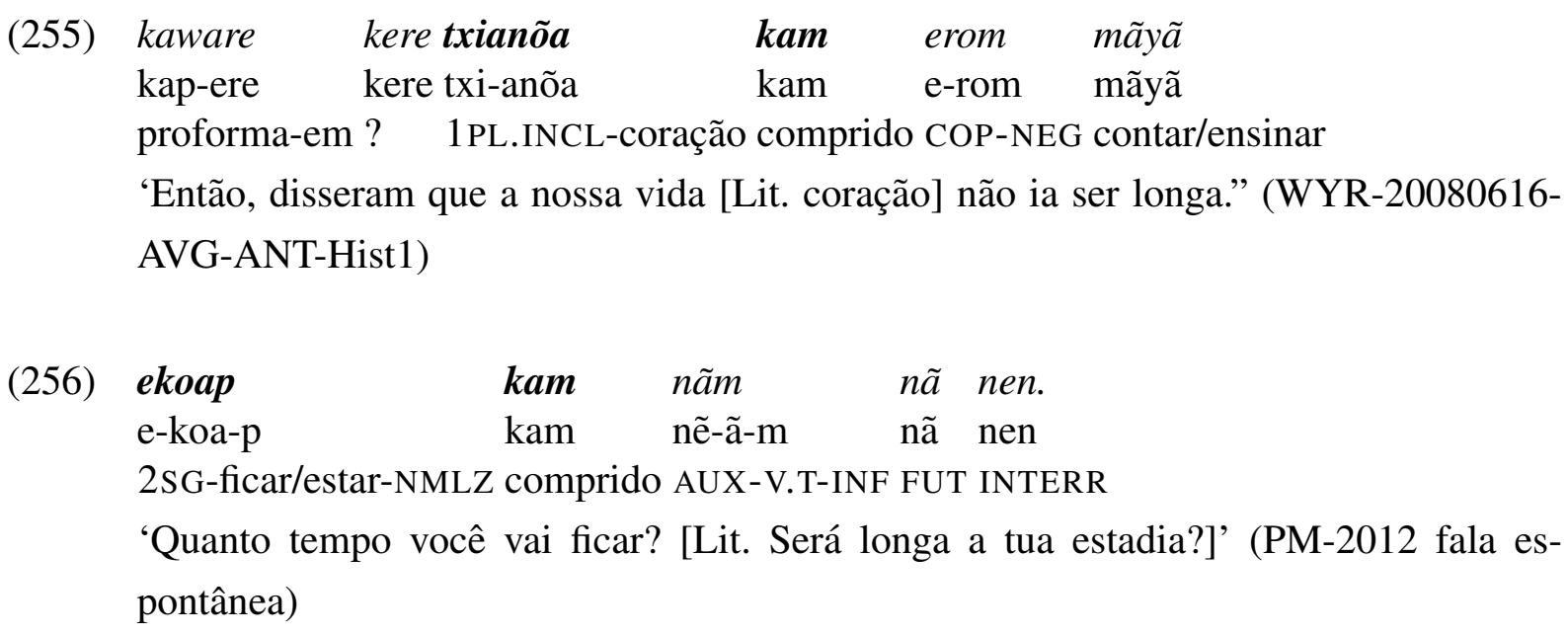

Em (257), por outro lado, kam, aparece modificando um verbo, adquirindo uma semântica de "por um longo período" (claramente relacionada à semântica do adjetivo, 'comprido'). Uma evidência de que o verbo não foi nominalizado é que (i) não há morfema de nominalização e (ii) o morfema de negação aparece diretamente ligado à raiz verbal, tal como os verbos típicos (ao passo que, como vimos, uma negação nominal requer cópula).

$\begin{array}{lll}\text { endu ningom kam on. } & \text { om } \\ \text { endu ning-om kam } & \text { on } \\ \text { marico tecer-NEG comprido eu }\end{array}$

'Nunca mais eu fiz marico.' (PM-2017 fala espontânea)

Assim, sem qualquer morfologia adicional, o adjetivo kam é usado como advérbio e pode modificar, então, um verbo.

\section{3 mbiro: verbo irregular 'existencial, ter' e posposição 'com'}

mbiro é claramente biargumental, porém não recebe vogal temática e marcas de tempo, como podemos ver em (258). Não há registros da coocorrência de prefixos de aumento de valência (como causativo) com esse verbo.

$\begin{array}{lll}\text { c. *Raquel Gleice teengu } & \text { ndaikut ega } & \text { nderat. } \\ \text { Raquel Gleice te-engu } & \text { ndaikut ega } & \text { nder-a-t }\end{array}$

R. G. 3C-chicha.INAL amanhã FRUST moer-V.T-NFUT

'Inter. pret.: Raquel e Gleice fizeram a chicha delas ontem.' (PM-2013) 

(258) aramira toapndia, ningãm mbiro. Toto, tigaap, tãyã, mulher top-a-p.ndia ning-a-m mbiro toto tigaa-p tãyã mulher ver-V.T-INF.querer tecer-V.T-NMLZ EXIST ?rosto pintar.corpo-NMLZ brinco yãpiakup, mbokãrãyãa, niam, toapndia! yãpia.kup mbo.kãããã niam top-a-p.ndia nariz.pau mão.castanha.fruto adereço.perna ver-V.T-INF.querer 'A mulher é bonita, tem o que é de tecer (como colar). Tem pintura de rosto, brinco, adereço de nariz, adereços de mão e braço (pulseira e anel), adereço de perna, é bonita!' (WYR-20100326-FN-PM-mulher-estrela-03-04)

O dado (259) mostra que mbiro compartilha com verbos a possibilidade de poder receber o sufixo de negação verbal -ap, o qual é utilizado na modalidade de evento irrealis indicado por $n \tilde{e}$, como em (260).

\begin{tabular}{|c|c|}
\hline txindetngap & mbiroap \\
\hline txi-ndet-ng-a-p & mbiro-ap \\
\hline
\end{tabular}

'Nós ainda não existíamos [Lit. Ainda não havia nos dado nome].' (WYR-200308-DMPK-origemdomundo 005)

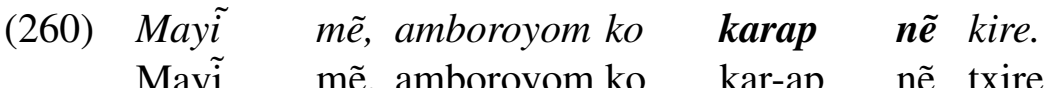
macaxeira TOP farinha comer AUX-NEG IRR 1PL.INCL

'Quanto à macaxeira, nós não [nunca] comíamos farinha.' (WYR-19900302-DM-PMroca-pesca1)

O dado agramatical em (259) foi testado pelos seguintes motivos. Apesar da tradução do exemplo (259) estar no passado, a expressão de futuro é obtida através da junção do sufixo infinitivo - $p$ mais o morfema de futuro $n \tilde{a}$, portanto, uma construção semelhante ao uso do morfema de negação - $a p+n \tilde{e}$ 'irrealis'. Outro motivo é o fato de haver o verbo nã 'fazer, tornarse' registrado também com uso auxiliar em outros casos, como (244). É interessante observar ainda que o morfema irrealis ne é homófono à raiz do verbo 'fazer, tornar-se' ñe, como se constata na construção de extração do objeto em (261).

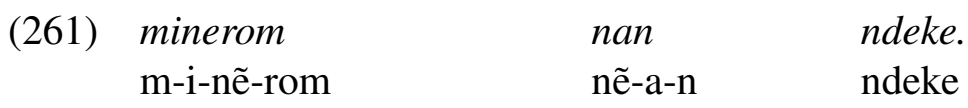

1SG-OBJ.EXTR-fazer-NEG fazer-V.T-NFUT 3SG

'Aquilo que não foi feito por mim, ela fez.' (WYR-201711-FN-PM-transc-aprend-pajePK-2) 


\subsubsection{Usos de mbiro como posposição 'com'}

Singerman (2018, p. 51-52) afirma que, em Tupari, há uma estratégia possessiva alternativa à justaposição de nomes Possuidor+Possuído (a justaposição N+N não apresenta qualquer marca morfológica). Trata-se do sufixo -psiro, cognato a mbiro de Wayoro e piro 'ter, existir' de Mekens (GALUCIO, 2001), o qual "deriva novos nomes com o sentido 'tendo X' ou 'possuindo X' (SINGERMAN, 2018, p. 51). Tais nomes derivados podem servir como predicado nominal, bem como podem sofrer verbalização e, então, flexionar-se como verbo. Ainda, é possível que tais nomes derivados com -psiro sirvam como argumento.

Identificamos dois contextos sintáticos em que mbiro apresenta comportamento como posposição, são eles: (i) o uso do sintagma com mbiro como adjunto de um argumento; (ii) mbiro como núcleo de um predicado não verbal.

Em (262), o SN yãy mbiro 'com dente' do nome uwoy 'peixe' (argumento do verbo 'ãam).

(262) Au yom. 'Ãam uwoy yãy mbiro.

au yom 'ãam uwoy yãy mbiro

curar dar NEG.EXIST peixe dente com

'Rezei (as comidas que trouxeram para o doente) e dei. Não havia peixe com dente (piranha, traíra).' (WYR-200308-DM-PK-tratamentodetertuliano)

Em (263), o termo usado para se referir ao roedor 'paca' (Agouti paca ou Cuniculus paca) é a construção com o adjunto ngwãra mbiro 'com listra (horizontal)', em que não se expressa o SN modificado pelo adjunto.

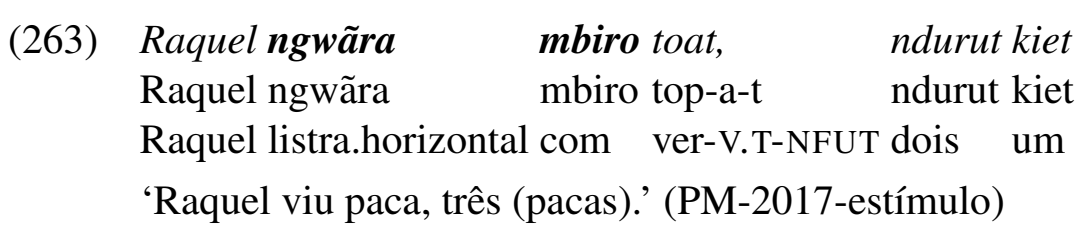

O dado (264) exemplifica o caso em que mbiro 'com' é núcleo de um predicado não verbal. Nesse exemplo, é possível tanto uma leitura de mbiro como 'existencial, ter' quanto de posposição 'com' (note que mbiro não funciona como adjunto, nesse exemplo).

(264) ngwaykup apoga tik kũỹ pite mbiro.
ngwaykup apoga tik kũyõ pite mbiro
homem chapéu preto terra QUANT EXIST/com
'O homem de chapéu preto tem/com muita/mais terra.' (PM-2017-estímulo)

\subsection{Localização e Existencial negativo ’ãam}

Nas sentenças afirmativas, o uso das posposições é suficiente para a expressão do predicado de localização, como se pode observar em (265), que tem como núcleo a posposição ere. 


\begin{tabular}{|c|c|c|}
\hline $\begin{array}{l}\text { a. txiakãra } \\
\text { txi-akãra }\end{array}$ & $\begin{array}{l}\text { txidja } \\
\text { txi-dja }\end{array}$ & $\begin{array}{l}\text { ndeat erap } \\
\text { ndeat er-a-p }\end{array}$ \\
\hline
\end{tabular}

1PL.INCL-osso 1 PL.INCL-cabeça 3PL dormir-V.T-NMLZ em

'Há ossos e cabeças da gente na pascana delas [local para dormir durante expedições].' (WYR-20080627-FN-PM-a-chefe-das-mulheres-16)

b. awõpe paut ere.

awõpe paut ere

banco terreiro em

'O banco está no terreiro.' (PM-2013)

O morfema 'ãam 'existencial negativo' não se comporta como verbo regular, no sentido de que não tem vogal temática, por consequência, também não aceita flexão de tempo; tampouco ocorre com os prefixos e clíticos pessoais (ou qualquer morfema de negação, como esperado, já que sua semântica é negativa). Overall, Vallejos e Gildea (2018, p. 20) lembram que existenciais podem estar associados a construções existencial-apresentativas, tal como definido por Givón. Este uso pode ser constatado na primeira frase do texto sobre a origem da água, Ugu 'ãam..., em que o narrador usa o existencial negativo 'ãam para dar ênfase à ausência de água, ugu, nos tempos antigos. No exemplo (266), há ocorrência do existencial negativo como biargumental, funcionando com a semântica de negação de Posse, e, nos exemplos (267) e (268), temos o uso como monoargumental em função de existencial negativo.

(266) en ngoyoto 'ãam nẽ.

en ngoyoto 'ãam nẽ

você feijão NEG.EXIST INTERR

'Você não tem feijão?' (JA-2013)

(267) mãkatxi ... ndeke emõ ’ãam.

mãkatxi ... ndeke emõ ãam

mãkatxi ... 3SG ENF NEG.EXIST

'mãkatxi (abacaxi), esse mesmo não tem/existe (palavra em Wayoro).' (DF-2008)

(268) Mẽpit ewato agopkap poga.

Kawate aramira dja 'õam.

mẽpit ewato agopkap po-g-a kawate aramira dja ãam

filho. ̨ avô lenha queimar-VZR-V.T CONJ mulher cabeça NEG.EXIST

'O sogro clareou [Lit. acendou o fogo]. Então, a cabeça da mulher não existia.' (WYR20080627-FN-PM-yangwareta-cabeça-se-solta-7)

É também a negação existencial que é usada para a negação da relação de localização, como mostra o exemplo (269). 
(269)

$\begin{array}{llll}\text { ndaikut ega, } & \text { awõpe paut } & \text { ere, kap } & \text { 'ãam. } \\ \text { ndaikut ega } & \text { awõpe paut } & \text { ere kap } & \text { 'ãam }\end{array}$

amanhã FRUST banco terreiro em PROFORMA NEG

'Ontem o banco estava no terreiro, não está mais lá.' (PM-2013)

Assim, podemos identificar as funções semânticas posse, existencial e locativa negativas através do morfema 'ãam.

\subsubsection{Estrutura argumental de 'ãam: posposição ou verbo?}

Os sintagmas posposicionais, para além do uso como núcleo de um predicado não verbal, discutido nesta seção, podem ocorrer como adjuntos de verbos, como a posposição pi 'dentro', em (270), e a posposição ere 'em', em (271).

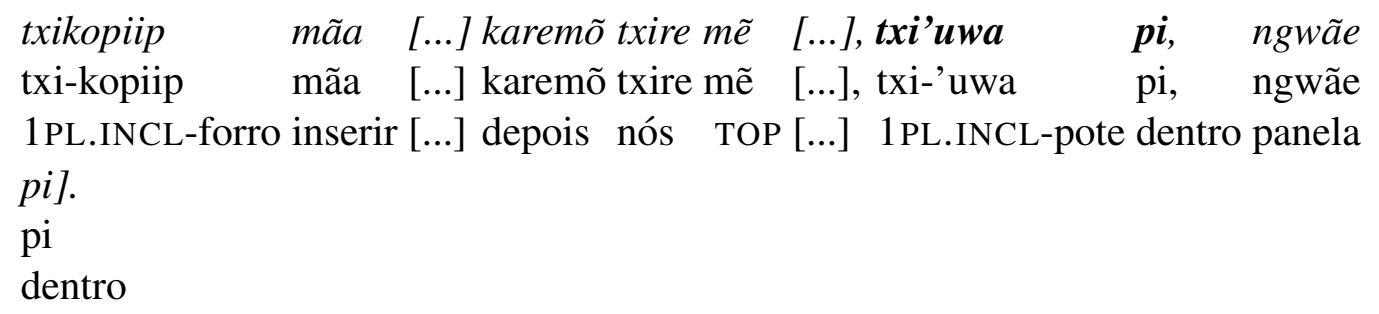

'Colocam o nosso forro, depois, a gente, [colocam] dentro do nosso pote (funerário), dentro da nossa panela (funerária).' (PK)

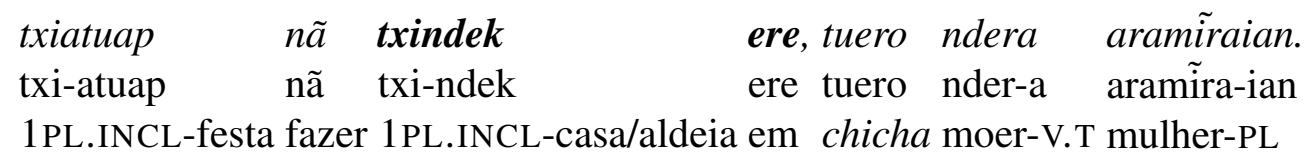

'Fazemos nossa festa na nossa aldeia, as mulheres fazem chicha.' (PM-2016)

Apesar de não haver registro de 'ãam como adjunto (como seria esperado para posposições), vale notar, nos exemplos (267) e (268), que este elemento pode ser comportar como monoargumental ou como biargumental. O diálogo em (272) reforça o comportamento biargumental com a semântica de negação da posse ${ }^{18}$.

a. amboro.yom mbiro nen.

amboro.yom mbiro nen

farinha.pó EXIST INTERR.2

'Você tem farinha?'

\footnotetext{
${ }^{18}$ Vale lembrar, como nota diacrônica, que Chousou-Polydouri et al. (2016) apresentam evidências para o desenvolvimento do morfema privativo denominal do Proto-Tupi-Guarani **e?im, gramaticalizando-se como * e Pam em Tupi-Guarani, e estendendo-se funcionalmente como - $\tilde{a}$ em Siriono. Uma investigação de 'ãam como morfema privativo também não pode ser descartada, uma vez que toma como argumento um SN. No entanto, não temos dados em que [SN-'ãam] ocorre como argumento de verbos.
} 
b. iih! ndeke 'ãam on.

iih! ndeke 'ãam on

INTJ 3SG NEG.EXIST eu

'Ah! Eu não tenho!' (PM-2013 fala-espontânea)

Os dados em (273) mostram um contraste claro entre 'ãam 'negação existencial', mbiro 'existencial' e a cópula negativa $e$-. Cada um desses morfemas funciona como núcleo de um predicado não verbal. Vale observar que as coocorrências são rejeitadas pela colaboradora.

$$
\begin{array}{ll}
\text { a. } & \text { ongõ } \quad \text { 'ãam. } \\
\text { o-ngõ } & \text { 'ãam } \\
\text { 1SG-criação NEG.EXIST } & \text { 'Não há minha criação (bichos de criação).' }
\end{array}
$$

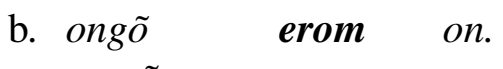

o-ngõ e-rom on

1 SG-criação COP.NEG eu

'Eu não tenho minha criação (bichos de criação).'

c. ongõ mbiro on.

o-ngõ mbiro on

1SG-criação EXIST eu

'Eu tenho minha criação (bichos de criação).' (PM-2013)

Se, por um lado, mbiro, se aproxima da categoria de verbos (irregular), devido à possibilidade de negação com - ap, dedicada ao modo irrealis marcado por ñe, 'ãam não apresenta qualquer flexão verbal. Contudo, vale lembrar da homofonia que existe entre mbiro verbo irregular existencial e mbiro posposição 'com'. Não é estranho afirmar, assim, que o uso transitivo de 'ãam a aproxima de verbos, mas também de posposições. Na proposta teórica de Hale e Keyser (2002), há verbos com semântica preposicional, por serem derivados de uma preposição em sua estrutura argumental, mas que não apresentam em sua forma fonológica qualquer resquício fonológico da preposição. Esta ideia pode ser interessante para entendermos o comportamento de 'ãam, bem como de mbiro homófono entre 'ter, existir' e também posposição 'com'.

Verbos como saddle do inglês, em She saddled the horse, são analisados por Hale e Keyser (2002) como portadores de uma semântica preposicional originada de uma estrutura argumental lexical (diádica básica) cujo núcleo é uma preposição. A forma analítica correspondente à saddle seria "get the horse with a saddle"(BASSANI, 2013, p. 97) ou "She fitted the horse with a saddle"(HALE; KEYSER, 2002, p. 19), como em (274a).

Podemos observar a derivação do verbo saddle, em She saddled the horse, em (274b). Um núcleo mais interno/baixo, pertencente à categoria $\mathrm{P}$, tem a propriedade sintática de tomar um complemento e de projetar um especificador (um SN, por exemplo, o cavalo). Adicionalmente, 
tal núcleo $\mathrm{P}^{0}$ tem a propriedade morfológica de ser vazio e, portanto, deve sofrer conflation com seu complemento. Tal estrutura é tomada como complemento de um núcleo verbal $\mathrm{V}$, que também é vazio e então sofre necessariamente conflation com seu complemento (com o núcleo do seu complemento) $\mathrm{P}$, que já é, em si, produto de conflation.

(274) Derivação de um verbo diádico básico

a.

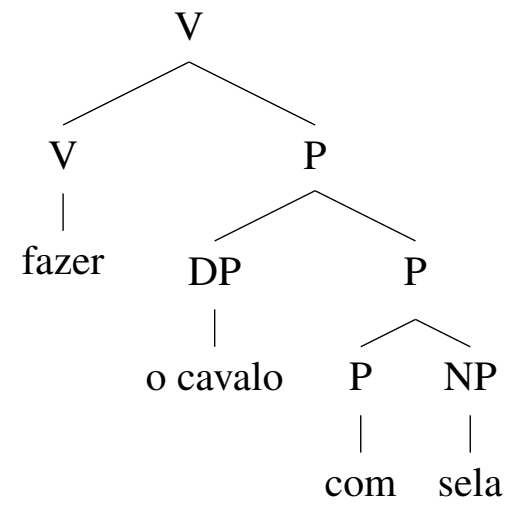

b.

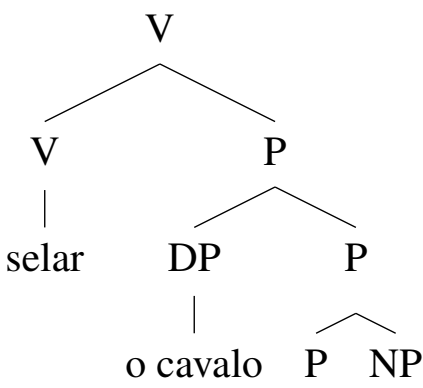

Uma vez que conflation é definido como um tipo específico de incorporação ${ }^{19}$, consideramos relevante descrever se há casos de incorporação na língua e se os mesmos envolvem posposições.

\subsubsection{Casos de incorporação: tandjora 'engravidar', ekentakwa 'vomitar', piora 'cavar' e 'ãamngora 'procurar (sem encontrar)'}

Podemos identificar, como raiz do verbo djora 'encher', o adjetivo djot, como em ngwãe djot 'panela cheia'. O verbo 'engravidar' tandjora é formado por incorporação ${ }^{20}$ do SN tan '?feto ou embrião' ${ }^{21}$ ao verbo djora 'encher' e foi descrito como verbo intransitivo em Nogueira (2011). Em (275b), SN e verbo djora 'encher' são itens independentes, em que tan é objeto do verbo. O comportamento como verbo transitivo pode ser constatado pelo fato de não aparecer o prefixo te-, obrigatório em sentenças intransitivas afirmativas ${ }^{22}$. Por outro lado, a versão com objeto incorporado aparece com o prefixo pessoal obrigatório, em (275c), bem como permite a transitivização através do morfema causativo õ-, em (275d); características exclusivas de verbos intransitivos (ou intransitivizados) na língua.

\footnotetext{
19 "Conflation may be a specific kind of incorporation, conforming to an especially strict version of the Head Movement Constraint (Travis 1984; Baker 1988 [...])"(HALE; KEYSER, 2002, p. 11)

${ }^{20}$ Uma das diferenças entre composição e incorporação nominal apontadas por Baker $(1988$, p. 78) é que "as combinações N-V em [composições] são necessariamente deverbais; a forma resultante é um nome (ou um adjetivo) e nunca um verbo".

${ }^{21}$ o-tan [1SG-?] também significa 'eu estou grávida'. Trata-se de um sintagma nominal possessivo, assim, uma possível tradução para tan é 'feto' ou 'embrião'.

${ }^{22}$ Vimos que verbos intransitivos não aceitam prefixo de $3^{a}$ pessoa correferencial nas negativas. O dado abaixo, publicado em Galucio e Nogueira (2018, p. 121), portanto, é melhor analisado como verbo transitivo.

(1) tetan djorom.

te-tan djot-om

3C-?feto cheio-NEG
} 
a. ngwãe tedjorat.

ngwãe te-djot-a-t

panela 3C-cheio-V.T-NFUT

'A panela está enchendo.' (PM-2008)

b. temen erom tan djorat.

te-men e-rom tan djor-a-t

3C-marido COP-NEG ?feto cheio-V.T-NFUT

'(Ela) não tem marido dela, [mesmo assim] está grávida.' (PM-2010)

c. Juca tetandjorat.

J. te-tan-djor-a-t

J. 3C-?feto-cheio-V.T-NFUT

'Juca engravidou.' (Nogueira, 2011, p. 153)

d. temen Juca õtandjorat.

te-men J. õ-tan-djor-a-t

3C-marido J. CAUS-?feto-cheio-V.T-NFUT

'O marido dela (mesma) engravidou a Juca.' (Nogueira, 2011, p. 153)

Outro verbo suspeito de ser formado por incorporação de um nome é ekentakwa 'vomitar'. O comportamento transitivo não foi registrado, porém o nome eken 'vômito' existe isoladamente, assim como o verbo transitivo taka 'derramar', que pode ser constatado em (276a). No dado (276b), a forma eken 'vômito' parece ter se incorporado ao verbo (que muda o sufixo verbalizador pelo sufixo iterativo $-k w a)$. Uma evidência dessa incorporação é a concordância entre prefixo pessoal e pronome, em (276b), e a possibilidade de causativização/transitivização com o prefixo $m \tilde{o}-$, em (276b).

a. mindiakwa takat on.

m-indiakwa ta-ka-t on

1SG-comida derramar-VZR-NFUT

'Eu derramei minha comida.' (Nogueira, 2011, p. 96)

b. mbekentakwat on.

mb-eken-ta-kwa-t on

1SG-vômito-derramar-ITER-NFUT eu

'Eu vomitei [Lit. Eu derramei meu vômito].'

c. on omẽpit mõekentakwat.

on o-mẽpit mõ-eken-ta-kwa-t

eu 1SG-filho.ọ CAUS-vômito-derramar-ITER-NFUT

'Eu fiz meu filho vomitar/provocar.' (PM-2010) 
Outros casos suspeitos de serem incorporação envolvem posposição. O verbo intransitivo ora 'ir' (como em (277a)) é usado como transitivo quando antecedido pela posposição pi 'dentro'. O verbo formado é piora 'cavar (Lit. ir para dentro)', como em (277b). Uma evidência de que houve a transitivização é a ausência de $3^{\text {a }}$ pessoa correferencial em piora 'cavar'.

a. ngiakop tegwepuat, ngiakop te-ngwepu-a-t sol 3C-entardecer-VT-NFUT cacique 3C-ir-V.T cacique-fêmea eremõ.

ere $=\mathrm{mõ}$

com $=$ ESS $/$ ALA

ngwandap teora ngwandaiperiat

ngwandap te-or-a ngwandap-iperiat

'Quando entardece, o cacique sai com a esposa.' (PM2-16)

b. kuy piora [...] ndeke nẽngara.

kuy pi-or-a [...] ndeke nẽngan-a terra dentro-ir-V.T [...] ele SIM-ENF

'[sobre o enterro tradicional], cava-se a terra [...] como ele mesmo.' (PK)

Outro caso envolve o morfema 'ãam negação existencial/posposição. É possível notar, no exemplo em (278), que o elemento 'ãam parece estar unido ao verbo transitivo ngora 'procurar'. Os exemplos (278a-b) mostram que, como verbo biargumental, ngora pode ter um objeto SN ou clítico de pessoa.
a. on emõ, orayape ngora on emõ
or=emõ, oraya.pe ngora or=emõ
$1 \mathrm{SG}-\mathrm{ENF}$ tucumã.palha procurar $1 \mathrm{SG}-\mathrm{ENF}$

'Só eu procuro palha de tucumã [para fazer marico].'

b. ongora.

$\mathrm{o}=$ ngora

$1 \mathrm{SG}=$ procurar

'me procurar'

c. o’ãamngorat nẽn.

$\mathrm{o}=$ 'ãam-ngor-a-t nẽn

$1 \mathrm{SG}=$ NEG.EXIST-procurar INTERR. 2

'Você me procurou [sem me encontrar]?' (PM-2013)

Uma evidência de que, no exemplo (278c), o clítico de pessoa está unido ao conjunto 'ãamngora (e não a 'ãam separadamente) é que o elemento 'ãam NEG.EXIST, isoladamente, não toma um clítico de pessoa como argumento (compare (279a-b)), são os pronomes livres que aparecem como seu argumento, como a $1^{a}$ pessoa do singular on, em (279c). Com relação 
ao uso posposicional de 'ãam, o dado em (279d) relembra que sintagmas posposicionais, como en eri 'de você', tomam um pronome livre como argumento interno. Contudo, é um clítico de pessoa (e não um pronome livre) que se liga à 'ãamngora, reforçando a possibilidade de 'ãam não estar separada do verbo ngora.

$$
\begin{aligned}
& \text { a. e'ãamngorat on. } \\
& \mathrm{e}=\text { 'ãam-ngor-a-t on } \\
& 2 \mathrm{SG}=\mathrm{NEG} \text {.EXIST-procurar eu }
\end{aligned}
$$

'Eu te procurei [sem te encontrar].' (PM-2013)

b. *e'ãam.

*e='ãam

2SG-NEG.EXIST

(PM-2013)

c. on, 'ãam on. Ndeke mbiro.

on 'ãam on ndeke mbiro

eu NEG.EXIST eu ele/ela EXIST

'Quanto a mim, eu não tenho. Ela tem.'

d. en eri mbekowat on

en eri mb-e-kowa-t on

você ABL 1SG-MED-esconder-NFUT eu

'Eu me escondi de você' (PM-2012)

Tais dados sugerem que 'ãamngora é uma unidade lexical, um sintagma verbal transitivo. Vale questionar, no entanto, nos casos que envolvem as posposições, qual elemento é o incorporante. Como a posposição é um predicado transitivo, é possível que os verbos estejam se incorporando à posposição. Note, no caso de 'ãamngora que o verbo transitivo ngora 'procurar' não mudou de transitividade (como vimos acontecer nos casos de incorporação nominal, como tandjora 'engravidar'). Além disso, o sentido da versão 'ãamngora ainda não é claro. Paráfrases para averiguar a semântica desses casos, bem como testes de inseparabilidade poderão ajudar a esclarecer as suspeitas de incorporação nesses dados e quais são suas propriedades.

Assim, podemos levantar a hipótese para testes futuros (como alternâncias média, causativa) de que 'ãam, quando aparece como núcleo de predicados não verbais, é um verbo (irregular) deposposicional que teria como núcleo $\mathrm{P}^{0}$ 'ãam, uma posposição com sentido relacionado a sem. Tal núcleo é tomado por um núcleo $\mathrm{V}$ fonologicamente vazio, de maneira semelhante à apresentada em (274). Processo semelhante deve explicar o comportamento de mbiro como verbo irregular existencial e posposição 'com'. 


\subsection{Considerações finais}

A descrição e análise de dados empreendida neste capítulo nos ajudou a elucidar a seguinte questão: por que raízes verbais nuas (como as que ocorrem nas subordinadas imperfectivas) não são nomes uma vez que temos justaposição como estratégia de predicação não verbal na língua?

Como vimos, temos evidência para distinguir nomes, adjetivos e verbos em Wayoro. Um nome ou adjetivo se comporta como verbo apenas quando seguido da vogal temática/verbalizador, como tiap 'feliz, alegre' em (280). Note ainda que a forma verbal etiawa 'alegrar-se' apresenta também o morfema verbal de voz média $e$-.

a. Nürum, aramiraian tuero ndera. tiap. nũrum aramira-ian tuero nder-a tiap fazer.alvoroço mulher-PL chicha moer-V.T feliz

'Alvoroçadas, a mulherada fazia chicha. [Elas] estavam alegres.' (WYR-20080627FN-PM-a-chefe-das-mulheres 28)

b. teetiawat.

te-e-tiap-a-t

3C-MED-feliz-V.T-NFUT

'Ela se alegrou.' (PM-2013)

c. otiap erom on.

o-tiap e-rom on

1SG-feliz COP-NEG eu

'Eu não estou feliz.' (PM-2013)

Vimos que a negação nominal se assemelha à negação de adjetivos, pois ambas são realizadas por meio do morfema de negação verbal afixado à copula $e$-. Compare em (281) a afirmação e a negação da palavra mõendop 'conhecimento'.

(281) a. omẽpiriat mõendop mãyrombokwa.

o-mẽpit-iat mõendop mãy-rom-o.kwa

1SG-filho.Q-PL conhecimento contar/ensinar-NEG-FRUST.ITER

'Eu quero ensinar minhas filhas o conhecimento, mas elas não aprendem mesmo.'

b. Kawate mõendop erom ndege aotenãmian.

kawate mõendop e-rom ndege aotenãm-ian

CONJ conhecimento COP-NEG QUANT pessoa-PL

'Mas ninguém sabe! [Lit. Mas todas as pessoas não tem conhecimento]' (WYR20100326-FN-PM-confeccao-rede-17) 
Vimos que os alomorfes da negação verbal são -rom -om. O alomorfe -rom é usado após raízes verbais que terminam por vogal, como ponẽ 'usar', em (282). O alomorfe -om, por sua vez, é usado após raízes que terminam por consoante, como ning 'tecer', em (283).

a. ngwerep, ngwerep ndoap emõ ponã.

ngwerep ngwerep ndo-a-p emõ ponẽ-a

não.indígena não.indígena deitar-V.T-NMLZ ENF usar-V.T

'[As mulheres] só usam a rede do branco, do branco.'

b. txindoap

ponẽrom!

txi-ndo-a-p

ponẽ-rom

1 PL.INCL-deitar-V.T-NMLZ usar-NEG

'[Elas] não usam nossa rede [tradicional].' (WYR-20100326-FN-PM-confeccaorede-22-23)

(283)

a. omẽpit, emen ndoapdoap, ningã!

o-mẽpit, e-men ete-ndo-a-p ndo-a-p ning-a

1 SG-filho. 2 2SG-marido SOC-deitar-V.T-INF deitar-V.T-NMLZ tecer-V.T

'Minha filha, costura rede, (para) deitar com teu marido.' (WYR-20100326-FN-

PM-confeccao-rede-08)

b. [...] on ningom, ombondaya, ongwaret ati nãene.

[...] on ning-om o-mbo.ndaya o-ngwaret ati nã.ene

[...] eu tecer-NEG 1SG-mão.mole 1SG-coluna ardido tornar.se.?

'Eu não costuro [mais], não tenho força [lit. minha mão está mole], minha coluna dói demais.' (WYR-20100326-FN-PM-confeccao-rede-25)

Dessa forma, um item nominal como mõendop 'conhecimento' e um item adjetival como tiap 'feliz' diferem de uma raiz verbal como ning 'tecer' quanto à construção empregada para negação. Note que, uma vez verbalizado, um nome ou adjetivo pode ser negado com o alomorfe da negação verbal apropriado. Em (284), pare 'bom', após ser verbalizado com o sufixo -kat, permite o uso do alomorfe de negação -om, tal como os demais verbos terminados em consoante. A verbalização também pode ser constatada pela possibilidade de uso do morfema causativo, em $(284 c)$.

a. opare erom.

o-pare e-rom

1 SG-bom COP-NEG

'Eu não sou boa ou não tenho bondade.' (PM-2013)

b. oparekarom on

o-pare-kar-om on

1 SG-bom-VZR-NEG eu 
'Eu não fiquei bom [da doença].' (PM-2012-51)

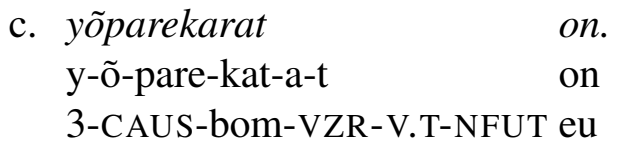

'Eu já aprontei isso.' (PM-2015)

O subordinador -rere -ere (-rere após vogal e -ere após consoante) é afixado à raiz verbal diretamente, sem vogal temática para expressar relações temporais traduzidas como 'enquanto' (simultaneamente) ou 'quando', ou seja, um subordinador aspectual imperfectivo. É o que podemos constatar com o verbo intransitivo tera 'ir' (compare (285) com (286)).

(285) nãram, teatoa

tetera ugu piõ.

nãram te-ato-a te-tet-a ugu $\mathrm{pi}=\tilde{\mathrm{o}}$

manhã 3C-banhar.se-V.T 3C-ir-V.T água dentro=ALA

'De manhã, ela foi tomar banho no rio.' (WYR-20080627-FN-PM-yangwareta-cabeçase-solta)

(286) ngemõ oterere, ombonẽrere, omẽpit indiakwapuga kwap. nge=mõ o-tet-ere, o-mbonẽ-rere, o-mẽpit indiakwa pug-a kwap roça=ALA 1 SG-ir-SUB 1SG-trabalhar-SUB 1SG-filho.९ comida cozinhar-V.T ?

'Enquanto eu vou para minha roça, enquanto eu estou trabalhando, minha filha cozinha comida.' (PM-2012)

Os dados acima evidenciam que uma oração subordinada preserva a estrutura argumental do verbo, ou seja, expressa o único argumento do verbo intransitivo, por exemplo.

Além da estrutura argumental, o morfema de negação que ocorre na subordinada se configura como evidência adicional para o seu caráter morfossintático verbal (e não nominal). Em (287), note que o verbo toa 'ver' aparece na forma negada. Utiliza-se o alomorfe -rom de negação verbal, da mesma forma que se constrói a negação de verbos em sentenças matrizes, cf. (287b).

(287) a. torom=ere, auwat nẽrom. top-rom=ere auwat nẽ-rom ver-NEG=SUB pajé tornar.se-NEG

'Quando [o aspirante] não vê [em sonhos], não se torna pajé.' (WYR-19900302DM-PK-aprend-paje-2)

b. endek mõ eorap torom on.

e-ndek=mõ e-or-a-p top-rom on

$2 \mathrm{SG}$-casa $=\mathrm{ALA} 2 \mathrm{SG}$-ir-V.T-INF ver-NEG eu

'Eu não vi você ir para sua casa.' (PM-2012) 


\section{Considerações finais}

Nesta pesquisa, à luz de novos dados oriundos de um corpus diverso (constituído de dados elicitados e de transcrições de textos), propomo-nos a:

- avaliar nossas análises anteriores das propriedades morfossintáticas e sintáticas das sentenças matrizes;

- avançar na descrição e análise da língua Wayoro, centrando-nos na discussão sobre finitude e a distinção entre orações subordinadas e nominalizações;

- descrever as estratégias de predicação não verbal presentes no corpus.

Como um dos resultados, correções de análises anteriores foram realizadas. Por exemplo, a análise atual dos morfemas pessoais presos os subdivide em prefixos pessoais de concordância, no paradigma verbal intransitivo, e clíticos de pessoa, no paradigma de verbos transitivos, uma vez que não há concordância nestes últimos. Outra correção é a atual análise do morfema de tempo - $t \sim-n$ como indicação de 'não-futuro', e não mais como 'passado'.

Investigamos diferenças aspectuais, diferenças entre os tipos sentenciais declarativo, imperativo, hortativo, bem como registramos marcas de modalidade e polaridade - não descritas antes - para as quais propomos glosas hipotéticas, dada a necessidade de refinamento de dados.

Como afirma Noonan (2007, p. 149), deve-se tentar extrair dados sobre complementação (ou quaisquer outros tipos de sentenças complexas), somente depois que um esboço básico da morfologia verbal e nominal e da sintaxe tenha sido obtido a partir do exame de sentenças simples.

As marcas de finitude verbal e as propriedades das sentenças matrizes identificadas serviram à comparação com as orações subordinadas e com as nominalizações. Analisamos como nominalização a construção que se comporta sintaticamente como sintagma nominal (sem qualquer marca de finitude), não admitindo, portanto, propriedades de sentenças matrizes. Como oração subordinada (infinitiva), analisamos a construção que funciona como objeto de um verbo e que permite afixos verbais (marcas de finitude), como marca de aspecto.

Portanto, em Wayoro, as marcas de finitude permitem distinguir as orações matrizes e as orações subordinadas, ao observarmos que sentenças matrizes apresentam concordância e indicação de tempo, o que não ocorre nas subordinadas infinitivas. As propriedades de finitude 
permitem distinguir também predicados verbais (sentenças matrizes e orações subordinadas) de predicados não verbais, uma vez que a cópula e os verbos existenciais não ocorrem com afixos de tempo/aspecto e pessoa.

Línguas que não apresentam morfologia de tempo, distinguem finitude e não-finitude de outras maneiras. Conforme Estrada-Fernández (2016, p. 48), a língua Pima Bajo (Uto-Azteca), por exemplo, não tem morfemas de tempo. Uma oração finita é identificada através de morfemas de aspecto, bem como através de marcas de força ilocucionária, a saber, elementos auxiliares modais, partículas de polaridade negativa ou afirmativa, elementos evidenciais e a partícula reportativa (ESTRADA-FERNÁNDEZ, 2016, p. 55).

Em uma perspectiva comparativa, vale ressaltar, que, dentro da subfamília Tupari, a língua Makurap não apresenta morfema de tempo no verbo. Makurap expressa diferença entre aspecto perfectivo e imperfectivo. Será interessante, futuramente, comparar as propriedades de finitude dentro da subfamília linguística Tupari. 


\section{Referências Bibliográficas}

ADGER, D. Core syntax: A minimalist approach. New York: Oxford University Press, 2003.

AIKHENVALD, A. Y. Typological distinctions in word formation. In: SHOPEN, T. (Org.). Language Typology and Syntactic Description. Cambridge: Cambridge University Press, 2007. v. 3, p. 1-56.

AIKHENVALD, A. Y. The semantics of clause linking in Manambu. In: DIXON, R. M. W.; AIKHENVALD, A. Y. (Ed.). The semantics of clause linking: a cross-linguistic typology. New York: Oxford University Press, 2009. p. 118-144.

AIKHENVALD, A. Y. Imperatives and commands. New York: Oxford University Press, 2010. ALCÁZAR, A.; SALTARELLI, M. The syntax of imperatives. Cambridge: Cambridge University Press, 2014.

ALVES, P. M. O léxico do Tuparí: proposta de um dicionário bilíngüe. Tese (Doutorado) Universidade de Araraquara, 2004.

ANDERSON, G. D. Auxiliary verb constructions. New York: Oxford University Press, 2006.

ANDREWS, A. D. The major functions of the NP. In: SHOPEN, T. (Org.). Language Typology and Syntactic Description. Cambridge: Cambridge University Press, 2007. v. 1, p. 62-154.

ARAGON, C. C. A grammar of Akuntsú, a Tupían language. Tese (Doutorado) - University of Hawai'i at Mānoa, 2014.

BAKER, M. C. Incorporation: A theory of grammatical function changing. Chicago: University of Chicago, 1988.

BASSANI, I. d. S. Uma abordagem localista para morfologia e estrutura argumental dos verbos complexos (parassintèticos) do português brasileiro. Tese (Doutorado) - Universidade de São Paulo, 2013.

BICKEL, B.; COMRIE, B.; HASPELMATH, M. The leipzig glossing rules. conventions for interlinear morpheme by morpheme glosses. 2015. Disponível em: <https://www.eva.mpg.de/lingua/resources/glossing-rules.php>. Acesso em: 15 jul. 2019. 
BIRCHALL, J. Argument marking patterns in South American languages. Utrecht: Netherlands Graduate School of Linguistics, 2014.

BOWERN, C. Linguistic fieldwork: a practical guide. London: Palgrave Macmillan, 2008.

BRAGA, A. Aspects morphosyntaxiques de la langue Makurap/Tupi. Tese (Doutorado) Université de Toulouse, 2005.

CAMPBELL, L. Typological characteristics of south american indigenous languages. In: CAMPBELL, L.; GRONDONA, V. (Eds.). The indigenous languages of South America: a comprehensive guide. Berlin/Boston: De Gruyter Mouton, 2012. p. 259-330.

CATFORD, J. C. A practical introduction to phonetics. New York: Clarendon Press Oxford, 1988.

COMRIE, B. Valency-changing derivations in Tsez. In: DIXON, R. M.; AIKHENVALD, A. Y. (Ed.). Changing valency: case studies in transitivity. Cambridge: Cambridge University Press, 2007. p. 360-74.

COMRIE, B.; SMITH, N. Lingua descriptive studies: questionnaire. Lingua, North-Holland, v. 42, n. 1, p. 1-72, 1977.

COMRIE, B.; THOMPSON, S. A. Lexical nominalization. In: SHOPEN, T. (Org.). Language Typology and Syntactic Description. Cambridge: Cambridge University Press, 2007. v. 3, p. 334-381.

CRAIN, S.; THORNTON, R. Investigations in universal grammar: A guide to experiments on the acquisition of syntax and semantics. Massachusetts: MIT Press, 2000.

CREVELS, M.; MUYSKEN, P. Inclusive-exclusive distinctions in the languages of centralwestern south america. In: FILIMONOVA, E. (Ed.). Clusivity: Typology and case studies of inclusive-exclusive distinction [Typological Studies in Language 63]. Amsterdam/Philadelphia: John Benjamins, 2005. p. 311-338.

CRISTOFARO, S. Subordination. New York: Oxford University Press, 2005.

CRUZ, A. D. Fonologia e Gramática do Nheengatú: A língua geral falada pelos povos Baré, Warekena e Baniwa. Utrecht: Netherlands Graduate School of Linguistics, 2011.

CRYSTAL, D. A dictionary of linguistics and phonetics. Malden: Blackwell Publishing, 2008. CYRINO, J. P. L. O sincretismo passivo-reflexivo: um estudo translinguístico. Tese (Doutorado) - Universidade de São Paulo, 2015.

DAVIES, W. D.; DUBINSKY, S. The grammar of raising and control: a course in syntactic argumentation. Malden: Blackwell Publishing, 2004. 
DIXON, R. M. Basic linguistic theory volume 2: grammatical topics. New York: Oxford University Press, 2010.

EPPS, P. A grammar of Hup. Berlin; New York: Walter de Gruyter, 2008.

ESTRADA-FERNÁNDEZ, Z. Exploring finiteness and non-finiteness in Pima Bajo (Uto-Aztecan). In: CHAMOREAU, C.; ESTRADA-FERNÁNDEZ, Z. (Ed.). Finiteness and Nominalization. Amsterdam/Philadelphia: John Benjamins, 2016. p. 43-68.

FUNDAÇÃO NACIONAL DE SAÚDE (FUNASA). População Wajuru. 2016. Disponível em: $<$ www.funasa.gov.br/ $>$.

GALUCIO, A. V. The morphosyntax of Mekens (Tupi). Tese (Doutorado) - The University of Chicago, 2001.

GALUCIO, A. V. Nominalization in the Mekens language. Amérindia, Paris, p. 238-260, 2011.

GALUCIO, A. V. Subordinate adverbial constructions in Mekens. In: GIJN, R. van; HAUDE, K.; MUYSKEN, P. (Ed.). Subordination in native South American languages. Amsterdam/Philadelphia: John Benjamins, 2011. p. 23-43.

GALUCIO, A. V. Argument marking and reference tracking in Mekens. In: GIJN, R. van; HAMMOND, J.; MATIĆ, D.; PUTTEN, S. van; GALUCIO, A. V. (Ed.). Information structure and reference tracking in complex sentences. Amsterdam/Philadelphia: John Benjamins, 2014a. p. 373-396.

GALUCIO, A. V. Discourse and epistemic modality in Mekens: The frustrative construction. Revista Linguíftica: Revista do Programa de Pós-Graduação em Linguística da Universidade Federal do Rio de Janeiro, v. 10, n. 2, p. 163-179, 2014b.

GALUCIO, A. V.; MEIRA, S.; BIRCHALL, J.; MOORE, D.; JÚNIOR, N. G.; DRUDE, S.; STORTO, L.; PICANÇO, G.; RODRIGUES, C. R. Genealogical relations and lexical distances within the tupian linguistic family. Boletim do Museu Paraense Emílio Goeldi. Ciências Humanas, Belém, v. 10, n. 2, p. 229-274, 2015.

GALUCIO, A. V.; NOGUEIRA, A. F. Comparative study of the Tupari branch of the Tupi family: contributions to understanding its historical development and internal classification. In: Memorias del V Congreso de Idiomas Indígenas de Latinoamérica. Austin: University of Texas, 2011.

GALUCIO, A. V.; NOGUEIRA, A. F. d. S. Causativização e alteração de valência em Mekens e wayoro. In: QUEIXALÓS, F.; TELLES, S.; BRUNO, A. C. (Ed.). Incremento de valencia en las lenguas amazónicas. Bogotá: Instituto Caro \& Cuervo, 2014. p. 211-233. 
GALUCIO, A. V.; NOGUEIRA, A. F. de S. From object nominalization to object focus. Journal of Historical Linguistics, Amsterdam/Philadelphia, v. 8, n. 1, p. 95-127, 2018.

GERLACH, B. Clitics between syntax and lexicon. Amsterdam/Philadelphia: John Benjamins, 2002.

GERLACH, B.; GRIJZENHOUT, J. Clitics in phonology, morphology and syntax. Amsterdam/Philadelphia: John Benjamins, 2001.

GIJN, R. v.; GALUCIO, A. V.; NOGUEIRA, A. F. Subordination strategies in tupian languages. Boletim do Museu Paraense Emílio Goeldi. Ciências Humanas, Belém, v. 10, n. 2, p. 297-324, 2015. Disponível em: <https://dx.doi.org/10.1590/1981-81222015000200006>.

GIJN, R. V.; HAUDE, K.; MUYSKEN, P. Subordination in South American Languages. Amsterdam/Philadelphia: John Benjamins, 2011a.

GIJN, R. V.; HAUDE, K.; MUYSKEN, P. Subordination in South America: an overview. In: GIJN, R. van; HAUDE, K.; MUYSKEN, P. (Ed.). Subordination in native South American languages. Amsterdam/Philadelphia: John Benjamins, 2011b. p. 1-23.

GILDEA, S. Semantic and pragmatic inverse: 'inverse alignment' and 'inverse voice' in Carib of Surinam. In: GIVÓN, T. (Ed.). Voice and inversion [Typological Studies in Language 28]. Amsterdam/Philadelphia: John Benjamins, 1994. p. 187-230.

GILDEA, S. Explaining similarities between main clauses and nominalized phrases. Amérindia, Paris, p. 57-75, 2008.

GILDEA, S.; ALVES, C. Counter-universal split ergativity in Jê and Cariban. International Journal of American Linguistics, Chicago, p. 159-199, 2010.

GIPPERT, J.; HIMMELMANN, N.; MOSEL, U. (Orgs.). Essentials of language documentation. Berlin/New York: Walter de Gruyter, 2006.

GIVÓN, T. Nominalization and re-finitization. In: CHAMOREAU, C.; ESTRADAFERNÁNDEZ, Z. (Ed.). Finiteness and Nominalization. Amsterdam/Philadelphia: John Benjamins, 2016. p. 271-296.

GOMES, D. M. Estudo morfológico e sintático da língua Mundurukú (Tupí). Tese (Doutorado) — Universidade de Brasília, 2006.

GOMES, D. M. Voz e valência verbal em Mundurukú (Tupí). In: QUEIXALóS, F.; TELLES, S.; BRUNO, A. C. (Ed.). Incremento de valencia en las lenguas amazónicas. Bogotá: Instituto Caro \& Cuervo, 2014. p. 235-260. 
GOMEZ, G. G.; VOORT, H. van der. (Orgs.) Reduplication in indigenous languages of South America. Leiden: Brill, 2014.

GRINEVALD, C.; BERT, M. Speakers and communities. In: AUSTIN, P.; SALLABANK, J. (Ed.). Cambridge Handbook of Endangered Languages. Cambridge: Cambridge University Press, 2011. p. 45-65.

GUILLAUME, A.; ROSE, F. Sociative causative markers in South-American languages: a possible areal feature. In: FLORICIC, F. (Ed.). Essais de typologie et de linguistique générale: mélanges offerts à Denis Creissels. Lyon: ENS Éditions, 2010. p. 383-402.

HAEGEMAN, L. X-bar theory. In: BROWN, K. (Ed.). Encyclopedia of Language and Linguistics. Amsterdam: Elsevier Science, 2006. p. 691-704.

HALE, K. L.; KEYSER, S. J. Prolegomenon to a theory of argument structure. Massachusetts: MIT press, 2002.

HASPELMATH, M. The serial verb construction: Comparative concept and cross-linguistic generalizations. Language and Linguistics, London, v. 17, n. 3, p. 291-319, 2016.

HEINE, B. Auxiliaries: cognitive forces and grammaticalization. Oxford: Oxford University Press, 1993.

HIMMELMANN, N. P. Prosody in language documentation. In: GIPPERT, J.; HIMMELMANN, N.; MOSEL, U. (Ed.). Essentials of language documentation. Berlin/New York: Walter de Gruyter, 2011. p. 163-181.

HOUAISS, A.; VILlAR, M.; FRANCO, F. M. de M. Dicionário Houaiss da língua portuguesa. Rio de Janeiro: Objetiva Rio de Janeiro, 2001.

INSTITUTO SOCIOAMBIENTAL. Wajuru. 2018. Disponível em: <https://pib.socioambiental.org/pt/Povo:Wajuru $>$.

KEMMER, S. The middle voice. Amsterdam/Philadelphia: John Benjamins, 1993.

KÖNIG, E.; SIEMUND, P. Speech act distinctions in grammar. In: SHOPEN, T. (Org.). Language Typology and Syntactic description. Cambridge: Cambridge University Press Cambridge, 2007. v. 1, p. 276-324.

LADEFOGED, P. Phonetic Data Analysis: An Introduction to Fieldwork and Instrumental Techniques. Malden: Blackwell Publishing, 2003.

LANDAU, I. Control in generative grammar: a research companion. Cambridge: Cambridge University Press, 2013. 
LEGATE, J. A. Warlpiri wh-scope marking. Syntax, Oxford/Malden, v. 14, n. 2, p. 97-121, 2011.

LONGACRE, R. E. Sentences as combinations of clauses. In: SHOPEN, T. (Org.). Language Typology and Syntactic Description. Cambridge: Cambridge University Press, 2007. v. 2, p. $372-420$.

MAGALHÃES, M. M. S. Causativização em guajá. In: QUEIXALÓS, F.; TELLES, S.; BRUNO, A. C. (Ed.). Incremento de valencia en las lenguas amazónicas. Bogotá: Instituto Caro \& Cuervo, 2014. p. 71-83.

MALDI, D. O complexo cultural do marico: sociedades indigenas dos rios Branco, Colorado e Mequens, afluentes do Medio Guaporé. Boletim do Museu Paraense Emílio Goeldi, Belém, v. 7, n. 2, p. 209-269, 1991.

MARCHESAN, A. C. A sintaxe das sentenças relativas livres no português brasileiro. In: OLIVEIRA, R. P. de; MIOTO, C. (Orgs.). Percursos em teoria da gramática. Florianópolis: Editora da UFSC, 2014a. p. 373-396.

MERE, G. Emil-Heinrich Snethlage (1897-1939): nota biográfica, expedições e legado de uma carreira interrompida. Boletim do Museu Paraense Emílio Goeldi. Ciências Humanas, Belém, v. 8, n. 3, p. 773-804, 2013.

MITHUN, M. How to avoid subordination. In: Proceedings of the Tenth Annual Meeting of the Berkeley Linguistics Society. Berkeley: Berkeley Linguistics Society. v. 10, p. 493-509.

MONACHESI, P. Linearization properties of romanian clitics. In: Clitics in Phonology, Morphology, and Syntax. Amstardam/Philadelphia: John Benjamins, 2000. p. 255-293.

MOORE, D.; GALUCIO, A. V.; JUNIOR, N. G. O desafio de documentar e preservar as línguas amazônicas. Scientific American Brasil, v. 3, p. 36-43, 2008.

MOSELEY, C. Atlas of the World's Languages in Danger. Paris: UNESCO Publishing, 2010. Disponível em: <http://www . unesco.org/culture/en/endangeredlanguages/atlas . Acesso em: 4 fev. 2019.

MÜLLER, N. J. Tense, aspect, modality, and evidentiality marking in South American indigenous languages. Tese (Doutorado) — Radboud Universiteit Nijmegen, Nijmegen, 2013. MUYSKEN, P. Nominalization. In: ASHER, R.; SIMPSON, J. M. (Eds.). The encyclopedia of language and linguistics. Oxford: Pergamon Press, 1993. p. 2811-2815.

NOGUEIRA, A. Em busca das classes de palavras da língua Wayoro. Revista Linguíftica, Rio de Janeiro, v. 10, n. 2, 2015. 
NOGUEIRA, A. F. Wayoro ẽmẽto: fonologia segmental e morfossintaxe verbal. Dissertação (Mestrado) — Universidade de São Paulo, 2011.

NOGUEIRA, A. F. Sistemas ortográficos de línguas indígenas: a importância de aspectos sociolinguísticos. In: II Congresso Internacional de Dialetologia e Sociolinguística. São Luis: EDUFMA, 2012. p. 400-415.

NOGUEIRA, A. F.; MACURAP, P.; WAJURU, J. Wayoro (Wajuru)- Tuero nderap eriat- A Dona do preparo da chicha. Revista Linguíftica, Rio de Janeiro, v. 15, n. 1, p. 336-356, 2019. Disponível em: $<$ https://revistas.ufrj.br/index.php/rl/article/view/25574 > .

NOGUEIRA, A. F. d. S. Descrição e análise do prefixo $\{\mathrm{e}-\}$ intr da língua Wayoro (Ayuru, tronco Tupí). Boletim do Museu Paraense Emílio Goeldi. Ciências Humanas, Belém, v. 2, n. 8, p. 325-341, 2013.

NOGUEIRA, A. F. de S. Dissimilação em Wayoro (família Tuparí, tronco Tupí). In: IX CONGRESSO INTERNACIONAL DA ABRALIN, 9., 2015, Belém. Anais... Belém: PPGL, UFPA, 2015. p. 76-80.

NOGUEIRA, A. F. de S.; COSTA, N. F. de O. Repetição na língua portuguesa e na língua wayoro. Revista eletrônica Falas Breves, Múltiplos Olhares, Breves, v. 1, p. 1-13, 2014.

NOONAN, M. Complementation. In: SHOPEN, T. (Org.). Language Typology and Syntactic Description. Cambridge: Cambridge University Press, 2007. v. 3, p. 52-150.

OLIVEIRA, C. Cunha de. Lexical categories and the status of descriptives in Apinajé. International Journal of American Linguistics, Chicago, v. 69, n. 3, p. 243-274, 2003.

OVERALL, S. E.; VALLEJOS, R.; GILDEA, S. Nonverbal predication in Amazonia. In: OVERALL, S. E.; VALLEJOS, R.; GILDEA, S. (Ed.). Nonverbal predication in Amazonian languages. Amsterdam/Philadelphia: John Benjamins, 2018. v. 122, p. 1-49.

PAYNE, T. E. Describing morphosyntax: a guide for field linguists. Cambridge: Cambridge University Press, 1997.

QUEIXALÓS, F. Grammaire Sikuani. Tese (Doutorado) — Paris 4, 1995.

QUEIXALÓS, F. Nom, verbe et prédicat en Sikuani (Colombie). Paris: Peeters Publishers, 1998.

RANGEL, J. Les derniers locuteurs: au croisement des typologies des locuteurs de langues en danger. Histoire Epistémologie Langage, Les Ulis, v. 39, n. 1, p. 107-133, 2017.

RODRIGUES, A.; CABRAL, A. S. A. C. Tupían. In: CAMPBELL, L.; GRONDONA, V. (Eds.). The indigenous languages of South America: a comprehensive guide. Berlin/Boston: De Gruyter Mouton, 2012. p. 495-574. 
RODRIGUES, A. D. Morfologia do verbo Tupi. Revista Letras, Curitiba, v. 1, p. 121-152, 1953.

SANTORINI, B.; KROCH, A. The syntax of natural language: an online introduction using the trees program. 2007. Disponível em: $<$ https://www.ling.upenn.edu/ ${ }^{2}$ beatrice/syntaxtextbook $>$.

SANTOS, J. F. Documentação da língua Wayoró: para a preservação das línguas indígenas amazônicas. Dissertação (Mestrado) — Fundação Universidade de Rondônia, 2010.

SECRETARIA DE SAÚDE INDÍGENA. Quantitativo populacional dos indígenas cadastrados no SIASI em 2013 por diversos parâmetros de territorialidade indígena ou nacional. 2013. Disponível em: <https://bit.ly/2SerzJ7>.

SHIBATANI, M.; MAKHASHEN, K. A. B. Nominalization in Soqotri, a South Arabian language of Yemen. In: LOT Occasional Series. Utrecht: LOT Netherlands Graduate School of Linguistics, 2009. v. 13, p. 311-332.

SIEWIERSKA, A. Person marking. In: SONG, J. J. (Ed.). The Oxford handbook of linguistic typology. New York: Oxford University Press, 2010.

SILVA, I. R. Não-finitude em Karitiana: subordinação versus nominalização. Tese (Doutorado) — Universidade de São Paulo, 2016.

SINGERMAN, A. R. The morphosyntax of Tupari, a Tupian language of the Brazilian Amazon. Tese (Doutorado) - University of Chicago, 2018.

SNETHLAGE, E. H. Atiko Y: meine Erlebnisse bei den Indianern des Guaporé. Berlin: Klinkhardt \& Biermann, 1937.

SOARES-PINTO, N. Do poder do sangue e da chicha: os Wajuru do Guaporé (Rondônia). Dissertação (Mestrado) — Universidade Federal do Paraná, 2009.

STORTO, L. Reduplication in Karitiana (Tupi). In: GOMEZ, G. G.; VOORT, H. van der (Orgs.). Reduplication in indigenous languages of South America. Leiden: Brill, 2014b.

STORTO, L. Caso e concordância nas línguas Tupi. Estudos Linguísticos, v. 34, p. 59-72, 2005.

STORTO, L. Anáfora ta- em Karitiana: um argumento de terceira pessoa não especificado para número. In: V Congresso Internacional da ABRALIN. Belo Horizonte: Universidade Federal de Minas Gerais, 2007.

STORTO, L. Marcação de concordância absolutiva em algumas construções sintáticas em Karitiana. Ameríndia, Paris, v. 32, 2008. 
STORTO, L. Constituent order and information structure in Karitiana. In: GIJN, R. van; HAMMOND, J.; MATIĆ, D.; PUTTEN, S. van; GALUCIO, A. V. (Eds.). Information structure and reference tracking in complex sentences. Amsterdam/Philadelphia: John Benjamins, 2014a. v. 105, p. 163-191.

STORTO, L.; BALDI, P. The Proto-Arikem vowel shift. In: Proceedings of the Annual Meeting of the Berkeley Linguistics Society. Berkeley: Berkeley Linguistics Society, 1994. v. 28.

TIMBERLAKE, A. Aspect, tense, mood. In: SHOPEN, T. (Org.). Language Typology and Syntactic Description. Cambridge: Cambridge University Press, 2007. v. 3, p. 280-333.

TREIS, Y.; VANHOVE, M. Introduction. In: TREIS, Y.; VANHOVE, M. (Ed.). Similative and equative constructions: a cross-linguistic perspective. Amsterdam/Philadelphia: John Benjamins, 2017. v. 117.

VIGÁRIO, M. On the prosodic status of stressless function words in european portuguese. In: HALL, T. A.; KLEINHENZ, U. (Ed.). Studies on the Phonological Word [Current Issues in Linguistic Theory 174]. Amsterdam/Philadelphia: John Benjamins, 1999. p. 255-294.

VIVANCO, K. Perguntas QU-, orações subordinadas e ordem de palavras em Karitiana. Tese (Doutorado) — Universidade de São Paulo, 2019.

ZWICKY, A. M. Clitics and particles. Language, Washington, v. 61, n. 2, p. 283-305, 1985. 